\title{
Magnitude and Frequency of Floods in Washington
}

By S.S. Sumioka, D.L. Kresch, and K.D. Kasnick

U.S. Geological Survey

Water-Resources Investigations Report 97-4277

Prepared in cooperation with

WASHINGTON STATE DEPARTMENT OF TRANSPORTATION and WASHINGTON STATE DEPARTMENT OF ECOLOGY 


\section{U.S. DEPARTMENT OF THE INTERIOR \\ BRUCE BABBITT, Secretary}

\section{U.S. GEOLOGICAL SURVEY}

Thomas J. Casadevalll

Acting Director

Any use of trade, product, or firm names is for descriptive purposes only and does not imply endorsement by the U.S. Government.

For additional information write to:

Copies of this report may be purchased from:

District Chief

U.S. Geological Survey

1201 Pacific Avenue - Suite 600

Tacoma, Washington 98402
U.S. Geological Survey

Branch of Information Services

Box 25286

Denver. Colorado 80225-0286 


\section{CONTENTS}

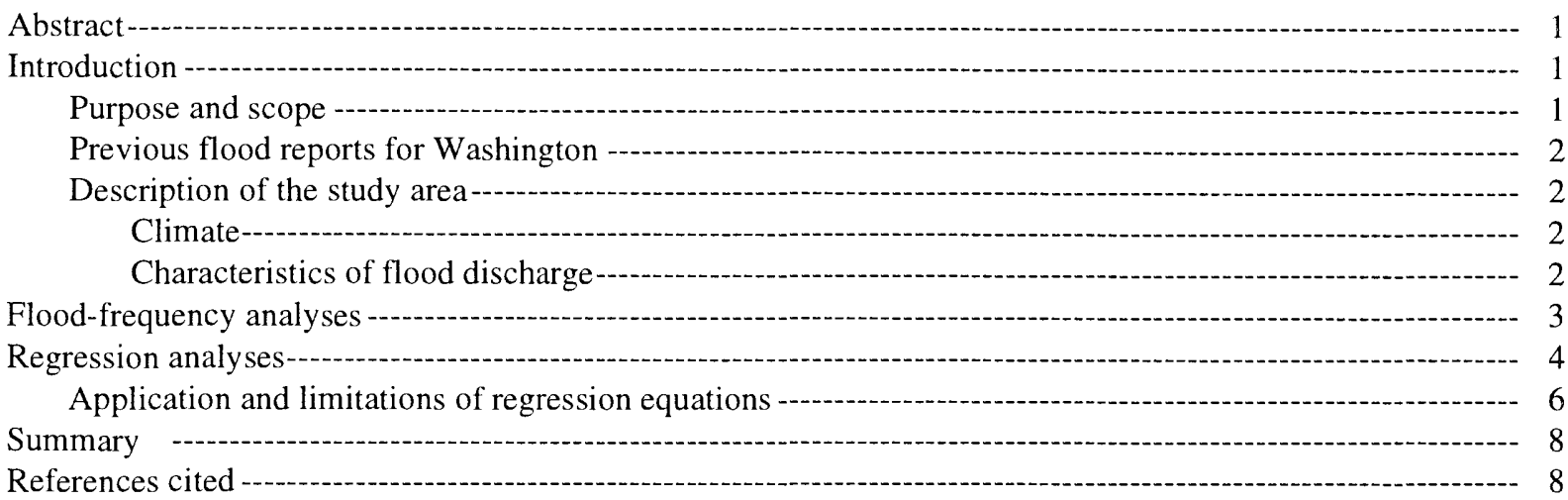

PLATES (Plate is located in the pocket at the end of the report)

1. Map showing mean annual precipitation for the State of Washington, 1930-57.

\section{FIGURES}

1. Map showing flood-frequency regression regions in Washington State------------------ 10

2-10. Maps showing distribution of gaging stations used in the development of the regression equation for:

2. Region 1 -

3. Region 2 --- 12

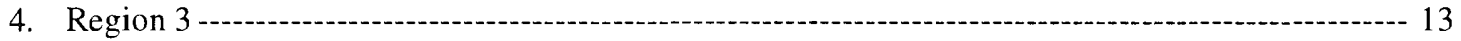

5. Region 4 - 14

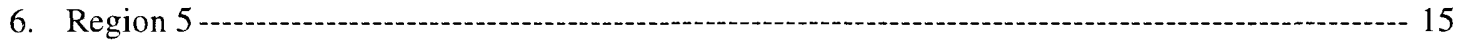

7. Region 6 - 16

8. Region 7 - 17

9. Region 8 - 18

10. Region 9 - 19

\section{TABLES}

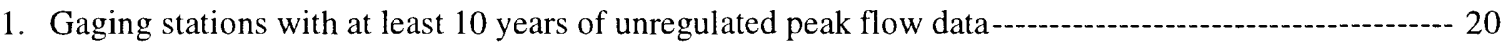

2. Flood discharges for selected exceedance probabilities at gaging stations on streams with unregulated flow --.-- 34

3. Basin characteristics used in the regression analyses-- 72

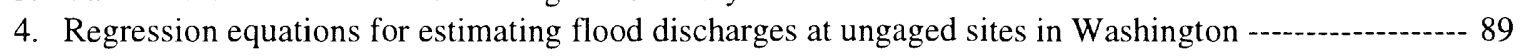

5. Maximum and minimum values of basin characteristics used in the regression analyses, by regions 
CONVERSION FACTORS AND VERTICAL DATUM

\begin{tabular}{lll} 
Multiply & By & \multicolumn{1}{c}{ To Obtain } \\
\hline inch (in) & 2.54 & centimeter \\
foot $(\mathrm{ft})$ & 0.3048 & meter \\
cubic feet per second $\left(\mathrm{ft}^{3} / \mathrm{s}\right)$ & 0.02832 & cubic meters per second \\
mile $(\mathrm{mi})$ & 1.609 & kilometer \\
foot per mile $(\mathrm{ft} / \mathrm{mi})$ & 0.18943 & meter per kilometer \\
square mile $\left(\mathrm{mi}^{2}\right)$ & 2.59 & square kilometer
\end{tabular}

Temperature: To correct temperature given in this report in degrees Fahrenheit $\left({ }^{\circ} \mathrm{F}\right)$ to degrees Celsius $\left({ }^{\circ} \mathrm{C}\right)$, use the following equation: ${ }^{\circ} \mathrm{C}=5 / 9\left({ }^{\circ} \mathrm{F}-32\right)$

Sea Level: In this report "sea level" refers to the National Geodetic Vertical Datum of 1929 (NGVD of 1929)—a geodetic datum derived from a general adjustment of the first-order level nets of both the United States and Canada, formerly called Sea Level Datum of 1929. 
By S.S. Sumioka, D.L. Kresch, and K.D. Kasnick

\begin{abstract}
Annual maximum instantaneous discharge data for 527 gaging stations with at least 10 years of peakdischarge record on unregulated streams were used to compute the magnitude and frequency of floods on Washington streams. Flood magnitudes having exceedance probabilities of $0.5,0.1,0.04,0.02$, and 0.01 were related to physical and climatic characteristics for 504 of the 527 gaging stations using generalized least-squares regression analyses. The regression relations can be used to estimate flood discharges having these exceedance probabilities for ungaged stream basins.
\end{abstract}

\section{INTRODUCTION}

Estimates of the magnitude and frequency of floods are used by engineers in the design of bridges, culverts, dams, and embankments, and by land-use managers to assess the hazards related to the development of flood plains. The U.S. Geological Survey (USGS) published estimates of flood frequencies in Washington in 1985 for stream-gaging stations with 10 or more years of annual flood records (Williams and others, 1985a,b; and Williams and Pearson, 1985a,b). However, these estimates were based on data collected only through the 1979 water year (the 12-month period from October 1, 1978, through September 30, 1979).

In 1993, the U.S. Geological Survey, in cooperation with the Washington State Department of Transportation, began a study to update these flood frequency estimates, incorporating data collected through the 1992 water year, and to develop regional regression equations by which flood discharges could be estimated at ungaged sites.
However, because some very large floods occurred after 1992, the USGS, in cooperation with the Washington State Department of Transportation and the Washington State Department of Ecology, expanded that study to include all data collected through the 1996 water year. Flood peaks that occurred during a prolonged and intense storm in February 1996 exceeded previous historic peak discharges recorded at several gaging stations in Washington.

The preferred method of expression of flood frequency is the annual exceedance probability. The annual exceedance probability is the probability that a flood of a certain magnitude will occur or be exceeded in any 1-year period. Thus, a flood discharge with an exceedance probability of 0.02 , or 2 percent, has a one-in-fifty chance of being equalled or exceeded each year. Another method of expressing flood frequency is as a recurrence interval-the average time interval in years between consecutive occurrences of an annual peak discharge equal to or greater than a certain magnitude. The recurrence interval corresponding to the annual peak discharge for a certain exceedance probability flood is given by the reciprocal of the exceedance probability. Thus, a flood with an exceedance probability of 0.02 has a recurrence interval of 50 years.

\section{Purpose and Scope}

This report presents the results of flood-frequency analyses for 527 gaging-station records on unregulated streams (defined in this report as being not significantly affected by reservoir operations, diversions, or urbanization) that have at least 10 years of annual maximum instantaneous discharge data. Also presented are equations and techniques by which the magnitude and frequency of floods can be estimated for any ungaged site on 
naturally flowing (unregulated) streams. The data and results are presented on figures 1 to 10 and in tables 1 to 5 at the end of the report.

The flood-frequency analyses used annual maximum instantaneous discharge data collected through the 1996 water year, which are stored in the USGS National Water Information System (NWIS) database. The results of the flood-frequency analyses were used in conjunction with data stored in the NWIS basin-characteristics file to develop regression equations for estimating flood frequencies at ungaged sites. The State was divided into nine regions for the regression analyses on the basis of hydrologic unit code boundaries.

\section{Previous Flood Reports for Washington}

Descriptions of floods and the computation of flood magnitude and frequency for specific river basins in Washington can be found in reports by Anderson (1948) for the Puyallup and Chehalis River Basins, Bailey (1960) for the Nooksack River Basin, Richardson (1965) for the upper Green River Basin, Walters (1974) for the Okanogan River Basin, Walters and Nassar (1974) for the Methow River Basin, Nassar and Walters (1975) for the Palouse River Basin, and Drost and Lombard (1978) for the Skagit River Basin. Results of regional and State-wide flood-frequency analyses can be found in reports by Rantz and Riggs (1949), Bodhaine and Thomas (1960 and 1964), Williams and Pearson (1985a and 1985b), and Williams and others (1985a and 1985b). Techniques for estimating flood magnitude and frequency at ungaged stream basins were developed by Bodhaine and Robinson (1952) for western Washington, Thomas and others (1963) for the Snake River Basin, Bodhaine and Thomas (1964) for Pacific Slope Basins, Cummans and others (1975) for the entire State, and Haushild (1979) for small, ephemeral streams in eastern Washington.

\section{Description of the Study Area}

The State of Washington encompasses several physiographic provinces (Fenneman, 1931): the Puget Border Province, consisting of the Puget Sound Basin, the Olympic Mountains, and the lowlands west of the Cascade Range extending southward to the Columbia River; the Sierra-Cascade Province, consisting of the Cascade Range; the Columbia Plateau Province, consisting of the area east of the Cascade Range and south of the Columbia River in Washington; and the Northern Rocky Mountain Province consisting of the Pend Oreille, Okanogan, and
Sanpoil River Basins in Washington. The topography of the State varies from lowlands at or near sea level to the mountainous areas of the Olympic Mountains and the Cascade Range. Land use and land cover in the State vary greatly, ranging from forested and agricultural areas to densely populated urban and suburban areas.

\section{Climate}

The Cascade Range separates Washington into two climatically different regions. Western Washington, influenced by the Pacific Ocean, has a predominantly marine climate, characterized by cool, dry summers and mild, wet winters. Eastern Washington has a continental climate, characterized by warm, dry summers and cold, clear winters.

Local and regional variations in precipitation are influenced primarily by the Olympic Mountains and the Cascade Range. In western Washington, mean annual precipitation ranges from less than 20 inches in the rain shadow of the Olympic Mountains to more than 220 inches along the crest of the Olympic Mountains (U.S. Department of Commerce, 1965). Precipitation along the crest of the Cascade Range exceeds 140 inches in some places. In eastern Washington, mean annual precipitation ranges from less than 10 inches in parts of the Columbia River Basin to about 40 inches near the southeastern and northeastern corners of the State.

\section{Characteristics of Flood Discharge}

Several types of floods occur in Washington. In most parts of western Washington, floods generally occur in late fall and winter as a result of prolonged rainstorms. These floods may be augmented by water from snowmelt if rain falls on snow. The rain-on-snow floods are usually of short duration. In basins at higher elevations, floods may occur in the spring as a result of rapid snowmelt. These floods are usually of longer duration than the winter floods.

In eastern Washington, floods generally occur in the foothills of the Cascade Range and in the highlands of northeastern Washington during spring snowmelt. In some areas of eastern Washington, flooding may occur during the winter when rain or unseasonably warm weather melts accumulations of snow. Flooding may also occur in small basins in response to summer thunderstorms. 


\section{FLOOD-FREQUENCY ANALYSES}

The data used in the flood-frequency analyses were the annual maximum instantaneous discharges for each of the 527 gaging stations on unregulated streams in Washington (fig. 1) with 10 or more years of record (table 1). In this report, these data will be referred to as peak flows, and the annual series of peak flows during the period of record for a particular gaging station will be referred to as the systematic record for that station. In some instances, the years of record for a station listed in table 1 may not agree with the number of peaks used in the flood-frequency analysis listed in table 2 because of the exclusion of peaks designated as being affected by regulation and of peaks that are outside of the range of discharges defined by high and low outlier thresholds. In some cases, peak flows have been determined for floods outside of the period when regular, systematic records of discharge have been kept. These peak flows, referred to as historic peaks, can be used to extend systematic records to longer historical periods (U.S. Water Resources Council, 1981).

The stations given in table 1 and all other tables containing gaging-station data are listed in downstream order by USGS gaging station numbers. The first two digits (12, 13, or 14) designate major basin subdivisions of the State. Stations with numbers beginning with 12 are located on streams tributary to the Pacific Ocean or the Columbia River upstream from the mouth of the Snake River; stations with numbers beginning with 13 are located on streams tributary to the Snake River; and stations with numbers beginning with 14 are on streams tributary to the Columbia River below the mouth of the Snake River.

Estimates of flood discharge and frequency were computed for all 527 gaging stations using an interactive version of USGS computer program J407 (Kirby, 1981), which implements guidelines established by the U.S. Water Resources Council (1981). The U.S. Water Resources Council suggests that separate flood-frequency curves be computed for each type of flood from a mixed population of floods (U.S. Water Resources Council, 1981), but the detailed study required to segregate peak flows by cause was beyond the scope of this project; therefore, no attempt was made to analyze any of the annual flood series separately for mixed populations. Statistical procedures were used to identify high and low outliers in systematic station records. High outliers known or believed to be the highest during an extended period of time were treated as historic flood peaks. Flood peaks identified as low outliers were deleted and then a conditional probability adjustment was applied to all the remaining peaks to determine the flood frequency estimates. In a few cases, visual inspection of the frequency curves identified small peaks that departed from the fitted relation (a sharp downward break in the curve), but were not identified as low outliers by the statistical procedures. A user-defined low-discharge threshold was used to omit such peaks from the flood-frequency analysis.

Not all of the available peak-flow data could be used in the flood-frequency analyses. Stations for which more than 25 percent of the peak-flow record consisted of zero flows were not included in the analyses (U.S. Water Resources Council, 1981, p. 5-1). Also, if part of the systematic record for a station included periods of regulated flow, those periods were not included in the analysis. In some cases, part of the systematic record for a station was excluded from the frequency analysis because only gage heights (and not discharge) were recorded for some years. Flood-frequency results were not included for stations at which the peak discharge data appeared to be representative of and significantly influenced by mixed populations of floods and for which it appeared that no single flood-frequency curve would adequately fit the peak discharge data.

In this study, a log-Pearson Type III distribution was fit to the data for each station using the method of moments as described by the U.S. Water Resources Council (1981). The base 10 logarithms of the mean, standard deviation, and skew coefficient were used to compute the logarithm of the discharge, $Q$, at a selected exceedance probability using the following equation:

$$
\log Q=\bar{x}+K S
$$

where

$$
\begin{aligned}
\bar{x}= & \text { mean of the logarithms of peak flows, } \\
K= & \text { factor that is a function of the logarithm of } \\
& \text { the skew coefficient and the selected } \\
& \text { exceedance probability, and } \\
S= & \text { standard deviation of the logarithms of peak } \\
& \text { flows. }
\end{aligned}
$$

Values of $K$ were obtained from the table in appendix 3 of the U.S. Water Resources Council guidelines (1981). For this study, the skew coefficient used to obtain $K$ in the above equation was estimated by weighting the station skew coefficient and a generalized skew coefficient in inverse proportion to their individual mean-square errors. The generalized skews and their mean-square errors used for this study were those determined by the U.S. Water 
Resources Council (1981). A detailed study of the regional (generalized) skews for the State of Washington was not done for this study.

Flood-frequency estimates were determined graphically for a small number of gaging-station records because the log-Pearson Type III distribution did not accurately fit the peak discharge data.

Flood discharges computed for exceedance probabilities of $0.5,0.1,0.04,0.02$, and 0.01 are given in table 2 (first line of data for each station), along with the 95-percent confidence interval for each computed flood magnitude (second line of data). This interval is the range that, with a probability of 95 percent, contains the true flood magnitude for a particular exceedance probability. Confidence intervals were not determined for flood-frequency estimates determined by graphical techniques.

\section{REGRESSION ANALYSES}

Flood magnitudes determined for 504 of the 527 gaging stations included in the flood-frequency analyses were used in conjunction with selected physical and climatic basin characteristics to develop generalized least-squares regression equations for estimating flood magnitudes and frequencies for ungaged, unregulated (hereafter referred to as ungaged) stream basins. Stations not used were omitted for a variety of different reasons, including uncertainties regarding the correct location of drainage boundaries and the amount of a basin that contributes to runoff. Stations for which a significant portion of the upstream drainage basin was located outside of the State boundaries were not used because they may not be representative of hydrologic conditions within the State. Also, stations for which flood frequency estimates were determined graphically were not included because the log-Pearson Type III station skewone of the variables used in the regression analysesdetermined for them would not be representative of the graphically determined relations.

A review of previous flood-frequency studies for Washington indicated that various combinations of nine identified physical and climatic basin characteristics should be sufficient to produce equations by which flood magnitudes and frequencies can be accurately estimated. Brief descriptions of the nine identified basin characteristics are as follows:
Contributing drainage area, $A$, in square miles, upstream from the gaging station; determined by planimetering the contributing drainage area on a topographic map;

Main channel slope, $S l$, in feet per mile; determined by extending the main stream channel upstream to the basin divide and then locating a point that is 10 percent of the distance from the gage to the divide and another point on the stream that is 85 percent of the distance from the gage to the divide; the slope is equal to the difference in elevation between the two points divided by the distance between the points;

Stream length, $L$, in miles, from the gage to the basin divide; measured along the channel from the gage to the basin divide;

Basin elevation, $E$ - the mean basin elevation, in feet above sea level; determined by finding the average elevation of at least 20 equally spaced points in the drainage basin as indicated by a transparent grid overlay;

Storage, $S t$-the percentage of the contributing drainage area made up of lakes, ponds, and swamps; determined by placing a transparent grid over the drainage-basin map and counting the number of squares occupied by water or swamp surfaces; to prevent computing the logarithm of zero, storage values of zero percent were changed to 0.01 percent before running regression analyses;

Forest cover, $F$-the percentage of the contributing drainage area covered by forests; estimates of forest cover were obtained from the Washington State Department of Natural Resources; forest cover may also be determined by the grid-sampling method on a suitable large-scale map; to prevent computing the logarithm of zero, forest cover values of zero percent were changed to 0.01 percent before running regression analyses;

Annual precipitation, $P$-mean annual precipitation, in inches, determined by locating the basin on the precipitation map (plate 1 and U.S. Weather Bureau, 1965), placing a transparent grid over the map, and averaging the values determined at each grid intersection;

Precipitation intensity, $I_{24,2}$-the 24-hour rainfall, in inches, that can be expected on the average of once every 2 years within the basin, obtained by using the 
grid-sampling method from precipitation-frequency maps for the State of Washington (Miller and others, 1973); and

Minimum January temperature, $J$-the mean minimum January air temperature, in degrees Fahrenheit; determined by using the grid-sampling method on an equal-temperature map from the U.S. Department of Commerce (1965).

All nine of these basin characteristics were used in ordinary least-squares regression analyses to obtain an indication of which explanatory variables (basin characteristics) were most significant for each of nine State regions. Generalized least-squares regression analyses were used to develop equations for estimating flood magnitudes and frequencies for ungaged stream basins in each region. The goal was to develop sets of equations using only a few easily obtainable basin characteristics that could be used to estimate flood discharges at selected exceedance probabilities for sites on ungaged streams.

Flood-frequency determinations for all of the gaging stations and their associated basin characteristics were placed in a single data set for an initial regression analysis to attempt to determine the geographic regions within the State for which separate regression equations should be developed. The residuals (the differences between the flood magnitudes obtained from the flood-frequency analyses and the flood magnitudes obtained from the regression equations) were plotted on a statewide map. Using this same procedure, Cummans and others (1975) were able to subdivide the State into 12 regions, each with its own set of regression coefficients and constants. However, no meaningful grouping of the residuals computed during this study could be made. Adjacent basins and, in some cases, parts of the same basin were located in different regions when residuals were used as the grouping criteria. Therefore, hydrologic-unit code boundaries were used instead to group the stations into separate geographic regions believed to have different hydrologic characteristics. The State of Washington is divided into eight hydrologic units, each composed of several cataloging units (U.S. Geological Survey, 1976). Each cataloging unit, in turn, contains one to several major stream basins. For this study, an additional region was created by dividing the Columbia River Basin hydrologic unit into two subunits: one encompassing the Columbia Plateau (Region 7) and the other encompassing mostly those areas east of the Cascade Range and north or west of the Columbia River (Region 4). The nine geographic regions are shown on figure 1, and the distribution of gaging stations used for the regression analysis in each region is shown on figures $2-10$.

Regression analyses for each region included the use of the ordinary least-squares technique to obtain a preliminary list of which basin characteristics were most influential in affecting peak flows at the 5 percent level of significance. All nine of the basin characteristics identified in previous reports as being the most important in determining flood discharges were considered for inclusion in each regional regression equation. In addition, a subjective decision was made in cases where two or more basin characteristics were about of equal significance in estimating flood magnitude. In these cases, the relative ease by which values for the basin characteristics could be obtained was considered in the selection of which characteristics to use in the development of the regression equations for estimating flood magnitudes and frequencies for ungaged streams. The objective in making such decisions was to greatly simplify the application of an equation with only a minor decrease in its accuracy. Consequently, a regression equation may contain a basin characteristic that is slightly less significant than another characteristic that was considered but not included in the equation or it may contain fewer basin characteristics than the "best" regression equation defined by the regression analysis.

The physical and climatic basin characteristics determined most significant in predicting flood discharge were contributing drainage area and mean annual precipitation for regions 1, 2, 3, 4, 6, and 9; and contributing drainage area only for regions 5,7 , and 8 . All basin characteristic values were computed in accordance with both the NWIS basin-characteristics file guidelines and the National Handbook of Recommended Methods for Water-Data Acquisition (U. S. Department of the Interior, 1977). The basin characteristic values for the stations used in the regression analyses are given in table 3 .

Main channel slope, one of the basin characteristics found to be statistically significant in the development of the regression equation for region 5 , was removed from the final regression equation because it had a negative regression coefficient, which doesn't seem physically realistic. It is believed that its statistical significance in the regression analysis may be the result of either a spurious relationship or the fact that it may be a surrogate for one or more other basin characteristics.

Once it was determined which basin characteristics should be used for each regression region, then the flood-frequency data for each region were analyzed using 
the generalized least-squares technique (Tasker and Stedinger, 1989) to determine equations for estimating flood magnitude and frequency for ungaged sites within the regions. This method differs from the ordinary least-squares method by weighting each station used in an analysis on the basis of the number of years of peak flows in the station record and by the distance between stations. Ordinary least squares were not used to develop the regression equations because two assumptions that are made in the use of that method-that the residuals of the data have equal variances and that each residual is independent of all others - are usually violated to some degree in hydrologic regression analysis. In the case of peak-flow data, both of these assumptions are often violated.

Peak-flow records are usually of differing lengths, and nearby basins may be affected by the same weather patterns, leading to unwanted correlations in the peak flows.

The mathematical model used to define the relation between flood discharge and basin characteristics for each region was

$$
Q=a A^{b} B^{c} \ldots N^{n},
$$

where

$$
\begin{aligned}
Q & =\text { flood discharge, in cubic feet per second } \\
A, B, \ldots, N & =\text { basin characteristics, } \\
a & =\text { regression constant, and } \\
b, c, \ldots, n & =\text { regression coefficients. }
\end{aligned}
$$

This model was converted to the following linear form by transforming the variables $(Q, A, B, \ldots, N)$ to base 10 logarithms:

$$
\log Q=\log a+b(\log A)+c(\log B)+\ldots+n(\log N)
$$

Logarithmic transformations were performed so that least-squares linear regression techniques could be used during the analyses.

The regression equations developed for the nine flood-frequency regression regions are presented in table 4. The standard error of prediction (given in table 4) is a measure of how well the regression equation predicts $Q$ from the data used in the analysis; a higher degree of uncertainty is associated with a higher standard error. The highest percent standard error of prediction is found in Region 8 (133 percent for an exceedance probability of $0.5)$. Although the exact source of this high value is not known, it is probably a combination of the time sampling error and model error. The time sampling error is the error due to using a peak flow record that might not represent the entire range of peak flows possible at a site. The model error is the error due to not having the most influential variable in the regression equation. Although the time sampling error may be reduced by accumulating more years of peak-flow data, a reduction in model error is limited by the availability of basin-characteristic data and the cost and effort involved in collecting other types of basin data. Also, including more explanatory variables in the regression equation may reduce the model error at the cost of ease of use and data availability for the user. The equivalent years of record (given in table 4) is also a measure of the predictive ability of the regression equation, expressed as the number of years of actual peak-flow data required to achieve results equal to those obtained from the regression equation.

Weighted estimates of flood magnitude for the 504 gaging stations used in the regression analyses (table 2) were obtained using the weighting procedures presented in appendix 8 of the guidelines of the U.S. Water Resources Council (1981), in which two different estimates of flood magnitude (from the frequency analysis and from the regression equation) are weighted inversely proportional to their variance. The weighted estimates generally provide better estimates of the true flood discharges than those determined from either the flood-frequency analysis or the regression analysis alone.

\section{Application and Limitations of Regression Equations}

The flood magnitude for a desired exceedance probability for an ungaged site in an ungaged stream basin can be computed as follows:

1. From the figure showing the hydrologic regions (fig. 1), select the region in which the basin is located.

2. From table 4, find the desired equation for the selected region and exceedance probability.

3. Determine which basin characteristics are required for the selected regression equation and obtain or determine the required data.

4. Substitute the data values obtained in step 3 into the regression equation and compute the flood magnitude.

For example, to determine the magnitude for a flood with an exceedance probability of 0.01 at an ungaged site in Region 1 , the appropriate equation from table 4 would be 


$$
Q=0.745 A^{0.922} P^{1.26} .
$$

Assuming the drainage area of the basin is $100 \mathrm{mi}^{2}$ and the mean annual precipitation is 40 inches,

$$
\begin{aligned}
& Q=0.745(100)^{0.922}(40)^{1.26} \\
& Q=5,430 \text { cubic feet per second } .
\end{aligned}
$$

However, the flood discharge at an ungaged site on a gaged stream can be computed by the following equation (Thomas and others, 1994), if the drainage area of the ungaged site is between 50 and 150 percent of the drainage area of the gaged site:

$$
Q_{u}=Q_{g}\left(\frac{A_{u}}{A_{g}}\right)^{x}
$$

where

$$
\begin{aligned}
& Q_{u}=\text { flood discharge, in cubic feet per second, } \\
& \text { at the ungaged site, } \\
& Q_{g}=\text { weighted flood discharge, in cubic feet per } \\
& \text { second, at the gaged site (from table 2), } \\
& A_{u}=\text { contributing drainage area, in square miles, } \\
& \text { at the ungaged site, } \\
& A_{g}=\text { contributing drainage area, in square miles, } \\
& \text { at the gaged site, and } \\
& x=\text { exponent for each region as follows. }
\end{aligned}
$$

\begin{tabular}{cc}
\hline $\begin{array}{c}\text { Flood-Frequency } \\
\text { Regression Region }\end{array}$ & Exponent, $x$ \\
\hline 1 & 0.92 \\
2 & .98 \\
3 & .93 \\
4 & .97 \\
5 & .76 \\
6 & .75 \\
7 & .58 \\
8 & .69 \\
9 & .59 \\
\hline
\end{tabular}

The exponent $x$ for each region was determined by regressing the discharges for each exceedance probability on the drainage areas for the stations in the region. The drainage area exponents determined from the regression analyses for each of the exceedance probabilities were averaged to produce the single exponent for each region.
Equation 5 should only be used if the basins of the gaged and ungaged sites have similar basin characteristics. Therefore, if a large tributary enters the stream between the gaged and ungaged sites, and the tributary basin has much different topography, vegetation, or other basin characteristics that could affect flood discharges, then the appropriate regression equation from this report should be used to estimate flood-frequency discharges for the ungaged site.

The following is an example of the determination of the flood discharge with an exceedance probability of 0.01 at an ungaged site on the Naselle River (Region 1). The contributing drainage area at the ungaged site $\left(A_{u}\right)$ is 47 square miles. The contributing drainage area at the gage $\left(A_{g}\right)$ on the Naselle River (station number 12010000 in table 2 ) is 54.8 square miles.

The drainage area of the ungaged site $A_{u}$, expressed as a percentage of the drainage area of the gaged site $A_{g}$, is given by:

$$
\left(\frac{A_{u}}{A_{g}}\right) 100=\left(\frac{47 \text { square miles }}{54.8 \text { square miles }}\right) 100=86 \text { percent },
$$

which satisfies the requirement for the use of equation 5 .

The weighted discharge, $Q_{g}$ (obtained from table 2, third line for station 12010000$)$ is 12,100 cubic feet per second. The exponent, $x$, for Region 1 is 0.92 . The computed discharge, $Q_{u}$, is

$$
\begin{aligned}
Q_{0.01} & =12,100\left(\frac{47}{54.8}\right)^{0.92} \\
& =10,500 \text { cubic feet per second } .
\end{aligned}
$$

There are some limitations to the use of the regional flood-frequency equations presented in this report. One is that the equations should not be used for streams in which the flow is significantly regulated or diverted because the regression coefficients were computed from gaging-station data for naturally flowing (unregulated) streams. Another limitation is that the equations should not be used to compute discharges for basins in which the values for one or more of the basin characteristics are significantly outside the range of values used in the development of the equations. Maximum and minimum basin characteristic values used in the development of the regression equations are listed in table 5 . 
A further limitation on the use of the regression equations is that they should not be used for basins in which urbanization has taken place. Because the regression equations were developed using data from unurbanized basins, application of the equations to urbanized basins could produce misleading results. Techniques for estimating flood discharges on urban streams are presented by Sauer and others (1983).

\section{SUMMARY}

The procedures recommended by the U.S. Water Resources Council (1981) were applied to the peak-flow records of 527 gaging stations on unregulated streams in the State of Washington to obtain discharges with exceedance probabilities of $0.5,0.1,0.04,0.02$, and 0.01 . The frequency analyses included peak-flow data collected through the 1996 water year.

The results of the frequency analysis were combined with physical and climatic basin characteristics values to develop equations that can be used to compute peak discharges for ungaged streams. The State was divided into nine regions, based on hydrologic unit boundaries, and a separate set of equations was developed for each region. Basin characteristics shown to be important in estimating flood discharge include contributing drainage area and mean annual precipitation.

\section{REFERENCES CITED}

Anderson, I.E., 1948, Floods of the Puyallup and Chehalis River Basins, Washington: U.S. Geological Survey Water-Supply Paper 968-B, p. 61-124.

Bailey, E.G., 1960, Floods in the Nooksack River Basin, in Water resources of the Nooksack River Basin and certain adjacent streams: State of Washington, Department of Conservation, Division of Water Resources Water-Supply Bulletin No. 12, p. 95-98.

Bodhaine, G.L. and Robinson, W.H., 1952, Floods in Western Washington, Frequency and magnitude in relation to drainage basin characteristics: Geological Survey Circular 191, 124 p.

Bodhaine, G.L. and Thomas, D.M., 1960, Floods in Washington, magnitude and frequency: U.S. Geological Survey Open-File Report, 25 p.
1964, Magnitude and frequency of floods in the United States, part 12, Pacific Slope Basins in Washington and upper Columbia River Basin: Geological Survey Water-Supply Paper 1687, 335 p.

Cummans, J.E., Collings, M.R., and Nassar, E.G., 1975, Magnitude and frequency of floods in Washington: U.S. Geological Survey Open-File Report 74-336, $46 \mathrm{p}$.

Drost, B.W. and Lombard, R.E., 1978, Water in the Skagit River Basin, Washington: State of Washington, Department of Ecology Water-Supply Bulletin 47, $247 \mathrm{p}$.

Fenneman, N.M., 1931, Physiography of western United States: New York, McGraw-Hill Book Company, Inc., $534 \mathrm{p}$.

Haushild, W.L., 1979, Estimation of floods of various frequencies for the small ephemeral streams in eastern Washington: U.S. Geological Survey WaterResources Investigations Open-File Report 79-81, $22 \mathrm{p}$.

Kirby, William, 1981, Annual flood frequency analysis using U.S. Water Resources Council guidelines (Program J407), chapter I, section C of WATSTORE user's guide: U.S. Geological Survey Open-File Report 76-435, v. 4, p. C-1 to C-57.

Miller, J.F., Frederick, A.H., and Tracey, R.J., 1973, Precipitation atlas of the western United States, vol. IX, Washington: National Oceanic and Atmospheric Administration NOAA Atlas 2, 43 p.

Nassar, E.G. and Walters, K.L., 1975, Water in the Palouse River Basin, Washington: State of Washington, Department of Ecology Water-Supply Bulletin 39, $246 \mathrm{p}$.

Rantz, S.E. and Riggs, H.C., 1949, Magnitude and frequency of floods in the Columbia River Basin, in U.S. Geological Survey, 1949, Floods of May-June 1948 in Columbia River basin: Geological Survey Water-Supply Paper 1080, p. 317-469.

Richardson, Donald, 1965, Effect of logging on runoff in upper Green River basin, Washington, a progress report: U.S. Geological Survey Open-File Report, $45 \mathrm{p}$. 
Sauer, V.B., Thomas, W.O., Jr., Stricker, V.A., and Wilson, K.V., 1983, Flood characteristics of urban watersheds in the United States: U.S. Geological Survey Water-Supply Paper 2207, 63 p.

Tasker, G.D., and Stedinger, J.R., 1989, An operational GLS model for hydrologic regression: Journal of Hydrology, v. III, nos. 1-4, p. 361-275.

Thomas, B.E., Hjalmarson, H.W., and Waltemeyer, S.D. 1994, Methods for estimating magnitude and frequency of floods in the southwestern United States: U.S. Geological Survey Open-File Report 93-419, $211 \mathrm{p}$.

Thomas, C.A., Broom, H.C., and Cummans, J.E., 1963, Magnitude and frequency of floods in the United States, part 13, Snake River basin: Geological Survey Water-Supply Paper 1688, 250 p.

U.S. Department of Commerce, 1965, Climates of the states-Climate of Washington, in Climatography of the United States, no. 60-45: U.S. Weather Bureau, $27 \mathrm{p}$.

U.S. Department of the Interior, 1977, National handbook of recommended methods for water-data acquisition:

U.S. Geological Survey Office of Water Data Coordination, variously paged.

U.S. Geological Survey, 1976, Hydrologic unit map--1974, State of Washington: Reston, Va, U.S. Geological Survey, 1 sheet, scale 1:500,000.

U.S. Water Resources Council, 1981, Guidelines for determining flood flow frequency: U.S. Water Resources Council Bulletin 17B, 28 p., 14 appendixes.
U.S. Weather Bureau, 1965, State of Washington, mean annual precipitation, 1930-1957: Portland, Oreg., Soil Conservation Service, map M-4430, 1 sheet, [no scale].

Walters, K.L., 1974, Water in the Okanogan River Basin, Washington: State of Washington, Department of Ecology Water-Supply Bulletin 34, $136 \mathrm{p}$.

Walters, K.L. and Nassar, E.G., 1974, Water in the Methow River Basin, Washington: State of Washington, Department of Ecology WaterSupply Bulletin 38, 73 p.

Williams, J.R., and Pearson, H.E., 1985a, Streamflow statistics and drainage-basin characteristics for the southwestern and eastern regions, Washington, Volume I, Southwestern Washington: U.S. Geological Survey Open-File Report 84-145-A, $424 \mathrm{p}$.

1985b, Streamflow statistics and drainage-basin characteristics for the southwestern and eastern regions, Washington, Volume II, Eastern Washington: U.S. Geological Survey Open-File Report 84-145-B, $662 \mathrm{p}$.

Williams, J.R., Pearson, H.E., and Wilson, J.D., 1985a, Streamflow statistics and drainage-basin characteristics for the Puget Sound region, Washington, Volume I, Western and southern Puget Sound: U.S. Geological Survey Open-File Report 84-144-A, 330 p.

1985b, Streamflow statistics and drainagebasin characteristics for the Puget Sound region, Washington, Volume II, Eastern Puget Sound from Seattle to the Canadian border: U.S. Geological Survey Open-File Report 84-144-B, 420 p. 


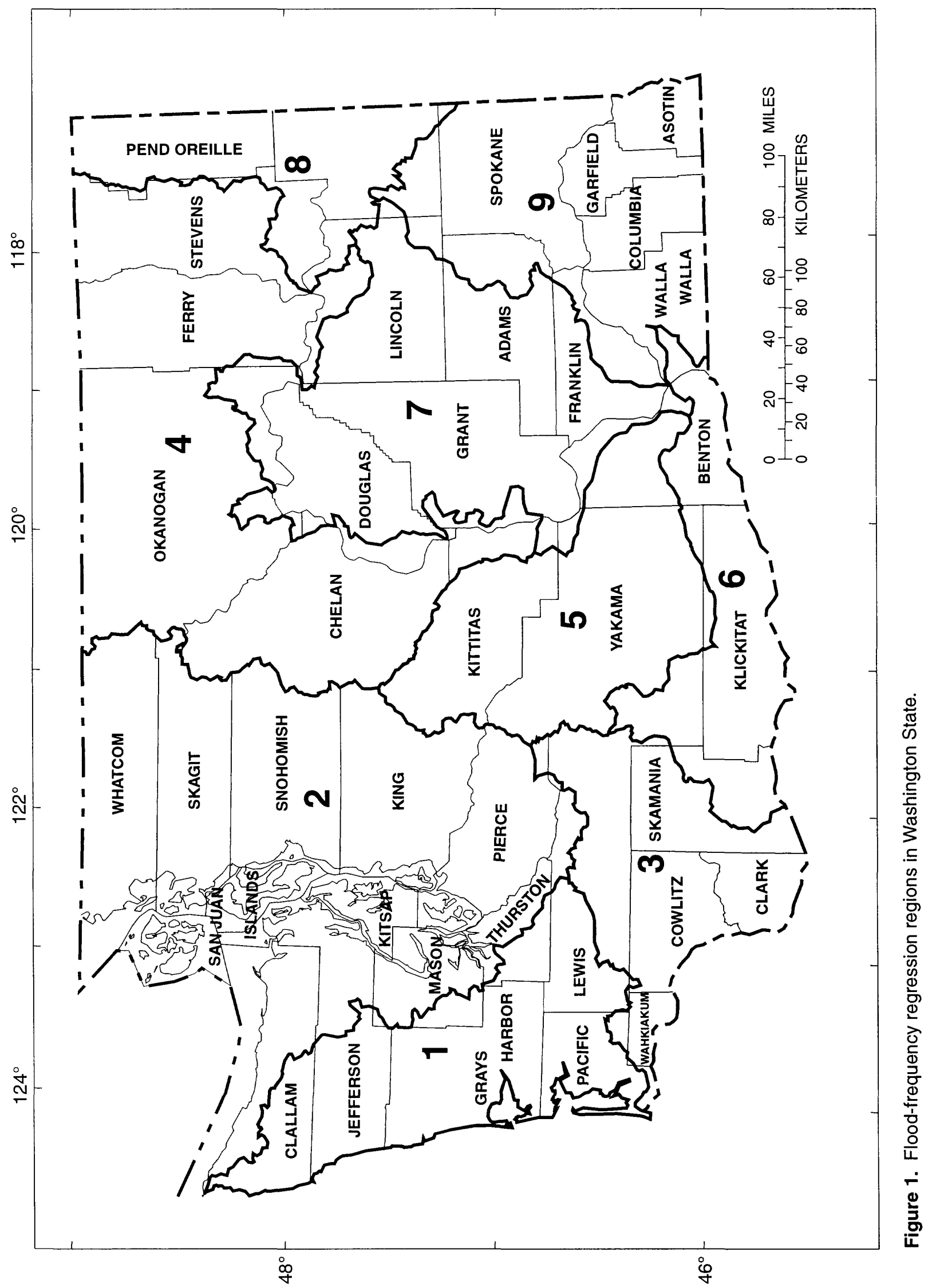




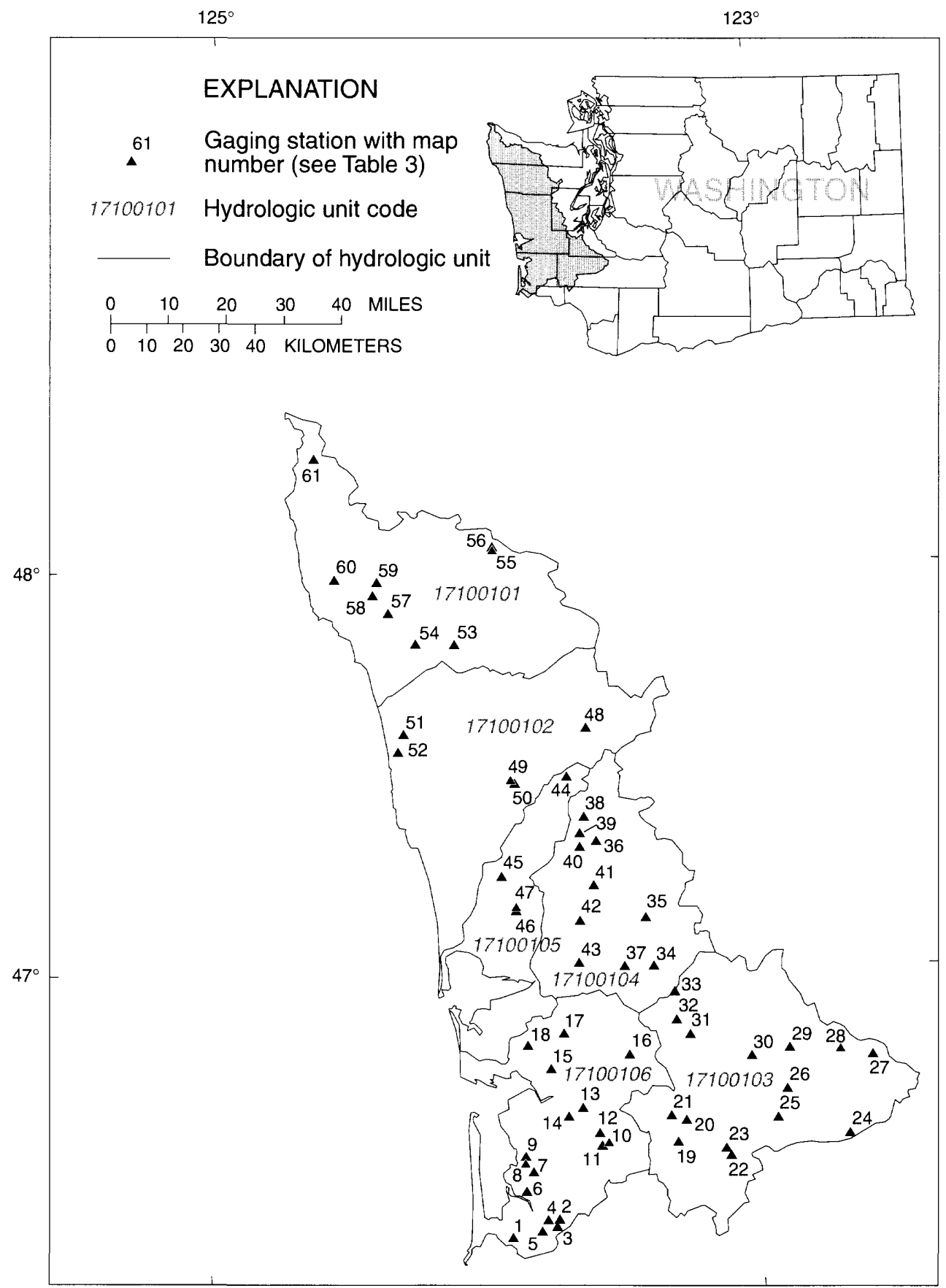

Figure 2. Distribution of gaging stations used in the development of the regression equation for region 1 . 


\section{EXPLANATION}

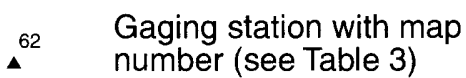

17110001 Hydrologic unit code

Boundary of hydrologic unit

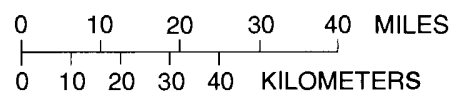

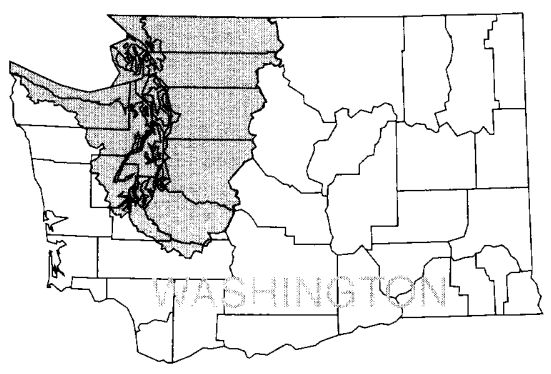

$49^{\circ}$

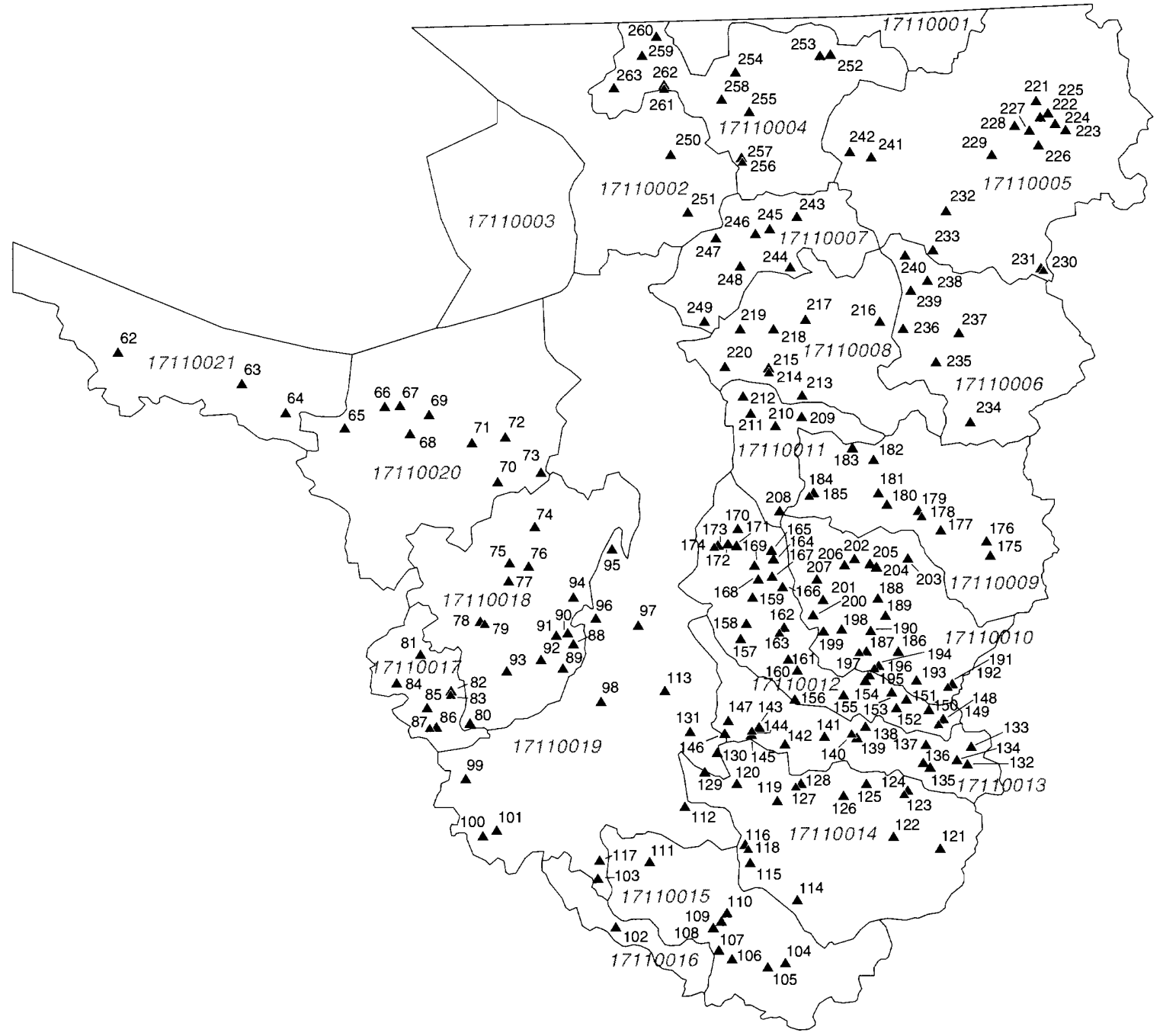

Figure 3 . Distribution of gaging stations used in the development of the regression equation for region 2 . 


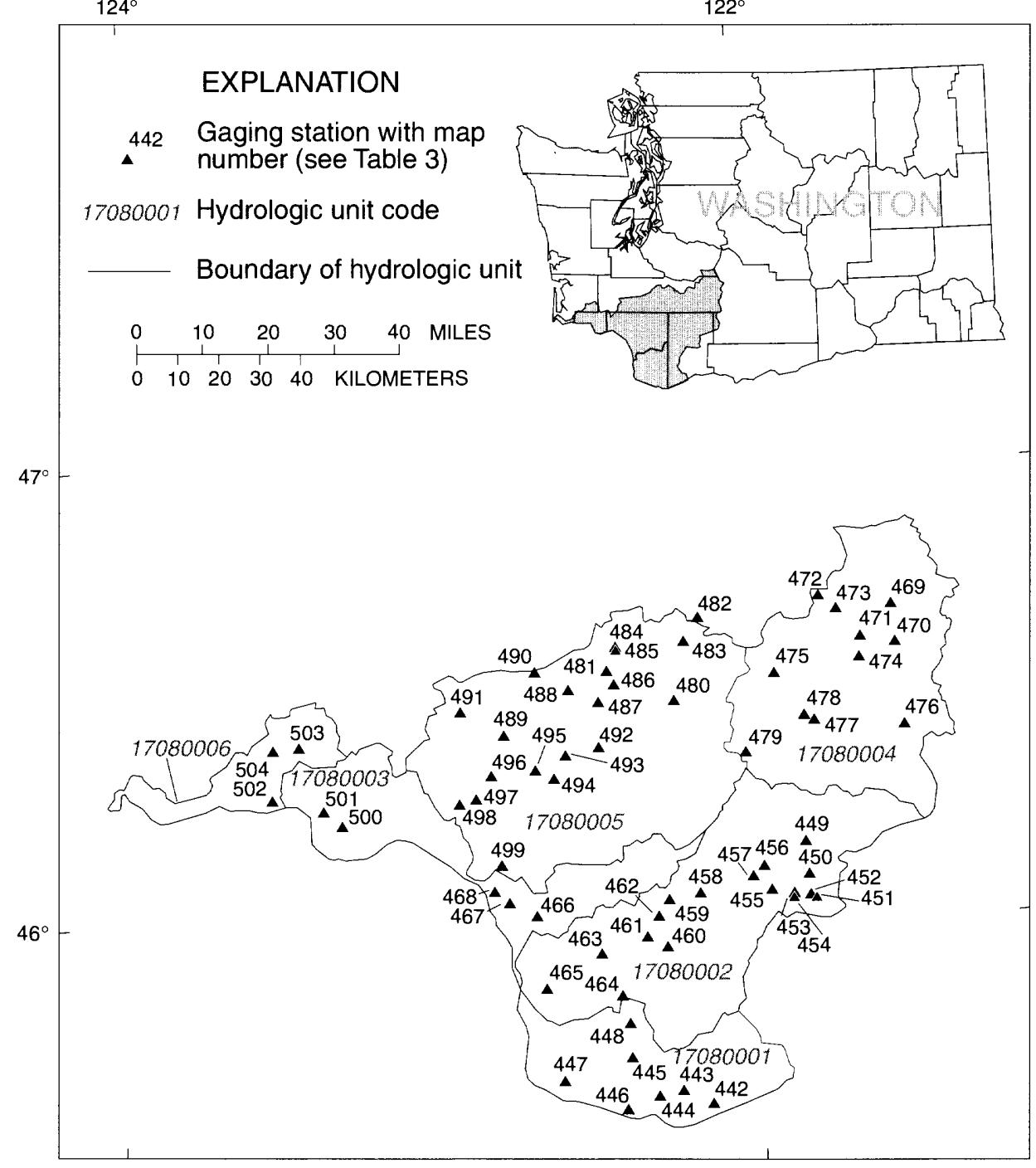

Figure 4. Distribution of gaging stations used in the development of the regression equation for region 3 . 


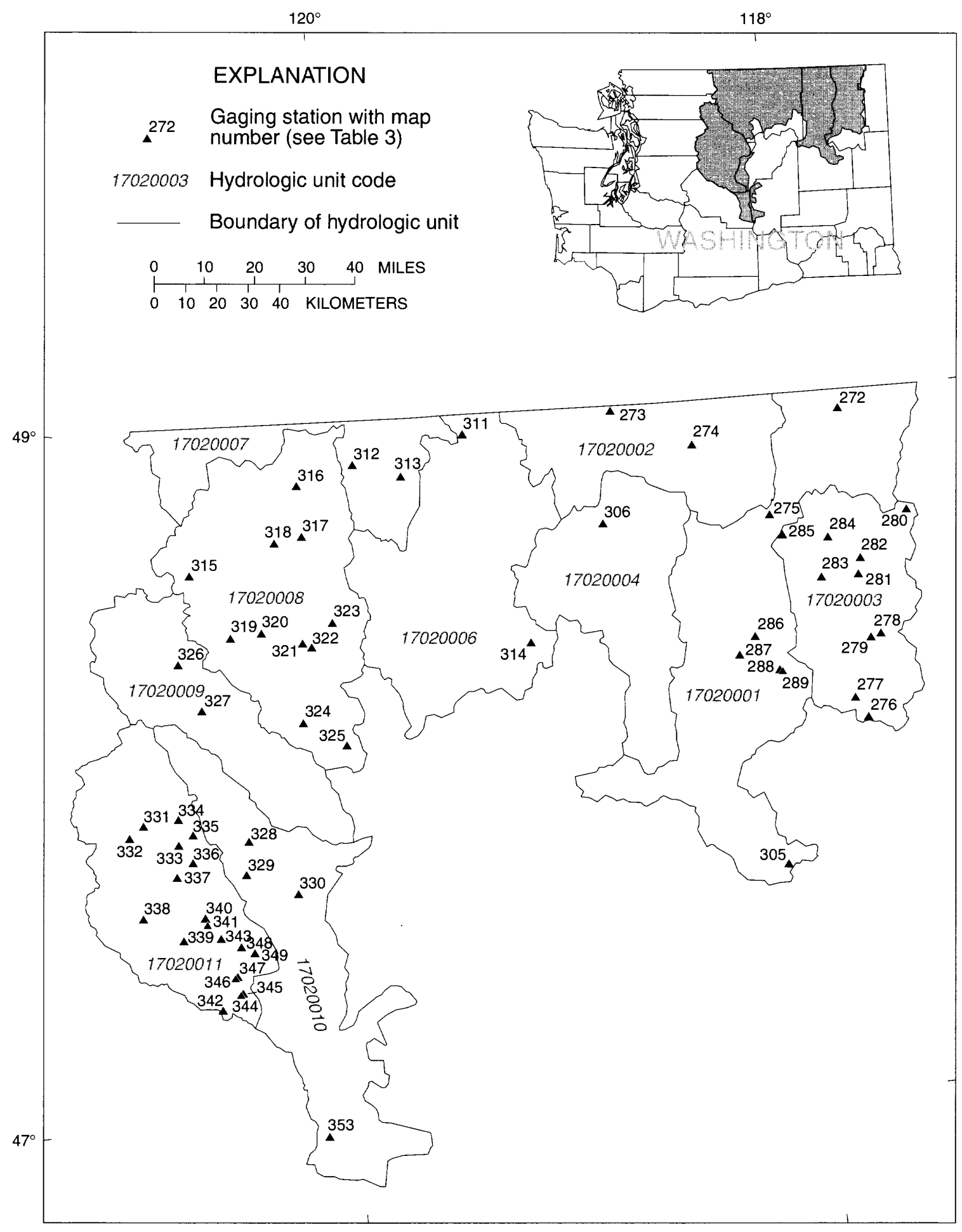

Figure 5. Distribution of gaging stations used in the development of the regression equation for region 4 . 


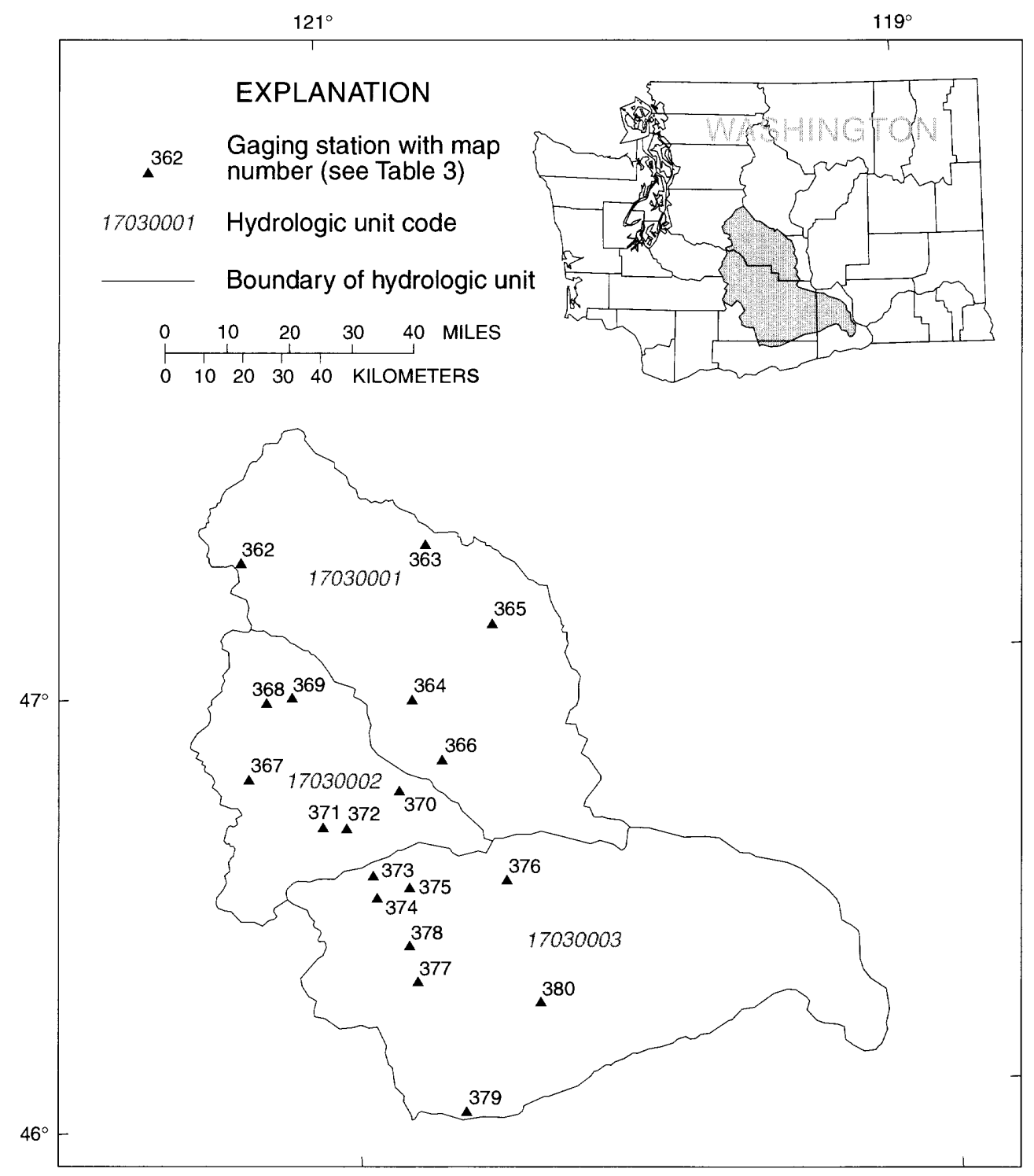

Figure 6. Distribution of gaging stations used in the development of the regression equation for region 5 . 


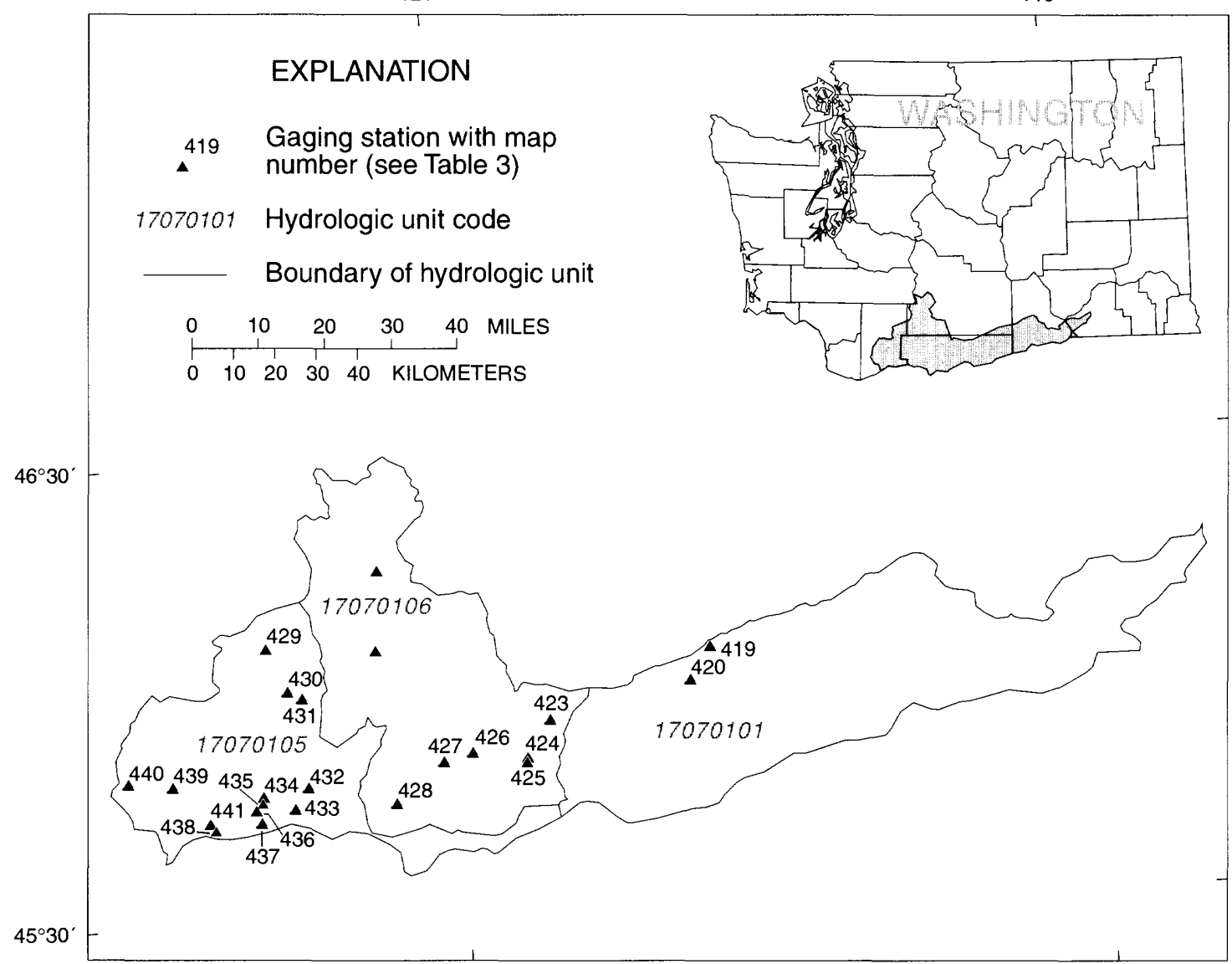

Figure 7. Distribution of gaging stations used in development of the regression equation for region 6 . 


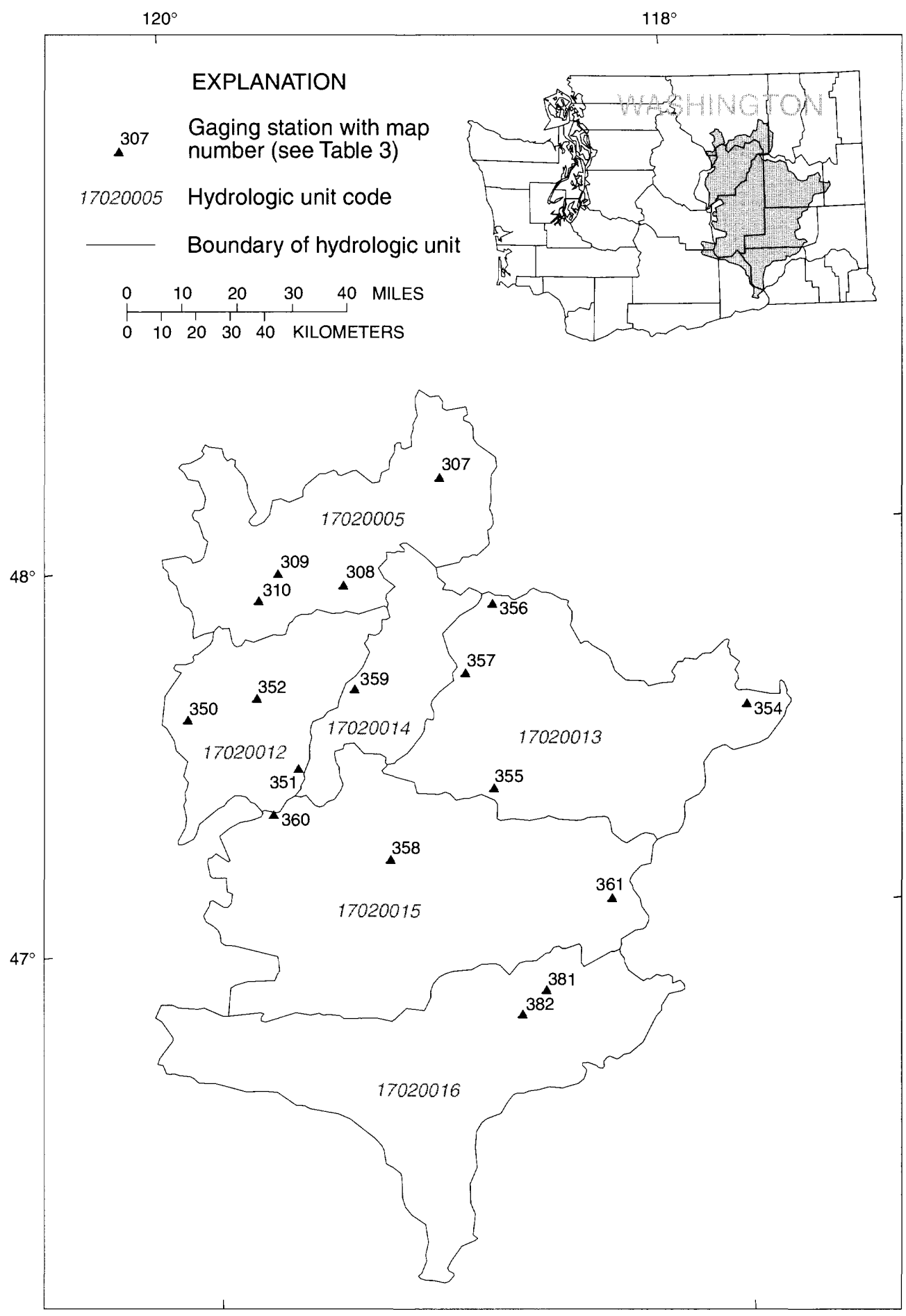

Figure 8. Distribution of gaging stations used in the development of the regression equation for region 7 . 


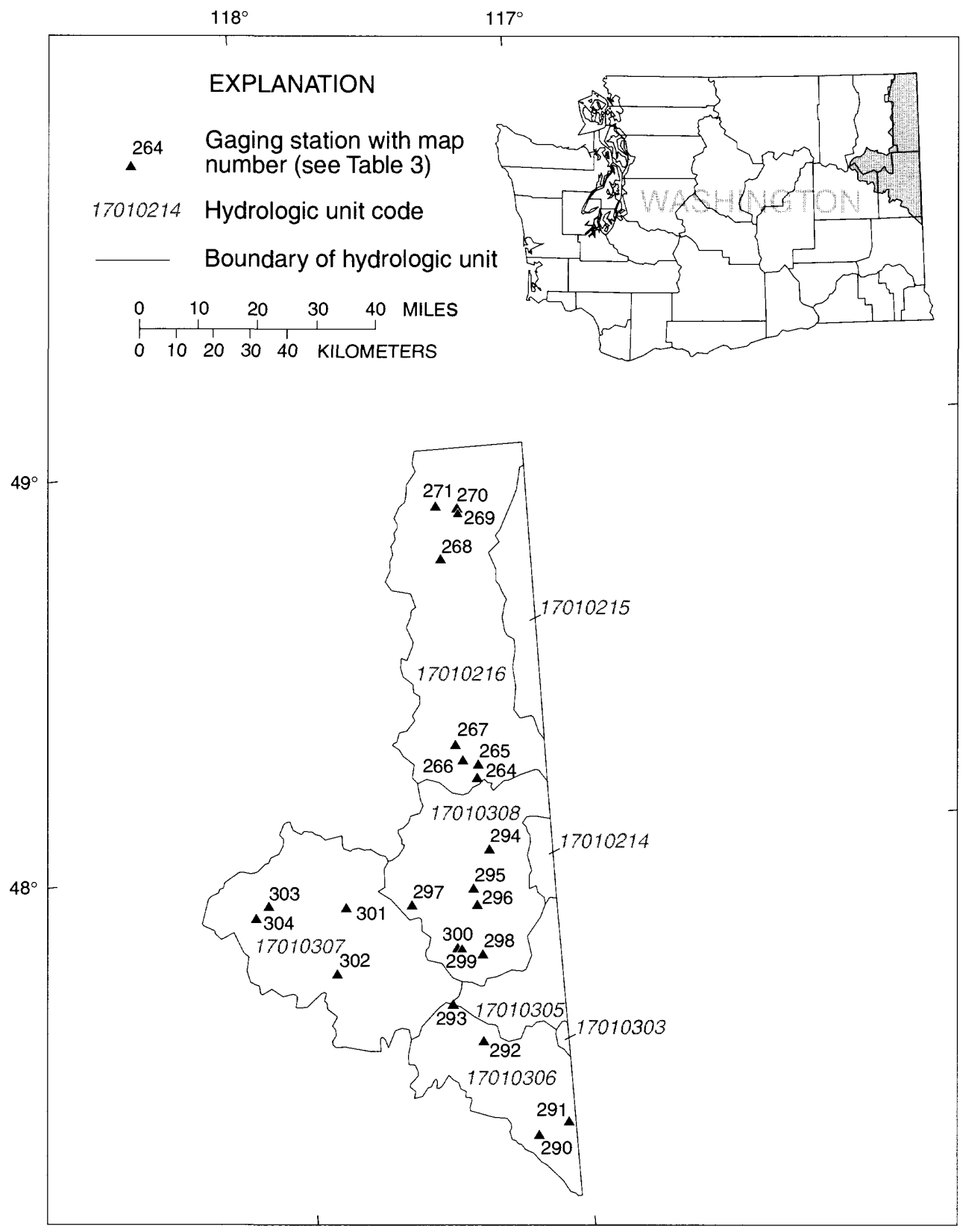

Figure 9. Distribution of gaging stations used in the development of the regression equation for region 8 . 


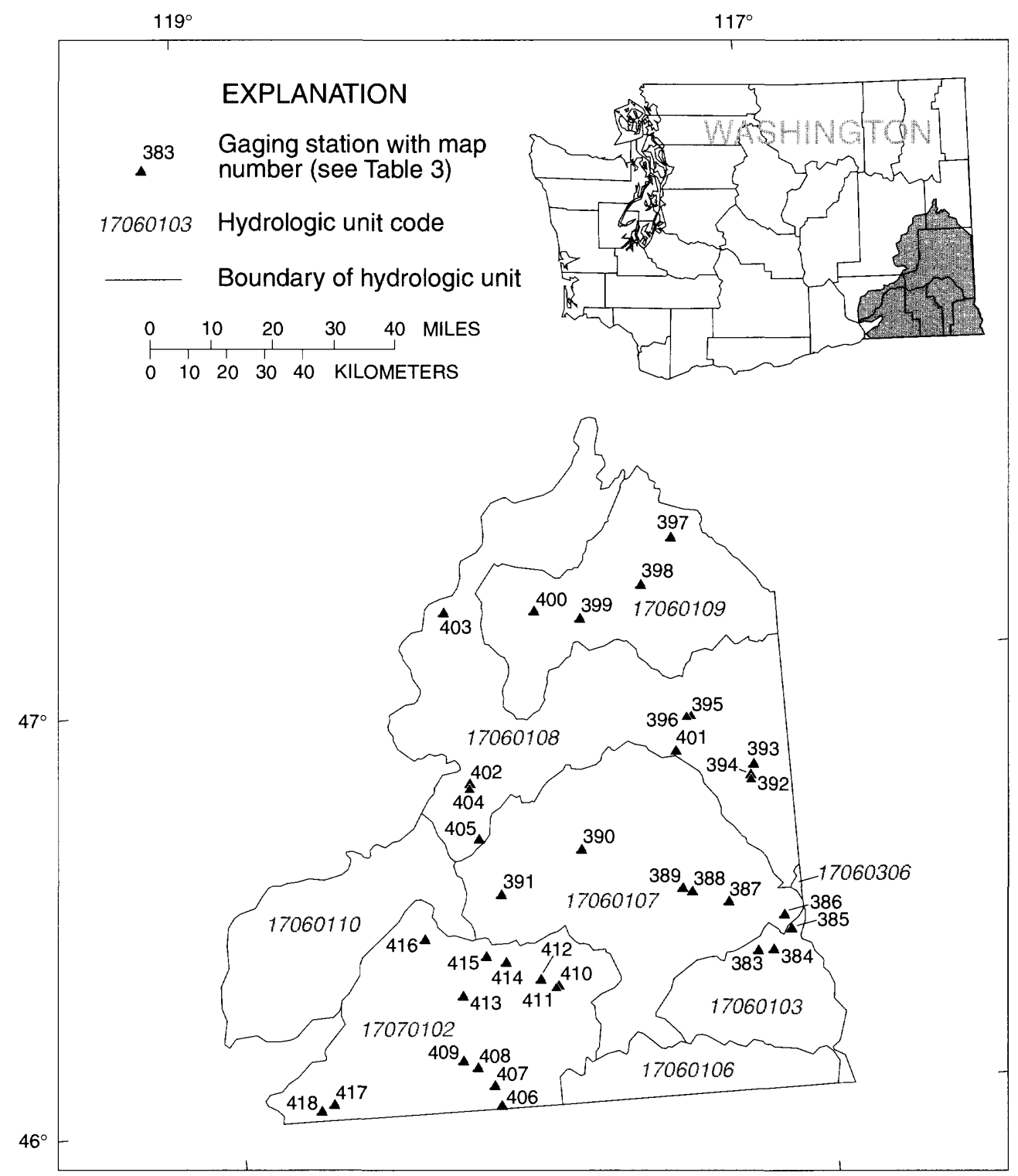

Figure 10. Distribution of gaging stations used in the development of the regression equation for region 9 . 
Table 1. Gaging stations with at least 10 years of unregulated peak-flow data

[R, water years for which peak discharges were affected by regulation]

\begin{tabular}{|c|c|c|}
\hline $\begin{array}{l}\text { Station } \\
\text { number }\end{array}$ & Station name & $\begin{array}{l}\text { Years of peak record } \\
\text { (Water years) }\end{array}$ \\
\hline 12009500 & Bear Branch near Naselle, Wash. & $(1964-79)$ \\
\hline 12010000 & Naselle River near Naselle, Wash. & $(1930-96)$ \\
\hline 12010500 & Salmon Creek near Naselle, Wash. & $(1954-65)$ \\
\hline 12010600 & Lane Creek near Naselle, Wash. & $(1950-70)$ \\
\hline 12010700 & South Fork Naselle River near Naselle, Wash. & $(1965-79)$ \\
\hline 12010800 & South Nemah River near Naselle, Wash. & $(1962-77)$ \\
\hline 12011000 & North Nemah River near South Bend, Wash. & $(1947-58,1960-61,1965-68,1977)$ \\
\hline 12011100 & North Nemah River Tributary near South Bend, Wash. & $(1949-66)$ \\
\hline 12011200 & Williams Creek near South Bend, Wash. & $(1965-79)$ \\
\hline 12011500 & Willapa River at Lebam, Wash. & $(1949-74)$ \\
\hline 12012000 & Fork Creek near Lebam, Wash. & $(1954-79)$ \\
\hline 12012200 & Green Creek near Lebam, Wash. & $(1950-69)$ \\
\hline 12013500 & Willapa River near Willapa, Wash. & $(1949-56,1958-59,1962-96)$ \\
\hline 12014500 & South Fork Willapa River near Raymond, Wash. & $(1954-76,1978-79)$ \\
\hline 12015100 & Clearwater Creek near Raymond, Wash. & $(1965-79)$ \\
\hline 12015500 & North River near Brooklyn, Wash. & $(1954-65)$ \\
\hline 12016700 & Joe Creek near Cosmopolis, Wash. & $(1949-70)$ \\
\hline 12017000 & North River near Raymond, Wash. & $(1928-34 \mathrm{R}, 1935-79,1996)$ \\
\hline 12019600 & Water Mill Creek near Pe Ell, Wash. & $(1950-70)$ \\
\hline 12020000 & Chehalis River near Doty, Wash. & $(1940-96)$ \\
\hline 12020500 & Elk Creek near Doty, Wash. & $(1945-50,1952-72,1974-79)$ \\
\hline 12020900 & South Fork Chehalis River near Boistfort, Wash. & $(1966-80)$ \\
\hline 12021000 & South Fork Chehalis River at Boistfort, Wash. & $(1945-65)$ \\
\hline 12024000 & South Fork Newaukum River near Onalaska, Wash. & $(1945-48,1958-76,1978-79,1996)$ \\
\hline 12025000 & Newaukum River near Chehalis, Wash. & $(1929-31,1943-81,1983-96)$ \\
\hline 12025300 & Salzer Creek near Centralia, Wash. & $(1969-79)$ \\
\hline 12025700 & Skookumchuck River near Vail, Wash. & $(1968-96)$ \\
\hline 12026000 & Skookumchuck River near Centralia, Wash. & $(1930-33,1940-69)$ \\
\hline 12026300 & Skookumchuck River Tributary near Bucoda, Wash. & $(1960-75)$ \\
\hline 12027500 & Chehalis River near Grand Mound, Wash. & $(1929-96)$ \\
\hline 12029700 & Chehalis River near Oakville, Wash. & $(1947-76)$ \\
\hline 12030000 & Rock Creek at Cedarville, Wash. & $(1945-74)$ \\
\hline 12031000 & Chehalis River at Porter, Wash. & $(1947-85,1987-96)$ \\
\hline 12032500 & Cloquallum River at Elma, Wash. & $(1945-79)$ \\
\hline 12034200 & East Fork Satsop River near Elma, Wash. & $(1958-73)$ \\
\hline 12034700 & West Fork Satsop River Tributary near Matlock, Wash. & $(1958-77)$ \\
\hline 12035000 & Satsop River near Satsop, Wash. & $(1930-96)$ \\
\hline 12035450 & Big Creek near Grisdale, Wash. & $(1973-96)$ \\
\hline 12035500 & Wynoochee River at Oxbow, near Aberdeen, Wash. & $(1926-52)$ \\
\hline 12036000 & Wynoochee River above Save Creek, near Aberdeen, Wash. & $(1926-72,1973-96 \mathrm{R})$ \\
\hline
\end{tabular}


Table 1. Gaging stations with at least 10 years of unregulated peak-flow data--Continued

\begin{tabular}{|c|c|c|}
\hline $\begin{array}{l}\text { Station } \\
\text { number }\end{array}$ & Station name & $\begin{array}{l}\text { Years of peak record } \\
\text { (Water years) }\end{array}$ \\
\hline 12036400 & Schafer Creek near Grisdale, Wash. & $(1987-96)$ \\
\hline 12036650 & Anderson Creek near Montesano, Wash. & $(1973-85)$ \\
\hline 12037400 & Wynoochee River above Black Creek near Montesano, Wash. & $(1957-72,1973-96 \mathrm{R})$ \\
\hline 12038750 & Gibson Creek near Quinault, Wash. & $(1965-75)$ \\
\hline 12039000 & Humptulips River near Humptulips, Wash. & $(1934-35,1943-79)$ \\
\hline 12039050 & Big Creek near Hoquiam, Wash. & $(1949-70)$ \\
\hline 12039100 & Big Creek Tributary near Hoquiam, Wash. & $(1949-68)$ \\
\hline 12039300 & North Fork Quinault River near Amanda Park, Wash. & $(1965-86)$ \\
\hline 12039400 & Higley Creek near Amanda Park, Wash. & $(1955-74)$ \\
\hline 12039500 & Quinault River at Quinault Lake, Wash. & $(1910,1912-22,1926-96)$ \\
\hline 12040000 & Clearwater River near Clearwater, Wash. & $(1932,1935,1938-46,1948-67)$ \\
\hline 12040500 & Queets River near Clearwater, Wash. & $(1931-67,1975-96)$ \\
\hline 12041000 & Hoh River near Forks, Wash. & $(1927-64)$ \\
\hline 12041200 & Hoh River at U.S. Highway 101 near Forks, Wash. & $(1961-96)$ \\
\hline 12041500 & Soleduck River near Fairholm, Wash. & $(1918-21,1934-80)$ \\
\hline 12041600 & Solduck River Tributary near Fairholm, Wash. & $(1956-75)$ \\
\hline 12042700 & May Creek near Forks, Wash. & $(1950-68)$ \\
\hline 12042900 & Grader Creek near Forks, Wash. & $(1950-88)$ \\
\hline 12043000 & Calawah River near Forks, Wash. & $(1898-1901,1976-80,1985-96)$ \\
\hline 12043100 & Dickey River near La Push, Wash. & $(1963-80)$ \\
\hline 12043163 & Sooes River below Miller Creek near Ozette, Wash. & $(1976-86)$ \\
\hline 12043300 & Hoko River near Sekiu, Wash. & $(1963-78,1996)$ \\
\hline 12043430 & East Twin River near Pysht, Wash. & $(1963-78)$ \\
\hline 12044000 & Lyre River at Piedmont, Wash. & $(1918-27)$ \\
\hline 12045500 & Elwha River at Mcdonald Bridge near Port Angeles, Wash. & $(1898-1902,1920-26,1927-96 \mathrm{R})$ \\
\hline 12046800 & East Valley Creek at Port Angeles, Wash. & $(1950-63)$ \\
\hline 12047100 & Lees Creek at Port Angeles, Wash. & $(1949-70)$ \\
\hline 12047300 & Morse Creek near Port Angeles, Wash. & $(1967-79)$ \\
\hline 12047500 & Siebert Creek near Port Angeles, Wash. & $(1953-69)$ \\
\hline 12047700 & Gold Creek near Blyn, Wash. & $(1965-75)$ \\
\hline 12048000 & Dungeness River near Sequim, Wash. & $(1924-30,1938-96)$ \\
\hline 12049400 & Dean Creek at Blyn, Wash. & $(1949-70)$ \\
\hline 12050500 & Snow Creek near Maynard, Wash. & $(1953-79)$ \\
\hline 12052400 & Penny Creek near Quilcene, Wash. & $(1949-68)$ \\
\hline 12053000 & Dosewallips River near Brinnon, Wash. & $(1931-68)$ \\
\hline 12053400 & Dosewallips River Tributary near Brinnon, Wash. & $(1951-70)$ \\
\hline 12054000 & Duckabush River near Brinnon, Wash. & $(1939-96)$ \\
\hline 12054500 & Hamma Hamma River near Eldon, Wash. & $(1952-79)$ \\
\hline 12054600 & Jefferson Creek near Eldon, Wash. & $(1958-79)$ \\
\hline 12056300 & Annas Bay Tributary near Potlatch, Wash. & $(1950-70)$ \\
\hline
\end{tabular}


Table 1. Gaging stations with at least 10 years of unregulated peak-flow data--Continued

\begin{tabular}{|c|c|c|}
\hline $\begin{array}{l}\text { Station } \\
\text { number }\end{array}$ & Station name & $\begin{array}{l}\text { Years of peak record } \\
\text { (Water years) }\end{array}$ \\
\hline 12056500 & N.F. Skokomish R. blw Staircase Rapids nr Hoodsport, Wash. & $(1925-96)$ \\
\hline 12057500 & North Fork Skokomish River near Hoodsport, Wash. & $(1914-25,1926-30 \mathrm{R})$ \\
\hline 12058000 & Deer Meadow Creek near Hoodsport, Wash. & $(1953-79)$ \\
\hline 12059800 & South Fork Skokomish River near Hoodsport, Wash. & $(1964-70,1972-79)$ \\
\hline 12060000 & South Fork Skokomish River near Potlatch, Wash. & $(1924-32,1947-64)$ \\
\hline 12060500 & South Fork Skokomish River near Union, Wash. & $(1932-84,1996)$ \\
\hline 12061200 & Fir Creek Tributary near Potlatch, Wash. & $(1955-74)$ \\
\hline 12063000 & Union River near Bremerton, Wash. & $(1946-56,1957-59 R)$ \\
\hline 12063500 & Union River near Belfair, Wash. & $(1948-57,1958-59 R)$ \\
\hline 12065500 & Gold Creek near Bremerton, Wash. & $(1946-70,1972-79)$ \\
\hline 12066000 & Tahuya River near Bremerton, Wash. & $(1946-56)$ \\
\hline 12067500 & Tahuya River near Belfair, Wash. & $(1946-49,1951-56)$ \\
\hline 12068500 & Dewatto River near Dewatto, Wash. & $(1948-57,1959-79)$ \\
\hline 12069550 & Big Beef Creek near Seabeck, Wash. & $(1970-81)$ \\
\hline 12070000 & Dogfish Creek near Poulsbo, Wash. & $(1948-73)$ \\
\hline 12072000 & Chico Creek near Bremerton, Wash. & $(1948-50,1962-79)$ \\
\hline 12072600 & Beaver Creek near Manchester, Wash. & $(1967-76)$ \\
\hline 12073500 & Huge Creek near Wauna, Wash. & $(1948-69,1978-96)$ \\
\hline 12076500 & Goldsborough Creek near Shelton, Wash. & $(1952-79)$ \\
\hline 12078400 & Kennedy Creek near Kamilche, Wash. & $(1961-74,1976-79,1992-93)$ \\
\hline 12078600 & Schneider Creek Tributary near Shelton, Wash. & $(1950-69)$ \\
\hline 12079000 & Deschutes River near Rainier, Wash. & $(1950-79,1981-82,1988-96)$ \\
\hline 12080000 & Deschutes River near Olympia, Wash. & $(1946-64)$ \\
\hline 12081000 & Woodland Creek near Olympia, Wash. & $(1950-69)$ \\
\hline 12081300 & Eaton Creek near Yelm, Wash. & $(1960-88)$ \\
\hline 12082500 & Nisqually River near National, Wash. & $(1943-96)$ \\
\hline 12083000 & Mineral Creek near Mineral, Wash. & $(1943-96)$ \\
\hline 12084000 & Nisqually River near Alder, Wash. & $(1932-44)$ \\
\hline 12084500 & Little Nisqually River near Alder, Wash. & $(1921-43)$ \\
\hline 12086500 & Nisqually River at La Grande, Wash. & $(1907-08,1910-11,1920-31,1945-96 \mathrm{R})$ \\
\hline 12087000 & Mashel River near La Grande, Wash. & $(1941-57,1992-96)$ \\
\hline 12088000 & Ohop Creek near Eatonville, Wash. & $(1928-32,1942-74,1993-96)$ \\
\hline 12090200 & Muck Creek at Roy, Wash. & $(1957-76,1996)$ \\
\hline 12090400 & North Fork Clover Creek near Parkland, Wash. & $(1960-75,1995-96)$ \\
\hline 12091700 & Judd Creek near Burton, Wash. & $(1969-79)$ \\
\hline 12092000 & Puyallup River near Electron, Wash. & $(1912-26,1945-49,1958-96)$ \\
\hline 12093000 & Kapowsin Creek near Kapowsin, Wash. & $(1928-32,1942-70)$ \\
\hline 12093500 & Puyallup River near Orting, Wash. & $(1932-96)$ \\
\hline 12093900 & Carbon River at Fairfax, Wash. & $(1966-78)$ \\
\hline 12094000 & Carbon River near Fairfax, Wash. & $(1930-78,1991-96)$ \\
\hline
\end{tabular}


Table 1. Gaging stations with at least 10 years of unregulated peak-flow data--Continued

\begin{tabular}{|c|c|c|}
\hline $\begin{array}{l}\text { Station } \\
\text { number }\end{array}$ & Station name & $\begin{array}{l}\text { Years of peak record } \\
\text { (Water years) }\end{array}$ \\
\hline 12095000 & South Prairie Creek at South Prairie, Wash. & $(1950-79,1988-96)$ \\
\hline 12096500 & Puyallup River at Alderton, Wash. & $(1916-27,1944-57,1996)$ \\
\hline 12096800 & Dry Creek near Greenwater, Wash. & $(1957-75)$ \\
\hline 12096950 & Jim Creek near Greenwater, Wash. & $(1965-75)$ \\
\hline 12097000 & White River at Greenwater, Wash. & $(1930-76,1978)$ \\
\hline 12097500 & Greenwater River at Greenwater, Wash. & $(1912,1930-78,1993-96)$ \\
\hline 12097700 & Cyclone Creek near Enumclaw, Wash. & $(1950-72)$ \\
\hline 12097850 & White River below Clearwater River near Buckley Wash. & $(1975-76,1983-96)$ \\
\hline 12099600 & Boise Creek at Buckley, Wash. & $(1978-96)$ \\
\hline 12100000 & White River at Buckley, Wash. & $(1900-02,1911-12,1914-19,1921-23,1935-38,1978-96 \mathrm{R})$ \\
\hline 12101500 & Puyallup River at Puyallup, Wash. & $(1915-41,1942-96 \mathrm{R})$ \\
\hline 12102800 & South Fork Hylebos Creek near Puyallup, Wash. & $(1949-66)$ \\
\hline 12103200 & Joes Creek at Tacoma, Wash. & $(1958-73)$ \\
\hline 12103400 & Green River below Intake Creek near Lester, Wash. & $(1967-77)$ \\
\hline 12103500 & Snow Creek near Lester, Wash. & $(1946-65)$ \\
\hline 12104000 & Friday Creek near Lester, Wash. & $(1946-77)$ \\
\hline 12104500 & Green River near Lester, Wash. & $(1946-90)$ \\
\hline 12104700 & Green Canyon Creek near Lester, Wash. & $(1961-70,1972-74)$ \\
\hline 12105000 & Smay Creek near Lester, Wash. & $(1948,1950-70,1972-73)$ \\
\hline 12105710 & North Fork Green River near Lemolo, Wash. & (1957-65 (Station 12105700), 1966-87) \\
\hline 12106000 & Bear Creek near Eagle Gorge, Wash & $(1947-56)$ \\
\hline 12106500 & Green River near Palmer, Wash. & $(1918,1932-61,1962-63 R)$ \\
\hline 12107200 & Deep Creek near Cumberland, Wash. & $(1950-70)$ \\
\hline 12108500 & Newaukum Creek near Black Diamond, Wash. & $(1945-96)$ \\
\hline 12112500 & Big Soos Creek near Auburn, Wash. & $(1945-56)$ \\
\hline 12112600 & Big Soos Creek above Hatchery, near Auburn, Wash. & $(1961-96)$ \\
\hline 12113000 & Green River near Auburn, Wash. & $(1937-61,1962-96 \mathrm{R})$ \\
\hline 12113200 & Mill Creek near Auburn, Wash. & $(1949-70)$ \\
\hline 12113300 & Mill Creek Tributary near Auburn, Wash. & $(1959-75)$ \\
\hline 12113500 & North Fork Cedar River near Lester, Wash. & $(1945-52,1954-64)$ \\
\hline 12114000 & South Fork Cedar River near Lester, Wash. & $(1945-83)$ \\
\hline 12114500 & Cedar River below Bear Creek, near Cedar Falls, Wash. & $(1946-64,1976-96)$ \\
\hline 12115000 & Cedar River near Cedar Falls, Wash. & $(1946-96)$ \\
\hline 12115300 & Green Point Creek near Cedar Falls, Wash. & $(1957-88)$ \\
\hline 12115500 & Rex River near Cedar Falls, Wash. & $(1946,1948-96)$ \\
\hline 12115700 & Boulder Creek near Cedar Falls, Wash. & $(1985-96)$ \\
\hline 12116100 & Canyon Creek near Cedar Falls, Wash. & $(1946-96)$ \\
\hline 12117000 & Taylor Creek near Selleck, Wash. & $(1957-96)$ \\
\hline 12118500 & Rock Creek near Maple Valley, Wash. & $(1946-76)$ \\
\hline 12119600 & May Creek at mouth, near Renton, Wash. & $(1946-50,1956-58,1965-71,1973-79)$ \\
\hline
\end{tabular}


Table 1. Gaging stations with at least 10 years of unregulated peak-flow data--Continued

\begin{tabular}{|c|c|c|}
\hline $\begin{array}{l}\text { Station } \\
\text { number }\end{array}$ & Station name & $\begin{array}{l}\text { Years of peak record } \\
\text { (Water years) }\end{array}$ \\
\hline 12119700 & Coal Creek near Bellevue, Wash. & $(1964-79)$ \\
\hline 12119800 & Valley (North Branch Mercer) Creek near Bellevue, Wash. & $(1949-67,1970-77)$ \\
\hline 12120600 & Issaquah Creek near Hobart, Wash. & $(1987-96)$ \\
\hline 12121000 & Issaquah Creek near Issaquah, Wash. & $(1946-64)$ \\
\hline 12121600 & Issaquah Creek near mouth, near Issaquah, Wash. & $(1964-96)$ \\
\hline 12121700 & Tibbetts Creek near Issaquah, Wash. & $(1964-68,1972-77)$ \\
\hline 12122500 & Bear Creek near Redmond, Wash. & $(1946-49,1980-81,1985-91,1994-96)$ \\
\hline 12123000 & Cottage Lake Creek near Redmond, Wash. & $(1956-65)$ \\
\hline 12123300 & Evans Creek Tributary near Redmond, Wash. & $(1949-69)$ \\
\hline 12124000 & Evans Creek (above mouth) near Redmond, Wash. & $(1956-77)$ \\
\hline 12125000 & Sammamish River near Redmond, Wash. & $(1940-57)$ \\
\hline 12125200 & Sammamish River near Woodinville, Wash. & $(1966-96)$ \\
\hline 12126000 & North Creek near Bothell, Wash. & $(1946-74)$ \\
\hline 12126500 & Sammamish River at Bothell, Wash. & $(1940-63)$ \\
\hline 12127100 & Swamp Creek at Kenmore, Wash. & $(1964-89,1990 \mathrm{R})$ \\
\hline 12127300 & Lyon Creek at Lake Forest Park, Wash. & $(1964-75)$ \\
\hline 12127600 & McAleer Creek at Lake Forest Park, Wash. & $(1964-74)$ \\
\hline 12130500 & South Fork Skykomish River near Skykomish, Wash. & $(1930-31,1947-70)$ \\
\hline 12131000 & Beckler River near Skykomish, Wash. & $(1930-33,1947-70)$ \\
\hline 12132700 & South Fork Skykomish River Tributary at Baring, Wash. & $(1951-70)$ \\
\hline 12133000 & South Fork Skykomish River near Index, Wash. & $(1897,1903-05,1912,1914-82)$ \\
\hline 12133500 & Troublesome Creek near Index, Wash. & $(1930-41)$ \\
\hline 12134000 & North Fork Skykomish River at Index, Wash. & $(1911-12,1914-21,1930-38,1947-48)$ \\
\hline 12134500 & Skykomish River near Gold Bar, Wash. & $(1929-96)$ \\
\hline 12135000 & Wallace River at Gold Bar, Wash. & $(1930-33,1947-78,1989-91)$ \\
\hline 12135500 & Olney Creek near Gold Bar, Wash. & $(1947-51,1953-68)$ \\
\hline 12137500 & Sultan River near Startup, Wash. & $(1935-45,1948-65,1966-74 R)$ \\
\hline 12141000 & Woods Creek near Monroe, Wash. & $(1947-78)$ \\
\hline 12141100 & Skykomish River at Monroe, Wash. & $(1922,1951,1958-75)$ \\
\hline 12141300 & Middle Fork Snoqualmie River near Tanner, Wash. & $(1961-96)$ \\
\hline 12141500 & Middle Fork Snoqualmie River near North Bend, Wash. & $(1909-10,1912-26,1930-32)$ \\
\hline 12142000 & N.F. Snoqualmie River near Snoqualmie Falls, Wash. & $(1930-54,1956-57,1959-96)$ \\
\hline 12142300 & Hancock Creek near Snoqualmie, Wash. & $(1965-79)$ \\
\hline 12143000 & N.F. Snoqualmie River near North Bend, Wash. & $(1909-12,1914-20,1922-26,1930-38,1961-78)$ \\
\hline 12143300 & S.F. Snoqualmie River Tributary near North Bend, Wash. & $(1951-70)$ \\
\hline 12143310 & S. F. Snoqualmie River Trib. No.9 near North Bend, Wash. & $(1962-72)$ \\
\hline 12143400 & S. F. Snoqualmie River above Alice Creek near Garcia, Wash. & $(1961-96)$ \\
\hline 12143600 & S. F. Snoqualmie River at Edgewick Wash & $(1964-65,1984-96)$ \\
\hline 12143700 & Boxley Creek near Cedar Falls, Wash. & $(1946-96)$ \\
\hline 12143900 & Boxley Creek near Edgewick, Wash. & $(1982-96)$ \\
\hline
\end{tabular}


Table 1. Gaging stations with at least 10 years of unregulated peak-flow data--Continued

\begin{tabular}{|c|c|c|}
\hline $\begin{array}{l}\text { Station } \\
\text { number }\end{array}$ & Station name & $\begin{array}{l}\text { Years of peak record } \\
\text { (Water years) }\end{array}$ \\
\hline 12144000 & South Fork Snoqualmie River at North Bend, Wash. & $(1909,1911-12,1914-26,1930-38,1946-50,1961-78,1985-96)$ \\
\hline 12144500 & Snoqualmie River near Snoqualmie, Wash. & $(1959-96)$ \\
\hline 12145500 & Raging River near Fall City, Wash. & $(1946-51,1953-96)$ \\
\hline 12146000 & Patterson Creek near Fall City, Wash. & $(1948-50,1956-79)$ \\
\hline 12147000 & Griffin Creek near Carnation, Wash. & $(1946-70,1972-79)$ \\
\hline 12147500 & North Fork Tolt River near Carnation, Wash. & $(1953-65,1968-96)$ \\
\hline 12147600 & South Fork Tolt River near Index, Wash. & $(1960-63,1968-96)$ \\
\hline 12148000 & South Fork Tolt River near Carnation, Wash. & $(1953-63,1970-96 \mathrm{R})$ \\
\hline 12148100 & South Fork Tolt River Tributary near Carnation, Wash. & $(1955-74)$ \\
\hline 12148500 & Tolt River near Carnation, Wash. & $(1929,1931,1938-96)$ \\
\hline 12149000 & Snoqualmie River near Carnation, Wash. & $(1930-96)$ \\
\hline 12150800 & Snohomish River near Monroe, Wash. & $(1964-96)$ \\
\hline 12152500 & Pilchuck River near Granite Falls, Wash. & $(1944-80)$ \\
\hline 12153000 & Little Pilchuck Creek near Lake Stevens, Wash. & $(1947-51,1953-74)$ \\
\hline 12155500 & Snohomish River at Snohomish, Wash. & $(1906,1917,1921,1932-33,1942-66)$ \\
\hline 12156400 & Munson Creek near Marysville, Wash. & $(1949-69)$ \\
\hline 12157000 & Quilceda Creek near Marysville, Wash. & $(1947-69)$ \\
\hline 12161000 & South Fork Stillaguamish River near Granite Falls, Wash. & $(1929-80)$ \\
\hline 12162500 & S.F. Stillaguamish R. above Jim Creek near Arlngtpn, Wash. & $(1938-57)$ \\
\hline 12164000 & Jim Creek near Arlington, Wash. & $(1938-51,1953-69)$ \\
\hline 12165000 & Squire Creek near Darrington, Wash. & $(1951-69)$ \\
\hline 12166500 & Deer Creek at Oso, Wash. & $(1918-30)$ \\
\hline 12167000 & North Fork Stillaguamish River near Arlington, Wash. & $(1929-96)$ \\
\hline 12168500 & Pilchuck Creek near Bryant, Wash. & $(1930-31,1951,1953-79)$ \\
\hline 12169500 & Fish Creek near Arlington, Wash. & $(1951-53,1955-72)$ \\
\hline 12172000 & Big Beaver Creek near Newhalem, Wash. & $(1941-48,1963-69)$ \\
\hline 12172500 & Skagit River near Newhalem, Wash. & $(1922,1930-39)$ \\
\hline 12173500 & Ruby Creek below Panther Creek near Newhalem, Wash. & $(1949-56,1963-69)$ \\
\hline 12174000 & Ruby Creek near Newhalem, Wash. & $(1929-49)$ \\
\hline 12174500 & Skagit River below Ruby Creek, near Newhalem, Wash. & $(1920-30)$ \\
\hline 12175500 & Thunder Creek near Newhalem, Wash. & $(1920-96)$ \\
\hline 12176000 & Thunder Creek near Marblemount, Wash. & $(1920-30)$ \\
\hline 12177500 & Stetattle Creek near Newhalem, Wash. & $(1934-83)$ \\
\hline 12178100 & Newhalem Creek near Newhalem, Wash. & $(1961-96)$ \\
\hline 12181100 & S.F. Cascade R. at S. Cascade Gl., near Marblemount, Wash. & $(1961-96)$ \\
\hline 12181200 & Salix Creek at South Cascade Gl near Marblemount, Wash. & $(1963-96)$ \\
\hline 12182500 & Cascade River at Marblemount, Wash. & $(1815,1898,1910-12,1918,1929-79)$ \\
\hline 12184300 & Iron Creek near Rockport, Wash. & $(1965-75)$ \\
\hline 12185300 & Elliot Creek at Goat Lake Outlet, near Monte Cristo & $(1983-93)$ \\
\hline 12186000 & Sauk River above Whitechuck River near Darrington, Wash. & $(1918-22,1929-96)$ \\
\hline
\end{tabular}


Table 1. Gaging stations with at least 10 years of unregulated peak-flow data--Continued

\begin{tabular}{|c|c|c|}
\hline $\begin{array}{l}\text { Station } \\
\text { number }\end{array}$ & Station name & $\begin{array}{l}\text { Years of peak record } \\
\text { (Water years) }\end{array}$ \\
\hline 12187500 & Sauk River at Darrington, Wash. & $(1815,1897,1910,1915-26,1929-32)$ \\
\hline 12188300 & Straight Creek near Darrington, Wash. & $(1965-75)$ \\
\hline 12189000 & Suiattle River near Mansford, Wash. & $(1939-50)$ \\
\hline 12189400 & Sauk River Tributary near Darrington, Wash. & $(1951-70,1978-88)$ \\
\hline 12189500 & Sauk River near Sauk, Wash. & $(1912,1929-96)$ \\
\hline 12191500 & Baker River below Anderson Creek, North Concrete, Wash. & $(1815,1897,1910-24,1929-31,1956-59)$ \\
\hline 12191800 & Sulphur Creek near Concrete, Wash. & $(1964-76,1982)$ \\
\hline 12196000 & Alder Creek near Hamilton, Wash. & $(1944-79)$ \\
\hline 12196200 & Day Creek Below Day Lake, near Lyman, Wash. & $(1964-79)$ \\
\hline 12196500 & Day Creek near Lyman, Wash. & $(1944-61)$ \\
\hline 12197200 & Parker Creek near Lyman, Wash. & $(1951-70)$ \\
\hline 12199000 & Skagit River near Sedro Woolley, Wash. & $(1815,1856,1897-98,1907,1909-19,1922-23,1976-80 \mathrm{R})$ \\
\hline 12199800 & East Fork Nookachamps Creek near Big Lake, Wash. & $(1962-72,1974-78)$ \\
\hline 12200700 & Carpenter Creek Tributary near Mount Vernon, Wash. & $(1949-70)$ \\
\hline 12200800 & Lake Creek near Bellingham, Wash. & $(1949-63,1965-68)$ \\
\hline 12201500 & Samish River near Burlington, Wash. & $(1944-83)$ \\
\hline 12204400 & Nooksack River Tributary near Glacier, Wash. & $(1956-60,1962-88)$ \\
\hline 12205000 & N.F. Nooksack R. below Cascade Creek near Glacier, Wash. & $(1938-96)$ \\
\hline 12207200 & North Fork Nooksack River near Deming, Wash. & $(1965-75)$ \\
\hline 12208000 & Middle Fork Nooksack River near Deming, Wash. & $(1965-77,1992-96)$ \\
\hline 12209000 & South Fork Nooksack River near Wickersham, Wash. & $(1935-79,1989-91,1994-96)$ \\
\hline 12209500 & Skookum Creek near Wickersham, Wash. & $(1949-69)$ \\
\hline 12210500 & Nooksack River at Deming, Wash. & $(1908,1910,1932,1935-48,1950-96)$ \\
\hline 12211500 & Nooksack River near Lynden, Wash. & $(1918,1922,1924,1932,1935,1945-67)$ \\
\hline 12212000 & Fishtrap Creek at Lynden, Wash. & $(1949-74)$ \\
\hline 12212700 & Tenmile Creek Tributary near Bellingham, Wash. & $(1949-67)$ \\
\hline 12212800 & Tenmile Creek Tributary No. 2 near Bellingham, Wash. & $(1956-87)$ \\
\hline 12213100 & Nooksack River at Ferndale, Wash. & $(1918,1922,1932,1935,1946,1950-96)$ \\
\hline 12323000 & Columbia River at Birchbank, British Columbia & $(1913-68,1969-96 \mathrm{R})$ \\
\hline 12395500 & Pend Oreille River at Newport, Idaho & $(1894,1904-41,1953-96 \mathrm{R})$ \\
\hline 12395800 & Deer Creek near Dalkena, Wash. & $(1954-73)$ \\
\hline 12395900 & Davis Creek near Dalkena, Wash. & $(1954-73)$ \\
\hline 12396000 & Calispell Creek near Dalkena, Wash. & $(1951-77,1979-96)$ \\
\hline 12396100 & Winchester Creek near Cusick, Wash. & $(1954-88)$ \\
\hline 12396450 & Little Muddy Creek at Ione, Wash. & $(1954-73)$ \\
\hline 12396900 & Sullivan Creek abv Outlet Creek near Metaline Falls, Wash. & $(1958-74,1994-96)$ \\
\hline 12397500 & Sullivan Creek near Metaline Falls, Wash. & $(1913-24)$ \\
\hline 12398000 & Sullivan Creek at Metaline Falls, Wash. & $(1954-68,1970,1994-96)$ \\
\hline 12398500 & Pend Oreille River blw Z Canyon near Metaline Falls, Wash. & $(1894,1913-51,1952-64 R)$ \\
\hline 12399500 & Columbia River at International Boundary & $(1894,1938-57,1958-96 \mathrm{R})$ \\
\hline
\end{tabular}


Table 1. Gaging stations with at least 10 years of unregulated peak-flow data--Continued

\begin{tabular}{|c|c|c|}
\hline $\begin{array}{l}\text { Station } \\
\text { number }\end{array}$ & Station name & $\begin{array}{l}\text { Years of peak record } \\
\text { (Water years) }\end{array}$ \\
\hline 12400500 & Sheep Creek near Northport, Wash. & $(1930-42,1948)$ \\
\hline 12401500 & Kettle River near Ferry, Wash. & $(1929-96)$ \\
\hline 12403700 & Third Creek near Curlew, Wash. & $(1954-73)$ \\
\hline 12404500 & Kettle River near Laurier, Wash. & $(1894,1930-96)$ \\
\hline 12405400 & Nancy Creek near Kettle Falls, Wash. & $(1952,1954-72)$ \\
\hline 12405500 & Columbia River at Kettle Falls, Wash. & $(1894,1913,1916-40)$ \\
\hline 12407500 & Sheep Creek at Springdale, Wash. & $(1953-72)$ \\
\hline 12407520 & Deer Creek near Valley, Wash. & $(1960-79)$ \\
\hline 12407600 & Thomason Creek near Chewelah, Wash. & $(1954-73)$ \\
\hline 12407700 & Chewelah Creek at Chewelah, Wash. & $(1957-74)$ \\
\hline 12408200 & Patchen (Bighorn) Creek near Tiger, Wash. & $(1954-73)$ \\
\hline 12408300 & Little Pend Oreille River near Colville, Wash. & $(1958-79)$ \\
\hline 12408400 & Narcisse Creek near Colville, Wash. & $(1954-73)$ \\
\hline 12408420 & Haller Creek near Arden, Wash. & $(1960-79)$ \\
\hline 12408500 & Mill Creek near Colville, Wash. & $(1940-86)$ \\
\hline 12409000 & Colville River at Kettle Falls, Wash. & $(1923-96)$ \\
\hline 12409500 & Hall Creek at Inchelium, Wash. & $(1913-29,1948,1972-73)$ \\
\hline 12410000 & Stranger Creek at Meteor, Wash. & $(1917-29)$ \\
\hline 12410600 & South Fork Harvey Creek near Cedonia, Wash. & $(1954-73)$ \\
\hline 12410650 & North Fork Harvey Creek near Cedonia, Wash. & $(1954-73)$ \\
\hline 12423550 & Hangman Creek Tributary near Latah, Wash. & $(1961-76)$ \\
\hline 12423700 & South Fork Rock Creek Tributary near Fairfield, Wash. & $(1962-76)$ \\
\hline 12423900 & Stevens Creek Tributary near Moran, Wash. & $(1954-73)$ \\
\hline 12424000 & Hangman Creek at Spokane, Wash. & $(1948-96)$ \\
\hline 12427000 & Little Spokane River at Elk, Wash. & $(1949-79)$ \\
\hline 12429200 & Bear Creek near Milan, Wash. & $(1963-75)$ \\
\hline 12429600 & Deer Creek near Chattaroy, Wash. & $(1962-75)$ \\
\hline 12429800 & Mud Creek near Deer Park, Wash. & $(1954-73)$ \\
\hline 12430370 & Bigelow Gulch near Spokane, Wash. & $(1950,1962-75)$ \\
\hline 12431000 & Little Spokane River at Dartford, Wash. & $(1929-32,1947-96)$ \\
\hline 12431100 & Little Creek at Dartford, Wash. & $(1963-77)$ \\
\hline 12433200 & Chamokane Creek below falls near Long Lake, Wash. & $(1971-79,1988-96)$ \\
\hline 12433300 & Spring Creek Tributary near Reardan, Wash. & $(1954-73)$ \\
\hline 12433542 & Blue Creek above Midnight Mine, Wash & $(1985-96)$ \\
\hline 12433556 & Midnight Mine Drainage & $(1985-96)$ \\
\hline 12433561 & Blue Creek near Mouth near Midnight Mine & $(1985-96)$ \\
\hline 12433580 & Cottonwood (Hawk) Creek at Davenport, Wash. & $(1957,1959,1963-77)$ \\
\hline 12433800 & Granite Creek near Republic, Wash. & $(1954-73)$ \\
\hline 12434500 & Sanpoil River near Keller, Wash. & $(1953-59,1972-79)$ \\
\hline 12437500 & Nespelem River at Nespelem, Wash. & $(1911-29)$ \\
\hline
\end{tabular}


Table 1. Gaging stations with at least 10 years of unregulated peak-flow data--Continued

\begin{tabular}{|c|c|c|}
\hline $\begin{array}{l}\text { Station } \\
\text { number }\end{array}$ & Station name & $\begin{array}{l}\text { Years of peak record } \\
\text { (Water years) }\end{array}$ \\
\hline 12437930 & East Fork Foster Creek at Leahy, Wash. & $(1959,1963-77)$ \\
\hline 12437950 & East Fork Foster Creek Tributary near Bridgeport, Wash. & $(1957-77)$ \\
\hline 12437960 & West Fork Foster Creek near Bridgeport, Wash. & $(1957,1963-77)$ \\
\hline 12439200 & Dry Creek Tributary near Molson, Wash. & $(1958-77)$ \\
\hline 12439300 & Tonasket Creek at Oroville, Wash. & $(1950,1967-91)$ \\
\hline 12441700 & Middle Fork Toats Coulee Creek near Loomis, Wash. & $(1965-70,1972-75)$ \\
\hline 12442000 & Toats Coulee Creek near Loomis, Wash. & $(1920-26,1948,1957-79)$ \\
\hline 12445800 & Omak Creek Tributary near Disautel, Wash. & $(1955-75)$ \\
\hline 12447380 & Pine Creek near Mazama, Wash. & $(1966-88)$ \\
\hline 12447390 & Andrews Creek near Mazama, Wash. & $(1969-96)$ \\
\hline 12447400 & Doe Creek near Winthrop, Wash. & $(1957-75)$ \\
\hline 12447430 & Ortell Creek near Winthrop, Wash. & $(1965-75)$ \\
\hline 12448700 & Williams Creek near Twisp, Wash. & $(1965-75)$ \\
\hline 12448900 & Little Bridge Creek near Twisp, Wash. & $(1965-75)$ \\
\hline 12448998 & Twisp River near Twisp & $(1948,1975-79,1990-96)$ \\
\hline 12449500 & Methow River at Twisp, Wash. & $(1920-29,1934-62,1991-96)$ \\
\hline 12449600 & Beaver Creek below South Fork, near Twisp, Wash. & $(1960-79)$ \\
\hline 12449790 & Rainy Creek near Methow, Wash. & $(1965-75)$ \\
\hline 12449950 & Methow River near Pateros, Wash. & $(1948,1959-96)$ \\
\hline 12450500 & Methow River at Pateros, Wash. & $(1904-20,1948,1959-74)$ \\
\hline 12451000 & Stehekin River at Stehekin, Wash. & $(1911-15,1927-96)$ \\
\hline 12451500 & Railroad Creek at Lucerne, Wash. & $(1911-13,1927-57)$ \\
\hline 12452800 & Entiat River near Ardenvoir, Wash. & $(1958-96)$ \\
\hline 12452880 & Tillicum Creek near Ardenvoir, Wash. & $(1965-75)$ \\
\hline 12453000 & Entiat River at Entiat, Wash. & $(1911-25,1948,1952-58)$ \\
\hline 12454000 & White River near Plain, Wash. & $(1955-83)$ \\
\hline 12454290 & Little Wenatchee River Tributary near Telma, Wash. & $(1965-75)$ \\
\hline 12455000 & Wenatchee River below Wenatchee Lake, Wash. & $(1932-79)$ \\
\hline 12456300 & Brush Creek near Telma, Wash. & $(1965-75)$ \\
\hline 12456500 & Chiwawa River near Plain, Wash. & $(1914,1937-49,1955-57,1991-96)$ \\
\hline 12457000 & Wenatchee River at Plain, Wash. & $(1911-29,1932-79,1990-96)$ \\
\hline 12457300 & Skinney Creek at Winton, Wash. & $(1954-73)$ \\
\hline 12457900 & Chatter Creek near Leavenworth, Wash. & $(1966-75)$ \\
\hline 12458000 & Icicle Creek above Snow Creek near Leavenworth, Wash. & $(1912-14,1937-79,1994-96)$ \\
\hline 12458900 & Posey Canyon near Leavenworth, Wash. & $(1954-73)$ \\
\hline 12459000 & Wenatchee River at Peshastin, Wash. & $(1929-96)$ \\
\hline 12459400 & Tronsen Creek near Peshastin, Wash. & $(1960-75)$ \\
\hline 12461000 & Wenatchee River at Dryden, Wash. & $(1905-06,1910-18,1948)$ \\
\hline 12461100 & East Branch Mission Creek near Cashmere, Wash. & $(1955-74)$ \\
\hline 12461200 & East Branch Mission Creek Tributary near Cashmere, Wash. & $(1955-88)$ \\
\hline
\end{tabular}


Table 1. Gaging stations with at least 10 years of unregulated peak-flow data--Continued

\begin{tabular}{|c|c|c|}
\hline $\begin{array}{l}\text { Station } \\
\text { number }\end{array}$ & Station name & $\begin{array}{l}\text { Years of peak record } \\
\text { (Water years) }\end{array}$ \\
\hline 12461400 & Mission Creek above Sand Creek near Cashmere, Wash. & $(1959-79)$ \\
\hline 12461500 & Sand Creek near Cashmere, Wash. & $(1954-73)$ \\
\hline 12462000 & Mission Creek at Cashmere, Wash. & $(1948,1954-73)$ \\
\hline 12462500 & Wenatchee River at Monitor, Wash. & $(1963-96)$ \\
\hline 12462800 & Moses Creek at Douglas, Wash. & $(1955-76)$ \\
\hline 12463000 & Douglas Creek near Alstown, Wash. & $(1948,1950-60,1963-68)$ \\
\hline 12463600 & Rattlesnake Creek Tributary near Soap Lake, Wash. & $(1959,1961-77)$ \\
\hline 12463700 & McCarteney Creek Tributary near Farmer, Wash. & $(1960,1962-76)$ \\
\hline 12464500 & Columbia River at Trinidad, Wash. & $(1894,1913-37,1938-63 R)$ \\
\hline 12464600 & Schnebly Coulee Tributary near Vantage, Wash. & $(1955-74)$ \\
\hline 12464650 & South Fork Crab Creek Tributary at Waukon, Wash. & $(1954-73)$ \\
\hline 12465000 & Crab Creek at Irby, Wash. & $(1943-96)$ \\
\hline 12465300 & Broadax Draw Tributary near Wilbur, Wash. & $(1955-74)$ \\
\hline 12465400 & Wilson Creek below Corbett Draw near Almira, Wash. & $(1969-79,1992-94)$ \\
\hline 12465500 & Wilson Creek at Wilson Creek, Wash. & $(1951-57,1959-79)$ \\
\hline 12467000 & Crab Creek near Moses Lake, Wash. & $(1943-96)$ \\
\hline 12467400 & Haynes Canyon near Coulee City, Wash. & $(1959-76)$ \\
\hline 12470300 & Iron Springs Creek near Winchester, Wash. & $(1959-76)$ \\
\hline 12471100 & Paha Coulee Tributary near Ritzville, Wash. & $(1962-76)$ \\
\hline 12471200 & Lind Coulee Tributary near Lind, Wash. & $(1956.1961-77)$ \\
\hline 12474700 & Mosquito Creek near Easton, Wash. & $(1968-77)$ \\
\hline 12480700 & Hovey Creek near Cle Elum, Wash. & $(1955-74)$ \\
\hline 12483300 & S.F. Manastash Creek Tributary near Ellensburg, Wash. & $(1955-74)$ \\
\hline 12483800 & Naneum Creek near Ellensburg, Wash. & $(1957-72,1974-78)$ \\
\hline 12485900 & Pine Canyon near Naches, Wash. & $(1961-76)$ \\
\hline 12487400 & Deep Creek near Goose Prairie, Wash. & $(1966-75)$ \\
\hline 12488300 & American River Tributary near Nile, Wash. & $(1955-74)$ \\
\hline 12488500 & American River near Nile, Wash. & $(1940-96)$ \\
\hline 12489500 & Naches River at Oak Flat near Nile, Wash. & $(1905-17)$ \\
\hline 12491700 & Hause Creek near Rimrock, Wash. & $(1955-88)$ \\
\hline 12492500 & Tieton River at Canal Headworks near Naches, Wash. & $(1908-25,1926-78 \mathrm{R})$ \\
\hline 12500500 & North Fork Ahtanum Creek near Tampico, Wash. & $(1908,1910-21,1932-79)$ \\
\hline 12501000 & S.F. Ahtanum Creek at Conrad Ranch near Tampico, Wash. & $(1915-24,1931-78)$ \\
\hline 12502000 & Ahtanum Creek at The Narrows near Tampico, Wash. & $(1909-13,1960-68)$ \\
\hline 12502500 & Ahtanum Creek at Union Gap, Wash. & $(1908,1910,1912-14,1952,1960-96)$ \\
\hline 12506000 & Toppenish Creek near Fort Simcoe, Wash. & $(1910-24)$ \\
\hline 12506500 & Simcoe Creek below Spring Creek near Fort Simcoe, Wash. & $(1909-23)$ \\
\hline 12507600 & Shinando Creek Tributary near Goldendale, Wash. & $(1955-74)$ \\
\hline 12507660 & Satus Creek Tributary near Toppenish, Wash. & $(1953,1956,1961,1963-77)$ \\
\hline 12508500 & Satus Creek Below Dry Creek near Toppenish, Wash. & $(1914-24)$ \\
\hline
\end{tabular}


Table 1. Gaging stations with at least 10 years of unregulated peak-flow data--Continued

\begin{tabular}{|c|c|c|}
\hline $\begin{array}{l}\text { Station } \\
\text { number }\end{array}$ & Station name & $\begin{array}{l}\text { Years of peak record } \\
\text { (Water years) }\end{array}$ \\
\hline 12512550 & Providence Coulee near Cunningham, Wash. & $(1978-96)$ \\
\hline 12512600 & Hatton Coulee Tributary No. 2 near Cunningham, Wash. & $(1961-76)$ \\
\hline 12512700 & Hatton Coulee Tributary near Hatton, Wash. & $(1956-75)$ \\
\hline 12513000 & Esquatzel Coulee at Connell, Wash. & $(1953-96)$ \\
\hline 13334500 & Asotin Creek near Asotin, Wash. & $(1904,1929-59)$ \\
\hline 13334700 & Asotin Creek below Kearney Gulch near Asotin, Wash. & $(1960-82,1990-96)$ \\
\hline 13335200 & Critchfield Draw near Clarkston, Wash. & $(1959-76)$ \\
\hline 13343450 & Dry Creek at mouth near Clarkston, Wash. & $(1963-77)$ \\
\hline 13343520 & Clayton Gulch near Alpowa, Wash. & $(1961-76)$ \\
\hline 13343620 & South Fork Deadman Creek Tributary near Pataha, Wash. & $(1961-76)$ \\
\hline 13343660 & Smith Gulch Tributary near Pataha, Wash. & $(1955-74)$ \\
\hline 13343800 & Meadow Creek near Central Ferry, Wash. & $(1964-78)$ \\
\hline 13344500 & Tucannon River near Starbuck, Wash. & $(1915-17,1929-31,1959-90,1995-96)$ \\
\hline 13346100 & Palouse River at Colfax, Wash. & $(1956-79)$ \\
\hline 13348000 & South Fork Palouse River at Pullman, Wash. & $(1934-42,1948,1959-81,1996)$ \\
\hline 13348400 & Missouri Flat Creek Tributary near Pullman, Wash. & $(1955-74)$ \\
\hline 13348500 & Missouri Flat Creek at Pullman, Wash. & $(1935-40,1948,1960-79,1996)$ \\
\hline 13349210 & Palouse River below South Fork at Colfax, Wash. & $(1963-96)$ \\
\hline 13349300 & Palouse River Tributary at Colfax, Wash. & $(1955-88)$ \\
\hline 13349350 & Hardman Draw Tributary at Plaza, Wash. & $(1955-74)$ \\
\hline 13349400 & Pine Creek at Pine City, Wash. & $(1962-79)$ \\
\hline 13349500 & Rock Creek near Ewan, Wash. & $(1904-05,1915-17,1959,1963,1965-75)$ \\
\hline 13349800 & Imbler Creek Tributary near Lamont, Wash. & $(1967-77)$ \\
\hline 13350500 & Union Flat Creek near Colfax, Wash. & $(1954-79)$ \\
\hline 13351000 & Palouse River at Hooper, Wash. & $(1898-99,1901-07,1909-16,1948,1951-96)$ \\
\hline 13352200 & Cow Creek Tributary near Ritzville, Wash. & $(1951,1955-73)$ \\
\hline 13352500 & Cow Creek at Hooper, Wash. & $(1952-53,1962-76,1978-79)$ \\
\hline 13352550 & Stewart Canyon Tributary near Riparia, Wash. & $(1958-75)$ \\
\hline 14013000 & Mill Creek near Walla Walla, Wash. & $(1914-17,1931,1940-96)$ \\
\hline 14013500 & Blue Creek near Walla Walla, Wash. & $(1940-42,1944-71)$ \\
\hline 14015900 & Spring Creek Tributary near Walla Walla, Wash. & $(1955-74)$ \\
\hline 14016000 & Dry Creek near Walla Walla, Wash. & $(1949-53,1955-67)$ \\
\hline 14016500 & East Fork Touchet River near Dayton, Wash. & $(1944-51,1956-68)$ \\
\hline 14016600 & Hatley Creek near Dayton, Wash. & $(1955-74)$ \\
\hline 14016650 & Davis Hollow near Dayton, Wash. & $(1956-75)$ \\
\hline 14017000 & Touchet River at Bolles, Wash. & $(1925-29,1952-89,1996)$ \\
\hline 14017040 & Thorn Hollow near Dayton, Wash. & $(1962-76)$ \\
\hline 14017070 & East Fork McKay Creek near Huntsville, Wash. & $(1963-77)$ \\
\hline 14017200 & Badger Hollow near Clyde, Wash. & $(1955-74)$ \\
\hline 14017500 & Touchet River near Touchet, Wash. & $(1942,1944,1946-53,1955-59,1965)$ \\
\hline
\end{tabular}


Table 1. Gaging stations with at least 10 years of unregulated peak-flow data--Continued

\begin{tabular}{|c|c|c|}
\hline $\begin{array}{l}\text { Station } \\
\text { number }\end{array}$ & Station name & $\begin{array}{l}\text { Years of peak record } \\
\text { (Water years) }\end{array}$ \\
\hline 14018500 & Walla Walla River near Touchet, Wash. & $(1949,1952-96)$ \\
\hline 14034250 & Glade Creek Tributary near Bickleton, Wash. & $(1961-76)$ \\
\hline 14034325 & Alder Creek near Bickleton, Wash. & $(1963-77)$ \\
\hline 14107000 & Klickitat River above West Fork near Glenwood, Wash. & $(1945-78,1992-96)$ \\
\hline 14110000 & Klickitat River near Glenwood, Wash. & $(1910-56,1958-79)$ \\
\hline 14111800 & West Prong Little Klickitat River near Goldendale, Wash. & $(1961-75)$ \\
\hline 14112000 & Little Klickitat River near Goldendale, Wash. & $(1911-12,1947-50,1958-78)$ \\
\hline 14112200 & Little Klickitat River Tributary near Goldendale, Wash. & $(1960-88)$ \\
\hline 14112400 & Mill Creek near Blockhouse, Wash. & $(1965-78)$ \\
\hline 14112500 & Little Klickitat River near Wahkiacus, Wash & $(1945-49,1951-81)$ \\
\hline 14113000 & Klickitat River near Pitt, Wash. & $(1910-12,1929-96)$ \\
\hline 14121300 & White Salmon R. blw Cascades Creek nr Trout Lake, Wash. & $(1958-78)$ \\
\hline 14121500 & Trout Lake Creek near Trout Lake, Wash. & $(1910-11,1960-69)$ \\
\hline 14122000 & White Salmon River near Trout Lake, Wash. & $(1929-31,1958-67)$ \\
\hline 14123000 & White Salmon River at Husum, Wash. & $(1910-18,1930-41,1958-62)$ \\
\hline 14123500 & White Salmon River near Underwood, Wash. & $(1916-30,1936-96)$ \\
\hline 14124500 & Little White Salmon River at Willard, Wash. & $(1945-61)$ \\
\hline 14125000 & Little White Salmon R. abv Lapham Creek, Willard, Wash. & $(1950-63)$ \\
\hline 14125200 & Rock Creek near Willard, Wash. & $(1949-68)$ \\
\hline 14125500 & Little White Salmon River near Cook, Wash. & $(1957-77)$ \\
\hline 14126300 & Columbia River Tributary at Home Valley, Wash. & $(1950-70)$ \\
\hline 14127000 & Wind River above Trout Creek near Carson, Wash. & $(1945-69)$ \\
\hline 14127200 & Layout Creek near Carson, Wash. & $(1966-75)$ \\
\hline 14128500 & Wind River near Carson, Wash. & $(1935-79)$ \\
\hline 14143200 & Canyon Creek near Washougal, Wash. & $(1949-70)$ \\
\hline 14143500 & Washougal River near Washougal, Wash. & $(1945-81,1996)$ \\
\hline 14144000 & Little Washougal River near Washougal, Wash. & $(1952-68)$ \\
\hline 14144550 & Shanghai Creek near Hockinson, Wash. & $(1950-70)$ \\
\hline 14144600 & Groeneveld Creek near Camas, Wash. & $(1958-81,1986)$ \\
\hline 14211900 & Burntbridge Creek at Vancouver, Wash. & $(1949-71)$ \\
\hline 14212000 & Salmon Creek near Battle Ground, Wash. & $(1944-79,1989)$ \\
\hline 14213200 & Lewis River near Trout Lake, Wash. & $(1959-72)$ \\
\hline 14213500 & Big Creek blw Skookum Meadow near Trout Lake, Wash. & $(1929-31,1956-79)$ \\
\hline 14214000 & Rush Creek above Meadow Creek near Trout Lake, Wash. & $(1956-65)$ \\
\hline 14214500 & Meadow Creek blw Lone Butte Meadow nr Trout Lake, Wash. & $(1929-31,1956-65)$ \\
\hline 14215000 & Rush Creek above falls near Cougar, Wash. & $(1929-31,1956-62,1964-74)$ \\
\hline 14215500 & Curly Creek near Cougar, Wash. & $(1956-74)$ \\
\hline 14216000 & Lewis River above Muddy River near Cougar, Wash. & $(1928-34,1955-70,1972-75,1977)$ \\
\hline 14216500 & Muddy River below Clear Creek near Cougar, Wash. & $(1928-34,1955-73,1984-96)$ \\
\hline 14216800 & Pine Creek near Cougar, Wash. & $(1958-70,1972)$ \\
\hline
\end{tabular}


Table 1. Gaging stations with at least 10 years of unregulated peak-flow data--Continued

\begin{tabular}{|c|c|c|}
\hline $\begin{array}{l}\text { Station } \\
\text { number }\end{array}$ & Station name & $\begin{array}{l}\text { Years of peak record } \\
\text { (Water years) }\end{array}$ \\
\hline 14218000 & Lewis River near Cougar, Wash. & $(1918,1925-45,1947-58,1959-78 \mathrm{R})$ \\
\hline 14218300 & Dog Creek at Cougar, Wash. & $(1956,1958-74)$ \\
\hline 14219000 & Canyon Creek near Amboy, Wash. & $(1923-34)$ \\
\hline 14219500 & Lewis River near Amboy, Wash. & $(1912-31)$ \\
\hline 14219800 & Speelyai Creek near Cougar, Wash. & $(1960-96)$ \\
\hline 14221500 & Cedar Creek near Ariel, Wash. & $(1952-55,1962-69,1989)$ \\
\hline 14222500 & East Fork Lewis River near Heisson, Wash. & $(1930-96)$ \\
\hline 14222700 & East Fork Lewis River Tributary near Woodland, Wash. & $(1950-67)$ \\
\hline 14223000 & Kalama River near Kalama, Wash. & $(1912-13,1917-34,1936-45,1947)$ \\
\hline 14223500 & Kalama River below Italian Creek near Kalama, Wash. & $(1947-79,1996)$ \\
\hline 14223800 & Columbia River Tributary at Carrolls, Wash. & $(1950-70)$ \\
\hline 14224500 & Clear Fork Cowlitz River near Packwood, Wash. & $(1908-11,1913-17,1931-41,1943,1950)$ \\
\hline 14225500 & Lake Creek near Packwood, Wash. & $(1912-17,1919-24,1931-42,1950-54,1960-63,1964-80 \mathrm{R})$ \\
\hline 14226500 & Cowlitz River at Packwood, Wash. & $(1912-20,1930-96)$ \\
\hline 14226800 & Skate Creek Tributary near Packwood, Wash. & $(1959-77)$ \\
\hline 14226900 & Skate Creek Tributary No. 2 near Packwood, Wash. & $(1959-75,1978-88)$ \\
\hline 14230000 & Johnson Creek near Packwood, Wash. & $(1908-14,1919-24,1947-48)$ \\
\hline 14231100 & Miller Creek at Randle, Wash. & $(1950-70)$ \\
\hline 14231700 & Chambers Creek near Packwood, Wash. & $(1966-75)$ \\
\hline 14232000 & Niggerhead Creek near Randle, Wash. & $(1951-63)$ \\
\hline 14232500 & Cispus River near Randle, Wash. & $(1911-12,1930-41,1943-96)$ \\
\hline 14233200 & Quartz Creek near Kosmos, Wash. & $(1965-75)$ \\
\hline 14233500 & Cowlitz River near Kosmos, Wash. & $(1949-68,1969-95$ (Station 14233400), 1996) \\
\hline 14235000 & Cowlitz River at Mossyrock, Wash. & $(1907,1913-17,1927-32,1934-35,1948-60)$ \\
\hline 14235300 & Tilton River near Mineral, Wash. & $(1950-70)$ \\
\hline 14235500 & West Fork Tilton River near Morton, Wash. & $(1951-79)$ \\
\hline 14236200 & Tilton River abv Bear Canyon Creek near Cinebar, Wash. & $(1957-96)$ \\
\hline 14236500 & Tilton River near Cinebar, Wash. & $(1942-59)$ \\
\hline 14237000 & Klickitat Creek at Mossyrock, Wash. & $(1949-72)$ \\
\hline 14237500 & Winston Creek near Silver Lake, Wash. & $(1950-77)$ \\
\hline 14238000 & Cowlitz River below Mayfield Dam, Wash. & $(1912,1935-62,1963-96 \mathrm{R})$ \\
\hline 14239000 & Salmon Creek near Toledo, Wash. & $(1962-79)$ \\
\hline 14239100 & North Fork Lacamas Creek near Ethel, Wash. & $(1950-69)$ \\
\hline 14239700 & Olequa Creek Tributary near Winlock, Wash. & $(1950-69)$ \\
\hline 14240800 & Green River above Beaver Creek near Kid Valley, Wash. & $(1981-94)$ \\
\hline 14241100 & North Fork Toutle River at Kid Valley, Wash. & $(1980-94)$ \\
\hline 14241490 & South Fork Toutle River at Camp 12 near Toutle, Wash. & (1940-57 (Station 14241500), 1981-96) \\
\hline 14242500 & Toutle River near Silver Lake, Wash. & $(1910-12,1920-23,1930-79,1982-96($ Station 14242580$))$ \\
\hline 14242600 & Toutle River Tributary near Castle Rock, Wash. & $(1950-70)$ \\
\hline 14243000 & Cowlitz River at Castle Rock, Wash. & $(1927-62,1963-96 \mathrm{R})$ \\
\hline
\end{tabular}


Table 1. Gaging stations with at least 10 years of unregulated peak-flow data--Continued

\begin{tabular}{lll}
\hline $\begin{array}{l}\text { Station } \\
\text { number }\end{array}$ & \multicolumn{1}{c}{ Station name } & $\begin{array}{l}\text { Years of peak record } \\
\text { (Water years) }\end{array}$ \\
\hline 14243500 & Delameter Creek near Castle Rock, Wash. & $(1950-69,1996)$ \\
14245000 & Coweman River near Kelso, Wash. & $(1950-84,1996)$ \\
14247500 & Elochoman River near Cathlamet, Wash. & $(1941-79)$ \\
14248100 & Risk Creek near Skamokawa, Wash. & $(1949-70)$ \\
14248200 & Jim Crow Creek near Grays River, Wash. & $(1965-79)$ \\
14249000 & Grays River above South Fork nr Grays River, Wash. & $(1956-79)$ \\
14250500 & West Fork Grays River near Grays River, Wash. & $(1949-69)$ \\
\hline
\end{tabular}


Table 2. Flood discharges for selected exceedance probabilities at gaging stations on streams with unregulated flow

\begin{tabular}{|c|c|c|c|c|c|c|c|}
\hline \multirow[b]{2}{*}{ Station number } & \multirow{2}{*}{$\begin{array}{l}\text { Number of } \\
\text { peaks used } \\
\text { in analysis }\end{array}$} & \multicolumn{4}{|c|}{$\begin{array}{l}\text { Flood discharge, in cubic feet per second } \\
\text { (95-percent confidence interval) } \\
\text { Weighted estimate of flood discharge, in cubic feet per second }\end{array}$} & \multirow{2}{*}{$\begin{array}{c}\begin{array}{l}\text { At indicated } \\
\text { exceedance } \\
\text { probabilities }\end{array} \\
0.01\end{array}$} & \multirow{2}{*}{$\begin{array}{l}\text { Maximum } \\
\text { peak used } \\
\text { in analysis } \\
\text { (cubic feet } \\
\text { per second) }\end{array}$} \\
\hline & & 0.5 & 0.1 & 0.04 & 0.02 & & \\
\hline 12009500 & 16 & $\begin{array}{c}1,130 \\
(936-1,360) \\
1,110\end{array}$ & $\begin{array}{c}2,000 \\
(1,630-2,740) \\
1,910\end{array}$ & $\begin{array}{c}2,490 \\
(1,960-3,690) \\
2,330\end{array}$ & $\begin{array}{c}2,880 \\
(2,210-4,520) \\
2,660\end{array}$ & $\begin{array}{c}3,300 \\
(2,470-5,440) \\
3,000\end{array}$ & 2,450 \\
\hline 12010000 & 67 & $\begin{array}{c}5,800 \\
(5,410-6,220) \\
5,780\end{array}$ & $\begin{array}{c}8,870 \\
(8,140-9,840) \\
8,820\end{array}$ & $\begin{array}{c}10,300 \\
(9,310-11,600) \\
10,200\end{array}$ & $\begin{array}{c}11,300 \\
(10,100-12,900) \\
11,200\end{array}$ & $\begin{array}{c}12,200 \\
(10,900-14,200) \\
12,100\end{array}$ & 11,300 \\
\hline 12010500 & 12 & $\begin{array}{c}1,730 \\
(1,550-1,920) \\
1,690\end{array}$ & $\begin{array}{c}2,320 \\
(2,070-2,820) \\
2,300\end{array}$ & $\begin{array}{c}2,640 \\
(2,300-3,380) \\
2,630\end{array}$ & $\begin{array}{c}2,870 \\
(2,460-3,850) \\
2,870\end{array}$ & $\begin{array}{c}3,110 \\
(2,620-4,340) \\
3,120\end{array}$ & 3,210 \\
\hline 12010600 & 21 & $\begin{array}{c}176 \\
(165-188) \\
179\end{array}$ & $\begin{array}{c}219 \\
(203-243) \\
231\end{array}$ & $\begin{array}{c}236 \\
(217-268) \\
256\end{array}$ & $\begin{array}{c}248 \\
(226-286) \\
274\end{array}$ & $\begin{array}{c}258 \\
(234-302) \\
290\end{array}$ & 249 \\
\hline 12010700 & 15 & $\begin{array}{c}2,280 \\
(1,940-2,680) \\
2,190\end{array}$ & $\begin{array}{c}3,670 \\
(3,080-4,840) \\
3,430\end{array}$ & $\begin{array}{c}4,400 \\
(3,580-6,200) \\
4,040\end{array}$ & $\begin{array}{c}4,960 \\
(3,950-7,320) \\
4,490\end{array}$ & $\begin{array}{c}5,520 \\
(4,310-8,530) \\
4,940\end{array}$ & 4,310 \\
\hline 12010800 & 16 & $\begin{array}{c}235 \\
(208-266) \\
233\end{array}$ & $\begin{array}{c}331 \\
(290-407) \\
331\end{array}$ & $\begin{array}{c}373 \\
(320-477) \\
377\end{array}$ & $\begin{array}{c}401 \\
(340-527) \\
408\end{array}$ & $\begin{array}{c}428 \\
(359-576) \\
439\end{array}$ & 344 \\
\hline 12011000 & 19 & $\begin{array}{c}1,400 \\
(1,310-1,510) \\
1,420\end{array}$ & $\begin{array}{c}1,770 \\
(1,640-1,990) \\
1,850\end{array}$ & $\begin{array}{c}1,930 \\
(1,760-2,220) \\
2,070\end{array}$ & $\begin{array}{c}2,030 \\
(1,840-2,390) \\
2,210\end{array}$ & $\begin{array}{c}2,140 \\
(1,920-2,550) \\
2,370\end{array}$ & 2,000 \\
\hline 12011100 & 18 & $\begin{array}{c}49 \\
(42-56) \\
50\end{array}$ & $\begin{array}{r}75 \\
(64-95) \\
78\end{array}$ & $\begin{array}{r}88 \\
(74-117) \\
92\end{array}$ & $\begin{array}{c}97 \\
(80-133) \\
102\end{array}$ & $\begin{array}{c}106 \\
(86-150) \\
113\end{array}$ & 101 \\
\hline 12011200 & 15 & $\begin{array}{c}691 \\
(544-874) \\
701\end{array}$ & $\begin{array}{c}1,400 \\
(1,080-2,110) \\
1,390\end{array}$ & $\begin{array}{c}1,840 \\
(1,360-3,070) \\
1,790\end{array}$ & $\begin{array}{c}2,210 \\
(1,570-3,950) \\
2,120\end{array}$ & $\begin{array}{c}2,600 \\
(1,800-4,980) \\
2,450\end{array}$ & 1,660 \\
\hline 12011500 & 26 & $\begin{array}{c}2,860 \\
(2,600-3,150) \\
2,850\end{array}$ & $\begin{array}{c}4,140 \\
(3,700-4,840) \\
4,140\end{array}$ & $\begin{array}{c}4,740 \\
(4,160-5,710) \\
4,760\end{array}$ & $\begin{array}{c}5,160 \\
(4,480-6,360) \\
5,190\end{array}$ & $\begin{array}{c}5,570 \\
(4,780-7,000) \\
5,620\end{array}$ & 4,930 \\
\hline 12012000 & 26 & $\begin{array}{c}2,310 \\
(2,090-2,560) \\
2,280\end{array}$ & $\begin{array}{c}3,480 \\
(3,090-4,090) \\
3,410\end{array}$ & $\begin{array}{c}4,080 \\
(3,550-4,980) \\
3,980\end{array}$ & $\begin{array}{c}4,530 \\
(3,890-5,700) \\
4,410\end{array}$ & $\begin{array}{c}5,000 \\
(4,220-6,450) \\
4,850\end{array}$ & 4,400 \\
\hline 12012200 & 20 & $\begin{array}{c}126 \\
(111-142) \\
126\end{array}$ & $\begin{array}{c}196 \\
(170-240) \\
197\end{array}$ & $\begin{array}{c}234 \\
(198-303) \\
236\end{array}$ & $\begin{array}{c}264 \\
(219-355) \\
266\end{array}$ & $\begin{array}{c}295 \\
(240-412) \\
297\end{array}$ & 233 \\
\hline 12013500 & 45 & $\begin{array}{c}8,330 \\
(7,800-8,900) \\
8,320\end{array}$ & $\begin{array}{c}11,600 \\
(10,700-12,800) \\
11,600\end{array}$ & $\begin{array}{c}13,000 \\
(11,900-14,600) \\
13,100\end{array}$ & $\begin{array}{c}14,000 \\
(12,700-16,000) \\
14,100\end{array}$ & $\begin{array}{c}15,000 \\
(13,400-17,300) \\
15,200\end{array}$ & 14,800 \\
\hline 12014500 & 25 & $\begin{array}{c}1,640 \\
(1,430-1,880) \\
1,670\end{array}$ & $\begin{array}{c}2,760 \\
(2,360-3,430) \\
2,820\end{array}$ & $\begin{array}{c}3,350 \\
(2,800-4,370) \\
3,430\end{array}$ & $\begin{array}{c}3,800 \\
(3,110-5,130) \\
3,900\end{array}$ & $\begin{array}{c}4,260 \\
(3,430-5,940) \\
4,370\end{array}$ & 3,400 \\
\hline
\end{tabular}


Table 2. Flood discharges for selected exceedance probabilities at gaging stations on streams with unregulated flow--Continued

\begin{tabular}{|c|c|c|c|c|c|c|c|}
\hline \multirow[b]{2}{*}{ Station number } & \multirow{2}{*}{$\begin{array}{l}\text { Number of } \\
\text { peaks used } \\
\text { in analysis }\end{array}$} & \multicolumn{4}{|c|}{$\begin{array}{l}\text { Flood discharge, in cubic feet per second } \\
\text { (95-percent confidence interval) } \\
\text { Weighted estimate of flood discharge, in cubic feet per second }\end{array}$} & \multirow{2}{*}{$\begin{array}{c}\begin{array}{l}\text { At indicated } \\
\text { exceedance } \\
\text { probabilities }\end{array} \\
0.01\end{array}$} & \multirow{2}{*}{$\begin{array}{l}\text { Maximum } \\
\text { peak used } \\
\text { in analysis } \\
\text { (cubic feet } \\
\text { per second }\end{array}$} \\
\hline & & 0.5 & 0.1 & 0.04 & 0.02 & & \\
\hline 12015100 & 15 & $\begin{array}{c}265 \\
(213-329) \\
269\end{array}$ & $\begin{array}{c}495 \\
(390-718) \\
498\end{array}$ & $\begin{array}{c}624 \\
(474-985) \\
622\end{array}$ & $\begin{array}{c}724 \\
(536-1,210) \\
718\end{array}$ & $\begin{array}{c}829 \\
(600-1,470) \\
816\end{array}$ & 625 \\
\hline 12015500 & 12 & $\begin{array}{c}1,660 \\
(1,400-1,990) \\
1,660\end{array}$ & $\begin{array}{c}2,560 \\
(2,120-3,500) \\
2,550\end{array}$ & $\begin{array}{c}2,980 \\
(2,420-4,350) \\
2,980\end{array}$ & $\begin{array}{c}3,280 \\
(2,600-5,000) \\
3,290\end{array}$ & $\begin{array}{c}3,570 \\
(2,790-5,680) \\
3,590\end{array}$ & 2,640 \\
\hline 12016700 & 22 & $\begin{array}{c}152 \\
(133-174) \\
155\end{array}$ & $\begin{array}{c}246 \\
(211=306) \\
253\end{array}$ & $\begin{array}{c}295 \\
(247-385) \\
305\end{array}$ & $\begin{array}{c}331 \\
(272-448) \\
344\end{array}$ & $\begin{array}{c}368 \\
(298-514) \\
383\end{array}$ & 329 \\
\hline 12017000 & 46 & $\begin{array}{c}8,210 \\
(7,490-8,980) \\
8,290\end{array}$ & $\begin{array}{c}14,000 \\
(12,500-16,000) \\
14,200\end{array}$ & $\begin{array}{c}17,600 \\
(15,400-21,000) \\
17,800\end{array}$ & $\begin{array}{c}20,600 \\
(17,700-25,400) \\
20,900\end{array}$ & $\begin{array}{c}24,000 \\
(20,200-30,400) \\
24,200\end{array}$ & ${ }^{1} 24,000$ \\
\hline 12019600 & 21 & $\begin{array}{c}89 \\
(79-102) \\
92\end{array}$ & $\begin{array}{c}138 \\
(119-170) \\
144\end{array}$ & $\begin{array}{c}161 \\
(136-207) \\
170\end{array}$ & $\begin{array}{c}177 \\
(148-235) \\
188\end{array}$ & $\begin{array}{c}193 \\
(159-263) \\
207\end{array}$ & 147 \\
\hline 12020000 & 57 & $\begin{array}{c}9,610 \\
(8,710-10,600) \\
9,560\end{array}$ & $\begin{array}{c}17,700 \\
(15,700-20,500) \\
17,400\end{array}$ & $\begin{array}{c}22,600 \\
(19,600-27,200) \\
22,100\end{array}$ & $\begin{array}{c}26,600 \\
(22,700-32,900) \\
25,800\end{array}$ & $\begin{array}{c}31,000 \\
(25,900-39,300) \\
29,900\end{array}$ & 28,900 \\
\hline 12020500 & 33 & $\begin{array}{c}1,710 \\
(1,520-1,920) \\
1,740\end{array}$ & $\begin{array}{c}2,920 \\
(2,540-3,510) \\
2,990\end{array}$ & $\begin{array}{c}3,590 \\
(3,050-4,510) \\
3,690\end{array}$ & $\begin{array}{c}4,120 \\
(3,440-5,340) \\
4,240\end{array}$ & $\begin{array}{c}4,680 \\
(3,830-6,230) \\
4,820\end{array}$ & 4,600 \\
\hline 12020900 & 15 & $\begin{array}{c}2,800 \\
(2,300-3,410) \\
2,790\end{array}$ & $\begin{array}{c}5,040 \\
(4,060-7,080) \\
4,930\end{array}$ & $\begin{array}{c}6,330 \\
(4,910-9,670) \\
6,100\end{array}$ & $\begin{array}{c}7,350 \\
(5,560-11,900) \\
7,010\end{array}$ & $\begin{array}{c}8,440 \\
(6,210-14,500) \\
7,950\end{array}$ & 6,200 \\
\hline 12021000 & 21 & $\begin{array}{c}3,200 \\
(2,900-3,530) \\
3,180\end{array}$ & $\begin{array}{c}4,550 \\
(4,060-5,350) \\
4,540\end{array}$ & $\begin{array}{c}5,200 \\
(4,560-6,360) \\
5,210\end{array}$ & $\begin{array}{c}5,690 \\
(4,920-7,140) \\
5,720\end{array}$ & $\begin{array}{c}6,160 \\
(5,260-7,940) \\
6,210\end{array}$ & 5,700 \\
\hline 12024000 & 26 & $\begin{array}{c}2,280 \\
(2,030-2,570) \\
2,270\end{array}$ & $\begin{array}{c}3,480 \\
(3,050-4,190) \\
3,470\end{array}$ & $\begin{array}{c}4,030 \\
(3,460-5,030) \\
4,020\end{array}$ & $\begin{array}{c}4,420 \\
(3,740-5,640) \\
4,410\end{array}$ & $\begin{array}{c}4,790 \\
(4,010-6,260) \\
4,790\end{array}$ & 4,310 \\
\hline 12025000 & 56 & $\begin{array}{c}5,780 \\
(5,340-6,260) \\
5,780\end{array}$ & $\begin{array}{c}9,160 \\
(8,310-10,300) \\
9,140\end{array}$ & $\begin{array}{c}10,800 \\
(9,680-12,500) \\
10,800\end{array}$ & $\begin{array}{c}12,100 \\
(10,700-14,200) \\
12,100\end{array}$ & $\begin{array}{c}13,300 \\
(11,600-15,900) \\
13,300\end{array}$ & 13,300 \\
\hline 12025300 & 11 & $\begin{array}{c}304 \\
(295-313) \\
310\end{array}$ & $\begin{array}{c}325 \\
(315-343) \\
353\end{array}$ & $\begin{array}{c}332 \\
(321-354) \\
376\end{array}$ & $\begin{array}{c}337 \\
(324-362) \\
395\end{array}$ & $\begin{array}{c}341 \\
(328-368) \\
412\end{array}$ & 320 \\
\hline 12025700 & 29 & $\begin{array}{c}2,600 \\
(2,170-3,100) \\
2,570\end{array}$ & $\begin{array}{c}5,440 \\
(4,410-7,210) \\
5,240\end{array}$ & $\begin{array}{c}7,160 \\
(5,620-10,100) \\
6,770\end{array}$ & $\begin{array}{c}8,570 \\
(6,560-12,600) \\
7,990\end{array}$ & $\begin{array}{c}10,100 \\
(7,540-15,500) \\
9,280\end{array}$ & 9,020 \\
\hline 12026000 & 34 & $\begin{array}{c}3,590 \\
(3,270-3,940) \\
3,570\end{array}$ & $\begin{array}{c}5,390 \\
(4,830-6,240) \\
5,340\end{array}$ & $\begin{array}{c}6,230 \\
(5,490-7,420) \\
6,170\end{array}$ & $\begin{array}{c}6,840 \\
(5,960-8,300) \\
6,780\end{array}$ & $\begin{array}{c}7,420 \\
(6,400-9,180) \\
7,360\end{array}$ & 6,710 \\
\hline
\end{tabular}


Table 2. Flood discharges for selected exceedance probabilities at gaging stations on streams with unregulated flow--Continued

\begin{tabular}{|c|c|c|c|c|c|c|c|}
\hline \multirow[b]{2}{*}{ Station number } & \multirow{2}{*}{$\begin{array}{l}\text { Number of } \\
\text { peaks used } \\
\text { in analysis }\end{array}$} & \multicolumn{4}{|c|}{$\begin{array}{l}\text { Flood discharge, in cubic feet per second } \\
\text { (95-percent confidence interval) } \\
\text { Weighted estimate of flood discharge, in cubic feet per second }\end{array}$} & \multirow{2}{*}{$\begin{array}{c}\begin{array}{l}\text { At indicated } \\
\text { exceedance } \\
\text { probabilities }\end{array} \\
0.01\end{array}$} & \multirow{2}{*}{$\begin{array}{l}\text { Maximum } \\
\text { peak used } \\
\text { in analysis } \\
\text { (cubic feet } \\
\text { per second) }\end{array}$} \\
\hline & & 0.5 & 0.1 & 0.04 & 0.02 & & \\
\hline 12026300 & 16 & $\begin{array}{c}35 \\
(30-42) \\
35\end{array}$ & $\begin{array}{r}57 \\
(48-75) \\
55\end{array}$ & $\begin{array}{r}68 \\
(55-95) \\
65\end{array}$ & $\begin{array}{c}76 \\
(60-110) \\
72\end{array}$ & $\begin{array}{c}84 \\
(66-126) \\
79\end{array}$ & 64 \\
\hline 12027500 & 68 & $\begin{array}{l}25,000 \\
(23,100-27,200) \\
25,100\end{array}$ & $\begin{array}{c}43,400 \\
(39,200-49,100) \\
43,500\end{array}$ & $\begin{array}{c}54,000 \\
(47,900-62,900) \\
54,100\end{array}$ & $\begin{array}{c}62,600 \\
(54,700-74,300) \\
62,700\end{array}$ & $\begin{array}{c}71,600 \\
(61,700-86,700) \\
71,600\end{array}$ & 74,800 \\
\hline 12029700 & 30 & $\begin{array}{c}28,800 \\
(26,400-31,400) \\
29,100\end{array}$ & $\begin{array}{c}41,900 \\
(37,900-48,100) \\
42,700\end{array}$ & $\begin{array}{c}48,500 \\
(43,100-57,500) \\
49,700\end{array}$ & $\begin{array}{c}53,500 \\
(46,800-64,800) \\
55,100\end{array}$ & $\begin{array}{c}58,500 \\
(50,500-72,400) \\
60,500\end{array}$ & 53,400 \\
\hline 12030000 & 30 & $\begin{array}{c}1,120 \\
(1,050-1,200) \\
1,120\end{array}$ & $\begin{array}{c}1,480 \\
(1,360-1,640) \\
1,500\end{array}$ & $\begin{array}{c}1,620 \\
(1,480-1,850) \\
1,650\end{array}$ & $\begin{array}{c}1,720 \\
(1,560-1,990) \\
1,760\end{array}$ & $\begin{array}{c}1,820 \\
(1,630-2,120) \\
1,880\end{array}$ & 1,640 \\
\hline 12031000 & 49 & $\begin{array}{c}29,100 \\
(26,900-31,500) \\
29,300\end{array}$ & $\begin{array}{c}46,100 \\
(41,800-52,100) \\
46,600\end{array}$ & $\begin{array}{c}55,500 \\
(49,400-64,600) \\
56,300\end{array}$ & $\begin{array}{c}62,900 \\
(55,200-74,800) \\
63,800\end{array}$ & $\begin{array}{c}70,700 \\
(61,200-85,800) \\
71,800\end{array}$ & 80,700 \\
\hline 12032500 & 35 & $\begin{array}{c}3,130 \\
(2,860-3,430) \\
3,130\end{array}$ & $\begin{array}{c}4,650 \\
(4,180-5,360) \\
4,680\end{array}$ & $\begin{array}{c}5,340 \\
(4,720-6,310) \\
5,390\end{array}$ & $\begin{array}{c}5,820 \\
(5,090-7,000) \\
5,890\end{array}$ & $\begin{array}{c}6,280 \\
(5,440-7,680) \\
6,380\end{array}$ & 5,080 \\
\hline 12034200 & 16 & $\begin{array}{c}3,000 \\
(2,610-3,460) \\
3,110\end{array}$ & $\begin{array}{c}4,510 \\
(3,860-5,720) \\
4,810\end{array}$ & $\begin{array}{c}5,210 \\
(4,360-6,940) \\
5,670\end{array}$ & $\begin{array}{c}5,710 \\
(4,710-7,870) \\
6,300\end{array}$ & $\begin{array}{c}6,190 \\
(5,030-8,790) \\
6,830\end{array}$ & 5,030 \\
\hline 12034700 & 20 & $\begin{array}{c}40 \\
(32-49) \\
41\end{array}$ & $\begin{array}{r}78 \\
(62-110) \\
79\end{array}$ & $\begin{array}{c}99 \\
(76-150) \\
100\end{array}$ & $\begin{array}{c}115 \\
(86-182) \\
115\end{array}$ & $\begin{array}{c}132 \\
(96-217) \\
131\end{array}$ & 77 \\
\hline 12035000 & 67 & $\begin{array}{c}24,700 \\
(23,000-26,600) \\
24,800\end{array}$ & $\begin{array}{c}38,200 \\
(35,000-42,500) \\
38,400\end{array}$ & $\begin{array}{c}44,400 \\
(40,100-50,300) \\
44,700\end{array}$ & $\begin{array}{c}48,800 \\
(43,700-56,000) \\
49,200\end{array}$ & $\begin{array}{c}53,000 \\
(47,100-61,500) \\
53,500\end{array}$ & 50,600 \\
\hline 12035450 & 24 & $\begin{array}{c}2,260 \\
(2,030-2510) \\
2,220\end{array}$ & $\begin{array}{c}3,330 \\
(2,940-3,960) \\
3,270\end{array}$ & $\begin{array}{c}3,820 \\
(3,310-4,700) \\
3,740\end{array}$ & $\begin{array}{c}4,170 \\
(3,570-5,250) \\
4,080\end{array}$ & $\begin{array}{c}4,500 \\
(3,810-5,790) \\
4,410\end{array}$ & 3,880 \\
\hline 12035500 & 27 & $\begin{array}{c}9,840 \\
(8,910-10,900) \\
9,970\end{array}$ & $\begin{array}{c}14,600 \\
(13,000-17,100) \\
15,000\end{array}$ & $\begin{array}{c}16,800 \\
(14,700-20,300) \\
17,500\end{array}$ & $\begin{array}{c}18,400 \\
(15,900-22,800) \\
19,300\end{array}$ & $\begin{array}{c}19,900 \\
(17,000-25,200) \\
21,000\end{array}$ & 18,000 \\
\hline 12036000 & 47 & $\begin{array}{c}10,900 \\
(9,970-11,900) \\
11,000\end{array}$ & $\begin{array}{c}17,500 \\
(15,800-20,000) \\
17,700\end{array}$ & $\begin{array}{c}21,000 \\
(18,500-24,700) \\
21,200\end{array}$ & $\begin{array}{c}23,600 \\
(20,600-28,400) \\
23,900\end{array}$ & $\begin{array}{c}26,400 \\
(22,700-32,300) \\
26,700\end{array}$ & 23,600 \\
\hline 12036400 & 10 & $\begin{array}{c}1,650 \\
(1,350-2,030)\end{array}$ & $\begin{array}{c}2,600 \\
(2,110-3,780) \\
1,670\end{array}$ & $\begin{array}{c}3,060 \\
(2,410-4,840) \\
2,650\end{array}$ & $\begin{array}{c}3,390 \\
(2,610-5,680) \\
3,140\end{array}$ & $\begin{array}{c}3,720 \\
(2,810-6,570) \\
3,4903,850\end{array}$ & 2,640 \\
\hline 12036650 & 13 & $\begin{array}{c}254 \\
(207-311) \\
260\end{array}$ & $\begin{array}{c}436 \\
(350-622) \\
449\end{array}$ & $\begin{array}{c}532 \\
(414-824) \\
549\end{array}$ & $\begin{array}{c}605 \\
(460-994) \\
624\end{array}$ & $\begin{array}{c}680 \\
(505-1,180) \\
700\end{array}$ & 452 \\
\hline
\end{tabular}


Table 2. Flood discharges for selected exceedance probabilities at gaging stations on streams with unregulated flow--Continued

\begin{tabular}{|c|c|c|c|c|c|c|c|}
\hline \multirow[b]{2}{*}{ Station number } & \multirow{2}{*}{$\begin{array}{l}\text { Number of } \\
\text { peaks used } \\
\text { in analysis }\end{array}$} & \multicolumn{4}{|c|}{$\begin{array}{l}\text { Flood discharge, in cubic feet per second } \\
\text { (95-percent confidence interval) } \\
\text { Weighted estimate of flood discharge, in cubic feet per second }\end{array}$} & \multirow{2}{*}{$\begin{array}{c}\begin{array}{l}\text { At indicated } \\
\text { exceedance } \\
\text { probabilities }\end{array} \\
0.01\end{array}$} & \multirow{2}{*}{$\begin{array}{l}\text { Maximum } \\
\text { peak used } \\
\text { in analysis } \\
\text { (cubic feet } \\
\text { per second) }\end{array}$} \\
\hline & & 0.5 & 0.1 & 0.04 & 0.02 & & \\
\hline 12037400 & 16 & $\begin{array}{l}16,400 \\
(14,200-19,000) \\
16,500\end{array}$ & $\begin{array}{c}25,200 \\
(21,500-32,400) \\
25,600\end{array}$ & $\begin{array}{c}29,400 \\
(24,400-39,700) \\
30,100\end{array}$ & $\begin{array}{c}32,400 \\
(26,500-45,400) \\
33,300\end{array}$ & $\begin{array}{c}35,400 \\
(28,400-51,200) \\
36,500\end{array}$ & 25,500 \\
\hline 12038750 & 11 & $\begin{array}{c}272 \\
(232-317) \\
269\end{array}$ & $\begin{array}{c}406 \\
(344-539) \\
405\end{array}$ & $\begin{array}{c}476 \\
(393-685) \\
476\end{array}$ & $\begin{array}{c}531 \\
(428-808) \\
531\end{array}$ & $\begin{array}{c}587 \\
(463-942) \\
586\end{array}$ & 495 \\
\hline 12039000 & 39 & $\begin{array}{c}18,900 \\
(17,300-20,600) \\
18,800\end{array}$ & $\begin{array}{c}28,400 \\
(25,600-32,500) \\
28,200\end{array}$ & $\begin{array}{c}32,800 \\
(29,100-38,500) \\
32,600\end{array}$ & $\begin{array}{c}35,900 \\
(31,500-42,900) \\
35,700\end{array}$ & $\begin{array}{c}38,900 \\
(33,800-47,200) \\
38,700\end{array}$ & 33,000 \\
\hline 12039050 & 22 & $\begin{array}{c}60 \\
(51-71) \\
61\end{array}$ & $\begin{array}{r}108 \\
(90-142) \\
108\end{array}$ & $\begin{array}{c}134 \\
(108-186) \\
134\end{array}$ & $\begin{array}{c}154 \\
(121-223) \\
153\end{array}$ & $\begin{array}{c}175 \\
(135-262) \\
173\end{array}$ & 123 \\
\hline 12039100 & 20 & $\begin{array}{c}16 \\
(15-18) \\
17\end{array}$ & $\begin{array}{r}24 \\
(21-29) \\
25\end{array}$ & $\begin{array}{r}27 \\
(23-34) \\
28\end{array}$ & $\begin{array}{r}29 \\
(25-38) \\
31\end{array}$ & $\begin{array}{r}31 \\
(26-41) \\
33\end{array}$ & 24 \\
\hline 12039300 & 22 & $\begin{array}{c}16,100 \\
(13,800-18,700) \\
15,900\end{array}$ & $\begin{array}{c}27,200 \\
(22,900-34,800) \\
26,500\end{array}$ & $\begin{array}{c}32,800 \\
(26,900-44,100) \\
31,700\end{array}$ & $\begin{array}{c}37,000 \\
(29,800-51,400) \\
35,500\end{array}$ & $\begin{array}{c}41,000 \\
(32,500-58,900) \\
39,100\end{array}$ & 30,000 \\
\hline 12039400 & 20 & $\begin{array}{c}177 \\
(149-210) \\
172\end{array}$ & $\begin{array}{c}316 \\
(260-419) \\
300\end{array}$ & $\begin{array}{c}393 \\
(314-555) \\
365\end{array}$ & $\begin{array}{c}453 \\
(354-669) \\
415\end{array}$ & $\begin{array}{c}515 \\
(394-792) \\
465\end{array}$ & 409 \\
\hline 12039500 & 83 & $\begin{array}{c}21,900 \\
(20,300-23,700) \\
22,100\end{array}$ & $\begin{array}{c}37,300 \\
(33,900-41,800) \\
37,900\end{array}$ & $\begin{array}{c}45,100 \\
(40,400-51,600) \\
45,900\end{array}$ & $\begin{array}{c}50,900 \\
(45,100-59,100) \\
52,000\end{array}$ & $\begin{array}{c}56,600 \\
(49,700-66,700) \\
57,900\end{array}$ & 52,600 \\
\hline 12040000 & 31 & $\begin{array}{c}19,800 \\
(17,900-21,800) \\
19,600\end{array}$ & $\begin{array}{c}30,700 \\
(27,300-36,000) \\
30,100\end{array}$ & $\begin{array}{c}36,300 \\
(31,600-44,200) \\
35,500\end{array}$ & $\begin{array}{c}40,600 \\
(34,800-50,700) \\
39,500\end{array}$ & $\begin{array}{c}45,000 \\
(38,000-57,500) \\
43,700\end{array}$ & 37,400 \\
\hline 12040500 & 59 & $\begin{array}{c}65,700 \\
(61,400-70,300) \\
65,300\end{array}$ & $\begin{array}{c}98,000 \\
(90,300-108,500) \\
97,200\end{array}$ & $\begin{array}{c}114,000 \\
(103,000-128,000) \\
113,000\end{array}$ & $\begin{array}{c}125,000 \\
(112,000-143,000) \\
124,000\end{array}$ & $\begin{array}{c}136,000 \\
(122,000-158,000) \\
135,000\end{array}$ & 130,000 \\
\hline 12041000 & 38 & $\begin{array}{c}18,800 \\
(17,000-20,900) \\
19,000\end{array}$ & $\begin{array}{c}30,900 \\
(27,300-36,200) \\
31,600\end{array}$ & $\begin{array}{c}37,200 \\
(32,300-45,200) \\
38,200\end{array}$ & $\begin{array}{c}42,100 \\
(36,000-52,400) \\
43,300\end{array}$ & $\begin{array}{c}47,100 \\
(39,600-60,000) \\
48,500\end{array}$ & 38,700 \\
\hline 12041200 & 36 & $\begin{array}{c}32,200 \\
(28,900-35,900) \\
32,200\end{array}$ & $\begin{array}{c}51,100 \\
(45,000-60,400) \\
51,000\end{array}$ & $\begin{array}{c}59,700 \\
(51,700-72,600) \\
59,600\end{array}$ & $\begin{array}{c}65,700 \\
(56,200-81,500) \\
65,700\end{array}$ & $\begin{array}{c}71,400 \\
(60,500-90,100) \\
71,500\end{array}$ & 54,500 \\
\hline 12041500 & 51 & $\begin{array}{c}9,460 \\
(8,570-10,400) \\
9,320\end{array}$ & $\begin{array}{c}16,200 \\
(14,400-18,900) \\
15,900\end{array}$ & $\begin{array}{c}19,800 \\
(17,200-23,700) \\
19,200\end{array}$ & $\begin{array}{c}22,500 \\
(19,300-27,400) \\
21,800\end{array}$ & $\begin{array}{c}25,200 \\
(21,300-31,400) \\
24,300\end{array}$ & 23,500 \\
\hline 12041600 & 20 & $\begin{array}{c}26 \\
(22-31) \\
27\end{array}$ & $\begin{array}{r}48 \\
(39-64) \\
50\end{array}$ & $\begin{array}{r}60 \\
(47-86) \\
62\end{array}$ & $\begin{array}{c}69 \\
(54-105) \\
73\end{array}$ & $\begin{array}{c}80 \\
(60-125) \\
83\end{array}$ & 52 \\
\hline
\end{tabular}


Table 2. Flood discharges for selected exceedance probabilities at gaging stations on streams with unregulated flow--Continued

\begin{tabular}{|c|c|c|c|c|c|c|c|}
\hline \multirow[b]{2}{*}{ Station number } & \multirow{2}{*}{$\begin{array}{l}\text { Number of } \\
\text { peaks used } \\
\text { in analysis }\end{array}$} & \multicolumn{4}{|c|}{$\begin{array}{l}\text { Flood discharge, in cubic feet per second } \\
\text { (95-percent confidence interval) } \\
\text { Weighted estimate of flood discharge, in cubic feet per second }\end{array}$} & \multirow{2}{*}{$\begin{array}{l}\begin{array}{l}\text { At indicated } \\
\text { exceedance } \\
\text { probabilities }\end{array} \\
0.01\end{array}$} & \multirow{2}{*}{$\begin{array}{l}\text { Maximum } \\
\text { peak used } \\
\text { in analysis } \\
\text { (cubic feet } \\
\text { per second) }\end{array}$} \\
\hline & & 0.5 & 0.1 & 0.04 & 0.02 & & \\
\hline 12042700 & 19 & $\begin{array}{c}485 \\
(429-549) \\
465\end{array}$ & $\begin{array}{c}708 \\
(617-865) \\
666\end{array}$ & $\begin{array}{c}804 \\
(688-1,020) \\
749\end{array}$ & $\begin{array}{c}870 \\
(736-1,130) \\
806\end{array}$ & $\begin{array}{c}932 \\
(780-1,240) \\
862\end{array}$ & 759 \\
\hline 12042900 & 39 & $\begin{array}{c}323 \\
(296-352) \\
317\end{array}$ & $\begin{array}{c}481 \\
(435-549) \\
469\end{array}$ & $\begin{array}{c}555 \\
(494-649) \\
538\end{array}$ & $\begin{array}{c}607 \\
(534-724) \\
587\end{array}$ & $\begin{array}{c}658 \\
(574-797) \\
635\end{array}$ & 597 \\
\hline 12043000 & 21 & $\begin{array}{c}18,400 \\
(16,000-21,100) \\
17,900\end{array}$ & $\begin{array}{c}29,300 \\
(25,000-36,700) \\
27,900\end{array}$ & $\begin{array}{c}34,400 \\
(28,800-45,200) \\
32,300\end{array}$ & $\begin{array}{c}38,200 \\
(31,400-51,700) \\
35,600\end{array}$ & $\begin{array}{c}41,800 \\
(33,900-58,300) \\
38,700\end{array}$ & 34,500 \\
\hline 12043100 & 18 & $\begin{array}{c}8,220 \\
(7,130-9,450) \\
8,060\end{array}$ & $\begin{array}{c}13,200 \\
(11,200-16,700) \\
12,700\end{array}$ & $\begin{array}{c}15,900 \\
(13,200-21,400) \\
15,200\end{array}$ & $\begin{array}{c}18,000 \\
(14,700-25,400) \\
17,000\end{array}$ & $\begin{array}{c}20,300 \\
(16,100-29,700) \\
19,100\end{array}$ & 17,300 \\
\hline 12043163 & 11 & $\begin{array}{c}3,490 \\
(2,820-4,340) \\
3,400\end{array}$ & $\begin{array}{c}5,780 \\
(4,610-8,520) \\
5,500\end{array}$ & $\begin{array}{c}6,900 \\
(5,340-11,100) \\
6,470\end{array}$ & $\begin{array}{c}7,720 \\
(5,840-13,100) \\
7,180\end{array}$ & $\begin{array}{c}8,520 \\
(6,320-15,200) \\
7,870\end{array}$ & 5,610 \\
\hline 12043300 & 17 & $\begin{array}{c}7,050 \\
(6,000-8,250) \\
6,890\end{array}$ & $\begin{array}{c}11,700 \\
(9,810-15,300) \\
11,300\end{array}$ & $\begin{array}{c}14,300 \\
(11,600-20,000) \\
13,700\end{array}$ & $\begin{array}{c}16,300 \\
(12,900-23,800) \\
15,500\end{array}$ & $\begin{array}{c}18,300 \\
(14,200-28,100) \\
17,300\end{array}$ & 14,100 \\
\hline 12043430 & 16 & $\begin{array}{c}940 \\
(840-1,060) \\
934\end{array}$ & $\begin{array}{c}1,280 \\
(1,130-1,550) \\
1,300\end{array}$ & $\begin{array}{c}1,420 \\
(1,240-1,780) \\
1,470\end{array}$ & $\begin{array}{c}1,510 \\
(1,300-1,940) \\
1,590\end{array}$ & $\begin{array}{c}1,600 \\
(1,360-2,080) \\
1,710\end{array}$ & 1,220 \\
\hline 12044000 & 10 & $\begin{array}{c}714 \\
(560-915) \\
779\end{array}$ & $\begin{array}{c}1,220 \\
(944-1,900) \\
1,450\end{array}$ & $\begin{array}{c}1,460 \\
(1,100-2,510) \\
1,840\end{array}$ & $\begin{array}{c}1,640 \\
(1,210-3,010) \\
2,170\end{array}$ & $\begin{array}{c}1,820 \\
(1,310-3,530) \\
2,500\end{array}$ & 1,180 \\
\hline 12045500 & 12 & $\begin{array}{c}14,700 \\
(10,600-20,300) \\
14,700\end{array}$ & $\begin{array}{c}34,300 \\
(24,200-61,400) \\
34,000\end{array}$ & $\begin{array}{c}47,400 \\
(31,600-98,000) \\
46,400\end{array}$ & $\begin{array}{c}58,500 \\
(37,500-134,000) \\
56,700\end{array}$ & $\begin{array}{c}71,000 \\
(43,700-179,000) \\
68,100\end{array}$ & 41,600 \\
\hline 12046800 & 14 & $\begin{array}{c}20 \\
(15-28) \\
20\end{array}$ & $\begin{array}{r}45 \\
(33-74) \\
40\end{array}$ & $\begin{array}{r}59 \\
(41-108) \\
50\end{array}$ & $\begin{array}{r}70 \\
(47-137) \\
57\end{array}$ & $\begin{array}{c}81 \\
(53-169) \\
64\end{array}$ & 52 \\
\hline 12047100 & 22 & $\begin{array}{c}92 \\
(71-120) \\
89\end{array}$ & $\begin{array}{c}238 \\
(176-365) \\
218\end{array}$ & $\begin{array}{c}340 \\
(240-576) \\
298\end{array}$ & $\begin{array}{c}430 \\
(293-780) \\
363\end{array}$ & $\begin{array}{c}533 \\
(350-1,030) \\
433\end{array}$ & 338 \\
\hline 12047300 & 13 & $\begin{array}{c}1,280 \\
(938-1,730) \\
1,280\end{array}$ & $\begin{array}{c}2,920 \\
(2,090-5,000) \\
2,850\end{array}$ & $\begin{array}{c}3,970 \\
(2,710-7,760) \\
3,790\end{array}$ & $\begin{array}{c}4,860 \\
(3,200-10,400) \\
4,560\end{array}$ & $\begin{array}{c}5,840 \\
(3,700-13,600) \\
5,360\end{array}$ & 3,160 \\
\hline 12047500 & 17 & $\begin{array}{c}430 \\
(297-625) \\
422\end{array}$ & $\begin{array}{c}1,330 \\
(878-2,480) \\
1,230\end{array}$ & $\begin{array}{c}1,990 \\
(1,240-4,250) \\
1,750\end{array}$ & $\begin{array}{c}2,580 \\
(1,540-6,040) \\
2,180\end{array}$ & $\begin{array}{c}3,250 \\
(1,860-8,270) \\
2,640\end{array}$ & 1,620 \\
\hline 12047700 & 11 & $\begin{array}{c}65 \\
(48-88) \\
66\end{array}$ & $\begin{array}{r}133 \\
(97-230) \\
134\end{array}$ & $\begin{array}{c}172 \\
(120-336) \\
173\end{array}$ & $\begin{array}{c}203 \\
(137-430) \\
204\end{array}$ & $\begin{array}{c}235 \\
(154-537) \\
234\end{array}$ & 173 \\
\hline
\end{tabular}


Table 2. Flood discharges for selected exceedance probabilities at gaging stations on streams with unregulated flow--Continued

\begin{tabular}{|c|c|c|c|c|c|c|c|}
\hline \multirow[b]{2}{*}{ Station number } & \multirow{2}{*}{$\begin{array}{l}\text { Number of } \\
\text { peaks used } \\
\text { in analysis }\end{array}$} & \multicolumn{4}{|c|}{$\begin{array}{l}\text { Flood discharge, in cubic feet per second } \\
\text { (95-percent confidence interval) } \\
\text { Weighted estimate of flood discharge, in cubic feet per second }\end{array}$} & \multirow{2}{*}{$\begin{array}{c}\begin{array}{l}\text { At indicated } \\
\text { exceedance } \\
\text { probabilities }\end{array} \\
0.01\end{array}$} & \multirow{2}{*}{$\begin{array}{l}\text { Maximum } \\
\text { peak used } \\
\text { in analysis } \\
\text { (cubic feet } \\
\text { per second }\end{array}$} \\
\hline & & 0.5 & 0.1 & 0.04 & 0.02 & & \\
\hline 12048000 & 66 & $\begin{array}{c}2,920 \\
(2,600-3,280) \\
2,930\end{array}$ & $\begin{array}{c}5,720 \\
(4,970-6,780) \\
5,740\end{array}$ & $\begin{array}{c}7,140 \\
(6,090-8,710) \\
7,180\end{array}$ & $\begin{array}{c}8,180 \\
(6,890-10,200) \\
8,230\end{array}$ & $\begin{array}{c}9,210 \\
(7,660-11,600) \\
9,270\end{array}$ & 7,120 \\
\hline 12049400 & 22 & $\begin{array}{c}27 \\
(22-34) \\
28\end{array}$ & $\begin{array}{r}60 \\
(46-86) \\
61\end{array}$ & $\begin{array}{r}80 \\
(60-124) \\
82\end{array}$ & $\begin{array}{c}96 \\
(70-158) \\
98\end{array}$ & $\begin{array}{c}114 \\
(80-196) \\
117\end{array}$ & 108 \\
\hline 12050500 & 27 & $\begin{array}{c}209 \\
(168-260) \\
209\end{array}$ & $\begin{array}{c}480 \\
(372-680) \\
475\end{array}$ & $\begin{array}{c}640 \\
(479-970) \\
628\end{array}$ & $\begin{array}{c}768 \\
(561-1,220) \\
748\end{array}$ & $\begin{array}{c}901 \\
(643-1,490) \\
870\end{array}$ & 733 \\
\hline 12052400 & 20 & $\begin{array}{c}207 \\
(160-269) \\
208\end{array}$ & $\begin{array}{c}461 \\
(345-702) \\
459\end{array}$ & $\begin{array}{c}600 \\
(432-982) \\
593\end{array}$ & $\begin{array}{c}702 \\
(495-1,210) \\
691\end{array}$ & $\begin{array}{c}806 \\
(556-1,450) \\
790\end{array}$ & 557 \\
\hline 12053000 & 38 & $\begin{array}{c}4,350 \\
(3,800-4,980) \\
4,360\end{array}$ & $\begin{array}{c}8,180 \\
(6,960-10,100) \\
8,200\end{array}$ & $\begin{array}{c}10,300 \\
(8,540-13,200) \\
10,300\end{array}$ & $\begin{array}{c}11,900 \\
(9,710-15,800) \\
11,900\end{array}$ & $\begin{array}{c}13,600 \\
(10,900-18,500) \\
13,600\end{array}$ & 13,200 \\
\hline 12053400 & 20 & $\begin{array}{c}38 \\
(33-43) \\
37\end{array}$ & $\begin{array}{r}57 \\
(50-70) \\
57\end{array}$ & $\begin{array}{r}67 \\
(57-86) \\
67\end{array}$ & $\begin{array}{r}74 \\
(62-98) \\
74\end{array}$ & $\begin{array}{c}81 \\
(66-110) \\
82\end{array}$ & 66 \\
\hline 12054000 & 58 & $\begin{array}{c}4,490 \\
(4,100-4,930) \\
4,490\end{array}$ & $\begin{array}{c}7,310 \\
(6,550-8,370) \\
7,340\end{array}$ & $\begin{array}{c}8,540 \\
(7,550-9,990) \\
8,610\end{array}$ & $\begin{array}{c}9,390 \\
(8,220-11,100) \\
9,510\end{array}$ & $\begin{array}{c}10,200 \\
(8,830-12,200) \\
10,400\end{array}$ & 9,240 \\
\hline 12054500 & 28 & $\begin{array}{c}3,460 \\
(3,060-3,910) \\
3,460\end{array}$ & $\begin{array}{c}5,560 \\
(4,820-6,740) \\
5,600\end{array}$ & $\begin{array}{c}6,560 \\
(5,580-8,260) \\
6,650\end{array}$ & $\begin{array}{c}7,280 \\
(6,110-9,400) \\
7,430\end{array}$ & $\begin{array}{c}7,990 \\
(6,610-10,600) \\
8,200\end{array}$ & 6,010 \\
\hline 12054600 & 22 & $\begin{array}{c}2,300 \\
(2,100-2,540) \\
2,270\end{array}$ & $\begin{array}{c}3,110 \\
(2,800-3,620) \\
3,080\end{array}$ & $\begin{array}{c}3,420 \\
(3,030-4,080) \\
3,420\end{array}$ & $\begin{array}{c}3,610 \\
(3,180-4,380) \\
3,640\end{array}$ & $\begin{array}{c}3,790 \\
(3,310-4,660) \\
3,860\end{array}$ & 3,160 \\
\hline 12056300 & 20 & $\begin{array}{c}51 \\
(39-68) \\
51\end{array}$ & $\begin{array}{r}134 \\
(97-213) \\
131\end{array}$ & $\begin{array}{c}192 \\
(133-340) \\
185\end{array}$ & $\begin{array}{c}244 \\
(162-464) \\
230\end{array}$ & $\begin{array}{c}302 \\
(194-616) \\
280\end{array}$ & 228 \\
\hline 12056500 & 72 & $\begin{array}{c}6,570 \\
(5,930-7,270) \\
6,570\end{array}$ & $\begin{array}{c}13,000 \\
(11,400-15,100) \\
13,000\end{array}$ & $\begin{array}{c}16,700 \\
(14,400-20,100) \\
16,700\end{array}$ & $\begin{array}{c}19,800 \\
(16,800-24,300) \\
19,800\end{array}$ & $\begin{array}{c}23,000 \\
(19,200-28,900) \\
22,900\end{array}$ & 27,000 \\
\hline 12057500 & 12 & $\begin{array}{c}7,820 \\
(6,540-9,310) \\
7,880\end{array}$ & $\begin{array}{c}12,400 \\
(10,300-17,000) \\
12,800\end{array}$ & $\begin{array}{c}14,800 \\
(11,900-22,000) \\
15,600\end{array}$ & $\begin{array}{c}16,600 \\
(13,100-26,100) \\
17,700\end{array}$ & $\begin{array}{c}18,500 \\
(14,200-30,600) \\
19,900\end{array}$ & 14,000 \\
\hline 12058000 & 26 & $\begin{array}{c}114 \\
(93-142) \\
112\end{array}$ & $\begin{array}{c}249 \\
(196-348) \\
256\end{array}$ & $\begin{array}{c}326 \\
(247-486) \\
348\end{array}$ & $\begin{array}{c}386 \\
(286-600) \\
423\end{array}$ & $\begin{array}{c}448 \\
(324-724) \\
504\end{array}$ & ${ }^{2} 355$ \\
\hline 12059800 & 15 & $\begin{array}{c}3,700 \\
(3,170-4,330) \\
3,680\end{array}$ & $\begin{array}{c}5,570 \\
(4,700-7,240) \\
5,650\end{array}$ & $\begin{array}{c}6,360 \\
(5,270-8,680) \\
6,560\end{array}$ & $\begin{array}{c}6,910 \\
(5,640-9,710) \\
7,240\end{array}$ & $\begin{array}{c}7,410 \\
(5,970-10,700) \\
7,900\end{array}$ & 5,340 \\
\hline
\end{tabular}


Table 2. Flood discharges for selected exceedance probabilities at gaging stations on streams with unregulated flow--Continued

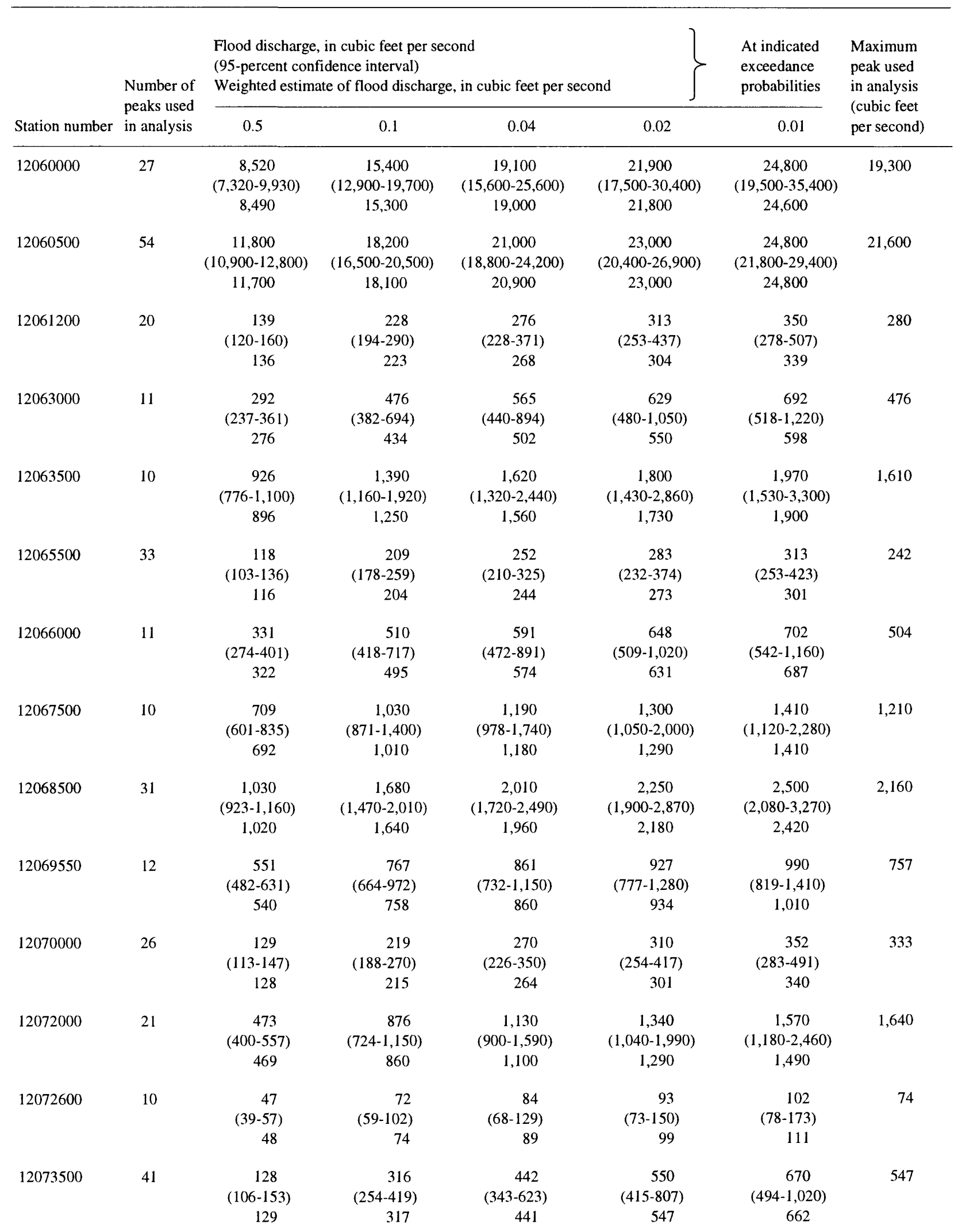


Table 2. Flood discharges for selected exceedance probabilities at gaging stations on streams with unregulated flow--Continued

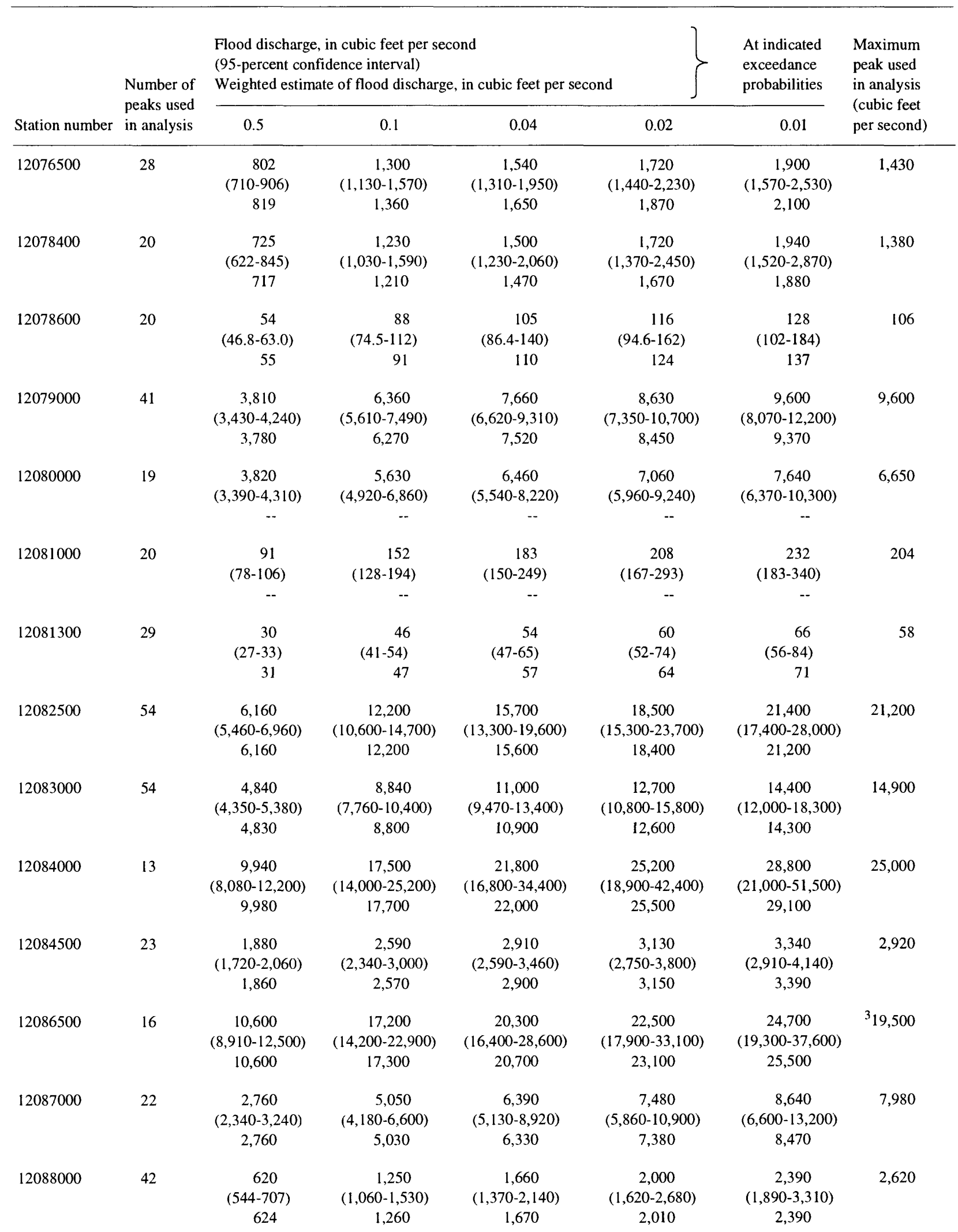


Table 2. Flood discharges for selected exceedance probabilities at gaging stations on streams with unregulated flow--Continued

\begin{tabular}{|c|c|c|c|c|c|c|c|}
\hline \multirow[b]{2}{*}{ Station number } & \multirow{2}{*}{$\begin{array}{l}\text { Number of } \\
\text { peaks used } \\
\text { in analysis }\end{array}$} & \multicolumn{4}{|c|}{$\begin{array}{l}\text { Flood discharge, in cubic feet per second } \\
\text { (95-percent confidence interval) } \\
\text { Weighted estimate of flood discharge, in cubic feet per second }\end{array}$} & \multirow{2}{*}{$\begin{array}{c}\begin{array}{l}\text { At indicated } \\
\text { exceedance } \\
\text { probabilities }\end{array} \\
0.01\end{array}$} & \multirow{2}{*}{$\begin{array}{l}\text { Maximum } \\
\text { peak used } \\
\text { in analysis } \\
\text { (cubic feet } \\
\text { per second }\end{array}$} \\
\hline & & 0.5 & 0.1 & 0.04 & 0.02 & & \\
\hline \multirow[t]{2}{*}{12090200} & 21 & $\begin{array}{c}403 \\
(340-475)\end{array}$ & $\begin{array}{c}727 \\
(601-959)\end{array}$ & $\begin{array}{c}919 \\
(735-1,300)\end{array}$ & $\begin{array}{c}1,070 \\
(838-1,600)\end{array}$ & $\begin{array}{c}1,240 \\
(944-1,930)\end{array}$ & 1,670 \\
\hline & & 414 & 766 & 983 & 1,160 & 1,350 & \\
\hline \multirow[t]{2}{*}{12090400} & 16 & $\begin{array}{c}148 \\
(138-158)\end{array}$ & $\begin{array}{c}179 \\
(166-200)\end{array}$ & $\begin{array}{c}191 \\
(175-218)\end{array}$ & $\begin{array}{c}199 \\
(182-231)\end{array}$ & $\begin{array}{c}206 \\
(187-242)\end{array}$ & 190 \\
\hline & & 145 & 176 & 190 & 200 & 209 & \\
\hline \multirow[t]{2}{*}{12091700} & 11 & $\begin{array}{c}92 \\
(77-110)\end{array}$ & $\begin{array}{c}144 \\
(120-200)\end{array}$ & $\begin{array}{c}172 \\
(138-260)\end{array}$ & $\begin{array}{c}194 \\
(152-311)\end{array}$ & $\begin{array}{c}216 \\
(165-366)\end{array}$ & 200 \\
\hline & & 93 & 147 & 178 & 202 & 227 & \\
\hline \multirow[t]{2}{*}{12092000} & 59 & $\begin{array}{c}4,310 \\
(3,840-4,830)\end{array}$ & $\begin{array}{c}8,470 \\
(7,370-10,000)\end{array}$ & $\begin{array}{c}10,900 \\
(9,240-13,300)\end{array}$ & $\begin{array}{c}12,800 \\
(10,700-16,100)\end{array}$ & $\begin{array}{c}14,800 \\
(12,200-19,000)\end{array}$ & 16,000 \\
\hline & & 4,320 & 8,510 & 11,000 & 12,900 & 14,900 & \\
\hline \multirow[t]{2}{*}{12093000} & 34 & $\begin{array}{c}337 \\
(296-385)\end{array}$ & $\begin{array}{c}590 \\
(506-723)\end{array}$ & $\begin{array}{c}716 \\
(600-912)\end{array}$ & $\begin{array}{c}808 \\
(668-1,060)\end{array}$ & $\begin{array}{c}900 \\
(733-1,200)\end{array}$ & 681 \\
\hline & & 341 & 605 & 742 & 844 & 947 & \\
\hline \multirow[t]{2}{*}{12093500} & 65 & $\begin{array}{c}6,500 \\
(5,880-7,190)\end{array}$ & $\begin{array}{c}11,700 \\
(10,300-13,500)\end{array}$ & $\begin{array}{c}14,200 \\
(12,400-16,900)\end{array}$ & $\begin{array}{c}16,000 \\
(13,800-19,400)\end{array}$ & $\begin{array}{c}17,800 \\
(15,200-21,900)\end{array}$ & 18,300 \\
\hline & & 6,500 & 11,700 & 14,200 & 16,000 & 17,900 & \\
\hline \multirow[t]{2}{*}{12093900} & 13 & $\begin{array}{c}4,440 \\
(3,310-5,970)\end{array}$ & $\begin{array}{c}9,380 \\
(6,840-15,600)\end{array}$ & $\begin{array}{c}12,200 \\
(8,510-22,600)\end{array}$ & $\begin{array}{c}14,300 \\
(9,730-28,600)\end{array}$ & $\begin{array}{c}16,600 \\
(10,900-35,300)\end{array}$ & 10,000 \\
\hline & & 4,400 & 9,090 & 11,600 & 13,500 & 15,400 & \\
\hline \multirow[t]{2}{*}{12094000} & 55 & $\begin{array}{c}4,200 \\
(3,700-4,770)\end{array}$ & $\begin{array}{c}8,520 \\
(7,310-10,300)\end{array}$ & $\begin{array}{c}11,000 \\
(9,180-13,800)\end{array}$ & $\begin{array}{c}12,900 \\
(10,600-16,600)\end{array}$ & $\begin{array}{c}14,800 \\
(12,000-19,500)\end{array}$ & 13,000 \\
\hline & & 4,200 & 8,480 & 10,900 & 12,800 & 14,600 & \\
\hline \multirow[t]{2}{*}{12095000} & 39 & $\begin{array}{c}2,990 \\
(2,630-3,410)\end{array}$ & $\begin{array}{c}5,520 \\
(4,730-6,750)\end{array}$ & $\begin{array}{c}6,870 \\
(5,750-8,740)\end{array}$ & $\begin{array}{c}7,910 \\
(6,500-10,300\end{array}$ & $\begin{array}{c}8,960 \\
(7,250-12,000)\end{array}$ & 8,200 \\
\hline & & 2,980 & 5,460 & 6,770 & 7,770 & 8,770 & \\
\hline \multirow[t]{2}{*}{12096500} & 27 & $\begin{array}{c}13,200 \\
(11,800-14,700)\end{array}$ & $\begin{array}{c}21,000 \\
(18,400-25,200)\end{array}$ & $\begin{array}{c}25,200 \\
(21,600-31,600)\end{array}$ & $\begin{array}{c}28,500 \\
(24,000-36,800)\end{array}$ & $\begin{array}{c}31,900 \\
(26,400-42,400)\end{array}$ & 41,500 \\
\hline & & 13,200 & 21,100 & 25,400 & 28,700 & 32,200 & \\
\hline \multirow[t]{2}{*}{12096800} & 19 & $\begin{array}{c}21 \\
(17-26)\end{array}$ & $\begin{array}{r}43 \\
(34-63)\end{array}$ & $\begin{array}{r}58 \\
(43-91)\end{array}$ & $\begin{array}{r}70 \\
(51-117)\end{array}$ & $\begin{array}{c}83 \\
(58-148)\end{array}$ & 67 \\
\hline & & 22 & 47 & 64 & 79 & 95 & \\
\hline \multirow[t]{2}{*}{12096950} & 11 & $\begin{array}{c}164 \\
(137-197)\end{array}$ & $\begin{array}{c}254 \\
(210-353)\end{array}$ & $\begin{array}{c}299 \\
(240-448)\end{array}$ & $\begin{array}{c}332 \\
(261-525)\end{array}$ & $\begin{array}{c}365 \\
(282-607)\end{array}$ & 291 \\
\hline & & 165 & 262 & 314 & 354 & 394 & \\
\hline \multirow[t]{2}{*}{12097000} & 48 & $\begin{array}{c}4,750 \\
(4,150-5,440)\end{array}$ & $\begin{array}{c}10,200 \\
(8,690-12,600)\end{array}$ & $\begin{array}{c}14,000 \\
(11,500-18,100)\end{array}$ & $\begin{array}{c}17,200 \\
(13,800-23,000)\end{array}$ & $\begin{array}{c}20,800 \\
(16,300-28,900)\end{array}$ & 18,100 \\
\hline & & 4,780 & 10,300 & 14,100 & 17,300 & 20,800 & \\
\hline \multirow[t]{2}{*}{12097500} & 54 & $\begin{array}{c}1,300 \\
(1,120-1,500)\end{array}$ & $\begin{array}{c}3,280 \\
(2,740-4,100)\end{array}$ & $\begin{array}{c}4,890 \\
(3,930-6,500)\end{array}$ & $\begin{array}{c}6,450 \\
(5,020-8,980)\end{array}$ & $\begin{array}{c}8,390 \\
(6,330-12,200)\end{array}$ & 10,500 \\
\hline & & 1,320 & 3,350 & 4,990 & 6,570 & 8,510 & \\
\hline
\end{tabular}


Table 2. Flood discharges for selected exceedance probabilities at gaging stations on streams with unregulated flow--Continued

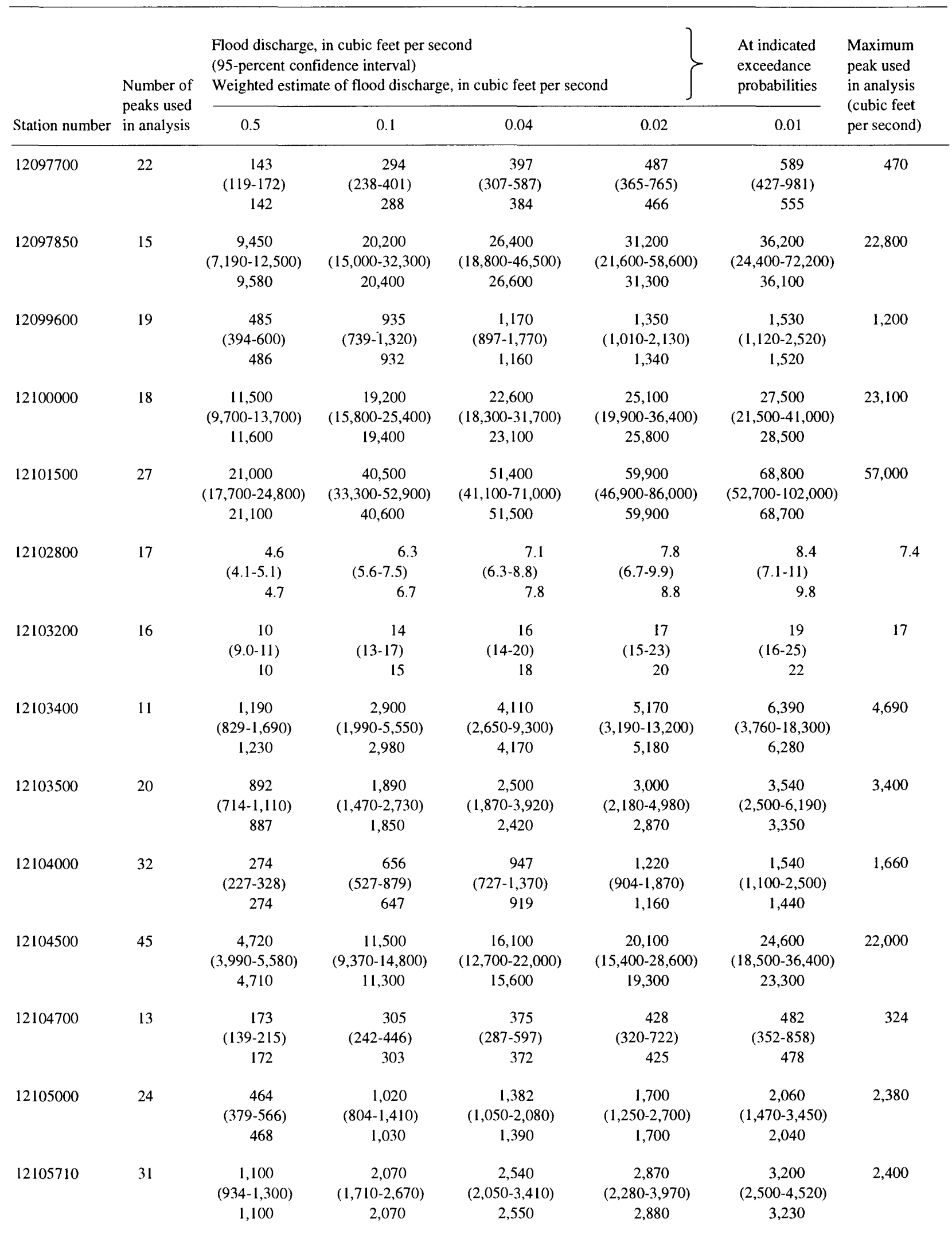


Table 2. Flood discharges for selected exceedance probabilities at gaging stations on streams with unregulated flow--Continued

\begin{tabular}{|c|c|c|c|c|c|c|c|}
\hline \multirow[b]{2}{*}{ Station number } & \multirow{2}{*}{$\begin{array}{l}\text { Number of } \\
\text { peaks used } \\
\text { in analysis }\end{array}$} & \multicolumn{4}{|c|}{$\begin{array}{l}\text { Flood discharge, in cubic feet per second } \\
\text { (95-percent confidence interval) } \\
\text { Weighted estimate of flood discharge, in cubic feet per second }\end{array}$} & \multirow{2}{*}{$\begin{array}{l}\begin{array}{l}\text { At indicated } \\
\text { exceedance } \\
\text { probabilities }\end{array} \\
0.01\end{array}$} & \multirow{2}{*}{$\begin{array}{l}\text { Maximum } \\
\text { peak used } \\
\text { in analysis } \\
\text { (cubic feet } \\
\text { per second) }\end{array}$} \\
\hline & & 0.5 & 0.1 & 0.04 & 0.02 & & \\
\hline 12106000 & 10 & $\begin{array}{c}416 \\
(310-556) \\
402\end{array}$ & $\begin{array}{c}822 \\
(606-1,410) \\
764\end{array}$ & $\begin{array}{c}1,060 \\
(750-2,100) \\
957\end{array}$ & $\begin{array}{c}1,260 \\
(858-2,740) \\
1,110\end{array}$ & $\begin{array}{c}1,470 \\
(968-3,500) \\
1,270\end{array}$ & 1,010 \\
\hline 12106500 & 32 & $\begin{array}{c}11,300 \\
(9,880-12,900) \\
11,200\end{array}$ & $\begin{array}{c}19,900 \\
(17,000-24,500) \\
19,700\end{array}$ & $\begin{array}{c}24,500 \\
(20,400-31,500) \\
24,200\end{array}$ & $\begin{array}{l}27,900 \\
(22,900-37,000) \\
27,400\end{array}$ & $\begin{array}{c}31,500 \\
(25,400-42,800) \\
30,900\end{array}$ & 27,800 \\
\hline 12107200 & 21 & $\begin{array}{c}65 \\
(56-77) \\
66\end{array}$ & $\begin{array}{c}110 \\
(92-142) \\
115\end{array}$ & $\begin{array}{c}131 \\
(107-178) \\
139\end{array}$ & $\begin{array}{c}146 \\
(117-206) \\
157\end{array}$ & $\begin{array}{c}161 \\
(127-233) \\
176\end{array}$ & 128 \\
\hline 12108500 & 52 & $\begin{array}{c}641 \\
(568-722) \\
640\end{array}$ & $\begin{array}{c}1,300 \\
(1,130-1,570) \\
1,290\end{array}$ & $\begin{array}{c}1,740 \\
(1,460-2,180) \\
1,710\end{array}$ & $\begin{array}{c}2,110 \\
(1,730-2,730) \\
2,060\end{array}$ & $\begin{array}{c}2,520 \\
(2,030-3,370) \\
2,450\end{array}$ & 2,640 \\
\hline 12112500 & 12 & $\begin{array}{c}647 \\
(520-804) \\
661\end{array}$ & $\begin{array}{c}1,130 \\
(895-1,670) \\
1,180\end{array}$ & $\begin{array}{c}1,390 \\
(1,060-2,250) \\
1,470\end{array}$ & $\begin{array}{c}1,590 \\
(1,190-2,750) \\
1,690\end{array}$ & $\begin{array}{c}1,800 \\
(1,310-3,300) \\
1,930\end{array}$ & 1,570 \\
\hline 12112600 & 36 & $\begin{array}{c}686 \\
(593-792) \\
691\end{array}$ & $\begin{array}{c}1,380 \\
(1,160-1,740) \\
1,400\end{array}$ & $\begin{array}{c}1,830 \\
(1,490-2,420) \\
1,860\end{array}$ & $\begin{array}{c}2,200 \\
(1,750-3,030) \\
2,230\end{array}$ & $\begin{array}{c}2,610 \\
(2,030-3,740) \\
2,640\end{array}$ & 4,200 \\
\hline 12113000 & 25 & $\begin{array}{c}11,700 \\
(10,000-13,700) \\
11,700\end{array}$ & $\begin{array}{c}20,700 \\
(17,400-26,600) \\
20,600\end{array}$ & $\begin{array}{c}25,400 \\
(20,700-34,200) \\
25,200\end{array}$ & $\begin{array}{c}28,900 \\
(23,100-40,200) \\
28,600\end{array}$ & $\begin{array}{c}32,300 \\
(25,400-46,400) \\
31,900\end{array}$ & 28,100 \\
\hline 12113200 & 22 & $\begin{array}{c}44 \\
(40-52) \\
47\end{array}$ & $\begin{array}{r}72 \\
(62-89) \\
74\end{array}$ & $\begin{array}{r}84 \\
(71-110) \\
89\end{array}$ & $\begin{array}{c}93 \\
(77-125) \\
100\end{array}$ & $\begin{array}{c}102 \\
(83-140) \\
110\end{array}$ & 112 \\
\hline 12113300 & 17 & $\begin{array}{r}5.2 \\
(4.3-6.1) \\
5.3\end{array}$ & $\begin{array}{r}9.2 \\
(7.6-12) \\
9.6\end{array}$ & $\begin{array}{r}12 \\
(9.3-17) \\
12\end{array}$ & $\begin{array}{r}14 \\
(11-21) \\
15\end{array}$ & $\begin{array}{r}16 \\
(12-26) \\
17\end{array}$ & 15 \\
\hline 12113500 & 19 & $\begin{array}{c}817 \\
(643-1,040) \\
819\end{array}$ & $\begin{array}{c}1,840 \\
(1,410-2,740) \\
1,820\end{array}$ & $\begin{array}{c}2,530 \\
(1,840-4,140) \\
2,470\end{array}$ & $\begin{array}{c}3,100 \\
(2,190-5,480) \\
3,000\end{array}$ & $\begin{array}{c}3,770 \\
(2,570-7,080) \\
3,590\end{array}$ & 3,160 \\
\hline 12114000 & 39 & $\begin{array}{c}447 \\
(384-520) \\
450\end{array}$ & $\begin{array}{c}981 \\
(817-1,240) \\
988\end{array}$ & $\begin{array}{c}1,350 \\
(1,090-1,820) \\
1,350\end{array}$ & $\begin{array}{c}1,680 \\
(1,320-2,360) \\
1,670\end{array}$ & $\begin{array}{c}2,060 \\
(1,570-3,020) \\
2,040\end{array}$ & 2,340 \\
\hline 12114500 & 40 & $\begin{array}{c}1,640 \\
(1,410-1,910) \\
1,650\end{array}$ & $\begin{array}{c}3,490 \\
(2,900-4,420) \\
3,520\end{array}$ & $\begin{array}{c}4,640 \\
(3,750-6,190) \\
4,680\end{array}$ & $\begin{array}{c}5,600 \\
(4,420-7,750) \\
5,640\end{array}$ & $\begin{array}{c}6,650 \\
(5,130-9,510) \\
6,670\end{array}$ & 7,620 \\
\hline 12115000 & 50 & $\begin{array}{c}2,700 \\
(2,370-3,070) \\
2,710\end{array}$ & $\begin{array}{c}5,330 \\
(4,570-6,470) \\
5,360\end{array}$ & $\begin{array}{c}6,790 \\
(5,680-8,560) \\
6,830\end{array}$ & $\begin{array}{c}7,920 \\
(6,520-10,200) \\
7,970\end{array}$ & $\begin{array}{c}9,090 \\
(7,360-12,000) \\
9,140\end{array}$ & 9,490 \\
\hline 12115300 & 32 & $\begin{array}{c}79 \\
-- \\
-.\end{array}$ & $\begin{array}{r}117 \\
-- \\
--\end{array}$ & $\begin{array}{r}126 \\
-- \\
--\end{array}$ & $\begin{array}{r}132 \\
-- \\
--\end{array}$ & $\begin{array}{r}138 \\
-- \\
--\end{array}$ & 125 \\
\hline
\end{tabular}


Table 2. Flood discharges for selected exceedance probabilities at gaging stations on streams with unregulated flow--Continued

\begin{tabular}{|c|c|c|c|c|c|c|c|}
\hline \multirow[b]{2}{*}{ Station number } & \multirow{2}{*}{$\begin{array}{l}\text { Number of } \\
\text { peaks used } \\
\text { in analysis }\end{array}$} & \multicolumn{4}{|c|}{$\begin{array}{l}\text { Flood discharge, in cubic feet per second } \\
\text { (95-percent confidence interval) } \\
\text { Weighted estimate of flood discharge, in cubic feet per second }\end{array}$} & \multirow{2}{*}{$\begin{array}{l}\begin{array}{l}\text { At indicated } \\
\text { exceedance } \\
\text { probabilities }\end{array} \\
0.01\end{array}$} & \multirow{2}{*}{$\begin{array}{l}\text { Maximum } \\
\text { peak used } \\
\text { in analysis } \\
\text { (cubic feet } \\
\text { per second) }\end{array}$} \\
\hline & & 0.5 & 0.1 & 0.04 & 0.02 & & \\
\hline \multirow[t]{2}{*}{12115500} & 50 & $\begin{array}{c}1,660 \\
(1,470-1,880)\end{array}$ & $\begin{array}{c}3,150 \\
(2,720-3,790)\end{array}$ & $\begin{array}{c}3,940 \\
(3,330-4,900)\end{array}$ & $\begin{array}{c}4,530 \\
(3,770-5,780)\end{array}$ & $\begin{array}{c}5,130 \\
(4,210-6,680)\end{array}$ & 4,200 \\
\hline & & 1,650 & 3,110 & 3,870 & 4,430 & 5,010 & \\
\hline \multirow[t]{3}{*}{12115700} & 12 & 550 & 1,520 & 2,210 & 2,800 & 3,470 & 1,800 \\
\hline & & $(367-825)$ & $(989-3,130)$ & $(1,350-5,390)$ & $(1,630-7,580)$ & $(1,940-10,400)$ & \\
\hline & & 545 & 1,430 & 2,000 & 2,450 & 2,940 & \\
\hline \multirow[t]{3}{*}{12116100} & 51 & 48 & 89 & 112 & 129 & 147 & 131 \\
\hline & & $(43-54)$ & $(78-106)$ & $(95-138)$ & $(109-163)$ & $(122-190)$ & \\
\hline & & 47 & 86 & 107 & 122 & 137 & \\
\hline \multirow[t]{3}{*}{12117000} & 40 & 884 & 1,910 & 2,560 & 3,110 & 3,710 & 3,130 \\
\hline & & $(758-1,030)$ & $(1,590-2,420)$ & $(2,060-3,430)$ & $(2,440-4,320)$ & $(2,850-5,340)$ & \\
\hline & & 883 & 1,900 & 2,520 & 3,050 & 3,610 & \\
\hline \multirow[t]{3}{*}{12118500} & 31 & 82 & 167 & 211 & 244 & 276 & 221 \\
\hline & & $(68-98)$ & $(135-221)$ & $(166-293)$ & $(189-350)$ & $(210-408)$ & \\
\hline & & 84 & 177 & 227 & 267 & 306 & \\
\hline \multirow[t]{3}{*}{12119600} & 22 & 218 & 380 & 460 & 519 & 577 & 510 \\
\hline & & $(185-257)$ & $(315-497)$ & $(372-633)$ & $(412-738)$ & $(450-846)$ & \\
\hline & & 219 & 385 & 468 & 531 & 593 & \\
\hline \multirow[t]{3}{*}{12119700} & 16 & 154 & 256 & 314 & 362 & 412 & 362 \\
\hline & & $(131-180)$ & $(214-336)$ & $(255-445)$ & $(286-539)$ & $(318-646)$ & \\
\hline & & 154 & 257 & 316 & 365 & 415 & \\
\hline \multirow[t]{3}{*}{12119800} & 27 & 42 & 86 & 116 & 143 & 173 & 241 \\
\hline & & $(36-50)$ & $(71-112)$ & $(92-163)$ & $(110-211)$ & $(129-270)$ & \\
\hline & & 43 & 88 & 120 & 147 & 178 & \\
\hline \multirow[t]{3}{*}{12120600} & 10 & 640 & 1,550 & 2,120 & 2,570 & 3,060 & 1,360 \\
\hline & & $(428-964)$ & $(1,020-3,260)$ & $(1,320-5,220)$ & $(1,540-7,070)$ & $(1,760-9,260)$ & \\
\hline & & 652 & 1,550 & 2,090 & 2,500 & 2,930 & \\
\hline \multirow[t]{3}{*}{12121000} & 19 & 662 & 1,300 & 1,700 & 2,050 & 2,440 & 2,610 \\
\hline & & $(546-799)$ & $(1,040-1,780)$ & $(1,320-2,560)$ & $(1,540-3,270)$ & $(1,770-4,120)$ & \\
\hline & & 670 & 1,320 & 1,730 & 2,080 & 2,460 & \\
\hline \multirow[t]{3}{*}{12121600} & 33 & 1,470 & 2,760 & 3,380 & 3,820 & 4,240 & 3,200 \\
\hline & & $(1,260-1,730)$ & $(2,300-3,520)$ & $(2,750-4,480)$ & $(3,060-5,200)$ & $(3,350-5,910)$ & \\
\hline & & 1,470 & 2,740 & 3,340 & 3,770 & 4,180 & \\
\hline \multirow[t]{3}{*}{12121700} & 11 & 153 & 310 & 398 & 466 & 535 & 359 \\
\hline & & $(113-208)$ & $(226-536)$ & $(277-774)$ & $(315-980)$ & $(351-1,210)$ & \\
\hline & & 151 & 299 & 378 & 437 & 495 & \\
\hline \multirow[t]{3}{*}{12122500} & 16 & 161 & 334 & 429 & 503 & 578 & 420 \\
\hline & & $(125-208)$ & $(252-512)$ & $(312-719)$ & $(356-893)$ & $(399-1,080)$ & \\
\hline & & 165 & 345 & 446 & 524 & 604 & \\
\hline \multirow[t]{3}{*}{12123000} & 10 & 78 & 135 & 165 & 187 & 209 & 132 \\
\hline & & $(61-100)$ & $(105-213)$ & $(123-288)$ & $(136-351)$ & $(149-419)$ & \\
\hline & & 83 & 153 & 194 & 227 & 260 & \\
\hline
\end{tabular}


Table 2. Flood discharges for selected exceedance probabilities at gaging stations on streams with unregulated flow--Continued

\begin{tabular}{|c|c|c|c|c|c|c|c|}
\hline \multirow[b]{2}{*}{ Station number } & \multirow{2}{*}{$\begin{array}{l}\text { Number of } \\
\text { peaks used } \\
\text { in analysis }\end{array}$} & \multicolumn{4}{|c|}{$\begin{array}{l}\text { Flood discharge, in cubic feet per second } \\
\text { (95-percent confidence interval) } \\
\text { Weighted estimate of flood discharge, in cubic feet per second }\end{array}$} & \multirow{2}{*}{$\begin{array}{c}\begin{array}{l}\text { At indicated } \\
\text { exceedance } \\
\text { probabilities }\end{array} \\
0.01\end{array}$} & \multirow{2}{*}{$\begin{array}{l}\text { Maximum } \\
\text { peak used } \\
\text { in analysis } \\
\text { (cubic feet } \\
\text { per second) }\end{array}$} \\
\hline & & 0.5 & 0.1 & 0.04 & 0.02 & & \\
\hline 12123300 & 21 & $\begin{array}{c}24 \\
(20-29)\end{array}$ & $\begin{array}{r}42 \\
(34-56)\end{array}$ & $\begin{array}{r}51 \\
(40-71)\end{array}$ & $\begin{array}{r}57 \\
(44-82)\end{array}$ & $\begin{array}{c}62 \\
(48.2-93)\end{array}$ & 60 \\
\hline & & 25 & 45 & 55 & 63 & 71 & \\
\hline 12124000 & 22 & $\begin{array}{c}126 \\
(112-141)\end{array}$ & $\begin{array}{c}186 \\
(163-224)\end{array}$ & $\begin{array}{c}213 \\
(184-266)\end{array}$ & $\begin{array}{c}233 \\
(198-298)\end{array}$ & $\begin{array}{c}252 \\
(212-329)\end{array}$ & 222 \\
\hline & & 129 & 197 & 231 & 258 & 284 & \\
\hline 12125000 & 18 & $\begin{array}{c}738 \\
(624-874) \\
775\end{array}$ & $\begin{array}{c}1,240 \\
(1,030-1,650) \\
1,370\end{array}$ & $\begin{array}{c}1,500 \\
(1,210-2,110) \\
1,710\end{array}$ & $\begin{array}{c}1,690 \\
(1,340-2,470) \\
1,980\end{array}$ & $\begin{array}{c}1,880 \\
(1,460-2,850) \\
2,260\end{array}$ & 1,520 \\
\hline 12125200 & 31 & $\begin{array}{c}1,440 \\
(1,290-1,600) \\
1,460\end{array}$ & $\begin{array}{c}2,190 \\
(1,940-2,590) \\
2,260\end{array}$ & $\begin{array}{c}2,520 \\
(2,190-3,070) \\
2,640\end{array}$ & $\begin{array}{c}2,750 \\
(2,360-3,400) \\
2,910\end{array}$ & $\begin{array}{c}2,960 \\
(2,520-3,730) \\
3,170\end{array}$ & 2,470 \\
\hline 12126000 & 29 & $\begin{array}{c}304 \\
(278-333) \\
305\end{array}$ & $\begin{array}{c}445 \\
(400-513) \\
452\end{array}$ & $\begin{array}{c}515 \\
(455-614) \\
528\end{array}$ & $\begin{array}{c}566 \\
(494-691) \\
584\end{array}$ & $\begin{array}{c}618 \\
(532-771) \\
642\end{array}$ & 680 \\
\hline 12126500 & 24 & $\begin{array}{c}1,140 \\
(1,020-1,280) \\
1,170\end{array}$ & $\begin{array}{c}1,690 \\
(1,490-2,020) \\
1,810\end{array}$ & $\begin{array}{c}1,940 \\
(1,680-2,400) \\
2,130\end{array}$ & $\begin{array}{c}2,110 \\
(1,800-2,670) \\
2,370\end{array}$ & $\begin{array}{c}2,280 \\
(1,920-2,940) \\
2,620\end{array}$ & 1,910 \\
\hline 12127100 & 26 & $\begin{array}{c}440 \\
(390-496) \\
438\end{array}$ & $\begin{array}{c}704 \\
(612-853) \\
700\end{array}$ & $\begin{array}{c}838 \\
(713-1,060) \\
833\end{array}$ & $\begin{array}{c}939 \\
(786-1,220) \\
934\end{array}$ & $\begin{array}{c}1,040 \\
(858-1,390) \\
1,030\end{array}$ & 1,090 \\
\hline 12127300 & 12 & $\begin{array}{c}109 \\
(97.1-123) \\
106\end{array}$ & $\begin{array}{c}147 \\
(129-181) \\
144\end{array}$ & $\begin{array}{c}162 \\
(141-210) \\
160\end{array}$ & $\begin{array}{c}174 \\
(148-231) \\
174\end{array}$ & $\begin{array}{c}184 \\
(155-252) \\
186\end{array}$ & 154 \\
\hline 12127600 & 11 & $\begin{array}{c}142 \\
(119-170) \\
142\end{array}$ & $\begin{array}{c}215 \\
(178-294) \\
217\end{array}$ & $\begin{array}{c}248 \\
(202-365) \\
253\end{array}$ & $\begin{array}{c}273 \\
(217-421) \\
282\end{array}$ & $\begin{array}{c}297 \\
(232-478) \\
310\end{array}$ & 214 \\
\hline 12130500 & 26 & $\begin{array}{c}6,410 \\
(5,410-7,580) \\
6,480\end{array}$ & $\begin{array}{c}12,600 \\
(10,300-16,500) \\
12,800\end{array}$ & $\begin{array}{c}16,300 \\
(12,900-22,700) \\
16,600\end{array}$ & $\begin{array}{c}19,300 \\
(15,000-28,200) \\
19,700\end{array}$ & $\begin{array}{c}22,500 \\
(17,100-34,300) \\
22,900\end{array}$ & 20,000 \\
\hline 12131000 & 28 & $\begin{array}{c}5,580 \\
(4,790-6,490) \\
5,620\end{array}$ & $\begin{array}{c}10,500 \\
(8,800-13,400) \\
10,600\end{array}$ & $\begin{array}{c}13,400 \\
(10,900-18,100) \\
13,600\end{array}$ & $\begin{array}{c}15,800 \\
(12,500-22,100) \\
16,100\end{array}$ & $\begin{array}{c}18,300 \\
(14,200-26,600) \\
18,700\end{array}$ & 17,100 \\
\hline 12132700 & 20 & $\begin{array}{c}107 \\
(91-127) \\
107\end{array}$ & $\begin{array}{c}183 \\
(152-240) \\
185\end{array}$ & $\begin{array}{c}220 \\
(178-304) \\
224\end{array}$ & $\begin{array}{c}246 \\
(196-353) \\
252\end{array}$ & $\begin{array}{c}272 \\
(213-404) \\
281\end{array}$ & 217 \\
\hline 12133000 & 73 & $\begin{array}{c}23,000 \\
(21,000-25,300) \\
23,200\end{array}$ & $\begin{array}{c}42,700 \\
(38,000-49,200) \\
43,900\end{array}$ & $\begin{array}{c}53,400 \\
(46,700-63,200) \\
55,500\end{array}$ & $\begin{array}{c}61,700 \\
(53,200-74,300) \\
64,500\end{array}$ & $\begin{array}{c}71,000 \\
(59,700-86,000) \\
73,800\end{array}$ & ${ }^{4} 55,000$ \\
\hline 12133500 & 12 & $\begin{array}{c}937 \\
(699-1,250)\end{array}$ & $\begin{array}{c}2,000 \\
(1,460-3,370)\end{array}$ & $\begin{array}{c}2,670 \\
(1,860-5,110)\end{array}$ & $\begin{array}{c}3,220 \\
(2,170-6,760)\end{array}$ & $\begin{array}{c}3,830 \\
(2,480-8,740)\end{array}$ & 2,300 \\
\hline
\end{tabular}


Table 2. Flood discharges for selected exceedance probabilities at gaging stations on streams with unregulated flow--Continued

\begin{tabular}{|c|c|c|c|c|c|c|c|}
\hline \multirow[b]{2}{*}{ Station number } & \multirow{2}{*}{$\begin{array}{l}\text { Number of } \\
\text { peaks used } \\
\text { in analysis }\end{array}$} & \multicolumn{4}{|c|}{$\begin{array}{l}\text { Flood discharge, in cubic feet per second } \\
\text { (95-percent confidence interval) } \\
\text { Weighted estimate of flood discharge, in cubic feet per second }\end{array}$} & \multirow{2}{*}{$\begin{array}{l}\begin{array}{l}\text { At indicated } \\
\text { exceedance } \\
\text { probabilities }\end{array} \\
0.01\end{array}$} & \multirow{2}{*}{$\begin{array}{l}\text { Maximum } \\
\text { peak used } \\
\text { in analysis } \\
\text { (cubic feet } \\
\text { per second) }\end{array}$} \\
\hline & & 0.5 & 0.1 & 0.04 & 0.02 & & \\
\hline 12134000 & 21 & $\begin{array}{l}13,700 \\
(11,600-16,300) \\
13,700\end{array}$ & $\begin{array}{c}24,700 \\
(20,300-32,700) \\
24,800\end{array}$ & $\begin{array}{c}30,600 \\
(24,400-43,000) \\
30,800\end{array}$ & $\begin{array}{c}35,100 \\
(27,400-51,400) \\
35,400\end{array}$ & $\begin{array}{c}39,700 \\
(30,400-60,400) \\
40,100\end{array}$ & 28,400 \\
\hline 12134500 & 68 & $\begin{array}{l}39,200 \\
(35,500-43,400) \\
39,100\end{array}$ & $\begin{array}{c}73,000 \\
(64,500-84,700) \\
72,700\end{array}$ & $\begin{array}{c}90,900 \\
(78,900-108,000) \\
90,400\end{array}$ & $\begin{array}{c}104,000 \\
(89,400-127,000) \\
103,000\end{array}$ & $\begin{array}{c}118,000 \\
(100,000-146,000) \\
117,000\end{array}$ & 102,000 \\
\hline 12135000 & 39 & $\begin{array}{c}2,120 \\
(1,960-2,300) \\
2,090\end{array}$ & $\begin{array}{c}3,160 \\
(2,870-3,580) \\
3,100\end{array}$ & $\begin{array}{c}3,680 \\
(3,290-4,300) \\
3,600\end{array}$ & $\begin{array}{c}4,080 \\
(3,590-4,850) \\
3,980\end{array}$ & $\begin{array}{c}4,470 \\
(3,890-5,420) \\
4,350\end{array}$ & 4,210 \\
\hline 12135500 & 21 & $\begin{array}{c}972 \\
(792-1,190) \\
942\end{array}$ & $\begin{array}{c}2,080 \\
(1,650-2,920) \\
1,940\end{array}$ & $\begin{array}{c}2,860 \\
(2,170-4,390) \\
2,570\end{array}$ & $\begin{array}{c}3,560 \\
(2,600-5,830) \\
3,110\end{array}$ & $\begin{array}{c}4,360 \\
(3,080-7,620) \\
3,700\end{array}$ & 4,020 \\
\hline 12137500 & 29 & $\begin{array}{c}15,600 \\
(13,400-18,200) \\
15,200\end{array}$ & $\begin{array}{c}28,400 \\
(23,800-36,100) \\
27,100\end{array}$ & $\begin{array}{c}35,000 \\
(28,600-46,500) \\
32,800\end{array}$ & $\begin{array}{c}39,900 \\
(32,000-54,700) \\
37,000\end{array}$ & $\begin{array}{c}44,800 \\
(35,400-63,100) \\
41,100\end{array}$ & 34,600 \\
\hline 12141000 & 32 & $\begin{array}{c}1,290 \\
(1,150-1,450) \\
1,280\end{array}$ & $\begin{array}{c}2,100 \\
(1,830-2,520) \\
2,090\end{array}$ & $\begin{array}{c}2,490 \\
(2,130-3,090) \\
2,480\end{array}$ & $\begin{array}{c}2,770 \\
(2,340-3,520) \\
2,760\end{array}$ & $\begin{array}{c}3,050 \\
(2,540-3,960) \\
3,040\end{array}$ & 2,350 \\
\hline 12141100 & 17 & $\begin{array}{c}56,000 \\
(49,600-63,000) \\
55,200\end{array}$ & $\begin{array}{c}82,200 \\
(71,900-101,000) \\
81,000\end{array}$ & $\begin{array}{c}95,400 \\
(81,600-123,000) \\
94,100\end{array}$ & $\begin{array}{c}105,000 \\
(88,500-140,000) \\
104,000\end{array}$ & $\begin{array}{c}115,000 \\
(95,300-159,000) \\
114,000\end{array}$ & 106,000 \\
\hline 12141300 & 35 & $\begin{array}{c}16,500 \\
(14,700-18,700) \\
16,400\end{array}$ & $\begin{array}{c}27,200 \\
(23,600-32,700) \\
27,000\end{array}$ & $\begin{array}{c}31,900 \\
(27,300-39,600) \\
31,700\end{array}$ & $\begin{array}{c}35,200 \\
(29,700-44,600) \\
35,100\end{array}$ & $\begin{array}{c}38,300 \\
(32,000-49,400) \\
38,300\end{array}$ & 30,200 \\
\hline 12141500 & 20 & $\begin{array}{c}12,500 \\
(10,400-15,100) \\
12,500\end{array}$ & $\begin{array}{c}23,700 \\
(19,200-32,400) \\
23,700\end{array}$ & $\begin{array}{c}30,100 \\
(23,500-44,000) \\
30,100\end{array}$ & $\begin{array}{c}35,100 \\
(26,700-53,900) \\
35,000\end{array}$ & $\begin{array}{c}40,300 \\
(30,000-64,800) \\
40,100\end{array}$ & 26,700 \\
\hline 12142000 & 65 & $\begin{array}{c}7,520 \\
(6,890-8,220) \\
7,490\end{array}$ & $\begin{array}{c}12,600 \\
(11,300-14,400) \\
12,500\end{array}$ & $\begin{array}{c}15,000 \\
(13,300-17,500) \\
14,900\end{array}$ & $\begin{array}{c}16,800 \\
(14,700-19,800) \\
16,700\end{array}$ & $\begin{array}{c}18,400 \\
(16,000-22,100) \\
18,300\end{array}$ & 15,800 \\
\hline 12142300 & 15 & $\begin{array}{c}440 \\
(368-526) \\
432\end{array}$ & $\begin{array}{c}734 \\
(603-996) \\
714\end{array}$ & $\begin{array}{c}884 \\
(706-1,290) \\
855\end{array}$ & $\begin{array}{c}998 \\
(780-1,520) \\
961\end{array}$ & $\begin{array}{c}1,110 \\
(852-1,770) \\
1,070\end{array}$ & 910 \\
\hline 12143000 & 43 & $\begin{array}{c}8,570 \\
(7,640-9,620) \\
8,710\end{array}$ & $\begin{array}{c}14,700 \\
(12,800-17,500) \\
14,600\end{array}$ & $\begin{array}{c}17,600 \\
(15,100-21,600) \\
17,500\end{array}$ & $\begin{array}{c}19,700 \\
(16,700-24,700) \\
19,600\end{array}$ & $\begin{array}{c}21,800 \\
(18,200-27,700) \\
21,700\end{array}$ & 15,800 \\
\hline 12143300 & 20 & $\begin{array}{c}23 \\
(19-28) \\
23\end{array}$ & $\begin{array}{r}41 \\
(33-55) \\
41\end{array}$ & $\begin{array}{r}49 \\
(39-70) \\
50\end{array}$ & $\begin{array}{r}55 \\
(43-80) \\
56\end{array}$ & $\begin{array}{r}60 \\
(46-91) \\
63\end{array}$ & 44 \\
\hline 12143310 & 11 & $\begin{array}{c}18 \\
(14-22) \\
19\end{array}$ & $\begin{array}{r}30 \\
(24-47) \\
36\end{array}$ & $\begin{array}{r}37 \\
(28-63) \\
46\end{array}$ & $\begin{array}{r}42 \\
(31-76) \\
54\end{array}$ & $\begin{array}{r}47 \\
(34-89) \\
62\end{array}$ & 31 \\
\hline
\end{tabular}


Table 2. Flood discharges for selected exceedance probabilities at gaging stations on streams with unregulated flow--Continued

\begin{tabular}{|c|c|c|c|c|c|c|c|}
\hline \multirow[b]{2}{*}{ Station number } & \multirow{2}{*}{$\begin{array}{l}\text { Number of } \\
\text { peaks used } \\
\text { in analysis }\end{array}$} & \multicolumn{4}{|c|}{$\begin{array}{l}\text { Flood discharge, in cubic feet per second } \\
\text { (95-percent confidence interval) } \\
\text { Weighted estimate of flood discharge, in cubic feet per second }\end{array}$} & \multirow{2}{*}{$\begin{array}{c}\begin{array}{l}\text { At indicated } \\
\text { exceedance } \\
\text { probabilities }\end{array} \\
0.01\end{array}$} & \multirow{2}{*}{$\begin{array}{l}\text { Maximum } \\
\text { peak used } \\
\text { in analysis } \\
\text { (cubic feet } \\
\text { per second) }\end{array}$} \\
\hline & & 0.5 & 0.1 & 0.04 & 0.02 & & \\
\hline 12143400 & 36 & $\begin{array}{c}3,800 \\
(3,280-4,400) \\
3,790\end{array}$ & $\begin{array}{c}7,190 \\
(6,050-9,010) \\
7,140\end{array}$ & $\begin{array}{c}8,940 \\
(7,350-11,700) \\
8,860\end{array}$ & $\begin{array}{c}10,200 \\
(8,280-13,800) \\
10,100\end{array}$ & $\begin{array}{c}11,500 \\
(9,180-15,900) \\
11,400\end{array}$ & 8,450 \\
\hline 12143600 & 15 & $\begin{array}{c}6,000 \\
(4,970-7,280) \\
5,920\end{array}$ & $\begin{array}{c}10,100 \\
(8,170-13,900) \\
9,930\end{array}$ & $\begin{array}{c}12,000 \\
(9,480-17,600) \\
11,800\end{array}$ & $\begin{array}{c}13,400 \\
(10,400-20,500) \\
13,200\end{array}$ & $\begin{array}{c}14,700 \\
(11,200-23,400) \\
14,500\end{array}$ & 10,800 \\
\hline 12143700 & 51 & $\begin{array}{c}81 \\
(71-92) \\
81\end{array}$ & $\begin{array}{c}158 \\
(135-191) \\
160\end{array}$ & $\begin{array}{c}198 \\
(166-248) \\
202\end{array}$ & $\begin{array}{c}227 \\
(188-292) \\
232\end{array}$ & $\begin{array}{c}257 \\
(210-337) \\
264\end{array}$ & 189 \\
\hline 12143900 & 15 & $\begin{array}{c}123 \\
(100-151) \\
127\end{array}$ & $\begin{array}{c}227 \\
(181-325) \\
242\end{array}$ & $\begin{array}{c}287 \\
(220-448) \\
313\end{array}$ & $\begin{array}{c}335 \\
(250-565) \\
370\end{array}$ & $\begin{array}{c}386 \\
(280-678) \\
432\end{array}$ & 256 \\
\hline 12144000 & 60 & $\begin{array}{c}5,050 \\
(4,530-5,620) \\
5,040\end{array}$ & $\begin{array}{c}9,360 \\
(8,210-11,000) \\
9,370\end{array}$ & $\begin{array}{c}11,600 \\
(9,970-14,000) \\
11,600\end{array}$ & $\begin{array}{c}13,300 \\
(11,300-16,400) \\
13,300\end{array}$ & $\begin{array}{c}14,900 \\
(12,500-18,700) \\
14,900\end{array}$ & 13,000 \\
\hline 12144500 & 38 & $\begin{array}{c}31,100 \\
(27,100-35,600) \\
30,900\end{array}$ & $\begin{array}{c}56,300 \\
(48,000-69,300) \\
55,600\end{array}$ & $\begin{array}{c}68,700 \\
(57,300-87,600) \\
67,600\end{array}$ & $\begin{array}{c}77,600 \\
(63,900-101,000) \\
76,200\end{array}$ & $\begin{array}{c}86,400 \\
(70,100-115,000) \\
84,600\end{array}$ & 78,800 \\
\hline 12145500 & 50 & $\begin{array}{c}1,920 \\
(1,720-2,140) \\
1,910\end{array}$ & $\begin{array}{c}3,590 \\
(3,140-4,260) \\
3,550\end{array}$ & $\begin{array}{c}4,580 \\
(3,910-5,640) \\
4,500\end{array}$ & $\begin{array}{c}5,380 \\
(4,510-6,800) \\
5,260\end{array}$ & $\begin{array}{c}6,240 \\
(5,140-8,090) \\
6,070\end{array}$ & 6,220 \\
\hline 12146000 & 27 & $\begin{array}{c}226 \\
(207-247) \\
228\end{array}$ & $\begin{array}{c}331 \\
(298-381) \\
341\end{array}$ & $\begin{array}{c}387 \\
(342-463) \\
404\end{array}$ & $\begin{array}{c}431 \\
(375-530) \\
454\end{array}$ & $\begin{array}{c}477 \\
(408-602) \\
507\end{array}$ & 480 \\
\hline 12147000 & 33 & $\begin{array}{c}369 \\
(324-420) \\
370\end{array}$ & $\begin{array}{c}668 \\
(572-820) \\
685\end{array}$ & $\begin{array}{c}840 \\
(701-1,080) \\
847\end{array}$ & $\begin{array}{c}977 \\
(799-1,300) \\
985\end{array}$ & $\begin{array}{c}1,120 \\
(900-1,540) \\
1,130\end{array}$ & 1,000 \\
\hline 12147500 & 42 & $\begin{array}{c}4,710 \\
(4,270-5,190) \\
4,650\end{array}$ & $\begin{array}{c}7,500 \\
(6,680-8,700) \\
7,350\end{array}$ & $\begin{array}{c}8,820 \\
(7,720-10,500) \\
8,600\end{array}$ & $\begin{array}{c}9,770 \\
(8,450-11,900) \\
9,500\end{array}$ & $\begin{array}{c}10,700 \\
(9,150-13,200) \\
10,400\end{array}$ & 9,560 \\
\hline 12147600 & 33 & $\begin{array}{c}1,140 \\
(1,020-1,280) \\
1,100\end{array}$ & $\begin{array}{c}1,840 \\
(1,610-2,190) \\
1,720\end{array}$ & $\begin{array}{c}2,180 \\
(1,870-2,680) \\
2,000\end{array}$ & $\begin{array}{c}2,420 \\
(2,060-3,050) \\
2,190\end{array}$ & $\begin{array}{c}2,660 \\
(2,230-3,430) \\
2,370\end{array}$ & 2,190 \\
\hline 12148000 & 11 & $\begin{array}{c}3,420 \\
(2,810-4,160) \\
3,300\end{array}$ & $\begin{array}{c}5,590 \\
(4,540-8,000) \\
5,280\end{array}$ & $\begin{array}{c}6,770 \\
(5,320-10,600) \\
6,300\end{array}$ & $\begin{array}{c}7,670 \\
(5,880-12,800) \\
7,060\end{array}$ & $\begin{array}{c}8,610 \\
(6,430-15,300) \\
7,840\end{array}$ & 6,500 \\
\hline 12148100 & 20 & $\begin{array}{c}124 \\
(106-146) \\
125\end{array}$ & $\begin{array}{c}214 \\
(178-280) \\
217\end{array}$ & $\begin{array}{c}261 \\
(211-361) \\
267\end{array}$ & $\begin{array}{c}296 \\
(235-426) \\
305\end{array}$ & $\begin{array}{c}331 \\
(258-495) \\
344\end{array}$ & 242 \\
\hline 12148500 & 61 & $\begin{array}{c}6,610 \\
(5,970-7,310) \\
6,570\end{array}$ & $\begin{array}{c}11,900 \\
(10,500-13,900) \\
11,800\end{array}$ & $\begin{array}{c}14,700 \\
(12,700-17,500) \\
14,500\end{array}$ & $\begin{array}{c}16,700 \\
(14,300-20,400) \\
16,400\end{array}$ & $\begin{array}{c}18,800 \\
(15,900-23,300) \\
18,400\end{array}$ & 17,400 \\
\hline
\end{tabular}


Table 2. Flood discharges for selected exceedance probabilities at gaging stations on streams with unregulated flow--Continued

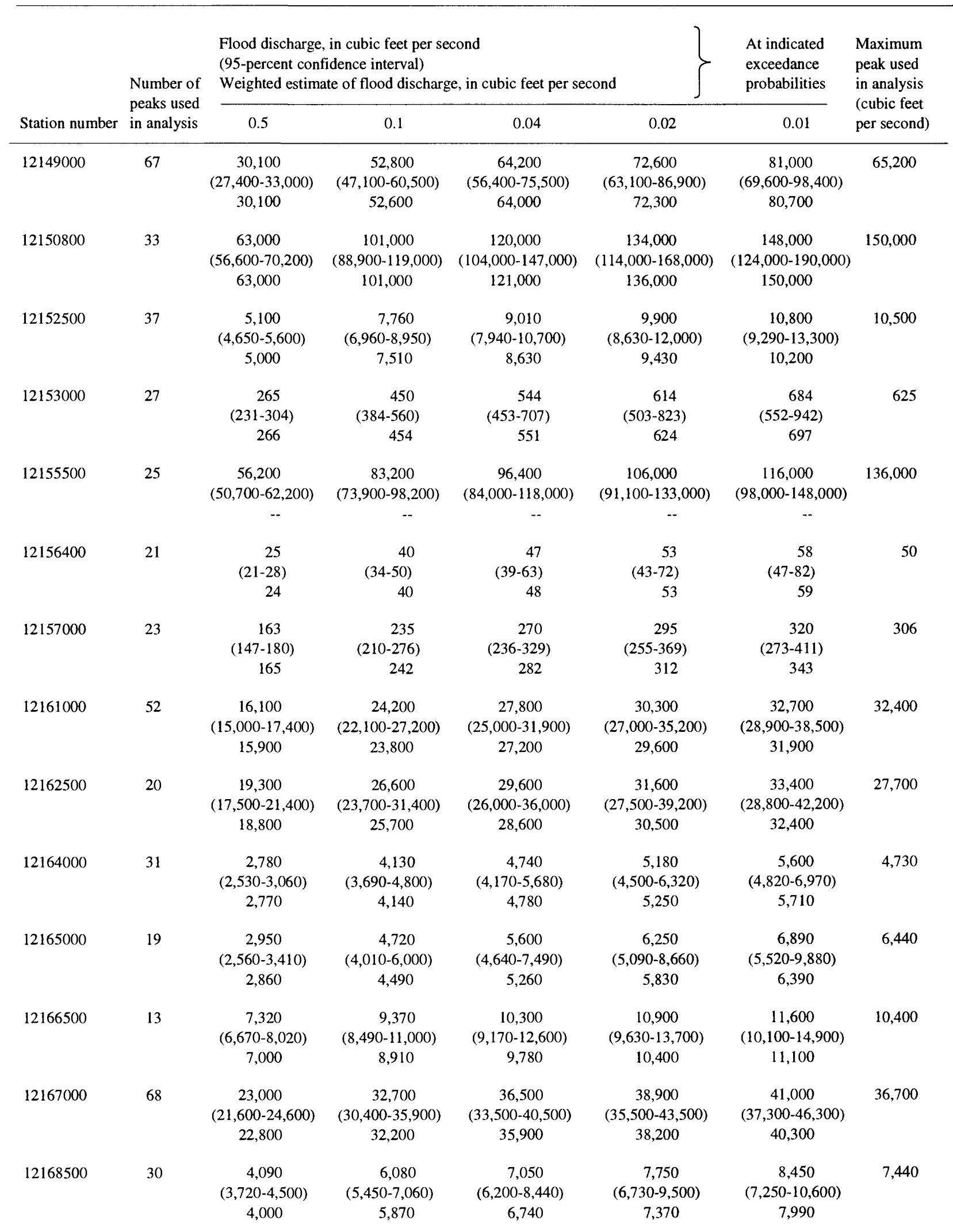


Table 2. Flood discharges for selected exceedance probabilities at gaging stations on streams with unregulated flow--Continued

\begin{tabular}{|c|c|c|c|c|c|c|c|}
\hline \multirow[b]{2}{*}{ Station number } & \multirow{2}{*}{$\begin{array}{l}\text { Number of } \\
\text { peaks used } \\
\text { in analysis }\end{array}$} & \multicolumn{4}{|c|}{$\begin{array}{l}\text { Flood discharge, in cubic feet per second } \\
\text { (95-percent confidence interval) } \\
\text { Weighted estimate of flood discharge, in cubic feet per second }\end{array}$} & \multirow{2}{*}{$\begin{array}{l}\begin{array}{l}\text { At indicated } \\
\text { exceedance } \\
\text { probabilities }\end{array} \\
0.01\end{array}$} & \multirow{2}{*}{$\begin{array}{l}\text { Maximum } \\
\text { peak used } \\
\text { in analysis } \\
\text { (cubic feet } \\
\text { per second) }\end{array}$} \\
\hline & & 0.5 & 0.1 & 0.04 & 0.02 & & \\
\hline \multirow[t]{2}{*}{12169500} & 20 & $\begin{array}{c}91 \\
(76-109)\end{array}$ & $\begin{array}{c}165 \\
(135-221)\end{array}$ & $\begin{array}{c}204 \\
(161-290)\end{array}$ & $\begin{array}{c}233 \\
(181-347)\end{array}$ & $\begin{array}{c}263 \\
(200-406)\end{array}$ & 245 \\
\hline & & 92 & 168 & 209 & 239 & 271 & \\
\hline \multirow[t]{2}{*}{12172000} & 15 & $\begin{array}{c}2,390 \\
(1,980-2,900)\end{array}$ & $\begin{array}{c}4,150 \\
(3,360-5,750)\end{array}$ & $\begin{array}{c}5,080 \\
(4,000-7,590)\end{array}$ & $\begin{array}{c}5,800 \\
(4,450-9,120)\end{array}$ & $\begin{array}{c}6,530 \\
(4,900-10,800)\end{array}$ & 4,420 \\
\hline & & 2,390 & 4,150 & 5,080 & 5,800 & 6,540 & \\
\hline \multirow[t]{2}{*}{12172500} & 11 & $\begin{array}{c}14,100 \\
(11,400-17,200)\end{array}$ & $\begin{array}{c}23,300 \\
(18,700-34,400)\end{array}$ & $\begin{array}{c}28,500 \\
(22,100-47,000)\end{array}$ & $\begin{array}{c}32,700 \\
(24,600-58,200)\end{array}$ & $\begin{array}{c}37,100 \\
(27,200-71,100)\end{array}$ & 33,000 \\
\hline & & 14,400 & 24,500 & 30,500 & 35,400 & 40,500 & \\
\hline \multirow[t]{2}{*}{12173500} & 15 & $\begin{array}{c}4,710 \\
(4,090-5,410)\end{array}$ & $\begin{array}{c}7,110 \\
(6,100-9,050)\end{array}$ & $\begin{array}{c}8,320 \\
(6,960-11,200)\end{array}$ & $\begin{array}{c}9,220 \\
(7,570-12,900)\end{array}$ & $\begin{array}{c}10,100 \\
(8,170-14,800)\end{array}$ & 8,640 \\
\hline & & 4,790 & 7,450 & 8,910 & 10,000 & 11,200 & \\
\hline \multirow[t]{2}{*}{12174000} & 21 & $\begin{array}{c}4,210 \\
(3,750-4,720)\end{array}$ & $\begin{array}{c}6,400 \\
(5,610-7,740)\end{array}$ & $\begin{array}{c}7,540 \\
(6,460-9,560)\end{array}$ & $\begin{array}{c}8,410 \\
(7,080-11,000)\end{array}$ & $\begin{array}{c}9,300 \\
(7,700-12,600)\end{array}$ & 9,920 \\
\hline & & 4,280 & 6,670 & 8,010 & 9,060 & 10,100 & \\
\hline \multirow[t]{2}{*}{12174500} & 11 & $\begin{array}{c}18,700 \\
(14,300-24,400)\end{array}$ & $\begin{array}{c}35,200 \\
(26,600-57,000)\end{array}$ & $\begin{array}{c}44,100 \\
(32,000-79,700)\end{array}$ & $\begin{array}{c}51,000 \\
(36,000-99,200)\end{array}$ & $\begin{array}{c}58,100 \\
(39,900-121,000)\end{array}$ & 45,700 \\
\hline & & 19,100 & 36,200 & 45,700 & 53,100 & 60,600 & \\
\hline \multirow[t]{2}{*}{12175500} & 77 & $\begin{array}{c}4,230 \\
(3,850-4,650)\end{array}$ & $\begin{array}{c}8,500 \\
(7,550-9,800)\end{array}$ & $\begin{array}{c}11,300 \\
(9,810-13,500)\end{array}$ & $\begin{array}{c}13,700 \\
(11,700-16,800)\end{array}$ & $\begin{array}{c}16,400 \\
(13,800-20,600)\end{array}$ & 15,400 \\
\hline & & 4,260 & 8,600 & 11,500 & 13,900 & 16,700 & \\
\hline \multirow[t]{2}{*}{12176000} & 11 & $\begin{array}{c}5,040 \\
(3,700-6,820)\end{array}$ & $\begin{array}{c}10,900 \\
(7,910-19,100)\end{array}$ & $\begin{array}{c}14,800 \\
(10,200-30,100)\end{array}$ & $\begin{array}{c}18,200 \\
(12,000-41,000)\end{array}$ & $\begin{array}{c}21,900 \\
(13,800-54,600)\end{array}$ & 15,400 \\
\hline & & 5,230 & 11,500 & 15,600 & 19,100 & 22,800 & \\
\hline \multirow[t]{2}{*}{12177500} & 50 & $\begin{array}{c}2,050 \\
(1,770-2,360)\end{array}$ & $\begin{array}{c}4,780 \\
(4,020-5,960)\end{array}$ & $\begin{array}{c}6,810 \\
(5,510-8,970)\end{array}$ & $\begin{array}{c}8,650 \\
(6,820-11,900)\end{array}$ & $\begin{array}{c}10,800 \\
(8,300-15,500)\end{array}$ & 9,540 \\
\hline & & 2,030 & 4,670 & 6,560 & 8,230 & 10,100 & \\
\hline \multirow[t]{2}{*}{12178100} & 36 & $\begin{array}{c}1,960 \\
(1,660-2,310)\end{array}$ & $\begin{array}{c}4,300 \\
(3,540-5,550)\end{array}$ & $\begin{array}{c}5,840 \\
(4,650-8,010)\end{array}$ & $\begin{array}{c}7,170 \\
(5,550-10,300)\end{array}$ & $\begin{array}{c}8,650 \\
(6,530-12,900)\end{array}$ & 8,430 \\
\hline & & 1,970 & 4,310 & 5,840 & 7,140 & 8,560 & \\
\hline \multirow[t]{2}{*}{12181100} & 36 & $\begin{array}{c}163 \\
(145-183)\end{array}$ & $\begin{array}{c}293 \\
(255-352)\end{array}$ & $\begin{array}{c}376 \\
(318-474)\end{array}$ & $\begin{array}{c}446 \\
(368-583)\end{array}$ & $\begin{array}{c}523 \\
(423-708)\end{array}$ & 454 \\
\hline & & 166 & 306 & 398 & 477 & 564 & \\
\hline \multirow[t]{2}{*}{12181200} & 34 & $\begin{array}{c}10 \\
(9.0-12)\end{array}$ & $\begin{array}{r}19 \\
(16-24)\end{array}$ & $\begin{array}{r}25 \\
(21-33)\end{array}$ & $\begin{array}{r}30 \\
(24-40)\end{array}$ & $\begin{array}{r}35 \\
(27-49)\end{array}$ & 29 \\
\hline & & 10 & 20 & 26 & 31 & 37 & \\
\hline \multirow[t]{2}{*}{12182500} & 55 & $\begin{array}{c}6,910 \\
(6,150-7,750)\end{array}$ & $\begin{array}{c}14,200 \\
(12,300-17,000)\end{array}$ & $\begin{array}{c}19,200 \\
(16,100-24,000)\end{array}$ & $\begin{array}{c}23,600 \\
(19,400-30,400)\end{array}$ & $\begin{array}{c}28,600 \\
(23,000-38,100)\end{array}$ & 46,000 \\
\hline & & 6,970 & 14,400 & 19,500 & 24,000 & 29,000 & \\
\hline \multirow[t]{2}{*}{12184300} & 11 & $\begin{array}{c}199 \\
(171-232)\end{array}$ & $\begin{array}{c}282 \\
(240-370)\end{array}$ & $\begin{array}{c}317 \\
(265-441)\end{array}$ & $\begin{array}{c}341 \\
(281-492)\end{array}$ & $\begin{array}{c}364 \\
(296-543)\end{array}$ & 288 \\
\hline & & 199 & 293 & 339 & 375 & 410 & \\
\hline
\end{tabular}


Table 2. Flood discharges for selected exceedance probabilities at gaging stations on streams with unregulated flow--Continued

\begin{tabular}{|c|c|c|c|c|c|c|c|}
\hline \multirow{2}{*}{ Station number } & \multirow{2}{*}{$\begin{array}{l}\text { Number of } \\
\text { peaks used } \\
\text { in analysis }\end{array}$} & \multicolumn{4}{|c|}{$\begin{array}{l}\text { Flood discharge, in cubic feet per second } \\
\text { (95-percent confidence interval) } \\
\text { Weighted estimate of flood discharge, in cubic feet per second }\end{array}$} & \multirow{2}{*}{$\begin{array}{c}\begin{array}{l}\text { At indicated } \\
\text { exceedance } \\
\text { probabilities }\end{array} \\
0.01\end{array}$} & \multirow{2}{*}{$\begin{array}{l}\text { Maximum } \\
\text { peak used } \\
\text { in analysis } \\
\text { (cubic feet } \\
\text { per second) }\end{array}$} \\
\hline & & 0.5 & 0.1 & 0.04 & 0.02 & & \\
\hline \multirow[t]{2}{*}{12185300} & 11 & $\begin{array}{c}427 \\
(256-720)\end{array}$ & $\begin{array}{c}1,380 \\
(806-3,480)\end{array}$ & $\begin{array}{c}2,070 \\
(1,130-6,290)\end{array}$ & $\begin{array}{c}2,660 \\
(1,380-9,180)\end{array}$ & $\begin{array}{c}3,310 \\
(1,640-12,800)\end{array}$ & 1,380 \\
\hline & & 435 & 1,340 & 1,920 & 2,390 & 2,880 & \\
\hline \multirow[t]{2}{*}{12186000} & 73 & $\begin{array}{c}9,220 \\
(8,300-10,200)\end{array}$ & $\begin{array}{c}19,400 \\
(17,000-22,600)\end{array}$ & $\begin{array}{c}26,300 \\
(22,500-31,900)\end{array}$ & $\begin{array}{c}32,300 \\
(27,100-40,300)\end{array}$ & $\begin{array}{c}39,100 \\
(32,200-50,200)\end{array}$ & 40,100 \\
\hline & & 9,250 & 19,500 & 26,400 & 32,400 & 39,100 & \\
\hline \multirow[t]{2}{*}{12187500} & 17 & $\begin{array}{c}16,000 \\
(12,800-19,700)\end{array}$ & $\begin{array}{c}32,500 \\
(25,500-47,000)\end{array}$ & $\begin{array}{c}44,000 \\
(33,000-70,900)\end{array}$ & $\begin{array}{c}54,200 \\
(39,100-94,600)\end{array}$ & $\begin{array}{c}65,900 \\
(45,800-124,000)\end{array}$ & 48,000 \\
\hline & & 16,100 & 32,800 & 44,200 & 54,000 & 65,000 & \\
\hline \multirow[t]{2}{*}{12188300} & 11 & $\begin{array}{c}295 \\
(250-349)\end{array}$ & $\begin{array}{c}437 \\
(367-590)\end{array}$ & $\begin{array}{c}503 \\
(412-726)\end{array}$ & $\begin{array}{c}550 \\
(443-831)\end{array}$ & $\begin{array}{c}596 \\
(472-939)\end{array}$ & 494 \\
\hline & & 305 & 481 & 580 & 657 & 737 & \\
\hline \multirow[t]{2}{*}{12189000} & 12 & $\begin{array}{c}10,400 \\
(7,960-13,400)\end{array}$ & $\begin{array}{c}20,900 \\
(15,800-33,400)\end{array}$ & $\begin{array}{c}27,500 \\
(19,800-49,900)\end{array}$ & $\begin{array}{c}33,000 \\
(22,900-65,400)\end{array}$ & $\begin{array}{c}39,100 \\
(26,200-84,200)\end{array}$ & 30,700 \\
\hline & & 10,900 & 22,700 & 30,400 & 36,900 & 43,900 & \\
\hline \multirow[t]{2}{*}{12189400} & 31 & $\begin{array}{c}107 \\
(93.9-121)\end{array}$ & $\begin{array}{c}179 \\
(154-219)\end{array}$ & $\begin{array}{c}214 \\
(180-271)\end{array}$ & $\begin{array}{c}239 \\
(198-310)\end{array}$ & $\begin{array}{c}263 \\
(216-350)\end{array}$ & 184 \\
\hline & & 106 & 178 & 213 & 238 & 263 & \\
\hline \multirow[t]{2}{*}{12189500} & 69 & $\begin{array}{c}29,900 \\
(27,000-33,100)\end{array}$ & $\begin{array}{c}58,400 \\
(51,500-68,000)\end{array}$ & $\begin{array}{c}75,300 \\
(65,000-90,500)\end{array}$ & $\begin{array}{c}89,000 \\
(75,600-110,000)\end{array}$ & $\begin{array}{c}104,000 \\
(86,700-130,000)\end{array}$ & 98,600 \\
\hline & & 30,000 & 58,700 & 75,800 & 89,600 & 105,000 & \\
\hline \multirow[t]{2}{*}{12191500} & 23 & $\begin{array}{c}16,600 \\
(13,800-20,000)\end{array}$ & $\begin{array}{c}31,700 \\
(25,700-42,900)\end{array}$ & $\begin{array}{c}40,000 \\
(31,400-57,600)\end{array}$ & $\begin{array}{c}46,400 \\
(35,600-69,800)\end{array}$ & $\begin{array}{c}53,100 \\
(39,800-83,100)\end{array}$ & 50,000 \\
\hline & & 16,500 & 31,400 & 39,500 & 45,600 & 52,000 & \\
\hline \multirow[t]{2}{*}{12191800} & 14 & $\begin{array}{c}412 \\
(327-520)\end{array}$ & $\begin{array}{c}783 \\
(609-1,170)\end{array}$ & $\begin{array}{c}994 \\
(744-1,630)\end{array}$ & $\begin{array}{c}1,160 \\
(844-2,030)\end{array}$ & $\begin{array}{c}1,330 \\
(944-2,470)\end{array}$ & 885 \\
\hline & & 429 & 845 & 1,100 & 1,300 & 1,520 & \\
\hline \multirow[t]{2}{*}{12196000} & 36 & $\begin{array}{c}315 \\
(275-361)\end{array}$ & $\begin{array}{c}577 \\
(492-712)\end{array}$ & $\begin{array}{c}715 \\
(595-918)\end{array}$ & $\begin{array}{c}819 \\
(670-1,080)\end{array}$ & $\begin{array}{c}925 \\
(744-1,250)\end{array}$ & 714 \\
\hline & & 315 & 578 & 717 & 821 & 927 & \\
\hline \multirow[t]{2}{*}{12196200} & 16 & $\begin{array}{c}552 \\
(484-629)\end{array}$ & $\begin{array}{c}812 \\
(703-1,010)\end{array}$ & $\begin{array}{c}934 \\
(792-1,220)\end{array}$ & $\begin{array}{c}1,020 \\
(853-1,390)\end{array}$ & $\begin{array}{c}1,110 \\
(912-1,550)\end{array}$ & 977 \\
\hline & & 539 & 790 & 908 & 994 & 1,080 & \\
\hline \multirow[t]{2}{*}{12196500} & 18 & $\begin{array}{c}4,390 \\
(4,080-4,710)\end{array}$ & $\begin{array}{c}5,490 \\
(5,070-6,190)\end{array}$ & $\begin{array}{c}5,960 \\
(5,440-6,890)\end{array}$ & $\begin{array}{c}6,280 \\
(5,680-7,390)\end{array}$ & $\begin{array}{c}6,580 \\
(5,900-7,870)\end{array}$ & 6,000 \\
\hline & & 4,200 & 5,180 & 5,590 & 5,880 & 6,170 & \\
\hline \multirow[t]{2}{*}{12197200} & 20 & $\begin{array}{c}135 \\
(122-149)\end{array}$ & $\begin{array}{c}187 \\
(167-220)\end{array}$ & $\begin{array}{c}210 \\
(185-255)\end{array}$ & $\begin{array}{c}226 \\
(196-281)\end{array}$ & $\begin{array}{c}241 \\
(208-306)\end{array}$ & 233 \\
\hline & & 132 & 183 & 206 & 222 & 238 & \\
\hline \multirow[t]{2}{*}{12199000} & 14 & $\begin{array}{c}94,400 \\
(75,100-117,000)\end{array}$ & $\begin{array}{c}183,000 \\
(144,000-272,000)\end{array}$ & $\begin{array}{c}245,000 \\
(183,000-411,000)\end{array}$ & $\begin{array}{c}299,000 \\
(215,000-551,000)\end{array}$ & $\begin{array}{c}362,000 \\
(249,000-729,000)\end{array}$ & 400,000 \\
\hline & & 91,500 & 171,000 & 221,000 & 263,000 & 310,000 & \\
\hline
\end{tabular}


Table 2. Flood discharges for selected exceedance probabilities at gaging stations on streams with unregulated flow--Continued

\begin{tabular}{|c|c|c|c|c|c|c|c|}
\hline \multirow[b]{2}{*}{ Station number } & \multirow{2}{*}{$\begin{array}{l}\text { Number of } \\
\text { peaks used } \\
\text { in analysis }\end{array}$} & \multicolumn{4}{|c|}{$\begin{array}{l}\text { Flood discharge, in cubic feet per second } \\
\text { (95-percent confidence interval) } \\
\text { Weighted estimate of flood discharge, in cubic feet per second }\end{array}$} & \multirow{2}{*}{$\begin{array}{l}\begin{array}{l}\text { At indicated } \\
\text { exceedance } \\
\text { probabilities }\end{array} \\
0.01\end{array}$} & \multirow{2}{*}{$\begin{array}{l}\text { Maximum } \\
\text { peak used } \\
\text { in analysis } \\
\text { (cubic feet } \\
\text { per second) }\end{array}$} \\
\hline & & 0.5 & 0.1 & 0.04 & 0.02 & & \\
\hline 12199800 & 16 & $\begin{array}{c}511 \\
(474-551) \\
476\end{array}$ & $\begin{array}{c}639 \\
(588-725) \\
579\end{array}$ & $\begin{array}{c}693 \\
(630-810) \\
619\end{array}$ & $\begin{array}{c}731 \\
(658-871) \\
648\end{array}$ & $\begin{array}{c}766 \\
(684-930) \\
678\end{array}$ & 676 \\
\hline 12200700 & 22 & $\begin{array}{c}34 \\
(28-41) \\
34\end{array}$ & $\begin{array}{r}66 \\
(53-89) \\
66\end{array}$ & $\begin{array}{r}83 \\
(65-120) \\
84\end{array}$ & $\begin{array}{c}97 \\
(74-146) \\
98\end{array}$ & $\begin{array}{c}111 \\
(83-174) \\
112\end{array}$ & 86.0 \\
\hline 12200800 & 19 & $\begin{array}{c}118 \\
(97-143) \\
115\end{array}$ & $\begin{array}{c}222 \\
(179-306) \\
212\end{array}$ & $\begin{array}{c}281 \\
(218-415) \\
264\end{array}$ & $\begin{array}{c}326 \\
(248-507) \\
302\end{array}$ & $\begin{array}{c}374 \\
(277-608) \\
342\end{array}$ & 250 \\
\hline 12201500 & 40 & $\begin{array}{c}2,590 \\
(2,230-3,000) \\
2,570\end{array}$ & $\begin{array}{c}5,330 \\
(4,460-6,710) \\
5,220\end{array}$ & $\begin{array}{c}6,950 \\
(5,650-9,170) \\
6,740\end{array}$ & $\begin{array}{c}8,250 \\
(6,570-11,200) \\
7,940\end{array}$ & $\begin{array}{c}9,630 \\
(7,520-13,500) \\
9,190\end{array}$ & 8,440 \\
\hline 12204400 & 32 & $\begin{array}{c}53 \\
(46-60) \\
53\end{array}$ & $\begin{array}{r}99 \\
(84-124) \\
101\end{array}$ & $\begin{array}{c}128 \\
(106-169) \\
131\end{array}$ & $\begin{array}{c}152 \\
(123-209) \\
156\end{array}$ & $\begin{array}{c}179 \\
(141-254) \\
183\end{array}$ & 181 \\
\hline 12205000 & 59 & $\begin{array}{c}5,640 \\
(5,230-6,070) \\
5,650\end{array}$ & $\begin{array}{c}8,760 \\
(8,000-9,800) \\
8,820\end{array}$ & $\begin{array}{c}10,300 \\
(9,260-11,800) \\
10,400\end{array}$ & $\begin{array}{c}11,400 \\
(10,200-13,300) \\
11,600\end{array}$ & $\begin{array}{c}12,500 \\
(11,000-14,800) \\
12,800\end{array}$ & 11,200 \\
\hline 12207200 & 11 & $\begin{array}{c}9,680 \\
(8,340-11,200) \\
9,780\end{array}$ & $\begin{array}{c}13,900 \\
(11,900-18,200) \\
14,500\end{array}$ & $\begin{array}{c}16,000 \\
(13,300-22,300) \\
17,200\end{array}$ & $\begin{array}{c}17,500 \\
(14,300-25,600) \\
19,200\end{array}$ & $\begin{array}{c}19,000 \\
(15,300-29,000) \\
21,200\end{array}$ & 16,000 \\
\hline 12208000 & 14 & $\begin{array}{c}5,660 \\
(4,550-7,010) \\
4,950\end{array}$ & $\begin{array}{c}10,400 \\
(8,230-15,200) \\
9,130\end{array}$ & $\begin{array}{c}13,100 \\
(10,000-20,900) \\
11,500\end{array}$ & $\begin{array}{c}15,300 \\
(11,300-26,000) \\
13,400\end{array}$ & $\begin{array}{c}17,600 \\
(12,600-31,600) \\
15,500\end{array}$ & 13,100 \\
\hline 12209000 & 51 & $\begin{array}{c}9,700 \\
(8,880-10,700) \\
9,610\end{array}$ & $\begin{array}{c}16,400 \\
(14,600-19,000) \\
16,100\end{array}$ & $\begin{array}{c}19,700 \\
(17,200-23,500) \\
19,300\end{array}$ & $\begin{array}{c}22,200 \\
(19,100-26,900) \\
21,600\end{array}$ & $\begin{array}{c}24,600 \\
(21,000-30,400) \\
23,900\end{array}$ & 22,400 \\
\hline 12209500 & 21 & $\begin{array}{c}1,160 \\
(1,050-1,290) \\
1,170\end{array}$ & $\begin{array}{c}1,730 \\
(1,540-2,060) \\
1,770\end{array}$ & $\begin{array}{c}2,060 \\
(1,780-2,580) \\
2,140\end{array}$ & $\begin{array}{c}2,320 \\
(1,970-3,010) \\
2,430\end{array}$ & $\begin{array}{c}2,600 \\
(2,160-3,500) \\
2,740\end{array}$ & 3,050 \\
\hline 12210500 & 62 & $\begin{array}{c}24,400 \\
(22,800-26,100) \\
24,400\end{array}$ & $\begin{array}{c}37,000 \\
(34,000-41,000) \\
37,100\end{array}$ & $\begin{array}{c}43,100 \\
(39,100-48,700) \\
43,300\end{array}$ & $\begin{array}{c}47,600 \\
(42,700-54,600) \\
47,900\end{array}$ & $\begin{array}{c}52,000 \\
(46,300-60,600) \\
52,400\end{array}$ & 49,300 \\
\hline 12211500 & 23 & $\begin{array}{c}28,800 \\
(25,600-32,500) \\
28,600\end{array}$ & $\begin{array}{c}43,700 \\
(38,100-53,000) \\
43,500\end{array}$ & $\begin{array}{c}50,400 \\
(43,200-63,400) \\
50,400\end{array}$ & $\begin{array}{c}55,100 \\
(46,600-71,100) \\
55,300\end{array}$ & $\begin{array}{c}59,700 \\
(49,800-78,800) \\
60,200\end{array}$ & 46,200 \\
\hline 12212000 & 26 & $\begin{array}{c}358 \\
(324-396) \\
359\end{array}$ & $\begin{array}{c}519 \\
(462-608) \\
526\end{array}$ & $\begin{array}{c}589 \\
(517-712) \\
603\end{array}$ & $\begin{array}{c}638 \\
(554-788) \\
659\end{array}$ & $\begin{array}{c}685 \\
(588-861) \\
714\end{array}$ & 550 \\
\hline 12212700 & 19 & $\begin{array}{c}25 \\
(21-30) \\
25\end{array}$ & $\begin{array}{r}46 \\
(37-62) \\
45\end{array}$ & $\begin{array}{r}57 \\
(45-83) \\
55\end{array}$ & $\begin{array}{r}66 \\
(50-100) \\
63\end{array}$ & $\begin{array}{r}75 \\
(56-119) \\
71\end{array}$ & 56 \\
\hline
\end{tabular}


Table 2. Flood discharges for selected exceedance probabilities at gaging stations on streams with unregulated flow--Continued

\begin{tabular}{|c|c|c|c|c|c|c|c|}
\hline \multirow[b]{2}{*}{ Station number } & \multirow{2}{*}{$\begin{array}{l}\text { Number of } \\
\text { peaks used } \\
\text { in analysis }\end{array}$} & \multicolumn{4}{|c|}{$\begin{array}{l}\text { Flood discharge, in cubic feet per second } \\
\text { (95-percent confidence interval) } \\
\text { Weighted estimate of flood discharge, in cubic feet per second }\end{array}$} & \multirow{2}{*}{$\begin{array}{c}\begin{array}{l}\text { At indicated } \\
\text { exceedance } \\
\text { probabilities }\end{array} \\
0.01\end{array}$} & \multirow{2}{*}{$\begin{array}{l}\text { Maximum } \\
\text { peak used } \\
\text { in analysis } \\
\text { (cubic feet } \\
\text { per second) }\end{array}$} \\
\hline & & 0.5 & 0.1 & 0.04 & 0.02 & & \\
\hline \multirow[t]{2}{*}{12212800} & 32 & $\begin{array}{c}23 \\
(19-27)\end{array}$ & $\begin{array}{r}46 \\
(38-60)\end{array}$ & $\begin{array}{r}59 \\
(47-81)\end{array}$ & $\begin{array}{r}68 \\
(54-97)\end{array}$ & $\begin{array}{c}78 \\
(60-114)\end{array}$ & 67 \\
\hline & & 22 & 44 & 54 & 62 & 70 & \\
\hline 12213100 & 47 & $\begin{array}{l}24,800 \\
(22,800-26,900) \\
24,800\end{array}$ & $\begin{array}{c}39,900 \\
(36,100-45,300) \\
39,900\end{array}$ & $\begin{array}{c}48,700 \\
(43,200-57,200) \\
48,700\end{array}$ & $\begin{array}{c}55,800 \\
(48,700-67,100) \\
55,800\end{array}$ & $\begin{array}{c}63,400 \\
(54,400-78,100) \\
63,500\end{array}$ & 57,000 \\
\hline \multirow[t]{2}{*}{12323000} & 56 & $\begin{array}{c}248,000 \\
(236,000-260,000)\end{array}$ & $\begin{array}{c}321,000 \\
(303,000-345,000)\end{array}$ & $\begin{array}{c}349,000 \\
(327,000-380,000)\end{array}$ & $\begin{array}{c}368,000 \\
(342,000-403,000)\end{array}$ & $\begin{array}{c}384,000 \\
(356,000-424,000)\end{array}$ & 377,000 \\
\hline & & -- & -- & -- & -- & -- & \\
\hline \multirow[t]{2}{*}{12395500} & 39 & $\begin{array}{c}85,000 \\
(77,400-93,500)\end{array}$ & $\begin{array}{c}129,000 \\
(115,000-149,000)\end{array}$ & $\begin{array}{c}148,000 \\
(130,000-175,000)\end{array}$ & $\begin{array}{c}161,000 \\
(140,000-194,000)\end{array}$ & $\begin{array}{c}173,000 \\
(150,000-212,000)\end{array}$ & 200,000 \\
\hline & & -- & -- & -- & -- & -- & \\
\hline \multirow[t]{2}{*}{12395800} & 20 & $\begin{array}{c}45 \\
(38-52)\end{array}$ & $\begin{array}{r}71 \\
(60-91)\end{array}$ & $\begin{array}{c}83 \\
(68-110)\end{array}$ & $\begin{array}{c}90 \\
(74-124)\end{array}$ & $\begin{array}{c}98 \\
(79-138)\end{array}$ & 78 \\
\hline & & 44 & 72 & 85 & 94 & 103 & \\
\hline \multirow[t]{2}{*}{12395900} & 20 & $\begin{array}{c}88 \\
(77-102)\end{array}$ & $\begin{array}{r}139 \\
(119-175)\end{array}$ & $\begin{array}{c}163 \\
(136-215)\end{array}$ & $\begin{array}{c}180 \\
(148-246)\end{array}$ & $\begin{array}{c}198 \\
(160-276)\end{array}$ & 175 \\
\hline & & 88 & 142 & 168 & 187 & 208 & \\
\hline \multirow[t]{2}{*}{12396000} & 45 & $\begin{array}{c}525 \\
(457-602)\end{array}$ & $\begin{array}{c}1,100 \\
(934-1,360)\end{array}$ & $\begin{array}{c}1,480 \\
(1,210-1,920)\end{array}$ & $\begin{array}{c}1,790 \\
(1,440-2,410)\end{array}$ & $\begin{array}{c}2,150 \\
(1,680-2,980)\end{array}$ & 3,190 \\
\hline & & 523 & 1,090 & 1,470 & 1,770 & 2,120 & \\
\hline \multirow[t]{2}{*}{12396100} & 35 & $\begin{array}{c}80 \\
(70-91)\end{array}$ & $\begin{array}{c}146 \\
(125-180)\end{array}$ & $\begin{array}{c}183 \\
(152-235)\end{array}$ & $\begin{array}{c}211 \\
(173-280)\end{array}$ & $\begin{array}{c}240 \\
(193-328)\end{array}$ & 250 \\
\hline & & 80 & 147 & 186 & 215 & 245 & \\
\hline \multirow[t]{2}{*}{12396450} & 20 & $\begin{array}{c}92 \\
(73-117)\end{array}$ & $\begin{array}{r}200 \\
(154-294)\end{array}$ & $\begin{array}{c}265 \\
(196-422)\end{array}$ & $\begin{array}{c}317 \\
(228-534)\end{array}$ & $\begin{array}{c}372 \\
(260-660)\end{array}$ & 300 \\
\hline & & 92 & 199 & 264 & 316 & 371 & \\
\hline \multirow[t]{2}{*}{12396900} & 20 & $\begin{array}{c}1,010 \\
(909-1,120)\end{array}$ & $\begin{array}{c}1,460 \\
(1,300-1,740)\end{array}$ & $\begin{array}{c}1,690 \\
(1,470-2,100)\end{array}$ & $\begin{array}{c}1,860 \\
(1,590-2,380)\end{array}$ & $\begin{array}{c}2,300 \\
(1,710-2,670)\end{array}$ & 2,290 \\
\hline & & 993 & 1,430 & 1,650 & 1,810 & 1,980 & \\
\hline \multirow[t]{2}{*}{12397500} & 12 & $\begin{array}{c}989 \\
(776-1,270)\end{array}$ & $\begin{array}{c}1,770 \\
(1,370-2,720)\end{array}$ & $\begin{array}{c}2,160 \\
(1,610-3,610)\end{array}$ & $\begin{array}{c}2,440 \\
(1,780-4,320)\end{array}$ & $\begin{array}{c}2,710 \\
(1,940-5,060)\end{array}$ & 1,650 \\
\hline & & 973 & 1,720 & 2,090 & 2,360 & 2,620 & \\
\hline \multirow[t]{2}{*}{12398000} & 18 & $\begin{array}{r}1,260 \\
(1,050-1,520)\end{array}$ & $\begin{array}{r}2,270 \\
(1,840-3,090)\end{array}$ & $\begin{array}{r}2,800 \\
(2,210-4,090)\end{array}$ & $\begin{array}{r}3,220 \\
(2,480-4,910)\end{array}$ & $\begin{array}{r}3,640 \\
(2,740-5,800)\end{array}$ & 3,550 \\
\hline & & 1,250 & 2,220 & 2,730 & 3,130 & 3,530 & \\
\hline \multirow[t]{2}{*}{12398500} & 39 & $\begin{array}{c}89,500 \\
(80,900-99,300)\end{array}$ & $\begin{array}{c}137,000 \\
(122,000-160,000)\end{array}$ & $\begin{array}{c}156,000 \\
(137,000-186,000)\end{array}$ & $\begin{array}{c}169,000 \\
(146,000-204,000)\end{array}$ & $\begin{array}{c}180,000 \\
(155,000-221,000)\end{array}$ & ${ }^{5} 171,300$ \\
\hline & & -- & -- & -- & -- & -- & \\
\hline 12399500 & 21 & $\begin{array}{c}328,000 \\
(296,000-365,000)\end{array}$ & $\begin{array}{c}464,000 \\
(412,000-552,000)\end{array}$ & $\begin{array}{c}525,000 \\
(458,000-647,000)\end{array}$ & $\begin{array}{c}568,000 \\
(490,000-717,000)\end{array}$ & $\begin{array}{c}609,000 \\
(519,000-786,000)\end{array}$ & 680,000 \\
\hline
\end{tabular}


Table 2. Flood discharges for selected exceedance probabilities at gaging stations on streams with unregulated flow--Continued

\begin{tabular}{|c|c|c|c|c|c|c|c|}
\hline \multirow[b]{2}{*}{ Station number } & \multirow{2}{*}{$\begin{array}{l}\text { Number of } \\
\text { peaks used } \\
\text { in analysis }\end{array}$} & \multicolumn{4}{|c|}{$\begin{array}{l}\text { Flood discharge, in cubic feet per second } \\
\text { (95-percent confidence interval) } \\
\text { Weighted estimate of flood discharge, in cubic feet per second }\end{array}$} & \multirow{2}{*}{$\begin{array}{c}\begin{array}{l}\text { At indicated } \\
\text { exceedance } \\
\text { probabilities }\end{array} \\
0.01\end{array}$} & \multirow{2}{*}{$\begin{array}{l}\text { Maximum } \\
\text { peak used } \\
\text { in analysis } \\
\text { (cubic feet } \\
\text { per second) }\end{array}$} \\
\hline & & 0.5 & 0.1 & 0.04 & 0.02 & & \\
\hline 12400500 & 14 & $\begin{array}{c}1,720 \\
(1,480-2,010) \\
1,660\end{array}$ & $\begin{array}{c}2,510 \\
(2,140-3,260) \\
2,430\end{array}$ & $\begin{array}{c}2,850 \\
(2,380-3,900) \\
2,760\end{array}$ & $\begin{array}{c}3,090 \\
(2,540-4,370) \\
3,010\end{array}$ & $\begin{array}{c}3,310 \\
(2,680-4,840) \\
3,240\end{array}$ & 3,070 \\
\hline 12401500 & 68 & $\begin{array}{c}12,300 \\
(11,800-12,900) \\
12,200\end{array}$ & $\begin{array}{c}16,200 \\
(15,300-17,400) \\
16,100\end{array}$ & $\begin{array}{c}17,800 \\
(16,700-19,300) \\
17,800\end{array}$ & $\begin{array}{c}18,900 \\
(17,600-20,600) \\
18,900\end{array}$ & $\begin{array}{c}19,900 \\
(18,400-21,800) \\
19,900\end{array}$ & 21,200 \\
\hline 12403700 & 19 & $\begin{array}{r}9.5 \\
(8.1-11) \\
9.3\end{array}$ & $\begin{array}{r}15 \\
(13-20) \\
15\end{array}$ & $\begin{array}{r}17 \\
(14-24) \\
18\end{array}$ & $\begin{array}{r}19 \\
(15-26) \\
20\end{array}$ & $\begin{array}{r}20 \\
(16-29) \\
21\end{array}$ & 16 \\
\hline 12404500 & 67 & $\begin{array}{c}21,100 \\
(20,200-22,100) \\
--\end{array}$ & $\begin{array}{c}27,700 \\
(26,200-29,600) \\
--\end{array}$ & $\begin{array}{c}30,500 \\
(28,600-33,000) \\
--\end{array}$ & $\begin{array}{c}32,300 \\
(30,200-35,200) \\
--\end{array}$ & $\begin{array}{c}34,000 \\
(31,600-37,400) \\
-.\end{array}$ & 35,000 \\
\hline 12405400 & 20 & $\begin{array}{c}54 \\
(42-70) \\
53\end{array}$ & $\begin{array}{r}126 \\
(94-190) \\
123\end{array}$ & $\begin{array}{c}170 \\
(122-282) \\
165\end{array}$ & $\begin{array}{c}207 \\
(144-364) \\
200\end{array}$ & $\begin{array}{c}246 \\
(167-458) \\
236\end{array}$ & 154 \\
\hline 12405500 & 26 & $\begin{array}{c}343,000 \\
(320,000-367,000) \\
-\end{array}$ & $\begin{array}{c}445,000 \\
(411,000-498,000) \\
--\end{array}$ & $\begin{array}{c}490,000 \\
(447,000-561,000) \\
--\end{array}$ & $\begin{array}{c}522,000 \\
(472,000-607,000) \\
--\end{array}$ & $\begin{array}{c}552,000 \\
(494,000-652,000) \\
--\end{array}$ & 700,000 \\
\hline 12407500 & 20 & $\begin{array}{c}44 \\
(36-53) \\
45\end{array}$ & $\begin{array}{r}78 \\
(63-106) \\
85\end{array}$ & $\begin{array}{r}94 \\
(74-134) \\
106\end{array}$ & $\begin{array}{c}105 \\
(82-156) \\
121\end{array}$ & $\begin{array}{c}116 \\
(89-177) \\
137\end{array}$ & 82 \\
\hline 12407520 & 20 & $\begin{array}{c}119 \\
(92-155) \\
118\end{array}$ & $\begin{array}{c}285 \\
(212-438) \\
281\end{array}$ & $\begin{array}{c}391 \\
(279-660) \\
384\end{array}$ & $\begin{array}{c}480 \\
(331-862) \\
485\end{array}$ & $\begin{array}{c}576 \\
(385-1,100) \\
561\end{array}$ & 454 \\
\hline 12407600 & 20 & $\begin{array}{r}6.0 \\
(5.2-6.9) \\
6.2\end{array}$ & $\begin{array}{r}10 \\
(8.5-13) \\
11\end{array}$ & $\begin{array}{r}12 \\
(10-16) \\
14\end{array}$ & $\begin{array}{r}14 \\
(11-20) \\
17\end{array}$ & $\begin{array}{r}16 \\
(12-23) \\
19\end{array}$ & 14 \\
\hline 12407700 & 18 & $\begin{array}{c}165 \\
(133-204) \\
168\end{array}$ & $\begin{array}{c}318 \\
(250-453) \\
331\end{array}$ & $\begin{array}{c}400 \\
(305-613) \\
423\end{array}$ & $\begin{array}{c}463 \\
(344-745) \\
495\end{array}$ & $\begin{array}{c}527 \\
(383-887) \\
570\end{array}$ & 392 \\
\hline 12408200 & 20 & $\begin{array}{r}9.3 \\
(7.2-12) \\
9.5\end{array}$ & $\begin{array}{r}21 \\
(16-31) \\
21\end{array}$ & $\begin{array}{r}27 \\
(20-44) \\
28\end{array}$ & $\begin{array}{r}32 \\
(22-55) \\
33\end{array}$ & $\begin{array}{r}37 \\
(26-67) \\
39\end{array}$ & 41 \\
\hline 12408300 & 22 & $\begin{array}{c}301 \\
(235-388) \\
306\end{array}$ & $\begin{array}{c}688 \\
(518-1,030) \\
703\end{array}$ & $\begin{array}{c}906 \\
(659-1,460) \\
930\end{array}$ & $\begin{array}{c}1,070 \\
(761-1,810) \\
1,100\end{array}$ & $\begin{array}{c}1,240 \\
(863-2,200) \\
1,280\end{array}$ & 1,060 \\
\hline 12408400 & 20 & $\begin{array}{c}28 \\
(23-35) \\
29\end{array}$ & $\begin{array}{r}58 \\
(46-83) \\
61\end{array}$ & $\begin{array}{r}76 \\
(57-116) \\
80\end{array}$ & $\begin{array}{r}89 \\
(66-145) \\
95\end{array}$ & $\begin{array}{c}104 \\
(75-176) \\
112\end{array}$ & 80 \\
\hline 12408420 & 20 & $\begin{array}{c}41 \\
(30-56) \\
43\end{array}$ & $\begin{array}{r}118 \\
(82-197) \\
123\end{array}$ & $\begin{array}{c}172 \\
(115-324) \\
181\end{array}$ & $\begin{array}{c}221 \\
(141-448) \\
233\end{array}$ & $\begin{array}{c}276 \\
(170-601) \\
292\end{array}$ & 148 \\
\hline
\end{tabular}


Table 2. Flood discharges for selected exceedance probabilities at gaging stations on streams with unregulated flow--Continued

\begin{tabular}{|c|c|c|c|c|c|c|c|}
\hline \multirow[b]{2}{*}{ Station number } & \multirow{2}{*}{$\begin{array}{l}\text { Number of } \\
\text { peaks used } \\
\text { in analysis }\end{array}$} & \multicolumn{4}{|c|}{$\begin{array}{l}\text { Flood discharge, in cubic feet per second } \\
\text { (95-percent confidence interval) } \\
\text { Weighted estimate of flood discharge, in cubic feet per second }\end{array}$} & \multirow{2}{*}{$\begin{array}{c}\begin{array}{l}\text { At indicated } \\
\text { exceedance } \\
\text { probabilities }\end{array} \\
0.01\end{array}$} & \multirow{2}{*}{$\begin{array}{l}\text { Maximum } \\
\text { peak used } \\
\text { in analysis } \\
\text { (cubic feet } \\
\text { per second) }\end{array}$} \\
\hline & & 0.5 & 0.1 & 0.04 & 0.02 & & \\
\hline 12408500 & 47 & $\begin{array}{c}298 \\
(261-341) \\
298\end{array}$ & $\begin{array}{c}562 \\
(480-685) \\
564\end{array}$ & $\begin{array}{c}690 \\
(578-868) \\
695\end{array}$ & $\begin{array}{c}782 \\
(646-1,000) \\
790\end{array}$ & $\begin{array}{c}870 \\
(710-1,140) \\
881\end{array}$ & 694 \\
\hline 12409000 & 74 & $\begin{array}{c}1,140 \\
(1,020-1,280) \\
1,140\end{array}$ & $\begin{array}{c}2,260 \\
(1,960-2,670) \\
2,280\end{array}$ & $\begin{array}{c}2,800 \\
(2,390-3,390) \\
2,830\end{array}$ & $\begin{array}{c}3,170 \\
(2,680-3,910) \\
3,220\end{array}$ & $\begin{array}{c}3,540 \\
(2,960-4,420) \\
3,600\end{array}$ & 3,440 \\
\hline 12409500 & 19 & $\begin{array}{c}390 \\
(295-519) \\
389\end{array}$ & $\begin{array}{c}897 \\
(656-1,420) \\
893\end{array}$ & $\begin{array}{c}1,170 \\
(825-2,000) \\
1,170\end{array}$ & $\begin{array}{c}1,370 \\
(946-2,470) \\
1,370\end{array}$ & $\begin{array}{c}1,580 \\
(1,060-2,970) \\
1,580\end{array}$ & ${ }^{6} 1,010$ \\
\hline 12410000 & 13 & $\begin{array}{c}56 \\
(32-100) \\
59\end{array}$ & $\begin{array}{c}226 \\
(122-607) \\
235\end{array}$ & $\begin{array}{c}358 \\
(181-1,160) \\
369\end{array}$ & $\begin{array}{c}476 \\
(228-1,740) \\
487\end{array}$ & $\begin{array}{c}608 \\
(278-2,480) \\
617\end{array}$ & 180 \\
\hline 12410600 & 20 & $\begin{array}{c}22 \\
(19-26) \\
23\end{array}$ & $\begin{array}{r}36 \\
(30-46) \\
39\end{array}$ & $\begin{array}{r}41 \\
(34-56) \\
47\end{array}$ & $\begin{array}{r}45 \\
(37-63) \\
53\end{array}$ & $\begin{array}{r}49 \\
(39-69) \\
59\end{array}$ & 41 \\
\hline 12410650 & 20 & $\begin{array}{r}5.7 \\
(4.7-7.0) \\
6.1\end{array}$ & $\begin{array}{r}10 \\
(8.4-14) \\
12\end{array}$ & $\begin{array}{r}13 \\
(10-18) \\
15\end{array}$ & $\begin{array}{r}14 \\
(11-22) \\
18\end{array}$ & $\begin{array}{r}16 \\
(12-25) \\
20\end{array}$ & 15 \\
\hline 12423550 & 15 & $\begin{array}{c}55 \\
(35-88) \\
54\end{array}$ & $\begin{array}{c}171 \\
(104-363) \\
161\end{array}$ & $\begin{array}{c}240 \\
(140-576) \\
221\end{array}$ & $\begin{array}{c}293 \\
(166-758) \\
267\end{array}$ & $\begin{array}{c}346 \\
(190-956) \\
313\end{array}$ & 155 \\
\hline 12423700 & 15 & $\begin{array}{c}25 \\
(22-30) \\
24\end{array}$ & $\begin{array}{r}37 \\
(32-48) \\
36\end{array}$ & $\begin{array}{r}42 \\
(35-57) \\
41\end{array}$ & $\begin{array}{r}45 \\
(37-63) \\
45\end{array}$ & $\begin{array}{r}48 \\
(39-68) \\
48\end{array}$ & 41 \\
\hline 12423900 & 20 & $\begin{array}{c}18 \\
(12-28) \\
18\end{array}$ & $\begin{array}{r}67 \\
(42-133) \\
67\end{array}$ & $\begin{array}{c}103 \\
(60-230) \\
101\end{array}$ & $\begin{array}{c}133 \\
(75-321) \\
130\end{array}$ & $\begin{array}{c}166 \\
(91-430) \\
161\end{array}$ & 125 \\
\hline 12424000 & 49 & $\begin{array}{c}6,510 \\
(5,620-7,560) \\
6,480\end{array}$ & $\begin{array}{c}13,300 \\
(11,100-16,500) \\
13,100\end{array}$ & $\begin{array}{c}16,600 \\
(13,700-21,400) \\
16,400\end{array}$ & $\begin{array}{c}19,000 \\
(15,400-25,100) \\
18,700\end{array}$ & $\begin{array}{c}21,400 \\
(17,100-28,700) \\
21,000\end{array}$ & 20,600 \\
\hline 12427000 & 31 & $\begin{array}{c}110 \\
(102-118) \\
111\end{array}$ & $\begin{array}{c}150 \\
(138-168) \\
155\end{array}$ & $\begin{array}{c}169 \\
(153-194) \\
177\end{array}$ & $\begin{array}{c}182 \\
(163-213) \\
194\end{array}$ & $\begin{array}{c}195 \\
(173-232) \\
207\end{array}$ & 205 \\
\hline 12429200 & 13 & $\begin{array}{r}50 \\
(41-61) \\
50\end{array}$ & $\begin{array}{r}82 \\
(67-115) \\
86\end{array}$ & $\begin{array}{c}98 \\
(77-147) \\
104\end{array}$ & $\begin{array}{c}109 \\
(84-172) \\
118\end{array}$ & $\begin{array}{c}120 \\
(91-199) \\
132\end{array}$ & 98.0 \\
\hline 12429600 & 14 & $\begin{array}{c}138 \\
(115-165) \\
139\end{array}$ & $\begin{array}{c}232 \\
(191-318) \\
237\end{array}$ & $\begin{array}{c}284 \\
(226-422) \\
294\end{array}$ & $\begin{array}{c}325 \\
(252-510) \\
339\end{array}$ & $\begin{array}{c}368 \\
(278-608) \\
386\end{array}$ & 391 \\
\hline 12429800 & 20 & $\begin{array}{c}12 \\
(10-15) \\
13\end{array}$ & $\begin{array}{r}23 \\
(18-30) \\
23\end{array}$ & $\begin{array}{r}28 \\
(22-40) \\
29\end{array}$ & $\begin{array}{r}32 \\
(24-47) \\
34\end{array}$ & $\begin{array}{r}36 \\
(27-55) \\
38\end{array}$ & 27 \\
\hline
\end{tabular}


Table 2. Flood discharges for selected exceedance probabilities at gaging stations on streams with unregulated flow--Continued

\begin{tabular}{|c|c|c|c|c|c|c|c|}
\hline \multirow[b]{2}{*}{ Station number } & \multirow{2}{*}{$\begin{array}{l}\text { Number of } \\
\text { peaks used } \\
\text { in analysis }\end{array}$} & \multicolumn{4}{|c|}{$\begin{array}{l}\text { Flood discharge, in cubic feet per second } \\
\text { ( } 95 \text {-percent confidence interval) } \\
\text { Weighted estimate of flood discharge, in cubic feet per second }\end{array}$} & \multirow{2}{*}{$\begin{array}{l}\begin{array}{l}\text { At indicated } \\
\text { exceedance } \\
\text { probabilities }\end{array} \\
0.01\end{array}$} & \multirow{2}{*}{$\begin{array}{l}\text { Maximum } \\
\text { peak used } \\
\text { in analysis } \\
\text { (cubic feet } \\
\text { per second) }\end{array}$} \\
\hline & & 0.5 & 0.1 & 0.04 & 0.02 & & \\
\hline \multirow[t]{3}{*}{12430370} & 15 & 23 & 126 & 252 & 400 & 614 & 1,510 \\
\hline & & $(13-40)$ & $(67-349)$ & $(119-912)$ & $(174-1,760)$ & $(245-3,260)$ & \\
\hline & & 23 & 120 & 231 & 354 & 525 & \\
\hline \multirow[t]{2}{*}{12431000} & 54 & 1,300 & 2,300 & $\begin{array}{c}2,760 \\
\text { (2) }\end{array}$ & $\begin{array}{c}3,080 \\
\text { (2) }\end{array}$ & $\begin{array}{c}3,400 \\
\text { (2) }\end{array}$ & 3,170 \\
\hline & & 1,300 & 2,310 & 2,770 & 3,090 & 3,420 & \\
\hline \multirow[t]{3}{*}{12431100} & 15 & 39 & 226 & 422 & 629 & 898 & 325 \\
\hline & & $(21-73)$ & $(114-653)$ & $(194-1,530)$ & $(270-2,670)$ & $(360-4,400)$ & \\
\hline & & 40 & 224 & 409 & 597 & 836 & \\
\hline \multirow[t]{3}{*}{12433200} & 18 & 373 & 1,230 & 1,860 & 2,420 & 3,050 & 2,200 \\
\hline & & $(253-551)$ & $(795-2,340)$ & $(1,140-4,400)$ & $(1,420-5,730)$ & $(1,720-7,840)$ & \\
\hline & & 376 & 1,230 & 1,850 & 2,400 & 3,000 & \\
\hline \multirow[t]{3}{*}{12433300} & 20 & 48 & 101 & 131 & 155 & 180 & 135 \\
\hline & & $(39-61)$ & $(78-146)$ & $(98-204)$ & $(113-254)$ & $(128-309)$ & \\
\hline & & 47 & 96 & 124 & 146 & 169 & \\
\hline \multirow[t]{3}{*}{12433542} & 12 & 5.6 & 24 & 40 & 54 & 71 & 33 \\
\hline & & $(3.0-10)$ & $(13-73)$ & $(19-148)$ & $(25-232)$ & $(31-344)$ & \\
\hline & & 6.0 & 27 & 45 & 61 & 80 & \\
\hline \multirow[t]{3}{*}{12433556} & 12 & 1.3 & 3.6 & 5.1 & 6.4 & 7.9 & 5.7 \\
\hline & & $(0.9-1.9)$ & $(2.3-7.3)$ & $(3.1-12)$ & $(3.8-17)$ & $(4.4-23)$ & \\
\hline & & - & -- & -- & -- & -- & \\
\hline \multirow[t]{3}{*}{12433561} & 12 & 16 & 89 & 161 & 236 & 331 & 101 \\
\hline & & $(8.3-33)$ & $(43-298)$ & $(70-706)$ & $(96-1,240)$ & $(126-2,040)$ & \\
\hline & & 17 & 94 & 171 & 248 & 343 & \\
\hline \multirow[t]{3}{*}{12433580} & 15 & 176 & 901 & 1,510 & 2,050 & 2,670 & ${ }^{7} 897$ \\
\hline & & $(94-337)$ & $(454-2,600)$ & $(704-5,220)$ & $(911-8,000)$ & $(1,130-11,500)$ & \\
\hline & & 161 & 732 & 1,130 & 1,460 & 1,800 & \\
\hline \multirow[t]{3}{*}{12433800} & 20 & 12 & 24 & 32 & 38 & 44 & 36 \\
\hline & & $(9.5-14)$ & $(19-34)$ & $(24-49)$ & $(28-61)$ & $(31-75)$ & \\
\hline & & 12 & 25 & 33 & 40 & 47 & \\
\hline \multirow[t]{3}{*}{12434500} & 15 & 1,510 & 3,160 & 4,210 & 5,090 & 6,060 & 4,790 \\
\hline & & $(1,180-1,930)$ & $(2,410-4,830)$ & $(3,070-7,160)$ & $(3,590-9,340)$ & $(4,130-11,900)$ & \\
\hline & & -- & -- & -- & -- & -- & \\
\hline \multirow[t]{3}{*}{12437500} & 19 & 171 & 498 & 706 & 875 & 1,050 & 483 \\
\hline & & $(120-245)$ & $(335-890)$ & $(453-1,400)$ & $(542-1,860)$ & $(632-2,370)$ & \\
\hline & & 172 & 580 & 949 & 1,280 & 1,630 & \\
\hline \multirow[t]{3}{*}{12437930} & 16 & 73 & 260 & 398 & 519 & 654 & 355 \\
\hline & & $(46-118)$ & $(156-576)$ & $(224-1,030)$ & $(278-1,480)$ & $(336-2,050)$ & \\
\hline & & 74 & 306 & 530 & 738 & 967 & \\
\hline \multirow[t]{3}{*}{12437950} & 21 & 24 & 102 & 178 & 258 & 363 & 982 \\
\hline & & $(16-36)$ & $(64-201)$ & $(103-415)$ & $(141-675)$ & $(187-1,060)$ & \\
\hline & & 24 & 108 & 194 & 282 & 389 & \\
\hline
\end{tabular}


Table 2. Flood discharges for selected exceedance probabilities at gaging stations on streams with unregulated flow--Continued

\begin{tabular}{|c|c|c|c|c|c|c|c|}
\hline \multirow[b]{2}{*}{ Station number } & \multirow{2}{*}{$\begin{array}{l}\text { Number of } \\
\text { peaks used } \\
\text { in analysis }\end{array}$} & \multicolumn{4}{|c|}{$\begin{array}{l}\text { Flood discharge, in cubic feet per second } \\
\text { (95-percent confidence interval) } \\
\text { Weighted estimate of flood discharge, in cubic feet per second }\end{array}$} & \multirow{2}{*}{$\begin{array}{l}\begin{array}{l}\text { At indicated } \\
\text { exceedance } \\
\text { probabilities }\end{array} \\
0.01\end{array}$} & \multirow{2}{*}{$\begin{array}{l}\text { Maximum } \\
\text { peak used } \\
\text { in analysis } \\
\text { (cubic feet } \\
\text { per second) }\end{array}$} \\
\hline & & 0.5 & 0.1 & 0.04 & 0.02 & & \\
\hline \multirow[t]{3}{*}{12437960} & 16 & 60 & 172 & 255 & 329 & 414 & 756 \\
\hline & & $(41-86)$ & $(115-322)$ & $(161-552)$ & $(198-787)$ & $(239-1,090)$ & \\
\hline & & 61 & 218 & 384 & 541 & 711 & \\
\hline \multirow[t]{3}{*}{12439200} & 20 & 21 & 42 & 50 & 56 & 62 & 47 \\
\hline & & -- & -- & -- & -- & -- & \\
\hline & & - & -- & -- & -- & -- & \\
\hline \multirow[t]{3}{*}{12439300} & 25 & 54 & 214 & 357 & 498 & 674 & ${ }^{8} 455$ \\
\hline & & $(38-78)$ & $(142-382)$ & $(221-724)$ & $(293-1,100)$ & $(378-1,620)$ & \\
\hline & & 55 & 216 & 355 & 490 & 653 & \\
\hline \multirow[t]{3}{*}{12441700} & 10 & 206 & 490 & 667 & 812 & 967 & 528 \\
\hline & & $(140-305)$ & $(328-1,000)$ & $(422-1,600)$ & $(494-2,180)$ & $(567-2,860)$ & \\
\hline & & 199 & 458 & 608 & 728 & 852 & \\
\hline \multirow[t]{3}{*}{12442000} & 31 & 523 & 1,220 & 1,700 & 2,120 & 2,600 & 6,010 \\
\hline & & $(431-633)$ & $(971-1,660)$ & $(1,300-2,490)$ & $(1,570-3,270)$ & $(1,870-4,220)$ & \\
\hline & & 524 & 1,220 & 1,690 & 2,100 & 2,570 & \\
\hline \multirow{3}{*}{12445800} & 19 & 6.2 & 12 & 16 & 19 & 21 & 14 \\
\hline & & $(5.0-7.7)$ & $(9.7-18)$ & $(12-25)$ & $(14-30)$ & $(15-36)$ & \\
\hline & & 6.4 & 14 & 18 & 21 & 25 & \\
\hline \multirow[t]{3}{*}{12447380} & 22 & 158 & 294 & 371 & 431 & 494 & 386 \\
\hline & & $(133-188)$ & $(241-390)$ & $(295-524)$ & $(335-636)$ & $(376-760)$ & \\
\hline & & 158 & 293 & 369 & 429 & 490 & \\
\hline \multirow[t]{3}{*}{12447390} & 28 & 368 & 638 & 805 & 945 & 1,100 & 1,120 \\
\hline & & $(324-415)$ & $(551-779)$ & $(675-1,040)$ & $(774-1,270)$ & $(879-1,540)$ & \\
\hline & & 362 & 625 & 784 & 916 & 1,060 & \\
\hline \multirow[t]{3}{*}{12447400} & 19 & 24 & 56 & 75 & 89 & 104 & 89 \\
\hline & & $(19-32)$ & $(42-88)$ & $(53-127)$ & $(62-161)$ & $(70-198)$ & \\
\hline & & 23 & 53 & 71 & 84 & 97 & \\
\hline \multirow[t]{3}{*}{12447430} & 11 & 54 & 100 & 122 & 137 & 151 & 103 \\
\hline & & $(41-72)$ & $(75-164)$ & $(88-218)$ & $(97-261)$ & $(105-304)$ & \\
\hline & & 50 & 89 & 108 & 121 & 133 & \\
\hline \multirow[t]{3}{*}{12448700} & 11 & 59 & 86 & 98 & 108 & 118 & 97 \\
\hline & & $(51-68)$ & $(73-112)$ & $(82-138)$ & $(88-159)$ & $(95-181)$ & \\
\hline & & 56 & 81 & 94 & 103 & 113 & \\
\hline \multirow[t]{3}{*}{12448900} & 11 & 132 & 232 & 281 & 318 & 354 & 232 \\
\hline & & $(103-169)$ & $(179-359)$ & $(211-479)$ & $(232-576)$ & $(253-678)$ & \\
\hline & & 132 & 234 & 285 & 325 & 365 & \\
\hline \multirow[t]{3}{*}{12448998} & 13 & 1,910 & 3,570 & 4,480 & 5,190 & 5,920 & 9,440 \\
\hline & & $(1,490-2,450)$ & $(2,740-5,550)$ & $(3,320-7,710)$ & $(3,730-9,560)$ & $(4,140-11,600)$ & \\
\hline & & 1,900 & 3,540 & 4,430 & 5,130 & 6,160 & \\
\hline \multirow[t]{3}{*}{12449500} & 45 & 11,200 & 18,500 & 21,700 & 23,900 & 25,900 & 40,800 \\
\hline & & $(9,990-12,500)$ & $(16,200-21,800)$ & $(18,800-26,300)$ & $(20,400-29,400)$ & $(21,900-32,300)$ & \\
\hline & & 11,100 & 18,400 & 21,500 & 23,700 & 25,700 & \\
\hline
\end{tabular}


Table 2. Flood discharges for selected exceedance probabilities at gaging stations on streams with unregulated flow--Continued

\begin{tabular}{|c|c|c|c|c|c|c|c|}
\hline \multirow[b]{2}{*}{ Station number } & \multirow{2}{*}{$\begin{array}{l}\text { Number of } \\
\text { peaks used } \\
\text { in analysis }\end{array}$} & \multicolumn{4}{|c|}{$\begin{array}{l}\text { Flood discharge, in cubic feet per second } \\
\text { (95-percent confidence interval) } \\
\text { Weighted estimate of flood discharge, in cubic feet per second }\end{array}$} & \multirow{2}{*}{$\begin{array}{c}\begin{array}{l}\text { At indicated } \\
\text { exceedance } \\
\text { probabilities }\end{array} \\
0.01\end{array}$} & \multirow{2}{*}{$\begin{array}{l}\text { Maximum } \\
\text { peak used } \\
\text { in analysis } \\
\text { (cubic feet } \\
\text { per second) }\end{array}$} \\
\hline & & 0.5 & 0.1 & 0.04 & 0.02 & & \\
\hline 12449600 & 20 & $\begin{array}{c}133 \\
(96.5-185) \\
135\end{array}$ & $\begin{array}{c}374 \\
(260-635) \\
379\end{array}$ & $\begin{array}{c}533 \\
(353-1000) \\
539\end{array}$ & $\begin{array}{c}665 \\
(426-1,340) \\
662\end{array}$ & $\begin{array}{c}808 \\
(501-1,730) \\
814\end{array}$ & 535 \\
\hline 12449790 & 11 & $\begin{array}{c}55 \\
(41-72) \\
55\end{array}$ & $\begin{array}{r}112 \\
(82-188) \\
112\end{array}$ & $\begin{array}{c}148 \\
(104-284) \\
149\end{array}$ & $\begin{array}{c}178 \\
(120-376) \\
179\end{array}$ & $\begin{array}{c}211 \\
(138-488) \\
211\end{array}$ & 168 \\
\hline 12449950 & 39 & $\begin{array}{c}11,800 \\
(10,500-13,300) \\
11,700\end{array}$ & $\begin{array}{c}20,600 \\
(17,900-24,800) \\
20,400\end{array}$ & $\begin{array}{c}25,300 \\
(21,500-31,500) \\
25,000\end{array}$ & $\begin{array}{c}28,800 \\
(24,000-36,800) \\
28,500\end{array}$ & $\begin{array}{c}32,300 \\
(26,600-42,400) \\
31,900\end{array}$ & 46,700 \\
\hline 12450500 & 34 & $\begin{array}{c}12,100 \\
(10,700-13,600) \\
--\end{array}$ & $\begin{array}{c}20,400 \\
(17,700-24,500) \\
--\end{array}$ & $\begin{array}{c}24,600 \\
(21,000-30,900) \\
--\end{array}$ & $\begin{array}{c}27,900 \\
(23,300-35,900) \\
--\end{array}$ & $\begin{array}{c}31,100 \\
(25,600-41,100) \\
\ldots\end{array}$ & 46,700 \\
\hline 12451000 & 75 & $\begin{array}{c}9,600 \\
(9,000-10,200) \\
9,600\end{array}$ & $\begin{array}{c}14,600 \\
(13,400-16,000) \\
14,600\end{array}$ & $\begin{array}{c}16,800 \\
(15,300-18,800) \\
16,800\end{array}$ & $\begin{array}{c}18,400 \\
(16,600-20,800) \\
18,400\end{array}$ & $\begin{array}{c}19,900 \\
(17,900-22,800) \\
19,900\end{array}$ & 21,000 \\
\hline 12451500 & 34 & $\begin{array}{c}1,270 \\
(1,130-1,420) \\
1,260\end{array}$ & $\begin{array}{c}2,150 \\
(1,880-2,580) \\
2,130\end{array}$ & $\begin{array}{c}2,650 \\
(2,260-3,320) \\
2,630\end{array}$ & $\begin{array}{c}3,050 \\
(2,550-3,940) \\
3,020\end{array}$ & $\begin{array}{c}3,470 \\
(2,850-4,610) \\
3,430\end{array}$ & 3,900 \\
\hline 12452800 & 39 & $\begin{array}{c}2,680 \\
(2,420-2,970) \\
2,680\end{array}$ & $\begin{array}{c}4,370 \\
(3,870-5,120) \\
4,370\end{array}$ & $\begin{array}{c}5,230 \\
(4,540-6,330) \\
5,230\end{array}$ & $\begin{array}{c}5,880 \\
(5,030-7,270) \\
5,880\end{array}$ & $\begin{array}{c}6,520 \\
(5,510-8,240) \\
6,520\end{array}$ & 6,430 \\
\hline 12452880 & 11 & $\begin{array}{r}32 \\
(24-44) \\
34\end{array}$ & $\begin{array}{r}67 \\
(49-118) \\
71\end{array}$ & $\begin{array}{r}87 \\
(60-173) \\
94\end{array}$ & $\begin{array}{c}103 \\
(69-222) \\
112\end{array}$ & $\begin{array}{c}120 \\
(77-278) \\
131\end{array}$ & 69 \\
\hline 12453000 & 23 & $\begin{array}{c}3,380 \\
(3,030-3,760) \\
3,380\end{array}$ & $\begin{array}{c}4,940 \\
(4,380-5,890) \\
4,960\end{array}$ & $\begin{array}{c}5,700 \\
(4,940-7,500) \\
5,740\end{array}$ & $\begin{array}{c}6,240 \\
(5,340-7,930) \\
6,290\end{array}$ & $\begin{array}{c}6,780 \\
(5,720-8,830) \\
6,860\end{array}$ & 10,800 \\
\hline 12454000 & 29 & $\begin{array}{c}4,640 \\
(4,250-5,050) \\
4,650\end{array}$ & $\begin{array}{c}6,910 \\
(6,240-7,940) \\
6,920\end{array}$ & $\begin{array}{c}8,250 \\
(7,280-9,860) \\
8,260\end{array}$ & $\begin{array}{c}9,330 \\
(8,090-11,500) \\
9,330\end{array}$ & $\begin{array}{c}10,500 \\
(8,930-13,300) \\
10,500\end{array}$ & 19,100 \\
\hline 12454290 & 11 & $\begin{array}{c}96 \\
(84-109) \\
85\end{array}$ & $\begin{array}{c}132 \\
(115-167) \\
113\end{array}$ & $\begin{array}{c}149 \\
(128-200) \\
124\end{array}$ & $\begin{array}{c}162 \\
(136-226) \\
133\end{array}$ & $\begin{array}{c}174 \\
(144-253) \\
141\end{array}$ & 153 \\
\hline 12455000 & 48 & $\begin{array}{c}7,040 \\
(6,590-7,510) \\
7,050\end{array}$ & $\begin{array}{c}10,000 \\
(9,240-11,100) \\
10,000\end{array}$ & $\begin{array}{c}11,400 \\
(10,400-12,900) \\
11,400\end{array}$ & $\begin{array}{c}12,400 \\
(11,200-14,200) \\
12,400\end{array}$ & $\begin{array}{c}13,400 \\
(12,000-15,600) \\
13,400\end{array}$ & 13,700 \\
\hline 12456300 & 11 & $\begin{array}{c}66 \\
(47-93) \\
65\end{array}$ & $\begin{array}{c}158 \\
(110-298) \\
150\end{array}$ & $\begin{array}{c}223 \\
(146-496) \\
206\end{array}$ & $\begin{array}{c}280 \\
(175-701) \\
254\end{array}$ & $\begin{array}{c}346 \\
(206-966) \\
307\end{array}$ & 205 \\
\hline 12456500 & 23 & $\begin{array}{c}3,140 \\
(2,690-3,650) \\
3,150\end{array}$ & $\begin{array}{c}5,470 \\
(4,590-7,000) \\
5,470\end{array}$ & $\begin{array}{c}6,720 \\
(5,490-9,080) \\
6,720\end{array}$ & $\begin{array}{c}7,680 \\
(6,150-10,800) \\
7,670\end{array}$ & $\begin{array}{c}8,660 \\
(6,800-12,600) \\
8,640\end{array}$ & 7,030 \\
\hline
\end{tabular}


Table 2. Flood discharges for selected exceedance probabilities at gaging stations on streams with unregulated flow--Continued

\begin{tabular}{|c|c|c|c|c|c|c|c|}
\hline \multirow[b]{2}{*}{ Station number } & \multirow{2}{*}{$\begin{array}{l}\text { Number of } \\
\text { peaks used } \\
\text { in analysis }\end{array}$} & \multicolumn{4}{|c|}{$\begin{array}{l}\text { Flood discharge, in cubic feet per second } \\
\text { (95-percent confidence interval) } \\
\text { Weighted estimate of flood discharge, in cubic feet per second }\end{array}$} & \multirow{2}{*}{$\begin{array}{c}\begin{array}{l}\text { At indicated } \\
\text { exceedance } \\
\text { probabilities }\end{array} \\
0.01\end{array}$} & \multirow{2}{*}{$\begin{array}{l}\text { Maximum } \\
\text { peak used } \\
\text { in analysis } \\
\text { (cubic feet } \\
\text { per second }\end{array}$} \\
\hline & & 0.5 & 0.1 & 0.04 & 0.02 & & \\
\hline 12457000 & 74 & $\begin{array}{c}11,600 \\
(10,800-12,400) \\
11,600\end{array}$ & $\begin{array}{c}18,700 \\
(17,200-20,700) \\
18,700\end{array}$ & $\begin{array}{c}22,500 \\
(20,400-25,500) \\
22,500\end{array}$ & $\begin{array}{c}25,500 \\
(22,800-29,400) \\
25,400\end{array}$ & $\begin{array}{c}28,600 \\
(25,300-33,500) \\
28,500\end{array}$ & 36,100 \\
\hline 12457300 & 20 & $\begin{array}{c}28 \\
(23-34) \\
28\end{array}$ & $\begin{array}{r}55 \\
(43-77) \\
55\end{array}$ & $\begin{array}{r}69 \\
(53-104) \\
70\end{array}$ & $\begin{array}{c}81 \\
(61-128) \\
82\end{array}$ & $\begin{array}{r}93 \\
(68-153) \\
94\end{array}$ & 75 \\
\hline 12457900 & 10 & $\begin{array}{r}54 \\
(44-67) \\
55\end{array}$ & $\begin{array}{r}87 \\
(70-128) \\
89\end{array}$ & $\begin{array}{c}103 \\
(80.6-166) \\
106\end{array}$ & $\begin{array}{c}115 \\
(87.9-196) \\
119\end{array}$ & $\begin{array}{c}127 \\
(94.8-228) \\
132\end{array}$ & 93 \\
\hline 12458000 & 49 & $\begin{array}{c}4,420 \\
(3,990-4,890) \\
4,420\end{array}$ & $\begin{array}{c}7,930 \\
(7,010-9,270) \\
7,930\end{array}$ & $\begin{array}{c}10,000 \\
(8,660-12,200) \\
9,990\end{array}$ & $\begin{array}{c}11,800 \\
(9,970-14,700) \\
11,800\end{array}$ & $\begin{array}{c}13,600 \\
(11,400-17,500) \\
13,700\end{array}$ & 19,800 \\
\hline 12458900 & 20 & $\begin{array}{r}2.3 \\
(1.4-3.6) \\
2.4\end{array}$ & $\begin{array}{r}9.4 \\
(5.6-20) \\
9.8\end{array}$ & $\begin{array}{r}15 \\
(8.4-36) \\
16\end{array}$ & $\begin{array}{r}20 \\
(11-52) \\
21\end{array}$ & $\begin{array}{r}26 \\
(13-72) \\
26\end{array}$ & 11 \\
\hline 12459000 & 68 & $\begin{array}{c}16,100 \\
(15,000-17,200) \\
16,100\end{array}$ & $\begin{array}{c}25,000 \\
(23,000-27,600) \\
25,000\end{array}$ & $\begin{array}{c}29,600 \\
(26,800-33,400) \\
29,600\end{array}$ & $\begin{array}{c}33,100 \\
(29,700-38,000) \\
33,000\end{array}$ & $\begin{array}{c}36,600 \\
(32,500-42,700) \\
36,500\end{array}$ & 41,300 \\
\hline 12459400 & 16 & $\begin{array}{c}27 \\
(20-36) \\
27\end{array}$ & $\begin{array}{r}62 \\
(45-99) \\
60\end{array}$ & $\begin{array}{r}82 \\
(57-146) \\
80\end{array}$ & $\begin{array}{r}98 \\
(66-186) \\
95\end{array}$ & $\begin{array}{c}114 \\
(75-231) \\
110\end{array}$ & 107 \\
\hline 12461000 & 12 & $\begin{array}{c}17,400 \\
(14,700-20,600) \\
17,300\end{array}$ & $\begin{array}{c}25,800 \\
(21,600-34,800) \\
25,600\end{array}$ & $\begin{array}{c}29,600 \\
(24,300-42,800) \\
29,400\end{array}$ & $\begin{array}{c}32,400 \\
(26,100-49,000) \\
32,200\end{array}$ & $\begin{array}{c}35,100 \\
(27,800-55,300) \\
34,900\end{array}$ & 34,600 \\
\hline 12461100 & 20 & $\begin{array}{c}22 \\
(16-29) \\
23\end{array}$ & $\begin{array}{r}61 \\
(44-101) \\
65\end{array}$ & $\begin{array}{r}91 \\
(61-169) \\
97\end{array}$ & $\begin{array}{c}118 \\
(76-238) \\
126\end{array}$ & $\begin{array}{c}150 \\
(92-325) \\
160\end{array}$ & 114 \\
\hline 12461200 & 34 & $\begin{array}{r}6.8 \\
(5.3-8.9) \\
6.9\end{array}$ & $\begin{array}{r}21 \\
(15-31) \\
21\end{array}$ & $\begin{array}{r}30 \\
(21-48) \\
30\end{array}$ & $\begin{array}{r}37 \\
(26-63) \\
38\end{array}$ & $\begin{array}{r}45 \\
(30-80) \\
46\end{array}$ & 35 \\
\hline 12461400 & 21 & $\begin{array}{c}181 \\
(134-242) \\
180\end{array}$ & $\begin{array}{c}559 \\
(398-916) \\
545\end{array}$ & $\begin{array}{c}902 \\
(599-1,700) \\
861\end{array}$ & $\begin{array}{c}1,250 \\
(788-2,600) \\
1,170\end{array}$ & $\begin{array}{c}1,700 \\
(1,020-3,910) \\
1,560\end{array}$ & 2,090 \\
\hline 12461500 & 20 & $\begin{array}{c}64 \\
(49-82) \\
64\end{array}$ & $\begin{array}{c}158 \\
(118-242) \\
159\end{array}$ & $\begin{array}{c}228 \\
(162-388) \\
228\end{array}$ & $\begin{array}{c}290 \\
(198-534) \\
288\end{array}$ & $\begin{array}{c}363 \\
(238-720) \\
358\end{array}$ & 325 \\
\hline 12462000 & 20 & $\begin{array}{c}182 \\
(150-219) \\
183\end{array}$ & $\begin{array}{c}361 \\
(2922-494) \\
367\end{array}$ & $\begin{array}{c}480 \\
(372-714) \\
491\end{array}$ & $\begin{array}{c}581 \\
(436-921) \\
597\end{array}$ & $\begin{array}{c}696 \\
(506-1,170) \\
716\end{array}$ & 560 \\
\hline 12462500 & 34 & $\begin{array}{c}17,500 \\
(15,800-19,300) \\
17,500\end{array}$ & $\begin{array}{c}28,200 \\
(25,100-32,900) \\
28,100\end{array}$ & $\begin{array}{c}34,500 \\
(30,000-42,000) \\
34,400\end{array}$ & $\begin{array}{c}39,600 \\
(33,800-49,700) \\
39,400\end{array}$ & $\begin{array}{c}45,200 \\
(37,800-58,300) \\
44,900\end{array}$ & 47,500 \\
\hline
\end{tabular}


Table 2. Flood discharges for selected exceedance probabilities at gaging stations on streams with unregulated flow--Continued

\begin{tabular}{|c|c|c|c|c|c|c|c|}
\hline \multirow[b]{2}{*}{ Station number } & \multirow{2}{*}{$\begin{array}{l}\text { Number of } \\
\text { peaks used } \\
\text { in analysis }\end{array}$} & \multicolumn{4}{|c|}{$\begin{array}{l}\text { Flood discharge, in cubic feet per second } \\
\text { (95-percent confidence interval) } \\
\text { Weighted estimate of flood discharge, in cubic feet per second }\end{array}$} & \multirow{2}{*}{$\begin{array}{c}\begin{array}{l}\text { At indicated } \\
\text { exceedance } \\
\text { probabilities }\end{array} \\
0.01\end{array}$} & \multirow{2}{*}{$\begin{array}{l}\text { Maximum } \\
\text { peak used } \\
\text { in analysis } \\
\text { (cubic feet } \\
\text { per second) }\end{array}$} \\
\hline & & 0.5 & 0.1 & 0.04 & 0.02 & & \\
\hline \multirow[t]{3}{*}{12462800} & 22 & 55 & 219 & 302 & 355 & 398 & 257 \\
\hline & & -- & -- & -- & -- & -- & \\
\hline & & -- & -- & -- & -- & -- & \\
\hline \multirow[t]{3}{*}{12463000} & 18 & 490 & 2,770 & 4,930 & 7,060 & 9,640 & 6,420 \\
\hline & & $(270-901)$ & $(1,420-7,500)$ & $(2,340-16,200)$ & $(3,160-26,200)$ & $(4,080-40,000)$ & \\
\hline & & 446 & 1,890 & 2,770 & 3,620 & 4,740 & \\
\hline \multirow[t]{3}{*}{12463600} & 18 & 9.0 & 70 & 147 & 238 & 366 & 129 \\
\hline & & $(4.7-17)$ & $(34-206)$ & $(64-549)$ & $(96-1,040)$ & $(136-1,870)$ & \\
\hline & & 9.4 & 73 & 146 & 222 & 319 & \\
\hline \multirow[t]{3}{*}{12463700} & 16 & 5.3 & 45 & 95 & 152 & 229 & 114 \\
\hline & & $(2.5-11)$ & $(20-160)$ & $(37-432)$ & $(55-818)$ & $(77-1,440)$ & \\
\hline & & 5.3 & 40 & 74 & 109 & 155 & \\
\hline \multirow[t]{3}{*}{12464500} & 26 & 393,000 & 535,000 & 595,000 & 636,000 & 674,000 & 740,000 \\
\hline & & $(361,000-428,000)$ & $(485,000-612,000)$ & $(532,000-699,000)$ & $(564,000-760,000)$ & $(593,000-819,000)$ & \\
\hline & & -- & -- & -- & -- & -- & \\
\hline \multirow[t]{3}{*}{12464600} & 20 & 6.6 & 49 & 94 & 139 & 194 & 160 \\
\hline & & $(3.5-13)$ & $(24-142)$ & $(41-324)$ & $(58-541)$ & $(77-842)$ & \\
\hline & & 5.7 & 35 & 58 & 79 & 101 & \\
\hline \multirow[t]{3}{*}{12464650} & 20 & 18 & 50 & 73 & 93 & 117 & 111 \\
\hline & & $(13-24)$ & $(35-82)$ & $(49-135)$ & $(60-186)$ & $(73-250)$ & \\
\hline & & 17 & 47 & 73 & 98 & 128 & \\
\hline \multirow[t]{2}{*}{12465000} & 54 & 814 & 4,580 & 7,640 & 10,300 & 13,100 & 8,370 \\
\hline & & $\begin{array}{c}(570-1,170) \\
810\end{array}$ & $\begin{array}{c}(3,000--7,740) \\
4370\end{array}$ & $\begin{array}{c}(4,770-13,800) \\
7060\end{array}$ & $\begin{array}{c}(6,240-19,500) \\
9390\end{array}$ & $\begin{array}{c}(7,780-25,900) \\
11,900\end{array}$ & \\
\hline \multirow[t]{3}{*}{12465300} & 20 & 23 & 86 & 134 & 176 & 224 & 205 \\
\hline & & $(15-35)$ & $(54-170)$ & $(79-300)$ & $(100-430)$ & $(122-590)$ & \\
\hline & & 22 & 77 & 119 & 160 & 209 & \\
\hline \multirow[t]{3}{*}{12465400} & 14 & 1,040 & 3,070 & 3,750 & 4,100 & 4,340 & 3,220 \\
\hline & & $(567-2,050)$ & $(1,610-8,110)$ & $(1,920-10,600)$ & $(2,070-12,000)$ & $(2,180-13,000)$ & \\
\hline & & 911 & 2,360 & 3,070 & 3,730 & 4,440 & \\
\hline \multirow[t]{3}{*}{12465500} & 28 & 894 & 3,830 & 6,130 & 8,160 & 10,400 & 12,900 \\
\hline & & $(604-1,340)$ & $(2,430-7,090)$ & $(3,680-12,600)$ & $(4,720-18,000)$ & $(5,830-24,500)$ & \\
\hline & & 840 & 3,840 & 6,350 & 8,790 & 11,800 & \\
\hline \multirow[t]{3}{*}{12467000} & 54 & 312 & 2,160 & 4,570 & 7,480 & 11,800 & 10,400 \\
\hline & & $(224-433)$ & $(1,450-3,580)$ & $(2,840-8,430)$ & $(4,410-15,000)$ & $(6,580-25,300)$ & \\
\hline & & 322 & 2,340 & 4,950 & 7,900 & 11,900 & \\
\hline \multirow[t]{3}{*}{12467400} & 18 & 5.8 & 36 & 68 & 100 & 140 & 154 \\
\hline & & $(3.2-11)$ & $(18-100)$ & $(31-226)$ & $(44-377)$ & $(58-594)$ & \\
\hline & & 6.4 & 49 & 101 & 152 & 212 & \\
\hline \multirow[t]{3}{*}{12470300} & 18 & 17 & 64 & 100 & 133 & 170 & 127 \\
\hline & & $(11-27)$ & $(40-130)$ & $(58-235)$ & $(74-341)$ & $(90-476)$ & \\
\hline & & 17 & 65 & 107 & 149 & 196 & \\
\hline
\end{tabular}


Table 2. Flood discharges for selected exceedance probabilities at gaging stations on streams with unregulated flow--Continued

\begin{tabular}{|c|c|c|c|c|c|c|c|}
\hline \multirow[b]{2}{*}{ Station number } & \multirow{2}{*}{$\begin{array}{l}\text { Number of } \\
\text { peaks used } \\
\text { in analysis }\end{array}$} & \multicolumn{4}{|c|}{$\begin{array}{l}\text { Flood discharge, in cubic feet per second } \\
\text { (95-percent confidence interval) } \\
\text { Weighted estimate of flood discharge, in cubic feet per second }\end{array}$} & \multirow{2}{*}{$\begin{array}{c}\begin{array}{l}\text { At indicated } \\
\text { exceedance } \\
\text { probabilities }\end{array} \\
0.01\end{array}$} & \multirow{2}{*}{$\begin{array}{l}\text { Maximum } \\
\text { peak used } \\
\text { in analysis } \\
\text { (cubic feet } \\
\text { per second) }\end{array}$} \\
\hline & & 0.5 & 0.1 & 0.04 & 0.02 & & \\
\hline \multirow[t]{2}{*}{12471100} & 15 & $\begin{array}{c}114 \\
(86-152)\end{array}$ & $\begin{array}{c}245 \\
(180-396)\end{array}$ & $\begin{array}{c}317 \\
(224-562)\end{array}$ & $\begin{array}{c}372 \\
(256-701)\end{array}$ & $\begin{array}{c}427 \\
(286-851)\end{array}$ & 264 \\
\hline & & 101 & 221 & 315 & 406 & 508 & \\
\hline \multirow[t]{3}{*}{12471200} & 18 & 7.2 & 36 & 65 & 96 & 132 & 60 \\
\hline & & -- & -- & -- & -- & -- & \\
\hline & &.- & $-\cdot$ & $\cdots$ & - & $-\cdot$ & \\
\hline \multirow[t]{2}{*}{12474700} & 10 & 82 & 144 & 177 & 203 & 230 & 166 \\
\hline & & $\begin{array}{c}(0)-100) \\
75\end{array}$ & 113 & 125 & 136 & $\begin{array}{c}(105-404) \\
148\end{array}$ & \\
\hline \multirow[t]{3}{*}{12480700} & 20 & 31 & 51 & 61 & 67 & 74 & 68 \\
\hline & & $(27-37)$ & $(43-66)$ & $(50-81)$ & $(55-94)$ & $(59-106)$ & \\
\hline & & 31 & 53 & 66 & 77 & 88 & \\
\hline \multirow[t]{3}{*}{12483300} & 20 & 33 & 69 & 92 & 111 & 132 & 102 \\
\hline & & $(26-40)$ & $(54-98)$ & $(69-143)$ & $(81-183)$ & $(94-231)$ & \\
\hline & & 32 & 68 & 91 & 110 & 131 & \\
\hline \multirow[t]{3}{*}{12483800} & 21 & 412 & 733 & 905 & 1,040 & 1,170 & 968 \\
\hline & & $(348-487)$ & $(606-965)$ & $(727-1,260)$ & $(816-1,510)$ & $(903-1,770)$ & \\
\hline & & 413 & 751 & 951 & 1,120 & 1,290 & \\
\hline \multirow[t]{3}{*}{12485900} & 16 & 12 & 48 & 84 & 124 & 178 & 137 \\
\hline & & $(7.5-18)$ & $(29-101)$ & $(47-219)$ & $(65-373)$ & $(87-615)$ & \\
\hline & & 12 & 50 & 86 & 121 & 164 & \\
\hline \multirow[t]{3}{*}{12487400} & 10 & $\begin{array}{c}464 \\
\end{array}$ & 742 & 876 & 972 & 1,070 & 811 \\
\hline & & $(376-575)$ & $(596-1,100)$ & $(683-1,410)$ & $(743-1,660)$ & $(799-1,920)$ & \\
\hline & & 433 & 620 & 685 & 736 & 780 & \\
\hline \multirow[t]{3}{*}{12488300} & 20 & 17 & 28 & 33 & 36 & 40 & 36 \\
\hline & & $(15-20)$ & $(23-35)$ & $(27-44)$ & $(30-50)$ & $(32-56)$ & \\
\hline & & 17 & 28 & 35 & 41 & 47 & \\
\hline \multirow[t]{3}{*}{12488500} & 57 & 1,460 & 2,530 & 3,100 & 3,550 & 4,010 & 4,230 \\
\hline & & $(1,330-1,600)$ & $(2,260-2,910)$ & $(2,720-3,680)$ & $(3,070-4,300)$ & $(3,420-5,000)$ & \\
\hline & & 1,450 & 2,460 & 2,960 & 3,350 & 3,750 & \\
\hline \multirow[t]{3}{*}{12489500} & 13 & 5,930 & 10,000 & 12,500 & 14,600 & 16,900 & 21,900 \\
\hline & & $(4,940-7,060)$ & $(8,250-13,800)$ & $(9,940-19,000)$ & $(11,200-23,700)$ & $(12,600-29,300)$ & \\
\hline & & 5,810 & 9,460 & 11,500 & 13,100 & 14,900 & \\
\hline \multirow[t]{3}{*}{12491700} & 34 & 26 & 63 & 89 & 113 & 140 & 133 \\
\hline & & $(21-31)$ & $(50-85)$ & $(68-129)$ & $(84-172)$ & $(101-224)$ & \\
\hline & & 26 & 65 & 93 & 120 & 149 & \\
\hline \multirow[t]{3}{*}{12492500} & 18 & 2,390 & 4,330 & 5,410 & 6,260 & 7,130 & ${ }^{9} 6,150$ \\
\hline & & $(1,990-2,880)$ & $(3,520-5,900)$ & $(4,260-7,900)$ & $(4,810-9,600)$ & $(5,360-11,500)$ & \\
\hline & & 2,370 & 4,220 & 5,210 & 5,970 & 6,800 & \\
\hline \multirow[t]{3}{*}{12500500} & 61 & 380 & 694 & 872 & 1,010 & 1,160 & 1,580 \\
\hline & & $(345-419)$ & $(616-804)$ & $(757-1,040)$ & $(866-1,240)$ & $(978-1,450)$ & \\
\hline & & 381 & 702 & 892 & 1,040 & 1,210 & \\
\hline
\end{tabular}


Table 2. Flood discharges for selected exceedance probabilities at gaging stations on streams with unregulated flow--Continued

\begin{tabular}{|c|c|c|c|c|c|c|c|}
\hline \multirow[b]{2}{*}{ Station number } & \multirow{2}{*}{$\begin{array}{l}\text { Number of } \\
\text { peaks used } \\
\text { in analysis }\end{array}$} & \multicolumn{4}{|c|}{$\begin{array}{l}\text { Flood discharge, in cubic feet per second } \\
\text { (95-percent confidence interval) } \\
\text { Weighted estimate of flood discharge, in cubic feet per second }\end{array}$} & \multirow{2}{*}{$\begin{array}{l}\begin{array}{l}\text { At indicated } \\
\text { exceedance } \\
\text { probabilities }\end{array} \\
0.01\end{array}$} & \multirow{2}{*}{$\begin{array}{l}\text { Maximum } \\
\text { peak used } \\
\text { in analysis } \\
\text { (cubic feet } \\
\text { per second) }\end{array}$} \\
\hline & & 0.5 & 0.1 & 0.04 & 0.02 & & \\
\hline 12501000 & 58 & $\begin{array}{c}96 \\
(82-113)\end{array}$ & $\begin{array}{c}253 \\
(209-322)\end{array}$ & $\begin{array}{c}370 \\
(294-496)\end{array}$ & $\begin{array}{c}476 \\
(368-662)\end{array}$ & $\begin{array}{c}599 \\
(452-866)\end{array}$ & 1,230 \\
\hline & & 97 & 258 & 381 & 493 & 621 & \\
\hline 12502000 & 14 & $\begin{array}{c}538 \\
(408-704) \\
543\end{array}$ & $\begin{array}{c}1,210 \\
(896-1,950) \\
1,240\end{array}$ & $\begin{array}{c}1,680 \\
(1,180-3,090) \\
1,730\end{array}$ & $\begin{array}{c}2,100 \\
(1,410-4,230) \\
2,160\end{array}$ & $\begin{array}{c}2,580 \\
(1,660-5,680) \\
2,640\end{array}$ & 1,900 \\
\hline 12502500 & 42 & $\begin{array}{c}421 \\
(341-521) \\
425\end{array}$ & $\begin{array}{c}1,190 \\
(923-1,640) \\
1,210\end{array}$ & $\begin{array}{c}1,730 \\
(1,290-2,550) \\
1,780\end{array}$ & $\begin{array}{c}2,190 \\
(1,590-3,380) \\
2,260\end{array}$ & $\begin{array}{c}2,720 \\
(1,920-4,370) \\
2,810\end{array}$ & 3,100 \\
\hline 12506000 & 15 & $\begin{array}{c}696 \\
(539-897) \\
697\end{array}$ & $\begin{array}{c}1,460 \\
(1,100-2,270) \\
1,470\end{array}$ & $\begin{array}{c}1,930 \\
(1,400-3,320) \\
1,950\end{array}$ & $\begin{array}{c}2,310 \\
(1,620-4,270) \\
2,340\end{array}$ & $\begin{array}{c}2,730 \\
(1,850-5,370) \\
2,760\end{array}$ & 1,680 \\
\hline 12506500 & 15 & $\begin{array}{c}241 \\
(155-376) \\
247\end{array}$ & $\begin{array}{c}850 \\
(522-1,810) \\
876\end{array}$ & $\begin{array}{c}1,340 \\
(768-3,370) \\
1,360\end{array}$ & $\begin{array}{c}1,790 \\
(977-5,060) \\
1,790\end{array}$ & $\begin{array}{c}2,330 \\
(1,210-7,300) \\
2,270\end{array}$ & 1,750 \\
\hline 12507600 & 20 & $\begin{array}{r}3.5 \\
(2.2-5.6) \\
3.6\end{array}$ & $\begin{array}{r}16 \\
(9.6-35) \\
16\end{array}$ & $\begin{array}{r}28 \\
(15-71) \\
27\end{array}$ & $\begin{array}{r}40 \\
(21-112) \\
37\end{array}$ & $\begin{array}{r}54 \\
(27-168) \\
49\end{array}$ & 33 \\
\hline 12507660 & 18 & $\begin{array}{r}110 \\
-- \\
--\end{array}$ & $\begin{array}{r}832 \\
-- \\
--\end{array}$ & $\begin{array}{r}1,150 \\
-- \\
--\end{array}$ & $\begin{array}{r}1,350 \\
-- \\
--\end{array}$ & $\begin{array}{r}1,700 \\
-- \\
--\end{array}$ & 955 \\
\hline 12508500 & 11 & $\begin{array}{c}1,410 \\
(1,000-1,990) \\
1,430\end{array}$ & $\begin{array}{c}3,260 \\
(2,270-6,070) \\
3,360\end{array}$ & $\begin{array}{c}4,450 \\
(2,940-9,630) \\
4,630\end{array}$ & $\begin{array}{c}5,450 \\
(3,450-13,100) \\
5,690\end{array}$ & $\begin{array}{c}6,540 \\
(3,990-17,300) \\
6,830\end{array}$ & 3,870 \\
\hline 12512550 & 19 & $\begin{array}{r}135 \\
-- \\
--\end{array}$ & $\begin{array}{r}740 \\
-- \\
--\end{array}$ & $\begin{array}{r}830 \\
-- \\
--\end{array}$ & $\begin{array}{r}890 \\
-- \\
--\end{array}$ & $\begin{array}{r}910 \\
-- \\
--\end{array}$ & 711 \\
\hline 12512600 & 16 & $\begin{array}{r}3.0 \\
(1.0-9.4) \\
3.6\end{array}$ & $\begin{array}{r}70 \\
(20-453) \\
75\end{array}$ & $\begin{array}{c}202 \\
(51-1,890) \\
177\end{array}$ & $\begin{array}{c}393 \\
(88-4,690) \\
288\end{array}$ & $\begin{array}{c}704 \\
(143-10,400) \\
441\end{array}$ & 86 \\
\hline 12512700 & 20 & $\begin{array}{r}4.1 \\
(1.8-9.2) \\
4.8\end{array}$ & $\begin{array}{r}53 \\
(21-194) \\
66\end{array}$ & $\begin{array}{c}126 \\
(45-598) \\
153\end{array}$ & $\begin{array}{c}217 \\
(72-1,220) \\
244\end{array}$ & $\begin{array}{c}351 \\
(108-2,300) \\
361\end{array}$ & 186 \\
\hline 12513000 & 44 & $\begin{array}{l}56 \\
-- \\
--\end{array}$ & $\begin{array}{r}1,780 \\
-- \\
--\end{array}$ & $\begin{array}{r}2,820 \\
-\cdot \\
--\end{array}$ & $\begin{array}{r}7,080 \\
-- \\
--\end{array}$ & $\begin{array}{r}14,100 \\
-- \\
--\end{array}$ & 5,560 \\
\hline 13334500 & 32 & $\begin{array}{c}338 \\
(285-401) \\
351\end{array}$ & $\begin{array}{c}715 \\
(584-937) \\
819\end{array}$ & $\begin{array}{c}952 \\
(752-1,330) \\
1,170\end{array}$ & $\begin{array}{c}1,150 \\
(885-1,670) \\
1,490\end{array}$ & $\begin{array}{c}1,360 \\
(1,020-2,070) \\
1,830\end{array}$ & 1,180 \\
\hline 13334700 & 30 & $\begin{array}{c}413 \\
(310-548) \\
427\end{array}$ & $\begin{array}{c}1,450 \\
(1,040-2,290) \\
1,550\end{array}$ & $\begin{array}{c}2,380 \\
(1,600-4,180) \\
2,570\end{array}$ & $\begin{array}{c}3,310 \\
(2,120-6,300) \\
3,550\end{array}$ & $\begin{array}{c}4,490 \\
(2,760-9,200) \\
4,760\end{array}$ & 3,700 \\
\hline
\end{tabular}


Table 2. Flood discharges for selected exceedance probabilities at gaging stations on streams with unregulated flow--Continued

\begin{tabular}{|c|c|c|c|c|c|c|c|}
\hline \multirow[b]{2}{*}{ Station number } & \multirow{2}{*}{$\begin{array}{l}\text { Number of } \\
\text { peaks used } \\
\text { in analysis }\end{array}$} & \multicolumn{4}{|c|}{$\begin{array}{l}\text { Flood discharge, in cubic feet per second } \\
\text { (95-percent confidence interval) } \\
\text { Weighted estimate of flood discharge, in cubic feet per second }\end{array}$} & \multirow{2}{*}{$\begin{array}{l}\begin{array}{l}\text { At indicated } \\
\text { exceedance } \\
\text { probabilities }\end{array} \\
0.01\end{array}$} & \multirow{2}{*}{$\begin{array}{l}\text { Maximum } \\
\text { peak used } \\
\text { in analysis } \\
\text { (cubic feet } \\
\text { per second }\end{array}$} \\
\hline & & 0.5 & 0.1 & 0.04 & 0.02 & & \\
\hline 13335200 & 18 & $\begin{array}{c}17 \\
(6.2-45) \\
17\end{array}$ & $\begin{array}{c}296 \\
(99-1,500) \\
220\end{array}$ & $\begin{array}{c}757 \\
(222-5,140) \\
441\end{array}$ & $\begin{array}{c}1,340 \\
(360-11,000) \\
661\end{array}$ & $\begin{array}{c}2,210 \\
(544-21,400) \\
942\end{array}$ & 705 \\
\hline 13343450 & 15 & $\begin{array}{c}78 \\
(42-140) \\
75\end{array}$ & $\begin{array}{c}473 \\
(244-1,360) \\
386\end{array}$ & $\begin{array}{c}996 \\
(455-3,860) \\
697\end{array}$ & $\begin{array}{c}1,650 \\
(686-7,920) \\
1,010\end{array}$ & $\begin{array}{c}2,650 \\
(1,000-15,600) \\
1,430\end{array}$ & 8,150 \\
\hline 13343520 & 16 & $\begin{array}{c}100 \\
(72-142) \\
93\end{array}$ & $\begin{array}{c}261 \\
(180-462) \\
260\end{array}$ & $\begin{array}{c}361 \\
(237-713) \\
390\end{array}$ & $\begin{array}{c}442 \\
(280-940) \\
511\end{array}$ & $\begin{array}{c}527 \\
(324-1,200) \\
653\end{array}$ & 298 \\
\hline 13343620 & 16 & $\begin{array}{c}26 \\
(16-44) \\
24\end{array}$ & $\begin{array}{r}107 \\
(60-253) \\
92\end{array}$ & $\begin{array}{c}168 \\
(89-466) \\
145\end{array}$ & $\begin{array}{c}222 \\
(112-678) \\
197\end{array}$ & $\begin{array}{c}281 \\
(137-940) \\
258\end{array}$ & 192 \\
\hline 13343660 & 20 & $\begin{array}{c}50 \\
(30-83) \\
47\end{array}$ & $\begin{array}{r}246 \\
(139-560 \\
207\end{array}$ & $\begin{array}{c}422 \\
(222-1,120) \\
338\end{array}$ & $\begin{array}{c}590 \\
(295-1,740) \\
461\end{array}$ & $\begin{array}{c}790 \\
(377-2,560) \\
609\end{array}$ & 656 \\
\hline 13343800 & 15 & $\begin{array}{c}676 \\
(460-991) \\
617\end{array}$ & $\begin{array}{c}1,830 \\
(1,220-3,460) \\
1,590\end{array}$ & $\begin{array}{c}2,550 \\
(1,610-5,400) \\
2,230\end{array}$ & $\begin{array}{c}3,110 \\
(1,900-7,130) \\
2,770\end{array}$ & $\begin{array}{c}3,710 \\
(2,220-9,100) \\
3,390\end{array}$ & 2,380 \\
\hline 13344500 & 40 & $\begin{array}{c}1,510 \\
(1,180-1,920) \\
1,520\end{array}$ & $\begin{array}{c}4,670 \\
(3,500-6,770) \\
4,660\end{array}$ & $\begin{array}{c}6,940 \\
(4,990-10,800) \\
6,880\end{array}$ & $\begin{array}{c}8,910 \\
(6,220-14,500) \\
8,780\end{array}$ & $\begin{array}{c}11,100 \\
(7,550-18,900) \\
10,900\end{array}$ & 7,980 \\
\hline 13346100 & 24 & $\begin{array}{c}4,610 \\
(3,900-5,440) \\
--\end{array}$ & $\begin{array}{c}8,390 \\
(6,940-11,000) \\
--\end{array}$ & $\begin{array}{c}10,400 \\
(8,350-14,300) \\
--\end{array}$ & $\begin{array}{c}11,900 \\
(9,380-17,000) \\
--\end{array}$ & $\begin{array}{c}13,400 \\
(10,400-19,800) \\
--\end{array}$ & 12,600 \\
\hline 13348000 & 34 & $\begin{array}{c}1,060 \\
(873-1,290) \\
1,050\end{array}$ & $\begin{array}{c}2,590 \\
(2,060-3,540) \\
2,540\end{array}$ & $\begin{array}{c}3,680 \\
(2,800-5,410) \\
3,600\end{array}$ & $\begin{array}{c}4,650 \\
(3,430-7,210) \\
4,540\end{array}$ & $\begin{array}{c}5,770 \\
(4,120-9,400) \\
5,610\end{array}$ & 5,000 \\
\hline 13348400 & 20 & $\begin{array}{c}36 \\
(26-49) \\
34\end{array}$ & $\begin{array}{r}110 \\
(76-187) \\
109\end{array}$ & $\begin{array}{c}169 \\
(110-328) \\
172\end{array}$ & $\begin{array}{c}225 \\
(140-477) \\
234\end{array}$ & $\begin{array}{c}292 \\
(174-675) \\
309\end{array}$ & 234 \\
\hline 13348500 & 27 & $\begin{array}{c}398 \\
(332-476) \\
388\end{array}$ & $\begin{array}{c}841 \\
(681-1,130) \\
839\end{array}$ & $\begin{array}{c}1,140 \\
(886-1,640) \\
1,170\end{array}$ & $\begin{array}{c}1,390 \\
(1,050-2,140) \\
1,450\end{array}$ & $\begin{array}{c}1,680 \\
(1,240-2,700) \\
1,790\end{array}$ & 1,500 \\
\hline 13349210 & 34 & $\begin{array}{c}5,950 \\
(4,890-7,280) \\
5,840\end{array}$ & $\begin{array}{c}13,000 \\
(10,400-17,600) \\
12,400\end{array}$ & $\begin{array}{c}16,600 \\
(12,900-23,600) \\
15,600\end{array}$ & $\begin{array}{c}19,200 \\
(14,600-28,100) \\
17,900\end{array}$ & $\begin{array}{c}21,800 \\
(16,300-32,700) \\
20,300\end{array}$ & 23,900 \\
\hline 13349300 & 34 & $\begin{array}{c}29 \\
(22-39) \\
30\end{array}$ & $\begin{array}{r}98 \\
(71-151) \\
108\end{array}$ & $\begin{array}{c}152 \\
(105-255) \\
176\end{array}$ & $\begin{array}{c}202 \\
(134-358) \\
241\end{array}$ & $\begin{array}{c}260 \\
(167-487) \\
319\end{array}$ & 183 \\
\hline 13349350 & 20 & $\begin{array}{r}32 \\
(23-45) \\
32\end{array}$ & $\begin{array}{r}112 \\
(77-195) \\
119\end{array}$ & $\begin{array}{c}193 \\
(122-394) \\
208\end{array}$ & $\begin{array}{c}280 \\
(167-647) \\
299\end{array}$ & $\begin{array}{c}400 \\
(223-1,040) \\
418\end{array}$ & 1,780 \\
\hline
\end{tabular}


Table 2. Flood discharges for selected exceedance probabilities at gaging stations on streams with unregulated flow--Continued

\begin{tabular}{|c|c|c|c|c|c|c|c|}
\hline \multirow[b]{2}{*}{ Station number } & \multirow{2}{*}{$\begin{array}{l}\text { Number of } \\
\text { peaks used } \\
\text { in analysis }\end{array}$} & \multicolumn{4}{|c|}{$\begin{array}{l}\text { Flood discharge, in cubic feet per second } \\
\text { (95-percent confidence interval) } \\
\text { Weighted estimate of flood discharge, in cubic feet per second }\end{array}$} & \multirow{2}{*}{$\begin{array}{l}\begin{array}{l}\text { At indicated } \\
\text { exceedance } \\
\text { probabilities }\end{array} \\
0.01\end{array}$} & \multirow{2}{*}{$\begin{array}{l}\text { Maximum } \\
\text { peak used } \\
\text { in analysis } \\
\text { (cubic feet } \\
\text { per second) }\end{array}$} \\
\hline & & 0.5 & 0.1 & 0.04 & 0.02 & & \\
\hline 13349400 & 18 & $\begin{array}{c}1,970 \\
(1,400-2,780) \\
1,880\end{array}$ & $\begin{array}{c}5,780 \\
(3,940-10,200) \\
5,130\end{array}$ & $\begin{array}{c}8,530 \\
(5,500-17,100) \\
7,250\end{array}$ & $\begin{array}{c}11,000 \\
(6,770-23,900) \\
9,070\end{array}$ & $\begin{array}{c}13,700 \\
(8,150-32,300) \\
11,100\end{array}$ & 10,600 \\
\hline 13349500 & 18 & $\begin{array}{c}1,140 \\
(759-1,750) \\
1,160\end{array}$ & $\begin{array}{c}3,680 \\
(2,320-7,240) \\
3,770\end{array}$ & $\begin{array}{c}5,280 \\
(3,180-11,600) \\
5,500\end{array}$ & $\begin{array}{c}6,540 \\
(3,810-15,400) \\
6,900\end{array}$ & $\begin{array}{c}7,840 \\
(4,430-19,700) \\
8,400\end{array}$ & 4,000 \\
\hline 13349800 & 11 & $\begin{array}{c}59 \\
(44-79) \\
45\end{array}$ & $\begin{array}{r}124 \\
(91-215) \\
113\end{array}$ & $\begin{array}{c}166 \\
(115-331) \\
175\end{array}$ & $\begin{array}{c}202 \\
(134-443) \\
237\end{array}$ & $\begin{array}{c}240 \\
(154-580) \\
313\end{array}$ & 198 \\
\hline 13350500 & 26 & $\begin{array}{c}889 \\
(710-1,120) \\
882\end{array}$ & $\begin{array}{c}2,050 \\
(1,580-2,920) \\
2,100\end{array}$ & $\begin{array}{c}2,720 \\
(2,030-4,170) \\
2,880\end{array}$ & $\begin{array}{c}3,260 \\
(2,370-5,230) \\
3,550\end{array}$ & $\begin{array}{c}3,820 \\
(2,710-6,380) \\
4,270\end{array}$ & 2,930 \\
\hline 13351000 & 63 & $\begin{array}{c}7,930 \\
(6,780-9,310) \\
7,860\end{array}$ & $\begin{array}{c}19,200 \\
(15,800-24,200) \\
18,700\end{array}$ & $\begin{array}{c}25,500 \\
(20,600-33,400) \\
24,600\end{array}$ & $\begin{array}{c}30,300 \\
(24,000-40,700) \\
29,100\end{array}$ & $\begin{array}{c}35,200 \\
(27,500-48,200) \\
33,800\end{array}$ & 33,500 \\
\hline 13352200 & 20 & $\begin{array}{c}22 \\
(13-36) \\
22\end{array}$ & $\begin{array}{r}100 \\
(58-224) \\
102\end{array}$ & $\begin{array}{c}167 \\
(89.5-435) \\
177\end{array}$ & $\begin{array}{c}229 \\
(117-662) \\
250\end{array}$ & $\begin{array}{c}302 \\
(147-957) \\
339\end{array}$ & 200 \\
\hline 13352500 & 19 & $\begin{array}{c}123 \\
(76-201) \\
146\end{array}$ & $\begin{array}{c}603 \\
(347-1,360) \\
882\end{array}$ & $\begin{array}{c}1,070 \\
(569-2,870) \\
1,720\end{array}$ & $\begin{array}{c}1,550 \\
(776-4,680) \\
2,590\end{array}$ & $\begin{array}{c}2,160 \\
(1,020-7,270) \\
3,660\end{array}$ & 1,150 \\
\hline 13352550 & 18 & $\begin{array}{c}21 \\
(12-36) \\
20\end{array}$ & $\begin{array}{r}119 \\
(65-291) \\
108\end{array}$ & $\begin{array}{c}225 \\
(113-674) \\
195\end{array}$ & $\begin{array}{c}341 \\
(159-1,180) \\
285\end{array}$ & $\begin{array}{c}496 \\
(217-1,950) \\
399\end{array}$ & 277 \\
\hline 14013000 & 62 & $\begin{array}{c}878 \\
(760-1,010) \\
880\end{array}$ & $\begin{array}{c}2,300 \\
(1,920-2,860) \\
2,290\end{array}$ & $\begin{array}{c}3,460 \\
(2,790-4,560) \\
3,420\end{array}$ & $\begin{array}{c}4,590 \\
(3,590-6,320) \\
4,510\end{array}$ & $\begin{array}{c}5,980 \\
(4,540-8,590) \\
5,830\end{array}$ & 11,000 \\
\hline 14013500 & 31 & $\begin{array}{c}324 \\
(266-394) \\
324\end{array}$ & $\begin{array}{c}719 \\
(572-977) \\
732\end{array}$ & $\begin{array}{c}947 \\
(730-1,360) \\
981\end{array}$ & $\begin{array}{c}1,130 \\
(849-1,690) \\
1,190\end{array}$ & $\begin{array}{c}1,310 \\
(968-2,040) \\
1,400\end{array}$ & 1,320 \\
\hline 14015900 & 20 & $\begin{array}{c}22 \\
(13-38) \\
24\end{array}$ & $\begin{array}{r}140 \\
(76-336) \\
146\end{array}$ & $\begin{array}{c}277 \\
(138-818) \\
276\end{array}$ & $\begin{array}{c}435 \\
(201-1,480) \\
413\end{array}$ & $\begin{array}{c}654 \\
(282-2,540) \\
587\end{array}$ & 228 \\
\hline 14016000 & 18 & $\begin{array}{c}548 \\
(392-791) \\
547\end{array}$ & $\begin{array}{c}1,660 \\
(1,100-3,020) \\
1,620\end{array}$ & $\begin{array}{c}2,430 \\
(1,530-4,990) \\
2,350\end{array}$ & $\begin{array}{c}3,080 \\
(1,880-6,870) \\
2,960\end{array}$ & $\begin{array}{c}3,810 \\
(2,230-9,140) \\
3,630\end{array}$ & 3,340 \\
\hline 14016500 & 21 & $\begin{array}{c}862 \\
(679-1,090) \\
864\end{array}$ & $\begin{array}{c}2,050 \\
(1,560-3,030) \\
2,080\end{array}$ & $\begin{array}{c}2,880 \\
(2,090-4,700) \\
2,940\end{array}$ & $\begin{array}{c}3,620 \\
(2,530-6,330) \\
3,700\end{array}$ & $\begin{array}{c}4,460 \\
(3,020-8,350) \\
4,550\end{array}$ & 5,450 \\
\hline 14016600 & 20 & $\begin{array}{c}77 \\
(51-117) \\
77\end{array}$ & $\begin{array}{c}267 \\
(168-520) \\
271\end{array}$ & $\begin{array}{c}396 \\
(237-861) \\
412\end{array}$ & $\begin{array}{c}502 \\
(290-1,170) \\
536\end{array}$ & $\begin{array}{c}614 \\
(343-1,530) \\
674\end{array}$ & 253 \\
\hline
\end{tabular}


Table 2. Flood discharges for selected exceedance probabilities at gaging stations on streams with unregulated flow--Continued

\begin{tabular}{|c|c|c|c|c|c|c|c|}
\hline \multirow[b]{2}{*}{ Station number } & \multirow{2}{*}{$\begin{array}{l}\text { Number of } \\
\text { peaks used } \\
\text { in analysis }\end{array}$} & \multicolumn{4}{|c|}{$\begin{array}{l}\text { Flood discharge, in cubic feet per second } \\
\text { (95-percent confidence interval) } \\
\text { Weighted estimate of flood discharge, in cubic feet per second }\end{array}$} & \multirow{2}{*}{$\begin{array}{l}\begin{array}{l}\text { At indicated } \\
\text { exceedance } \\
\text { probabilities }\end{array} \\
0.01\end{array}$} & \multirow{2}{*}{$\begin{array}{l}\text { Maximum } \\
\text { peak used } \\
\text { in analysis } \\
\text { (cubic feet } \\
\text { per second) }\end{array}$} \\
\hline & & 0.5 & 0.1 & 0.04 & 0.02 & & \\
\hline 14016650 & 20 & $\begin{array}{c}10 \\
(4.9-21) \\
12\end{array}$ & $\begin{array}{r}111 \\
(49-368) \\
131\end{array}$ & $\begin{array}{c}260 \\
(102-1,100) \\
289\end{array}$ & $\begin{array}{c}448 \\
(160-2,240) \\
464\end{array}$ & $\begin{array}{c}726 \\
(240-4,250) \\
694\end{array}$ & 305 \\
\hline 14017000 & 44 & $\begin{array}{c}2,700 \\
(2,320-3,140) \\
2,670\end{array}$ & $\begin{array}{c}5,790 \\
(4,820-7,300) \\
5,680\end{array}$ & $\begin{array}{c}7,630 \\
(6,180-10,100) \\
7,460\end{array}$ & $\begin{array}{c}9,100 \\
(7,220-12,400) \\
8,890\end{array}$ & $\begin{array}{c}10,700 \\
(8,300-15,000) \\
10,500\end{array}$ & 9,350 \\
\hline 14017040 & 15 & $\begin{array}{c}35 \\
(19-67) \\
37\end{array}$ & $\begin{array}{r}182 \\
(92-520) \\
186\end{array}$ & $\begin{array}{c}308 \\
(144-1,060) \\
314\end{array}$ & $\begin{array}{c}424 \\
(188-1,660) \\
433\end{array}$ & $\begin{array}{c}558 \\
(236-2,430) \\
573\end{array}$ & 218 \\
\hline 14017070 & 15 & $\begin{array}{c}59 \\
(31-111) \\
60\end{array}$ & $\begin{array}{c}366 \\
(183-1,080) \\
332\end{array}$ & $\begin{array}{c}717 \\
(323-2,720) \\
590\end{array}$ & $\begin{array}{c}1,110 \\
(462-4,980) \\
843\end{array}$ & $\begin{array}{c}1,640 \\
(634-8,620) \\
1,150\end{array}$ & 733 \\
\hline 14017200 & 20 & $\begin{array}{c}47 \\
(29-76) \\
48\end{array}$ & $\begin{array}{c}264 \\
(152-590) \\
253\end{array}$ & $\begin{array}{c}524 \\
(274-1,440) \\
466\end{array}$ & $\begin{array}{c}829 \\
(402-2,630) \\
688\end{array}$ & $\begin{array}{c}1,270 \\
(570-4,610) \\
977\end{array}$ & 1,560 \\
\hline 14017500 & 15 & $\begin{array}{c}3,520 \\
(2,660-4,650) \\
3,400\end{array}$ & $\begin{array}{c}7,820 \\
(5,760-12,600) \\
7,380\end{array}$ & $\begin{array}{c}10,500 \\
(7,380-18,800) \\
9,820\end{array}$ & $\begin{array}{c}12,700 \\
(8,620-24,500) \\
11,800\end{array}$ & $\begin{array}{c}15,000 \\
(9,890-31,100) \\
14,000\end{array}$ & 13,300 \\
\hline 14018500 & 45 & $\begin{array}{c}6,110 \\
(5,140-7,250) \\
6,060\end{array}$ & $\begin{array}{c}14,900 \\
(12,100-19,400) \\
14,500\end{array}$ & $\begin{array}{c}20,800 \\
(16,300-28,500) \\
20,000\end{array}$ & $\begin{array}{c}25,700 \\
(19,700-36,800) \\
24,500\end{array}$ & $\begin{array}{c}31,300 \\
(23,400-46,300) \\
29,600\end{array}$ & 33,400 \\
\hline 14034250 & 16 & $\begin{array}{r}7.3 \\
(4.8-11) \\
7.8\end{array}$ & $\begin{array}{r}25 \\
(16-50) \\
27\end{array}$ & $\begin{array}{r}38 \\
(22-90) \\
43\end{array}$ & $\begin{array}{r}50 \\
(28-131) \\
57\end{array}$ & $\begin{array}{r}64 \\
(35-184) \\
74\end{array}$ & 43 \\
\hline 14034325 & 15 & $\begin{array}{c}207 \\
(138-308) \\
171\end{array}$ & $\begin{array}{c}693 \\
(445-1,380) \\
530\end{array}$ & $\begin{array}{c}1,110 \\
(663-2,650) \\
805\end{array}$ & $\begin{array}{c}1,520 \\
(858-4,110) \\
1,060\end{array}$ & $\begin{array}{c}2,030 \\
(1,080-6,170) \\
1,370\end{array}$ & 992 \\
\hline 14107000 & 39 & $\begin{array}{c}1,840 \\
(1,660-2,040) \\
1,850\end{array}$ & $\begin{array}{c}3,130 \\
(2,760-3,690) \\
3,170\end{array}$ & $\begin{array}{c}3,880 \\
(3,340-4,750) \\
3,950\end{array}$ & $\begin{array}{c}4,480 \\
(3,790-5,640) \\
4,580\end{array}$ & $\begin{array}{c}5,110 \\
(4,250-6,620) \\
5,250\end{array}$ & 5,500 \\
\hline 14110000 & 69 & $\begin{array}{c}3,180 \\
(2,930-3,450) \\
3,190\end{array}$ & $\begin{array}{c}5,500 \\
(4,970-6,220) \\
5,550\end{array}$ & $\begin{array}{c}6,820 \\
(6,050-7,930) \\
6,900\end{array}$ & $\begin{array}{c}7,870 \\
(6,880-9,330) \\
7,990\end{array}$ & $\begin{array}{c}8,970 \\
(7,740-10,800) \\
9,130\end{array}$ & 9,870 \\
\hline 14111800 & 15 & $\begin{array}{c}105 \\
(74-149) \\
110\end{array}$ & $\begin{array}{c}302 \\
(206-554) \\
321\end{array}$ & $\begin{array}{c}459 \\
(292-981) \\
491\end{array}$ & $\begin{array}{c}605 \\
(366-1,440) \\
647\end{array}$ & $\begin{array}{c}781 \\
(450-2,070) \\
832\end{array}$ & 569 \\
\hline 14112000 & 26 & $\begin{array}{c}1,070 \\
(822-1,390) \\
1,050\end{array}$ & $\begin{array}{c}3,060 \\
(2,250-4,670) \\
2,950\end{array}$ & $\begin{array}{c}4,560 \\
(3,190-7,680) \\
4,330\end{array}$ & $\begin{array}{c}5,940 \\
(4,000-10,700) \\
5,570\end{array}$ & $\begin{array}{c}7,550 \\
(4,900-14,500) \\
6,990\end{array}$ & 5,200 \\
\hline 14112200 & 29 & $\begin{array}{c}25 \\
(19-33) \\
25\end{array}$ & $\begin{array}{r}88 \\
(63-140) \\
85\end{array}$ & $\begin{array}{c}148 \\
(99-263) \\
140\end{array}$ & $\begin{array}{c}208 \\
(132-404) \\
192\end{array}$ & $\begin{array}{c}287 \\
(174-603) \\
259\end{array}$ & 229 \\
\hline
\end{tabular}


Table 2. Flood discharges for selected exceedance probabilities at gaging stations on streams with unregulated flow--Continued

\begin{tabular}{|c|c|c|c|c|c|c|c|}
\hline \multirow[b]{2}{*}{ Station number } & \multirow{2}{*}{$\begin{array}{l}\text { Number of } \\
\text { peaks used } \\
\text { in analysis }\end{array}$} & \multicolumn{4}{|c|}{$\begin{array}{l}\text { Flood discharge, in cubic feet per second } \\
\text { (95-percent confidence interval) } \\
\text { Weighted estimate of flood discharge, in cubic feet per second }\end{array}$} & \multirow{2}{*}{$\begin{array}{c}\begin{array}{l}\text { At indicated } \\
\text { exceedance } \\
\text { probabilities }\end{array} \\
0.01\end{array}$} & \multirow{2}{*}{$\begin{array}{l}\text { Maximum } \\
\text { peak used } \\
\text { in analysis } \\
\text { (cubic feet } \\
\text { per second) }\end{array}$} \\
\hline & & 0.5 & 0.1 & 0.04 & 0.02 & & \\
\hline 14112400 & 14 & $\begin{array}{c}113 \\
(84-152) \\
126\end{array}$ & $\begin{array}{c}250 \\
(182-415) \\
310\end{array}$ & $\begin{array}{c}331 \\
(230-613) \\
442\end{array}$ & $\begin{array}{c}397 \\
(267-791) \\
560\end{array}$ & $\begin{array}{c}466 \\
(304-993) \\
694\end{array}$ & 430 \\
\hline 14112500 & 36 & $\begin{array}{c}3,260 \\
(2,560-4,150) \\
3,190\end{array}$ & $\begin{array}{c}9,250 \\
(6,970-13,400) \\
8,860\end{array}$ & $\begin{array}{c}13,200 \\
(9,550-20,400) \\
12,500\end{array}$ & $\begin{array}{c}16,400 \\
(11,600-26,600) \\
15,400\end{array}$ & $\begin{array}{c}19,900 \\
(13,700-33,600) \\
18,500\end{array}$ & 17,500 \\
\hline 14113000 & 71 & $\begin{array}{c}7,840 \\
(6,790-9,040) \\
7,840\end{array}$ & $\begin{array}{c}20,500 \\
(17,200-25,400) \\
20,400\end{array}$ & $\begin{array}{c}29,700 \\
(24,100-38,500) \\
29,500\end{array}$ & $\begin{array}{c}37,800 \\
(30,000-50,700) \\
37,400\end{array}$ & $\begin{array}{c}47,200 \\
(36,600-65,300) \\
46,600\end{array}$ & 51,000 \\
\hline 14121300 & 21 & $\begin{array}{c}699 \\
(605-807) \\
709\end{array}$ & $\begin{array}{c}1,150 \\
(978-1,460) \\
1,170\end{array}$ & $\begin{array}{c}1,390 \\
(1,150-1,850) \\
1,420\end{array}$ & $\begin{array}{c}1,560 \\
(1,270-2,160) \\
1,610\end{array}$ & $\begin{array}{c}1,740 \\
(1,390-2,500) \\
1,800\end{array}$ & 1,510 \\
\hline 14121500 & 12 & $\begin{array}{c}1,590 \\
(1,300-1,930) \\
1,600\end{array}$ & $\begin{array}{c}2,610 \\
(2,120-3,700) \\
2,650\end{array}$ & $\begin{array}{c}3,140 \\
(2,470-4,830) \\
3,200\end{array}$ & $\begin{array}{c}3,540 \\
(2,720-5,760) \\
3,630\end{array}$ & $\begin{array}{c}3,940 \\
(2,970-6,770) \\
4,060\end{array}$ & 2,900 \\
\hline 14122000 & 13 & $\begin{array}{c}1,970 \\
(1,620-2,400) \\
2,020\end{array}$ & $\begin{array}{c}3,380 \\
(2,730-4,790) \\
3,530\end{array}$ & $\begin{array}{c}4,150 \\
(3,240-6,410) \\
4,390\end{array}$ & $\begin{array}{c}4,750 \\
(3,610-7,780) \\
5,070\end{array}$ & $\begin{array}{c}5,360 \\
(3,980-9,300) \\
5,770\end{array}$ & 3,860 \\
\hline 14123000 & 26 & $\begin{array}{c}2,760 \\
(2,380-3,180) \\
2,790\end{array}$ & $\begin{array}{c}5,020 \\
(4,240-6,330) \\
5,120\end{array}$ & $\begin{array}{c}6,410 \\
(5,250-8,590) \\
6,570\end{array}$ & $\begin{array}{c}7,570 \\
(6,050-10,600) \\
7,790\end{array}$ & $\begin{array}{c}8,830 \\
(6,880-12,900) \\
9,110\end{array}$ & 10,800 \\
\hline 14123500 & 75 & $\begin{array}{c}4,600 \\
(4,190-5,050) \\
4,610\end{array}$ & $\begin{array}{c}8,500 \\
(7,580-9,760) \\
8,520\end{array}$ & $\begin{array}{c}10,600 \\
(9,270-12,500) \\
10,600\end{array}$ & $\begin{array}{c}12,200 \\
(10,500-14,600) \\
12,200\end{array}$ & $\begin{array}{c}13,800 \\
(11,800-16,900) \\
13,900\end{array}$ & ${ }^{10} 15,300$ \\
\hline 14124500 & 17 & $\begin{array}{c}2,780 \\
(2,510-3,090) \\
2,760\end{array}$ & $\begin{array}{c}3,780 \\
(3,360-4,490) \\
3,800\end{array}$ & $\begin{array}{c}4,190 \\
(3,680-5,160) \\
4,270\end{array}$ & $\begin{array}{c}4,480 \\
(3,890-5,640) \\
4,610\end{array}$ & $\begin{array}{c}4,740 \\
(4,080-6,100) \\
4,940\end{array}$ & 4,140 \\
\hline 14125000 & 14 & $\begin{array}{c}2,520 \\
(2,220-2,840) \\
2,510\end{array}$ & $\begin{array}{c}3,600 \\
(3,140-4,460) \\
3,650\end{array}$ & $\begin{array}{c}4,150 \\
(3,540-5,440) \\
4,250\end{array}$ & $\begin{array}{c}4,560 \\
(3,820-6,220) \\
4,720\end{array}$ & $\begin{array}{c}4,970 \\
(4,100-7,040) \\
5,220\end{array}$ & 4,330 \\
\hline 14125200 & 20 & $\begin{array}{c}192 \\
(162-226) \\
191\end{array}$ & $\begin{array}{c}345 \\
(286-455) \\
345\end{array}$ & $\begin{array}{c}435 \\
(348-614) \\
436\end{array}$ & $\begin{array}{c}508 \\
(396-752) \\
510\end{array}$ & $\begin{array}{c}585 \\
(446-909) \\
588\end{array}$ & 491 \\
\hline 14125500 & 21 & $\begin{array}{c}3,300 \\
(2,710-4,000) \\
3,280\end{array}$ & $\begin{array}{c}6,770 \\
(5,420-9,350) \\
6,650\end{array}$ & $\begin{array}{c}9,040 \\
(6,950-13,600) \\
8,810\end{array}$ & $\begin{array}{c}11,000 \\
(8,180-17,500) \\
10,600\end{array}$ & $\begin{array}{c}13,200 \\
(9,490-22,200) \\
12,600\end{array}$ & 9,560 \\
\hline 14126300 & 21 & $\begin{array}{c}44 \\
(38-51) \\
44\end{array}$ & $\begin{array}{r}75 \\
(63-96) \\
75\end{array}$ & $\begin{array}{r}91 \\
(74-124) \\
92\end{array}$ & $\begin{array}{c}104 \\
(83-147) \\
106\end{array}$ & $\begin{array}{c}116 \\
(92-171) \\
118\end{array}$ & 103 \\
\hline 14127000 & 25 & $\begin{array}{c}5,240 \\
(4,710-5,830 \\
5,190\end{array}$ & $\begin{array}{c}7,780 \\
(6,880-9,220) \\
7,680\end{array}$ & $\begin{array}{c}8,950 \\
(7,780-11,000) \\
8,810\end{array}$ & $\begin{array}{c}9,790 \\
(8,400-12,300) \\
9,610\end{array}$ & $\begin{array}{c}10,600 \\
(8,990-13,600) \\
10,400\end{array}$ & 8,880 \\
\hline
\end{tabular}


Table 2. Flood discharges for selected exceedance probabilities at gaging stations on streams with unregulated flow--Continued

\begin{tabular}{|c|c|c|c|c|c|c|c|}
\hline \multirow[b]{2}{*}{ Station number } & \multirow{2}{*}{$\begin{array}{l}\text { Number of } \\
\text { peaks used } \\
\text { in analysis }\end{array}$} & \multicolumn{4}{|c|}{$\begin{array}{l}\text { Flood discharge, in cubic feet per second } \\
\text { (95-percent confidence interval) } \\
\text { Weighted estimate of flood discharge, in cubic feet per second }\end{array}$} & \multirow{2}{*}{$\begin{array}{c}\begin{array}{l}\text { At indicated } \\
\text { exceedance } \\
\text { probabilities }\end{array} \\
0.01\end{array}$} & \multirow{2}{*}{$\begin{array}{l}\text { Maximum } \\
\text { peak used } \\
\text { in analysis } \\
\text { (cubic feet } \\
\text { per second) }\end{array}$} \\
\hline & & 0.5 & 0.1 & 0.04 & 0.02 & & \\
\hline \multirow[t]{2}{*}{14127200} & 10 & $\begin{array}{c}342 \\
(270-434)\end{array}$ & $\begin{array}{r}578 \\
(452-890)\end{array}$ & $\begin{array}{c}696 \\
(528-1,180)\end{array}$ & $\begin{array}{c}783 \\
(580-1,420)\end{array}$ & $\begin{array}{c}871 \\
(630-1,680)\end{array}$ & 575 \\
\hline & & 335 & 556 & 661 & 737 & 812 & \\
\hline \multirow[t]{2}{*}{14128500} & 45 & $\begin{array}{c}13,800 \\
(12,200-15,600)\end{array}$ & $\begin{array}{c}25,900 \\
(22,300-31,200)\end{array}$ & $\begin{array}{c}32,400 \\
(27,400-40,600)\end{array}$ & $\begin{array}{c}37,600 \\
(31,200-48,300)\end{array}$ & $\begin{array}{c}42,800 \\
(35,000-56,400)\end{array}$ & 45,700 \\
\hline & & 13,700 & 25,400 & 31,500 & 36,400 & 41,200 & \\
\hline \multirow[t]{2}{*}{14143200} & 22 & $\begin{array}{c}128 \\
(110-147)\end{array}$ & $\begin{array}{c}220 \\
(18 \dot{6}-279)\end{array}$ & $\begin{array}{c}274 \\
(225-369)\end{array}$ & $\begin{array}{c}317 \\
(255-447)\end{array}$ & $\begin{array}{c}364 \\
(285-534)\end{array}$ & 281 \\
\hline & & 129 & 223 & 279 & 325 & 374 & \\
\hline \multirow[t]{2}{*}{14143500} & 37 & $\begin{array}{c}14,200 \\
(12,900-15,500)\end{array}$ & $\begin{array}{c}22,000 \\
(19,800-25,400)\end{array}$ & $\begin{array}{c}26,200 \\
(23,000-31,200)\end{array}$ & $\begin{array}{c}29,300 \\
(25,400-35,800)\end{array}$ & $\begin{array}{c}32,600 \\
(27,900-40,600)\end{array}$ & 40,400 \\
\hline & & 13,900 & 21,200 & 24,900 & 27,600 & 30,400 & \\
\hline \multirow[t]{2}{*}{14144000} & 17 & $\begin{array}{c}1,250 \\
(1,060-1,460)\end{array}$ & $\begin{array}{c}2,020 \\
(1,700-2,630)\end{array}$ & $\begin{array}{c}2,420 \\
(1,980-3,340)\end{array}$ & $\begin{array}{c}2,720 \\
(2,180-3,910)\end{array}$ & $\begin{array}{c}3,010 \\
(2,370-4,510)\end{array}$ & 2,430 \\
\hline & & 1,240 & 1,990 & 2,380 & 2,670 & 2,960 & \\
\hline \multirow[t]{2}{*}{14144550} & 21 & $\begin{array}{c}76 \\
(65-88)\end{array}$ & $\begin{array}{c}128 \\
(107-165)\end{array}$ & $\begin{array}{c}154 \\
(126-209)\end{array}$ & $\begin{array}{c}174 \\
(140-244)\end{array}$ & $\begin{array}{c}193 \\
(152-281)\end{array}$ & 127 \\
\hline & & 77 & 131 & 159 & 181 & 202 & \\
\hline \multirow[t]{2}{*}{14144600} & 25 & $\begin{array}{c}42 \\
(37-47)\end{array}$ & $\begin{array}{r}68 \\
(59-82)\end{array}$ & $\begin{array}{r}82 \\
(70-105)\end{array}$ & $\begin{array}{c}94 \\
(78-124)\end{array}$ & $\begin{array}{c}106 \\
(86-145)\end{array}$ & 103 \\
\hline & & 41 & 66 & 79 & 89 & 100 & \\
\hline \multirow[t]{2}{*}{14211900} & 23 & $\begin{array}{c}77 \\
(67-88)\end{array}$ & $\begin{array}{r}130 \\
(110-162)\end{array}$ & $\begin{array}{c}159 \\
(132-210)\end{array}$ & $\begin{array}{c}182 \\
(148-251)\end{array}$ & $\begin{array}{c}207 \\
(165-295)\end{array}$ & 176 \\
\hline & & 80 & 142 & 179 & 210 & 245 & \\
\hline \multirow[t]{2}{*}{14212000} & 37 & $\begin{array}{c}832 \\
(746-927)\end{array}$ & $\begin{array}{c}1,370 \\
(1,210-1,620)\end{array}$ & $\begin{array}{c}1,640 \\
(1,420-2,010)\end{array}$ & $\begin{array}{c}1,850 \\
(1,570-2,310)\end{array}$ & $\begin{array}{c}2,050 \\
(1,720-2,620)\end{array}$ & 2,600 \\
\hline & & 832 & 1,370 & 1,650 & 1,860 & 2,070 & \\
\hline \multirow[t]{2}{*}{14213200} & 14 & $\begin{array}{c}5,900 \\
(4,720-7,340)\end{array}$ & $\begin{array}{c}11,100 \\
(8,730-16,400)\end{array}$ & $\begin{array}{c}14,200 \\
(10,700-23,000)\end{array}$ & $\begin{array}{c}16,700 \\
(12,200-29,000)\end{array}$ & $\begin{array}{c}19,400 \\
(13,800-35,800)\end{array}$ & 15,600 \\
\hline & & 5,910 & 11,100 & 14,200 & 16,600 & 19,200 & \\
\hline \multirow[t]{2}{*}{14213500} & 27 & $\begin{array}{c}398 \\
(337-469)\end{array}$ & $\begin{array}{r}759 \\
(627-987)\end{array}$ & $\begin{array}{c}960 \\
(770-1,320)\end{array}$ & $\begin{array}{c}1,120 \\
(878-1,590)\end{array}$ & $\begin{array}{c}1,280 \\
(985-1,890)\end{array}$ & 1,070 \\
\hline & & 406 & 790 & 1,020 & 1,200 & 1,390 & \\
\hline \multirow[t]{2}{*}{14214000} & 10 & $\begin{array}{c}471 \\
(344-648)\end{array}$ & $\begin{array}{c}952 \\
(686-1,700)\end{array}$ & $\begin{array}{c}1,220 \\
(842-2,490)\end{array}$ & $\begin{array}{c}1,430 \\
(956-3,190)\end{array}$ & $\begin{array}{c}1,650 \\
(1,070-3,980)\end{array}$ & 1,180 \\
\hline & & 463 & 905 & 1,130 & 1,310 & 1,480 & \\
\hline \multirow[t]{2}{*}{14214500} & 13 & $\begin{array}{c}278 \\
(234-329)\end{array}$ & $\begin{array}{c}447 \\
(371-604)\end{array}$ & $\begin{array}{c}539 \\
(434-788)\end{array}$ & $\begin{array}{c}610 \\
(480-944)\end{array}$ & $\begin{array}{c}684 \\
(526-1,120)\end{array}$ & 528 \\
\hline & & 290 & 493 & 620 & 725 & 839 & \\
\hline \multirow[t]{2}{*}{14215000} & 21 & $\begin{array}{c}720 \\
(602-858)\end{array}$ & $\begin{array}{c}1,390 \\
1,130-1,860)\end{array}$ & $\begin{array}{c}1,810 \\
(1,420-2,620)\end{array}$ & $\begin{array}{c}2,170 \\
(1,660-3,320)\end{array}$ & $\begin{array}{c}2,560 \\
(1,900-4,140)\end{array}$ & 2,750 \\
\hline & & 735 & 1,440 & 1,900 & 2,290 & 2,720 & \\
\hline
\end{tabular}


Table 2. Flood discharges for selected exceedance probabilities at gaging stations on streams with unregulated flow--Continued

\begin{tabular}{|c|c|c|c|c|c|c|c|}
\hline \multirow[b]{2}{*}{ Station number } & \multirow{2}{*}{$\begin{array}{l}\text { Number of } \\
\text { peaks used } \\
\text { in analysis }\end{array}$} & \multicolumn{4}{|c|}{$\begin{array}{l}\text { Flood discharge, in cubic feet per second } \\
\text { (95-percent confidence interval) } \\
\text { Weighted estimate of flood discharge, in cubic feet per second }\end{array}$} & \multirow{2}{*}{$\begin{array}{l}\begin{array}{l}\text { At indicated } \\
\text { exceedance } \\
\text { probabilities }\end{array} \\
0.01\end{array}$} & \multirow{2}{*}{$\begin{array}{l}\text { Maximum } \\
\text { peak used } \\
\text { in analysis } \\
\text { (cubic feet } \\
\text { per second) }\end{array}$} \\
\hline & & 0.5 & 0.1 & 0.04 & 0.02 & & \\
\hline 14215500 & 19 & $\begin{array}{c}582 \\
(443-764) \\
588\end{array}$ & $\begin{array}{c}1,450 \\
(1,060-2,270) \\
1,450\end{array}$ & $\begin{array}{c}2,040 \\
(1,430-3,560) \\
2,020\end{array}$ & $\begin{array}{c}2,550 \\
(1,720-4,800) \\
2,490\end{array}$ & $\begin{array}{c}3,130 \\
(2,040-6,310) \\
3,020\end{array}$ & 1,880 \\
\hline 14216000 & 28 & $\begin{array}{c}9,310 \\
(7,690-11,300) \\
9,340\end{array}$ & $\begin{array}{c}19,500 \\
(15,600-26,400) \\
19,500\end{array}$ & $\begin{array}{c}25,200 \\
(19,600-36,100) \\
25,100\end{array}$ & $\begin{array}{c}29,600 \\
(22,500-44,100) \\
29,500\end{array}$ & $\begin{array}{c}34,200 \\
(25,400-52,800) \\
34,000\end{array}$ & 27,000 \\
\hline 14216500 & 39 & $\begin{array}{c}6,450 \\
(5,670-7,310) \\
6,470\end{array}$ & $\begin{array}{c}12,400 \\
(10,600-15,100) \\
12,500\end{array}$ & $\begin{array}{c}16,100 \\
(13,400-20,600) \\
16,200\end{array}$ & $\begin{array}{c}19,300 \\
(15,700-25,600) \\
19,400\end{array}$ & $\begin{array}{c}22,800 \\
(18,200-31,300) \\
22,900\end{array}$ & 30,600 \\
\hline 14216800 & 13 & $\begin{array}{c}978 \\
(817-1,170) \\
1,010\end{array}$ & $\begin{array}{c}1,590 \\
(1,310-2,180) \\
1,720\end{array}$ & $\begin{array}{c}1,900 \\
(1,520-2,820) \\
2,130\end{array}$ & $\begin{array}{c}2,150 \\
(1,680-3,350) \\
2,480\end{array}$ & $\begin{array}{c}2,390 \\
(1,830-3,920) \\
2,850\end{array}$ & 1,840 \\
\hline 14218000 & 33 & $\begin{array}{c}18,500 \\
(16,300-21,000) \\
18,600\end{array}$ & $\begin{array}{c}32,500 \\
(28,000-39,700) \\
32,900\end{array}$ & $\begin{array}{c}40,100 \\
(33,600-51,100) \\
40,800\end{array}$ & $\begin{array}{c}45,900 \\
(37,800-60,300) \\
47,000\end{array}$ & $\begin{array}{c}51,900 \\
(42,100-70,100) \\
53,500\end{array}$ & 54,400 \\
\hline 14218300 & 18 & $\begin{array}{c}311 \\
(268-359) \\
307\end{array}$ & $\begin{array}{r}507 \\
(430-648) \\
497\end{array}$ & $\begin{array}{c}616 \\
(508-838) \\
601\end{array}$ & $\begin{array}{c}702 \\
(566-999) \\
686\end{array}$ & $\begin{array}{c}792 \\
(625-1,180) \\
773\end{array}$ & 724 \\
\hline 14219000 & 12 & $\begin{array}{c}5,910 \\
(4,750-7,340) \\
5,750\end{array}$ & $\begin{array}{c}10,400 \\
(8,240-15,400) \\
9,860\end{array}$ & $\begin{array}{c}12,900 \\
(9,860-21,000) \\
12,000\end{array}$ & $\begin{array}{c}14,900 \\
(11,000-25,800) \\
13,700\end{array}$ & $\begin{array}{c}16,900 \\
(12,200-31,300) \\
15,300\end{array}$ & 11,700 \\
\hline 14219500 & 20 & $\begin{array}{c}33,600 \\
(27,800-40,700) \\
33,500\end{array}$ & $\begin{array}{c}62,200 \\
(50,100-85,000) \\
61,600\end{array}$ & $\begin{array}{c}77,000 \\
(60,300-112,000) \\
76,300\end{array}$ & $\begin{array}{c}88,100 \\
(67,600-134,000) \\
87,000\end{array}$ & $\begin{array}{c}99,200 \\
(74,600-156,000) \\
97,900\end{array}$ & 79,300 \\
\hline 14219800 & 37 & $\begin{array}{c}1,700 \\
(1,500-1,940) \\
1,670\end{array}$ & $\begin{array}{c}3,000 \\
(2,580-3,660) \\
2,900\end{array}$ & $\begin{array}{c}3,640 \\
(3,070-4,600) \\
3,480\end{array}$ & $\begin{array}{c}4,110 \\
(3,410-5,320) \\
3,900\end{array}$ & $\begin{array}{c}4,580 \\
(3,740-6,050) \\
4,330\end{array}$ & 3,600 \\
\hline 14221500 & 13 & $\begin{array}{c}1,480 \\
(1,290-1,690) \\
1,490\end{array}$ & $\begin{array}{c}2,150 \\
(1,860-2,730) \\
2,220\end{array}$ & $\begin{array}{c}2,490 \\
(2,100-3,360) \\
2,630\end{array}$ & $\begin{array}{c}2,750 \\
(2,270-3,880) \\
2,950\end{array}$ & $\begin{array}{c}3,000 \\
(2,440-4,420) \\
3,290\end{array}$ & 2,230 \\
\hline 14222500 & 67 & $\begin{array}{c}8,900 \\
(8,220-9,640) \\
8,860\end{array}$ & $\begin{array}{c}14,700 \\
(13,400-16,600) \\
14,600\end{array}$ & $\begin{array}{c}17,700 \\
(15,800-20,400) \\
17,500\end{array}$ & $\begin{array}{c}19,900 \\
(17,600-23,400) \\
19,700\end{array}$ & $\begin{array}{c}22,200 \\
(19,400-26,400) \\
21,900\end{array}$ & 28,600 \\
\hline 14222700 & 18 & $\begin{array}{c}36 \\
(28-44) \\
35\end{array}$ & $\begin{array}{r}77 \\
(60-113) \\
74\end{array}$ & $\begin{array}{r}105 \\
(78-171) \\
98\end{array}$ & $\begin{array}{c}130 \\
(93-228) \\
118\end{array}$ & $\begin{array}{c}159 \\
(109-298) \\
140\end{array}$ & 192 \\
\hline 14223000 & 31 & $\begin{array}{c}7,580 \\
(6,780-8,430) \\
7,590\end{array}$ & $\begin{array}{c}12,800 \\
(11,200-15,200) \\
12,900\end{array}$ & $\begin{array}{c}16,100 \\
(13,700-20,100) \\
16,200\end{array}$ & $\begin{array}{c}18,900 \\
(15,700-24,500) \\
19,000\end{array}$ & $\begin{array}{c}21,900 \\
(17,900-29,600) \\
22,000\end{array}$ & 42,000 \\
\hline 14223500 & 34 & $\begin{array}{c}10,400 \\
(9,580-11,400) \\
10,300\end{array}$ & $\begin{array}{c}15,600 \\
(14,100-17,900) \\
15,500\end{array}$ & $\begin{array}{c}18,400 \\
(16,300-21,800) \\
18,300\end{array}$ & $\begin{array}{c}20,600 \\
(18,000-25,100) \\
20,500\end{array}$ & $\begin{array}{c}22,900 \\
(19,700-28,500) \\
22,800\end{array}$ & 24,000 \\
\hline
\end{tabular}


Table 2. Flood discharges for selected exceedance probabilities at gaging stations on streams with unregulated flow--Continued

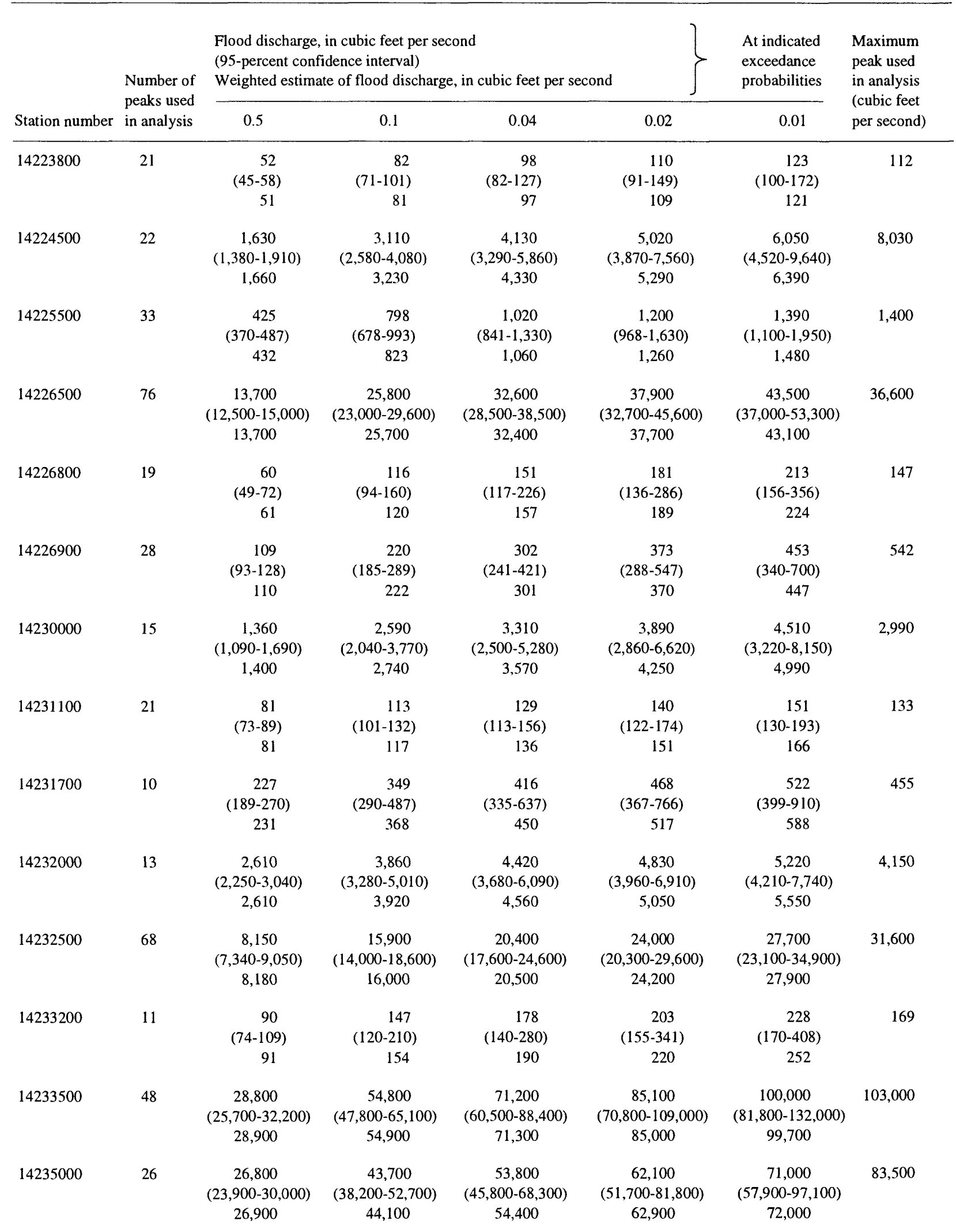


Table 2. Flood discharges for selected exceedance probabilities at gaging stations on streams with unregulated flow--Continued

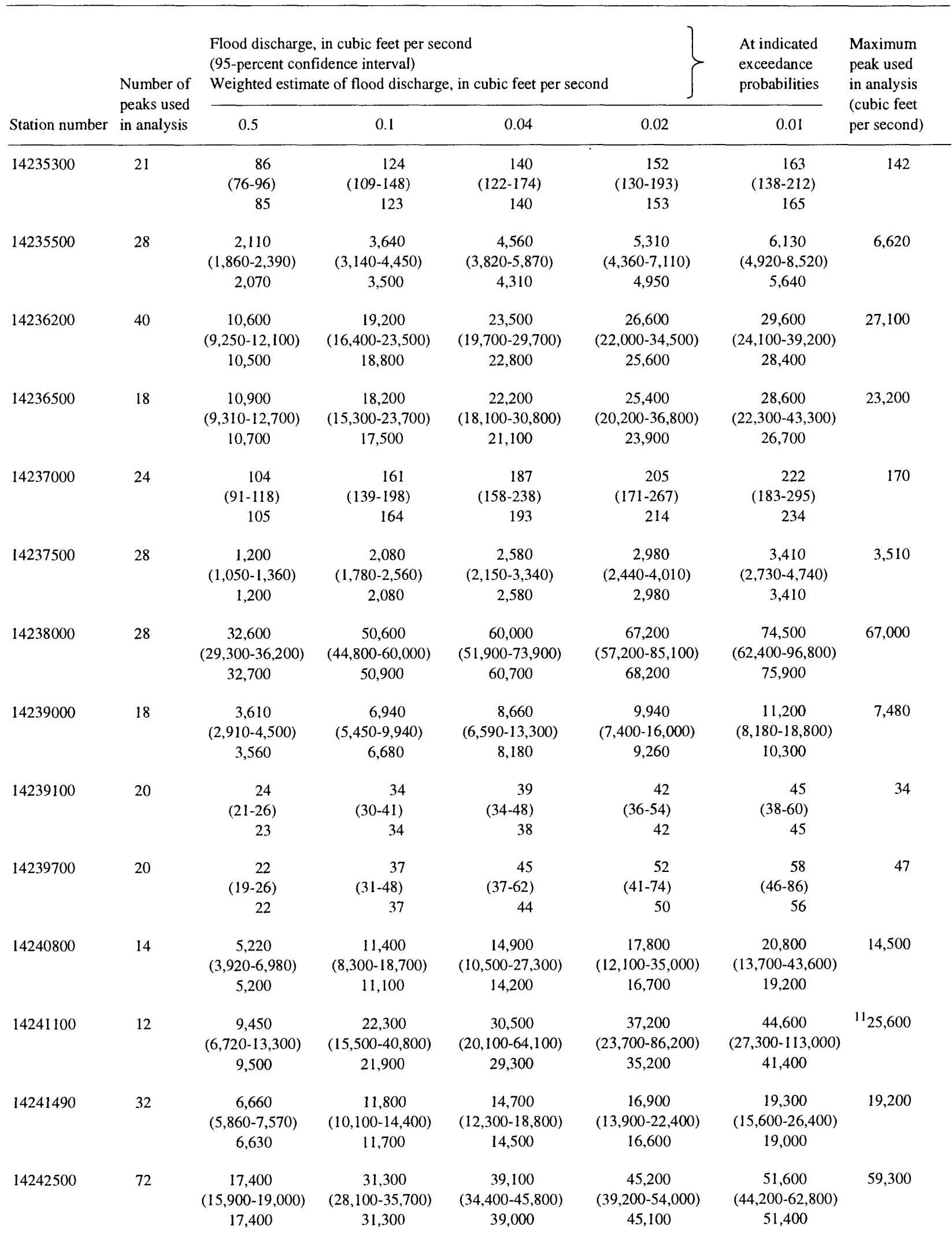


Table 2. Flood discharges for selected exceedance probabilities at gaging stations on streams with unregulated flow--Continued

\begin{tabular}{|c|c|c|c|c|c|c|c|}
\hline \multirow[b]{2}{*}{ Station number } & \multirow{2}{*}{$\begin{array}{l}\text { Number of } \\
\text { peaks used } \\
\text { in analysis }\end{array}$} & \multicolumn{4}{|c|}{$\begin{array}{l}\text { Flood discharge, in cubic feet per second } \\
\text { (95-percent confidence interval) } \\
\text { Weighted estimate of flood discharge, in cubic feet per second }\end{array}$} & \multirow{2}{*}{$\begin{array}{c}\begin{array}{l}\text { At indicated } \\
\text { exceedance } \\
\text { probabilities }\end{array} \\
0.01\end{array}$} & \multirow{2}{*}{$\begin{array}{l}\text { Maximum } \\
\text { peak used } \\
\text { in analysis } \\
\text { (cubic feet } \\
\text { per second) }\end{array}$} \\
\hline & & 0.5 & 0.1 & 0.04 & 0.02 & & \\
\hline 14242600 & 21 & $\begin{array}{c}39 \\
(33-47) \\
39\end{array}$ & $\begin{array}{r}76 \\
(62-104) \\
75\end{array}$ & $\begin{array}{c}98 \\
(77-143) \\
95\end{array}$ & $\begin{array}{c}116 \\
(88-178) \\
112\end{array}$ & $\begin{array}{c}135 \\
(100-217) \\
129\end{array}$ & 99 \\
\hline 14243000 & 36 & $\begin{array}{l}51,200 \\
(46,900-56,000) \\
51,200\end{array}$ & $\begin{array}{c}75,700 \\
(68,200-86,800) \\
76,100\end{array}$ & $\begin{array}{l}86,700 \\
(76,900-102,000) \\
87,500\end{array}$ & $\begin{array}{l}94,400 \\
(82,900-113,000) \\
95,700\end{array}$ & $\begin{array}{l}102,000 \\
(88,500-124,000) \\
104,000\end{array}$ & 139,000 \\
\hline 14243500 & 21 & $\begin{array}{c}1,280 \\
(1,090-1,500) \\
1,270\end{array}$ & $\begin{array}{c}2,220 \\
(1,860-2,880) \\
2,170\end{array}$ & $\begin{array}{c}2,750 \\
(2,230-3,800) \\
2,660\end{array}$ & $\begin{array}{c}3,170 \\
(2,520-4,590) \\
3,040\end{array}$ & $\begin{array}{c}3,620 \\
(2,800-5,460) \\
3,440\end{array}$ & 3,500 \\
\hline 14245000 & 36 & $\begin{array}{c}4,970 \\
(4,510-5,470) \\
4,950\end{array}$ & $\begin{array}{c}7,950 \\
(7,080-9,260) \\
7,900\end{array}$ & $\begin{array}{c}9,610 \\
(8,380-11,600) \\
9,530\end{array}$ & $\begin{array}{c}10,900 \\
(9,360-13,600) \\
10,800\end{array}$ & $\begin{array}{c}12,300 \\
(10,400-15,700) \\
12,200\end{array}$ & 11,700 \\
\hline 14247500 & 39 & $\begin{array}{c}4,900 \\
(4,500-5,350) \\
4,860\end{array}$ & $\begin{array}{c}7,400 \\
(6,670-8,460) \\
7,320\end{array}$ & $\begin{array}{c}8,590 \\
(7,620-10,100) \\
8,490\end{array}$ & $\begin{array}{c}9,450 \\
(8,290-11,300) \\
9,360\end{array}$ & $\begin{array}{c}10,300 \\
(8,930-12,500) \\
10,200\end{array}$ & 8,900 \\
\hline 14248100 & 22 & $\begin{array}{c}78 \\
(64-94) \\
79\end{array}$ & $\begin{array}{c}148 \\
(120-201) \\
150\end{array}$ & $\begin{array}{c}186 \\
(146-268) \\
190\end{array}$ & $\begin{array}{c}214 \\
(164-322) \\
221\end{array}$ & $\begin{array}{c}243 \\
(183-379) \\
252\end{array}$ & 151 \\
\hline 14248200 & 15 & $\begin{array}{c}560 \\
(473-663) \\
548\end{array}$ & $\begin{array}{c}918 \\
(762-1,230) \\
884\end{array}$ & $\begin{array}{c}1,110 \\
(892-1,580) \\
1,060\end{array}$ & $\begin{array}{c}1,250 \\
(986-1,880) \\
1,180\end{array}$ & $\begin{array}{c}1,400 \\
(1,080-2,190) \\
1,320\end{array}$ & 1,020 \\
\hline 14249000 & 24 & $\begin{array}{c}5,370 \\
(4,760-6,060) \\
5,260\end{array}$ & $\begin{array}{c}8,320 \\
(7,240-10,100) \\
8,060\end{array}$ & $\begin{array}{c}9,720 \\
(8,290-12,300) \\
7,170\end{array}$ & $\begin{array}{c}10,700 \\
(9,030-13,900) \\
10,300\end{array}$ & $\begin{array}{c}11,700 \\
(9,730-15,600) \\
11,200\end{array}$ & 9,280 \\
\hline 14250500 & 21 & $\begin{array}{c}2,420 \\
(2,130-2,740) \\
2,350\end{array}$ & $\begin{array}{c}3,820 \\
(3,310-4,710) \\
3,640\end{array}$ & $\begin{array}{c}4,590 \\
(3,870-5,950) \\
4,290\end{array}$ & $\begin{array}{c}5,180 \\
(4,290-6,980) \\
4,800\end{array}$ & $\begin{array}{c}5,800 \\
(4,710-8,100) \\
5,320\end{array}$ & 4,770 \\
\hline
\end{tabular}

\footnotetext{
1 Maximum peak of record $\left(35,000 \mathrm{ft}^{3} / \mathrm{s}\right.$ on December 10, 1933) was not used in analysis because it resulted from a dam failure.

2 Maximum peak of record $\left(445 \mathrm{ft}^{3} / \mathrm{s}\right.$ on January 15,1961$)$ was not used in analysis because it was caused in part by failure of a large beaver dam.

3 Maximum peak of record $\left(39,500 \mathrm{ft}^{3} / \mathrm{s}\right.$ on February 8, 1996) was not used in analysis because it was affected by regulation.

4 Historic peak of 1897 (about 70,000 $\mathrm{ft}^{3} / \mathrm{s}$ ) was not used in analysis because it is significantly below the high-outlier threshold.

5 Historic peak of June $1984\left(195,000 \mathrm{ft}^{3} / \mathrm{s}\right)$ was not used in analysis because it is significantly below the high-outlier threshold.

6 Historic peak of May 6, $1948\left(1,770 \mathrm{ft}^{3} / \mathrm{s}\right)$ was not used in analysis because it is significantly below the high-outlier threshold.

7 Historic peaks of February 26, $1957\left(2,200 \mathrm{ft}^{3} / \mathrm{s}\right)$ and January 24, $1959\left(1,010 \mathrm{ft}^{3} / \mathrm{s}\right)$ were not used in analysis because both are significantly below the high-outlier threshold.

8 Historic peak of April 12, $1950\left(484 \mathrm{ft}^{3} / \mathrm{s}\right)$ was not used in analysis because it is significantly below the high-outlier threshold.

9 Maximum peak of record $\left(8,910 \mathrm{ft}^{3} / \mathrm{s}\right.$ on December 22,1933$)$ was not used in analysis because it was affected by regulation.

10 Maximum peak of record $\left(45,200 \mathrm{ft}^{3} / \mathrm{s}\right.$ on February 8,1996$)$ was not used in analysis because it resulted from the failure of a flashboard on Condit Dam.

11 Maximum peak of record $\left(34,000 \mathrm{ft}^{3} / \mathrm{s}\right.$ on March 19, 1982) was not used in analysis because it was affected by an eruption of Mount St. Helens.
} 


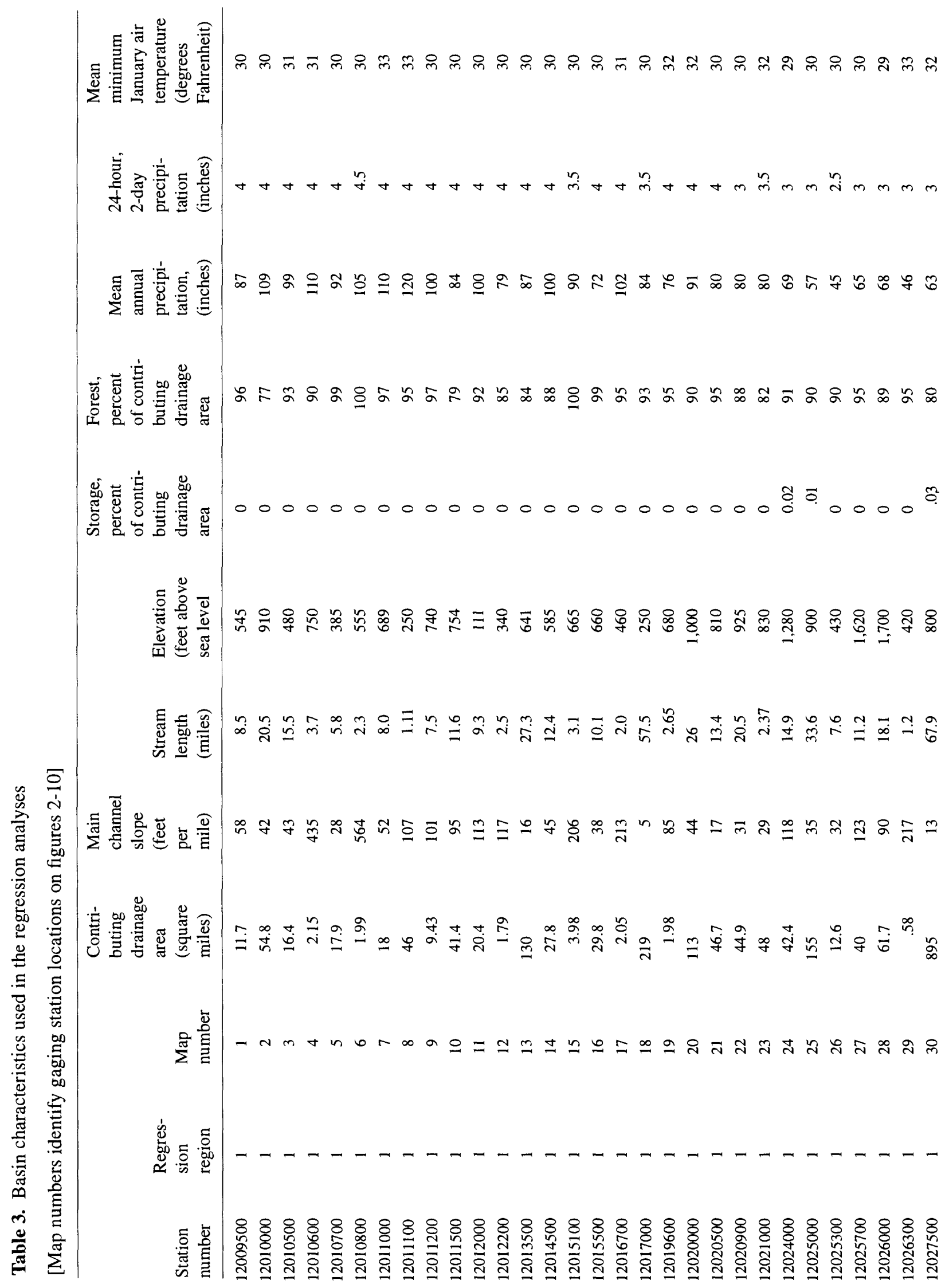




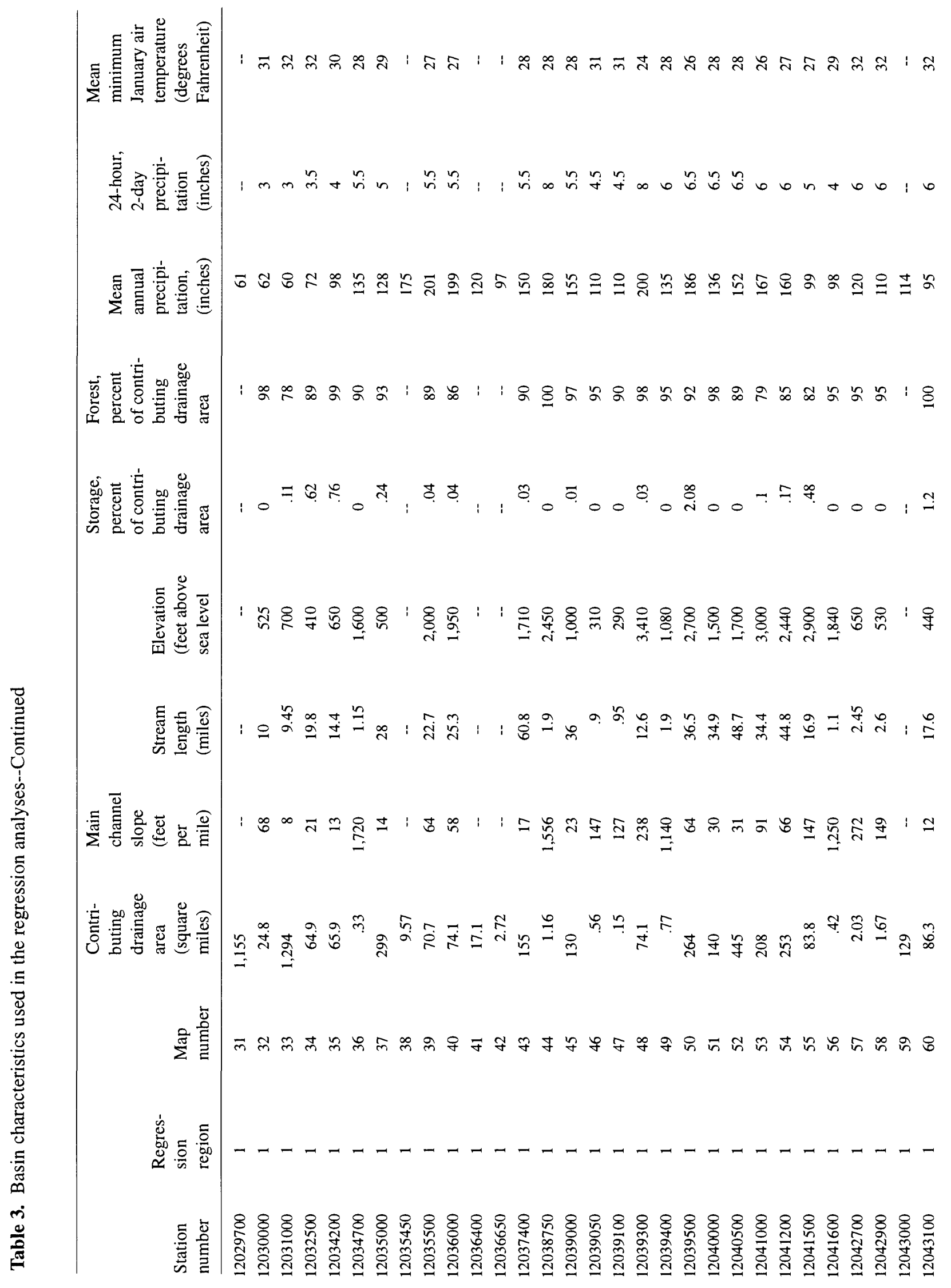




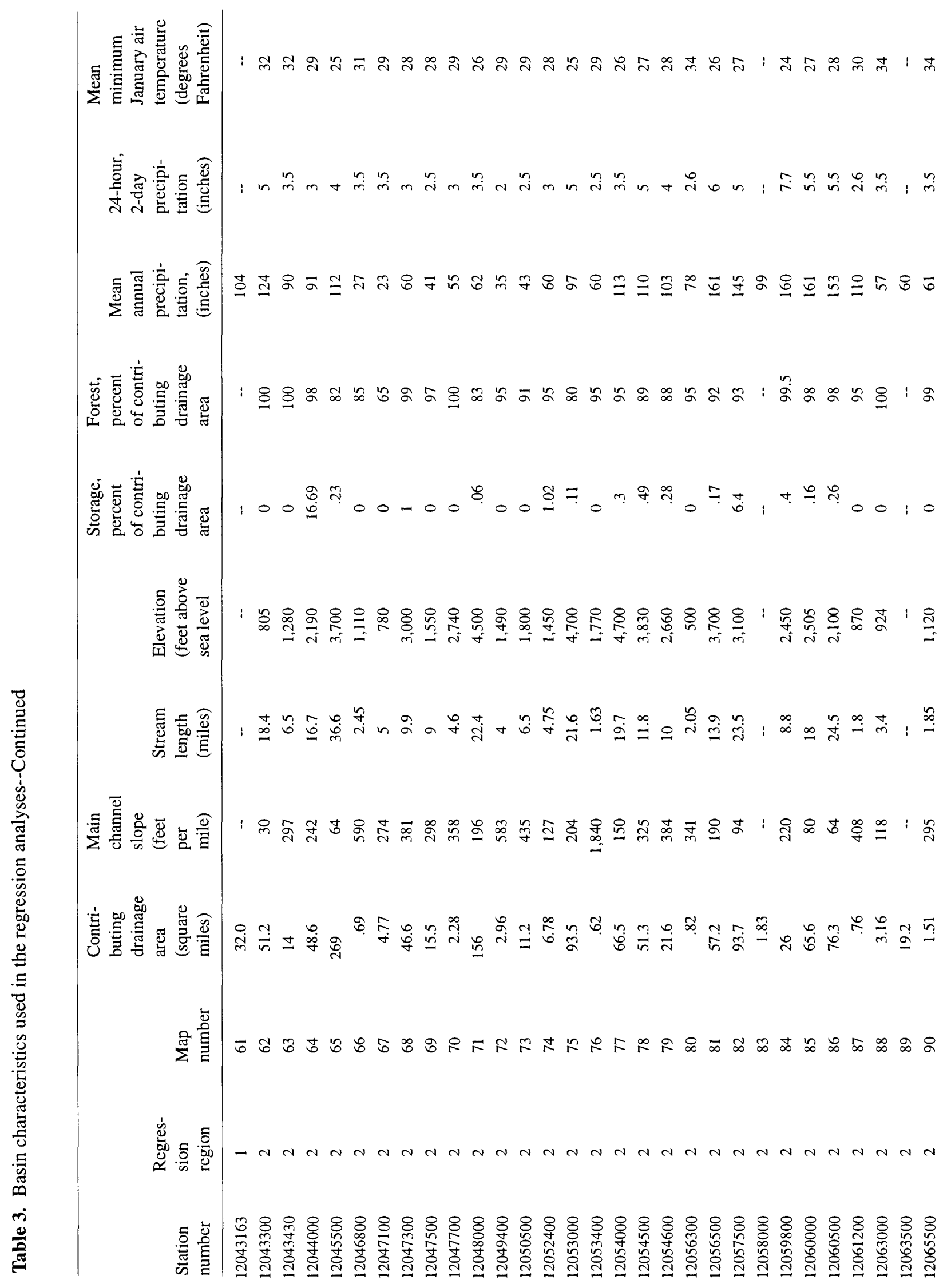




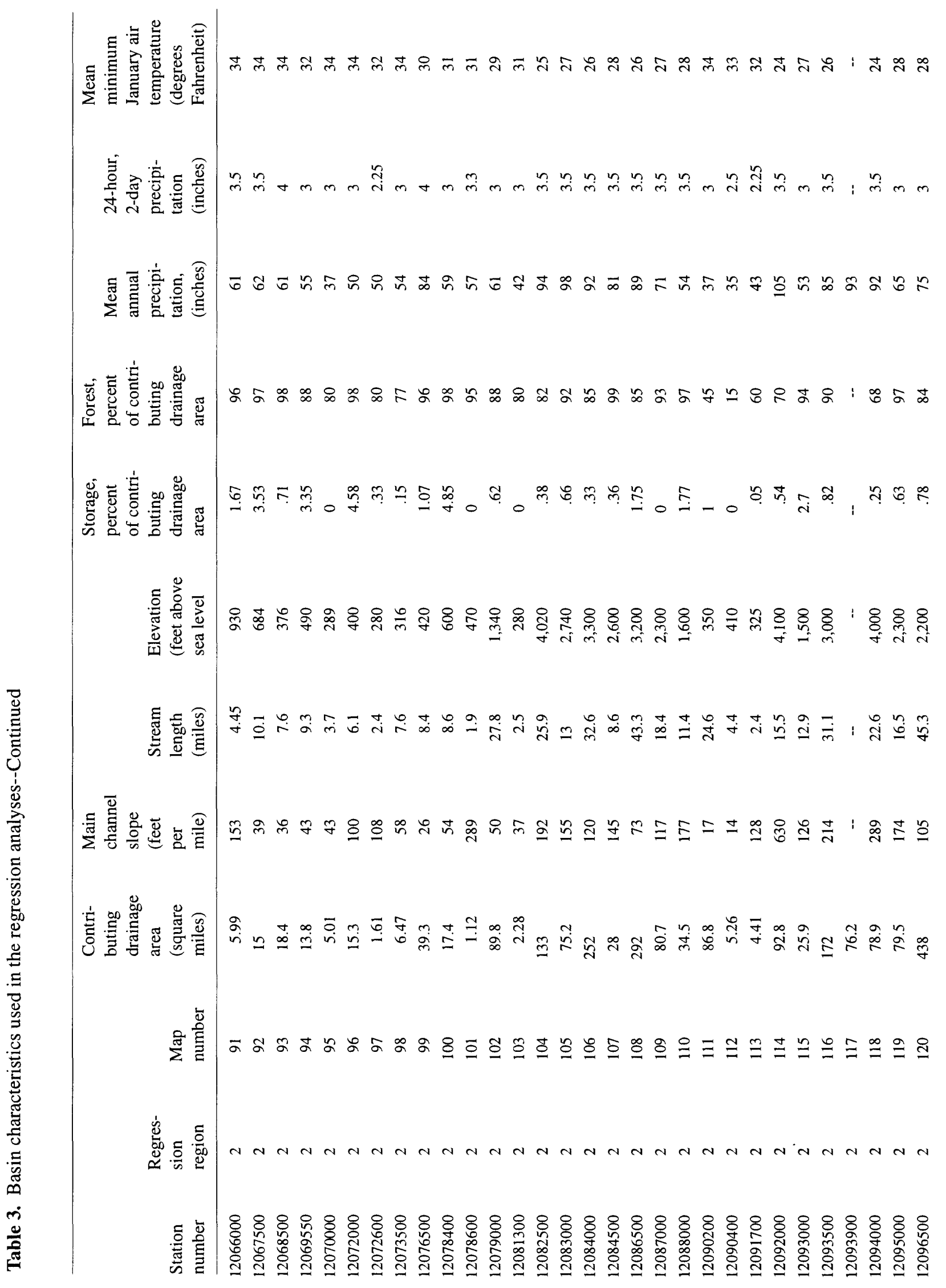




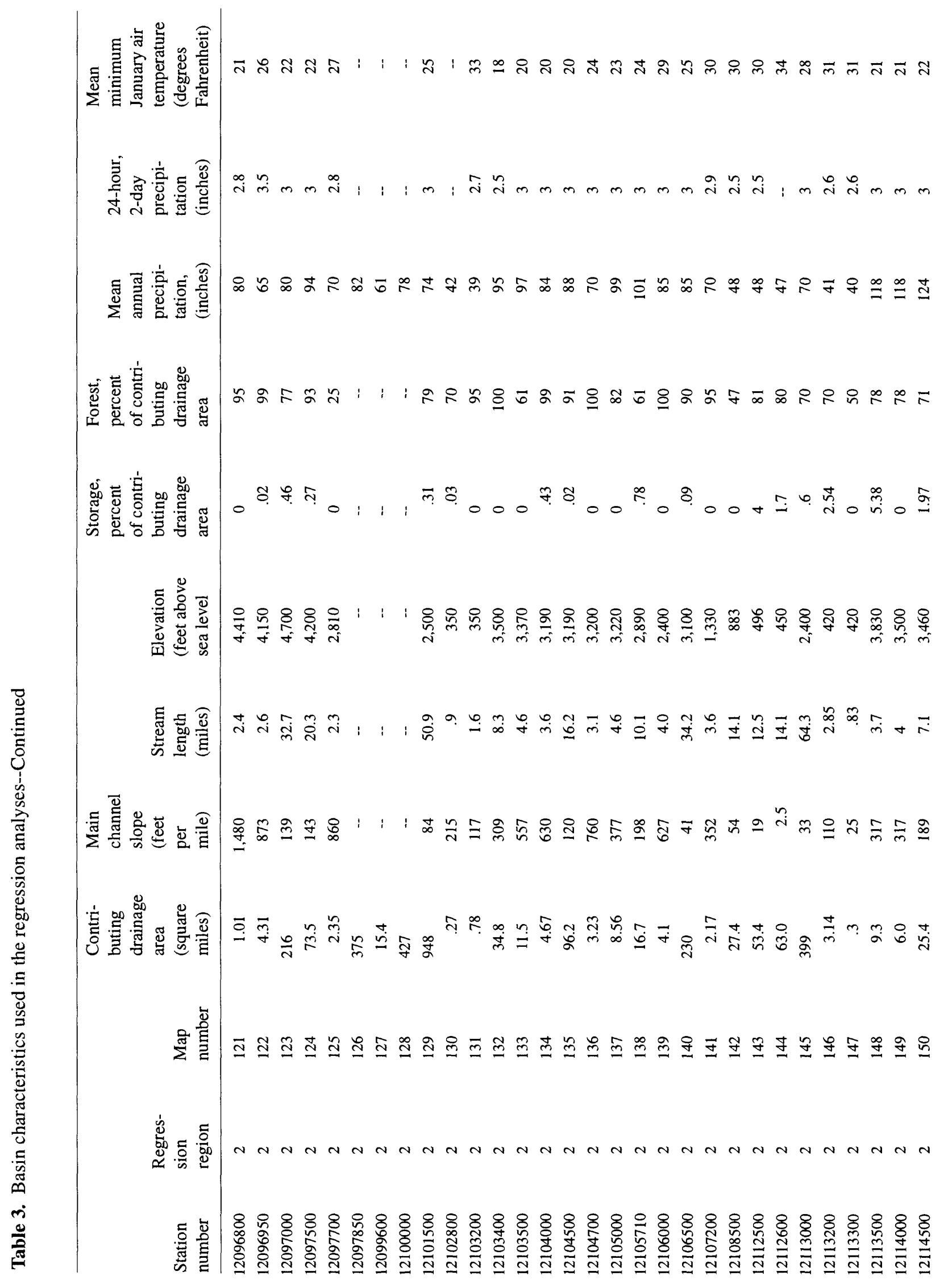




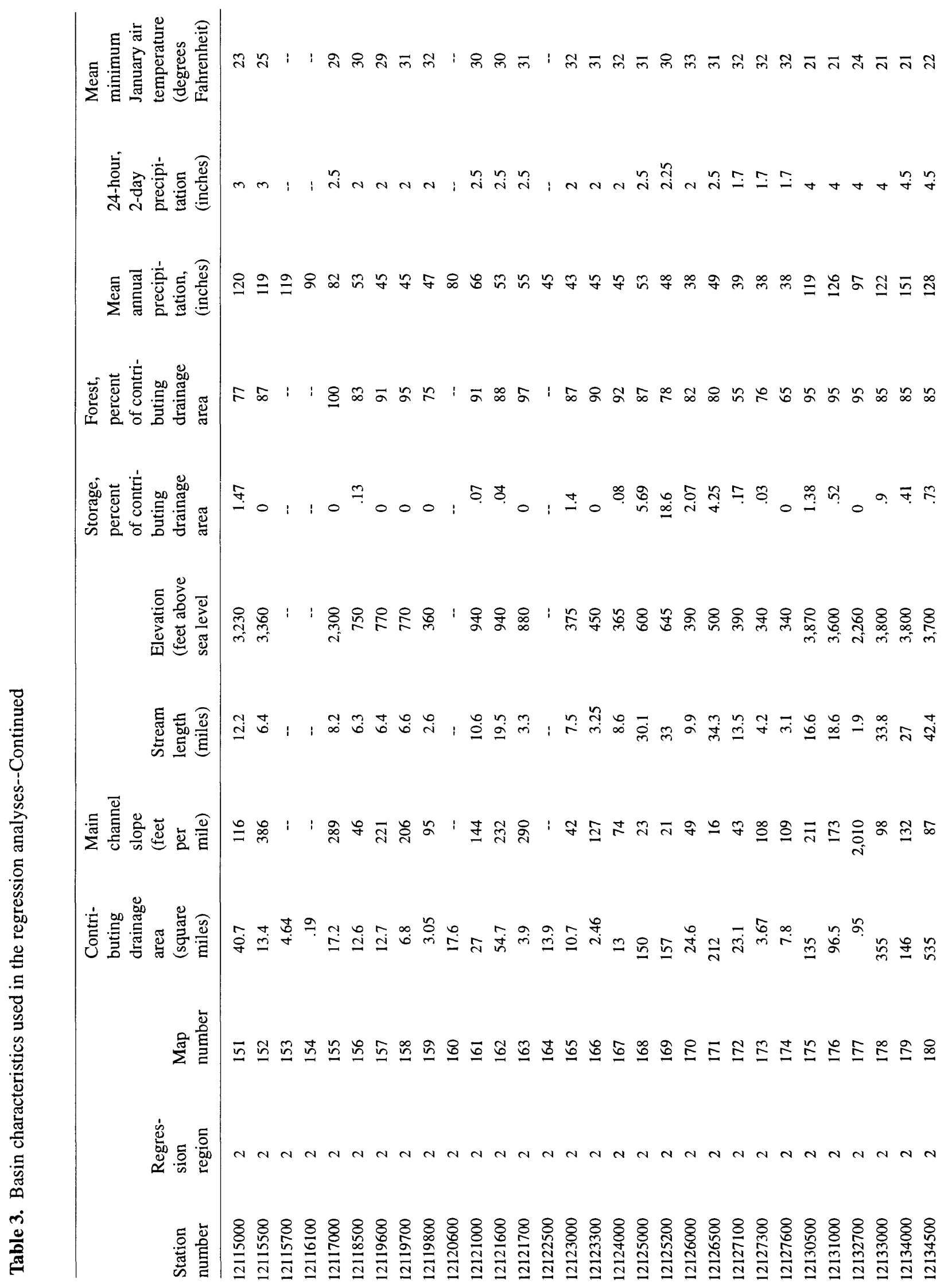




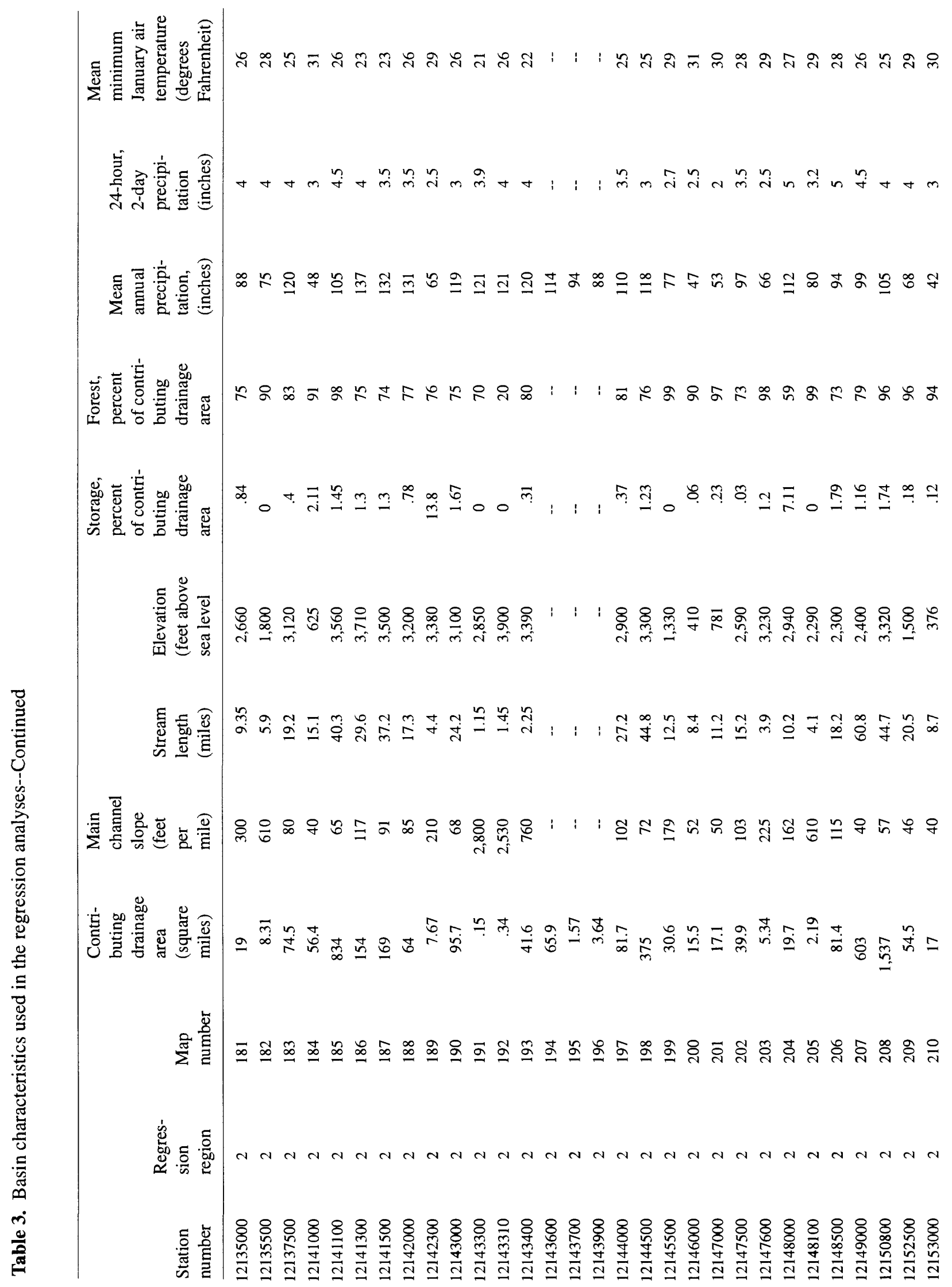




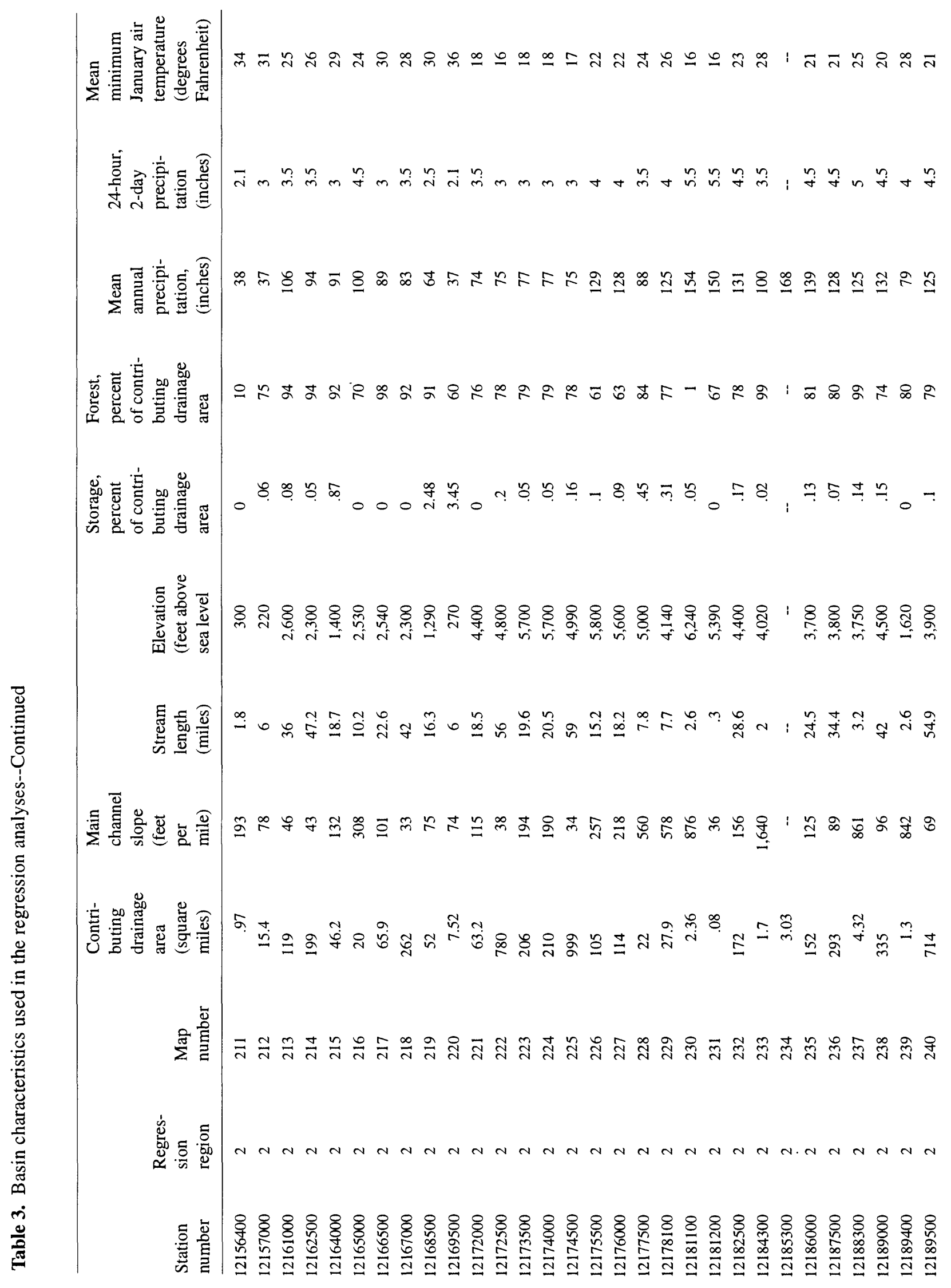




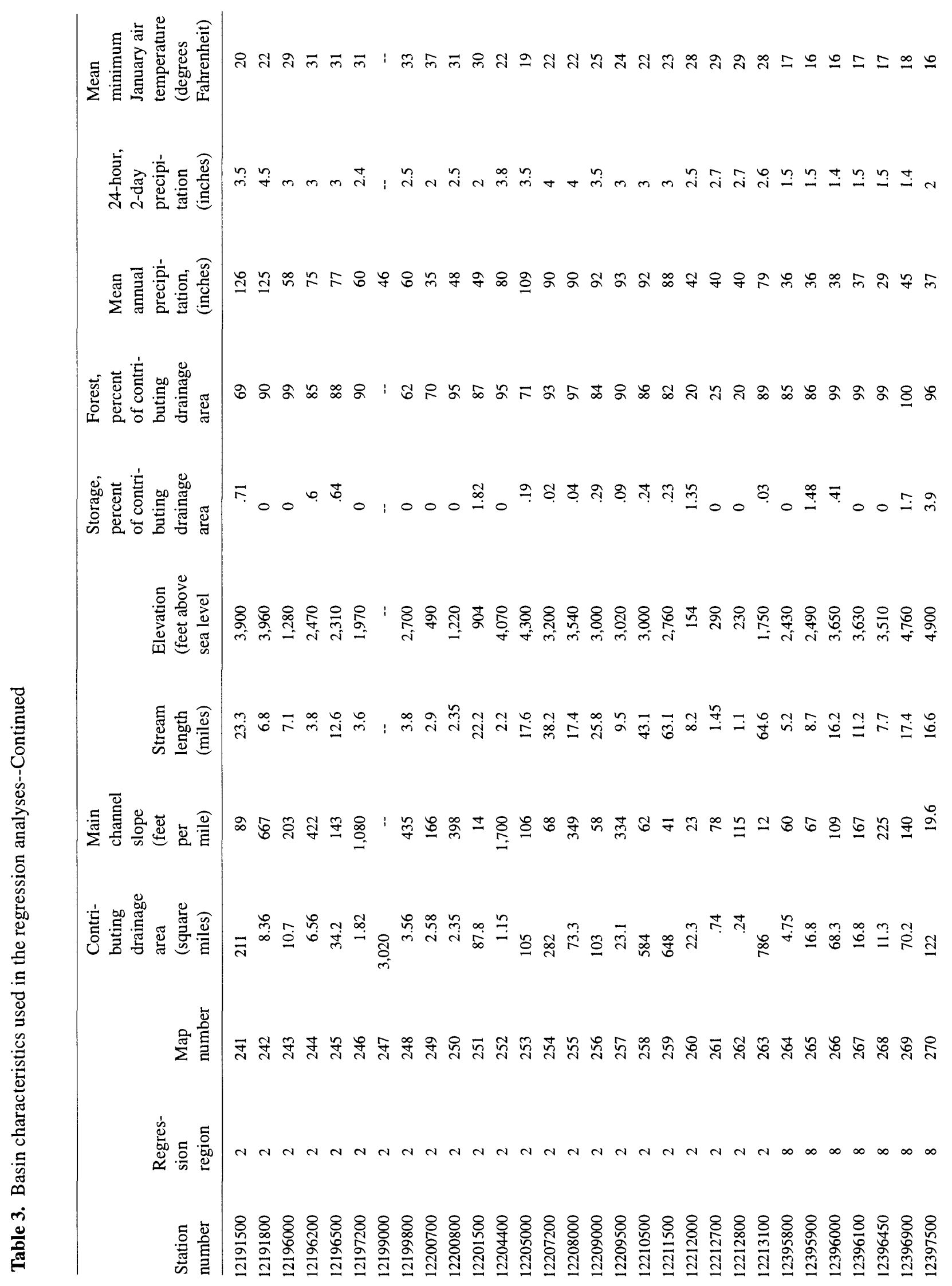




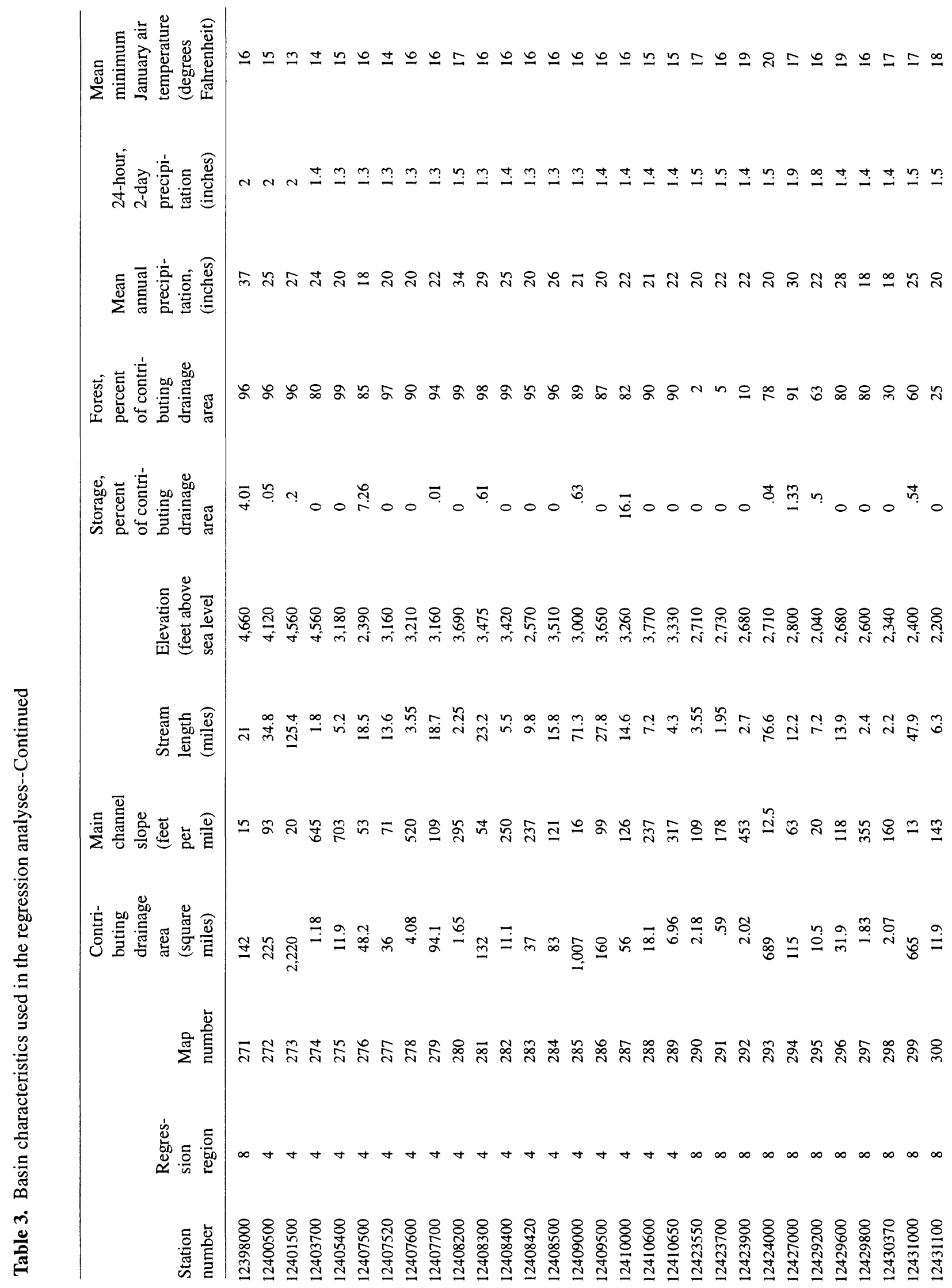




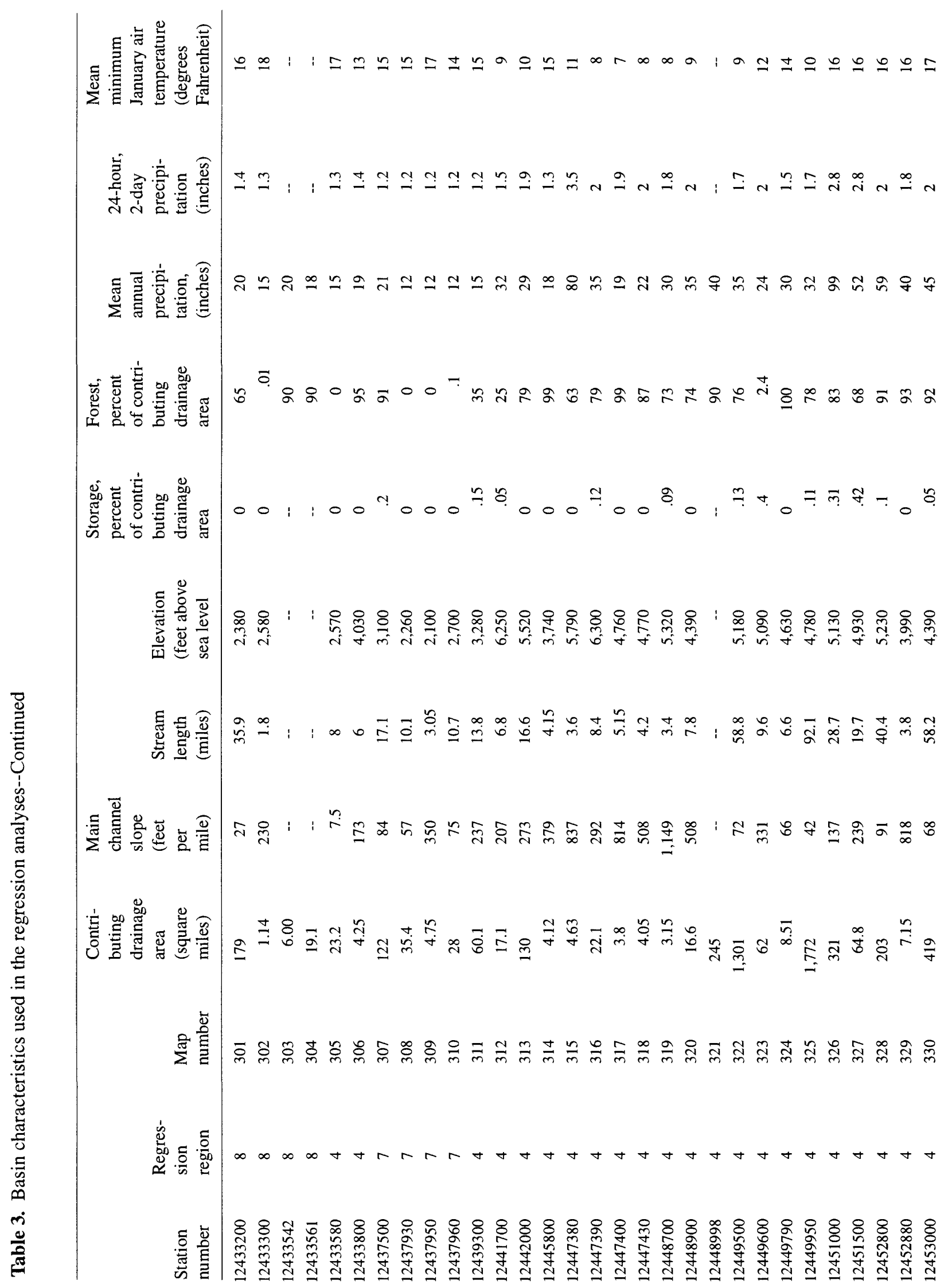




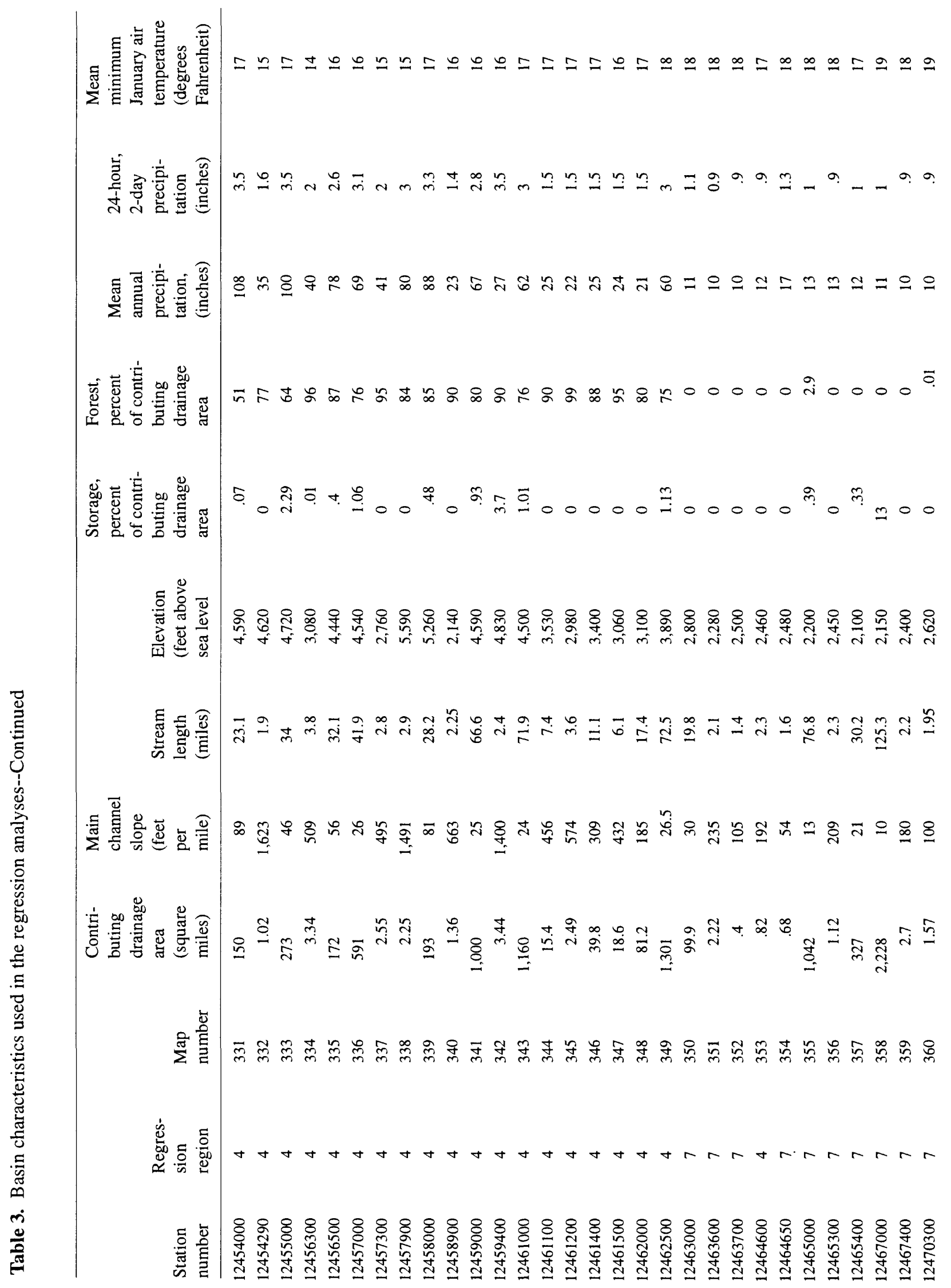




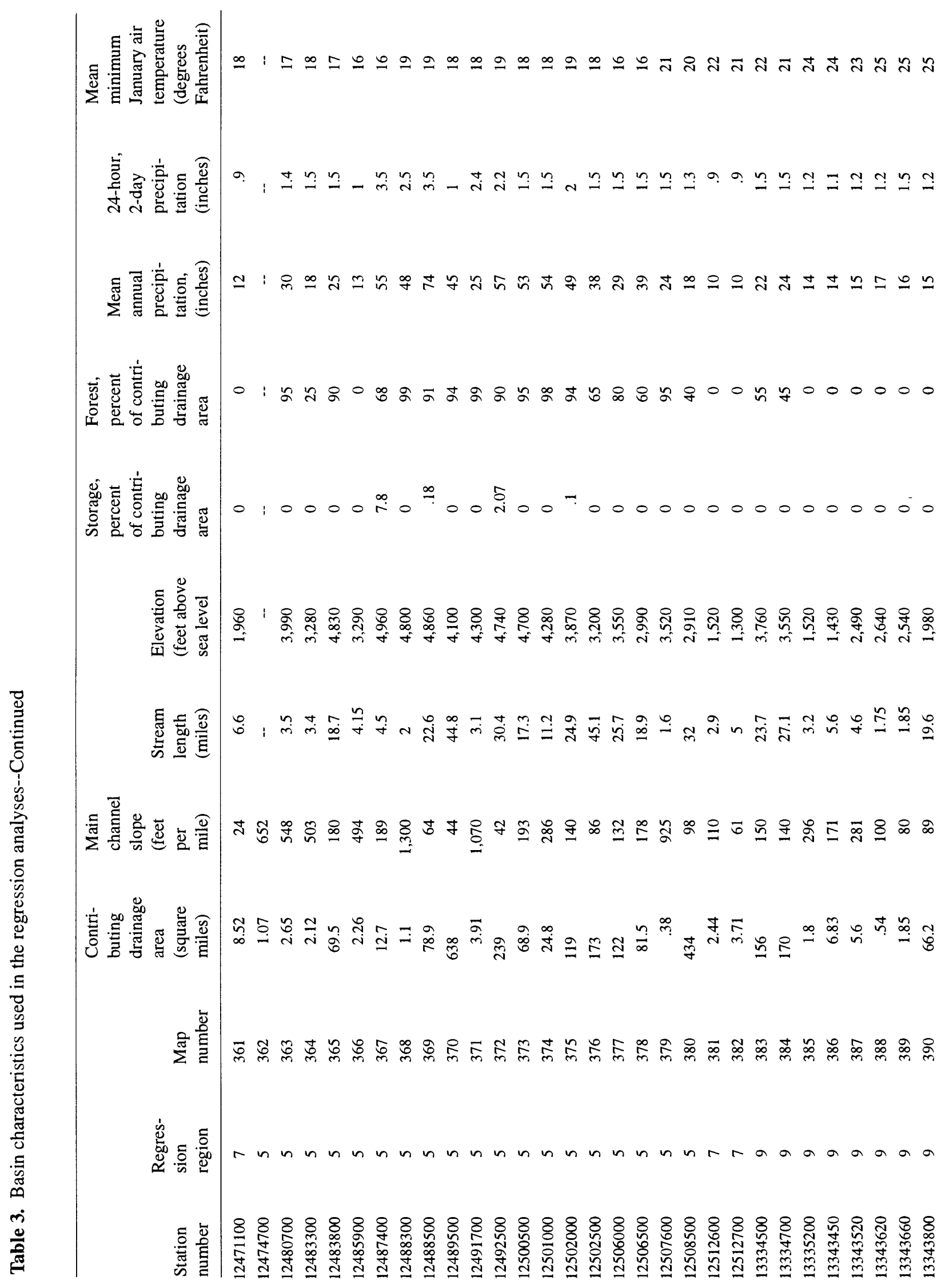




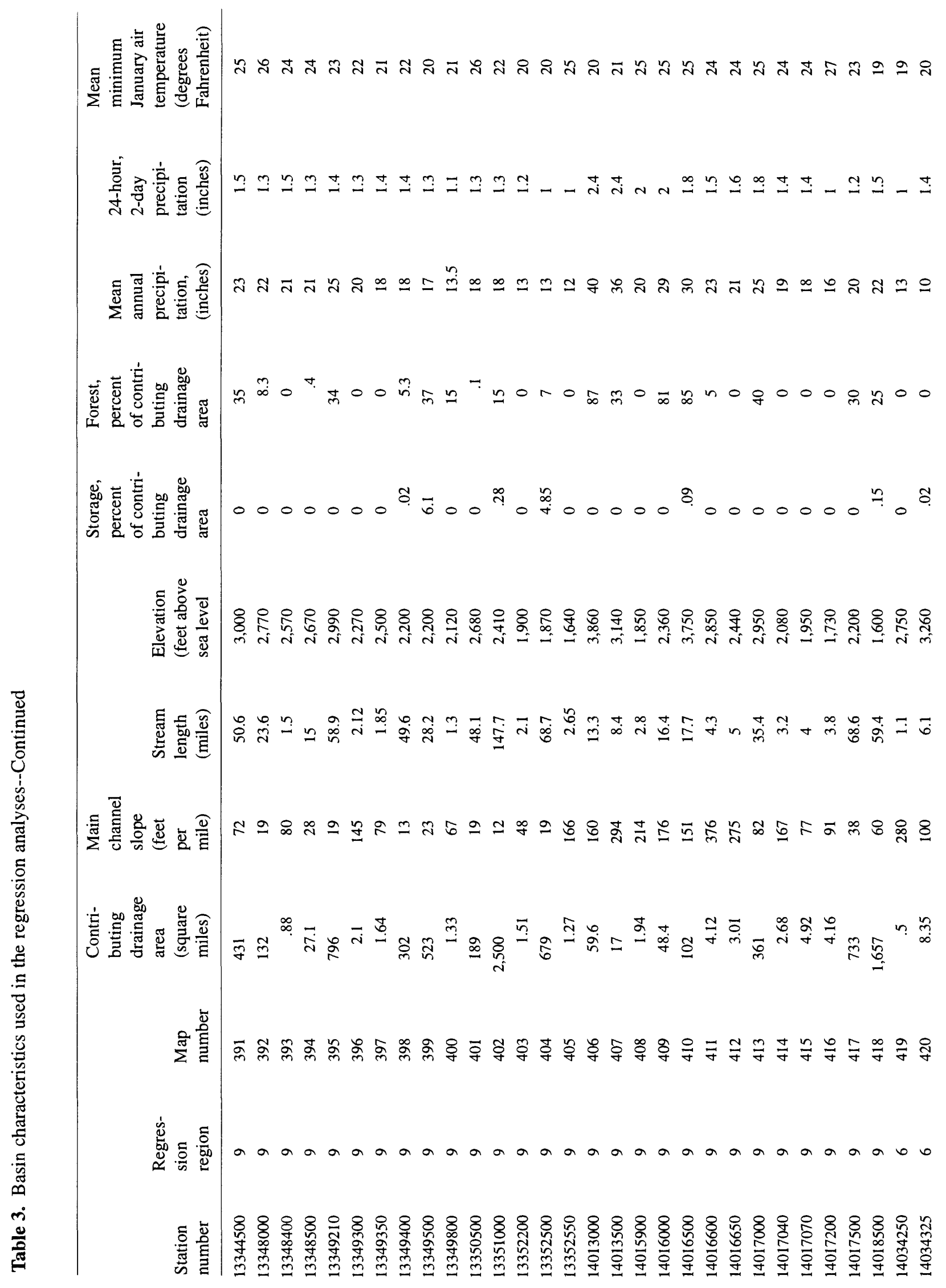




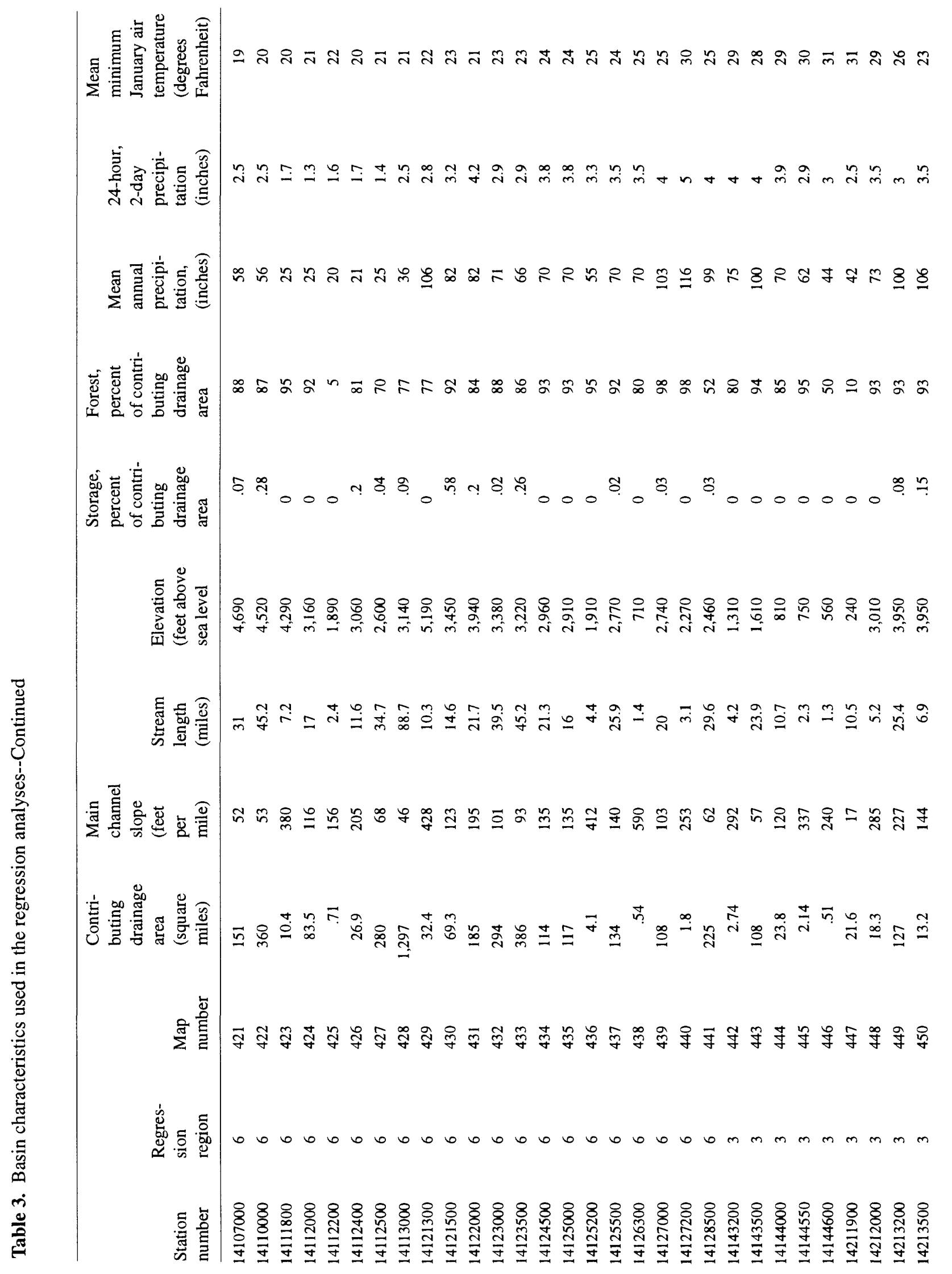




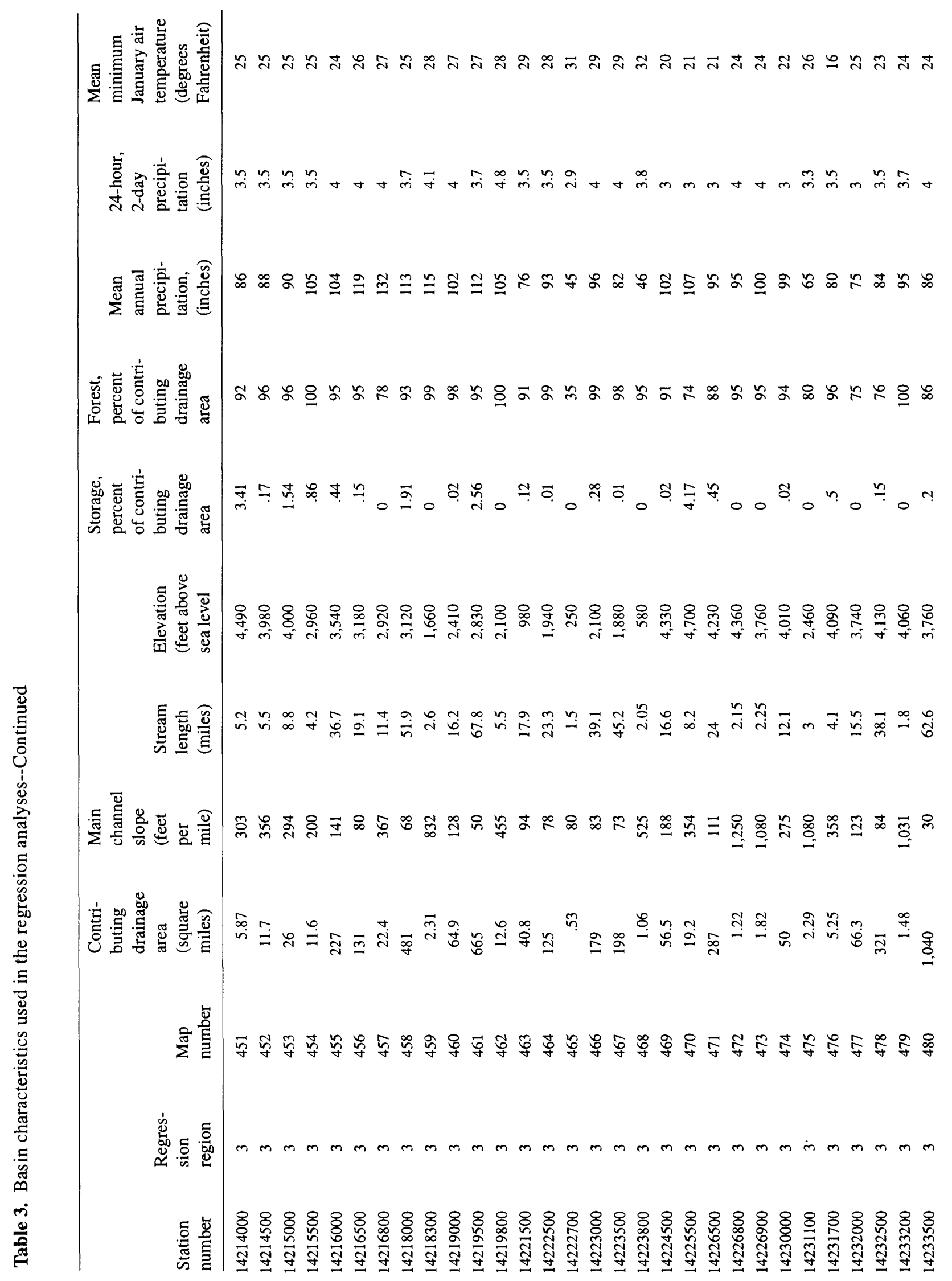




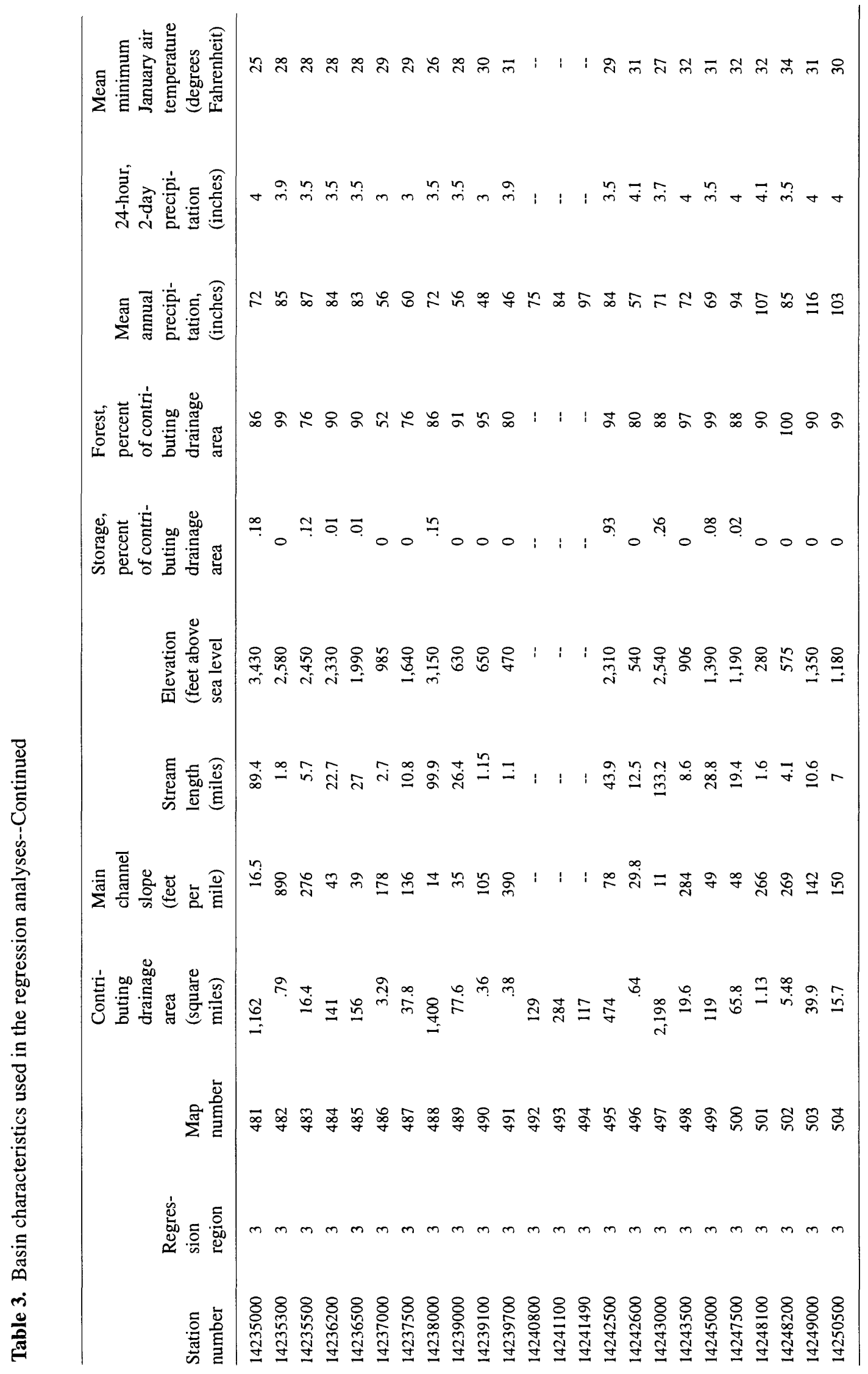


Table 4. Regression equations for estimating flood discharges at ungaged sites in Washington

[Q, flood magnitude, in cubic feet per second; A, total drainage area, in square miles; $\mathrm{P}$, mean annual precipitation, in inches; $\mathrm{F}$, forest cover, in percent of contributing drainage area; a, regression constant; b, c, and d, regression coefficients; --, regression coefficient not determined; <, less than]

\begin{tabular}{|c|c|c|c|c|c|c|c|c|}
\hline \multirow[b]{2}{*}{ Region } & \multirow{2}{*}{$\begin{array}{l}\text { Number of } \\
\text { stations } \\
\text { used in } \\
\text { analysis }\end{array}$} & \multirow{2}{*}{$\begin{array}{l}\text { Regres- } \\
\text { sion } \\
\text { equation }\end{array}$} & \multirow{2}{*}{$\begin{array}{l}\text { Exceedance } \\
\text { probability }\end{array}$} & \multirow{2}{*}{$\begin{array}{c}\text { Constant } \\
\text { a }\end{array}$} & \multicolumn{2}{|c|}{ Coefficients } & \multirow{2}{*}{$\begin{array}{l}\text { Equivalent } \\
\text { years of } \\
\text { record }\end{array}$} & \multirow{2}{*}{$\begin{array}{l}\text { Standard } \\
\text { error of } \\
\text { prediction, } \\
\text { percent }\end{array}$} \\
\hline & & & & & $\mathrm{b}$ & $\mathrm{c}$ & & \\
\hline \multirow[t]{5}{*}{1} & 61 & $Q=a A^{b} P^{c}$ & 0.5 & 0.350 & 0.923 & 1.24 & 1 & 32 \\
\hline & & & .1 & .502 & .921 & 1.26 & 2 & 33 \\
\hline & & & .04 & .590 & .921 & 1.26 & 3 & 34 \\
\hline & & & .02 & .666 & .921 & 1.26 & 3 & 36 \\
\hline & & & .01 & .745 & .922 & 1.26 & 4 & 37 \\
\hline \multirow[t]{5}{*}{2} & 202 & $Q=a A^{b} P^{c}$ & .5 & .090 & .877 & 1.51 & 1 & 56 \\
\hline & & & .1 & .129 & .868 & 1.57 & 1 & 53 \\
\hline & & & .04 & .148 & .864 & 1.59 & 2 & 53 \\
\hline & & & .02 & .161 & .862 & 1.61 & 2 & 53 \\
\hline & & & .01 & .174 & .861 & 1.62 & 3 & 54 \\
\hline \multirow[t]{5}{*}{3} & 63 & $Q=a A^{b} P^{c}$ & .5 & .817 & .877 & 1.02 & 1 & 57 \\
\hline & & & .1 & .845 & .875 & 1.14 & 1 & 55 \\
\hline & & & .04 & .912 & .874 & 1.17 & 2 & 54 \\
\hline & & & .02 & .808 & .872 & 1.23 & 2 & 54 \\
\hline & & & .01 & .801 & .871 & 1.26 & 3 & 55 \\
\hline \multirow[t]{5}{*}{4} & 60 & $Q=a A^{b} P^{c}$ & .5 & .025 & .880 & 1.70 & 1 & 82 \\
\hline & & & .1 & .179 & .856 & 1.37 & 1 & 84 \\
\hline & & & .04 & .341 & .850 & 1.26 & 1 & 87 \\
\hline & & & .02 & .505 & .845 & 1.20 & 2 & 90 \\
\hline & & & .01 & .703 & .842 & 1.15 & 2 & 92 \\
\hline \multirow[t]{5}{*}{5} & 19 & $Q=a A^{b}$ & .5 & 14.7 & .815 & -- & 1 & 96 \\
\hline & & & .1 & 35.2 & .787 & - & 2 & 63 \\
\hline & & & .04 & 48.2 & .779 & -- & 3 & 56 \\
\hline & & & .02 & 59.1 & .774 & -- & 5 & 53 \\
\hline & & & .01 & 71.2 & .769 & -- & 6 & 52 \\
\hline \multirow[t]{5}{*}{6} & 23 & $Q=a A^{b} P^{c}$ & .5 & 2.24 & .719 & .833 & 1 & 63 \\
\hline & & & .1 & 17.8 & .716 & .487 & 2 & 69 \\
\hline & & & .04 & 38.6 & .714 & .359 & 2 & 72 \\
\hline & & & .02 & 63.6 & .713 & .276 & 3 & 74 \\
\hline & & & .01 & 100 & .713 & .201 & 3 & 77 \\
\hline \multirow[t]{5}{*}{7} & 17 & $Q=a A^{b}$ & .5 & 8.77 & .629 & -- & 2 & 128 \\
\hline & & & .1 & 50.9 & .587 & -- & 7 & 63 \\
\hline & & & .04 & 91.6 & .574 & -- & 12 & 54 \\
\hline & & & .02 & 131 & .566 & -- & 15 & 53 \\
\hline & & & .01 & 179 & .558 & - & 16 & 56 \\
\hline
\end{tabular}


Table 4. Regression equations for estimating flood discharges at ungaged sites in Washington--Continued

\begin{tabular}{|c|c|c|c|c|c|c|c|c|}
\hline \multirow[b]{2}{*}{ Region } & \multirow{2}{*}{$\begin{array}{l}\text { Number of } \\
\text { stations } \\
\text { used in } \\
\text { analysis }\end{array}$} & \multirow{2}{*}{$\begin{array}{l}\text { Regres- } \\
\text { sion } \\
\text { equation }\end{array}$} & \multirow{2}{*}{$\begin{array}{l}\text { Exceedance } \\
\text { probability }\end{array}$} & \multirow{2}{*}{$\begin{array}{l}\text { Constant } \\
\quad \mathrm{a}\end{array}$} & \multicolumn{2}{|c|}{ Coefficients } & \multirow{2}{*}{$\begin{array}{l}\text { Equivalent } \\
\text { years of } \\
\text { record }\end{array}$} & \multirow{2}{*}{$\begin{array}{l}\text { Standard } \\
\text { error of } \\
\text { prediction, } \\
\text { percent }\end{array}$} \\
\hline & & & & & $\mathrm{b}$ & c & & \\
\hline \multirow[t]{5}{*}{8} & 23 & $Q=a A^{b}$ & 0.5 & 12.0 & 0.761 & -- & $<1$ & 133 \\
\hline & & & .1 & 32.6 & .706 & -- & 1 & 111 \\
\hline & & & .04 & 46.2 & .687 & -. & 1 & 114 \\
\hline & & & .02 & 57.3 & .676 & -. & 1 & 119 \\
\hline & & & .01 & 69.4 & .666 & -- & 1 & 126 \\
\hline \multirow[t]{5}{*}{9} & 36 & $Q=a A^{b} P^{c}$ & .5 & 0.803 & .672 & 1.16 & 2 & 80 \\
\hline & & & .1 & 15.4 & .597 & .662 & 6 & 57 \\
\hline & & & .04 & 41.1 & .570 & .508 & 8 & 55 \\
\hline & & & .02 & 74.7 & .553 & .420 & 10 & 55 \\
\hline & & & .01 & 126 & .538 & .344 & 12 & 56 \\
\hline
\end{tabular}


Table 5. Maximum and minimum values of basin characteristics used in the regression analysis, by regions [--, basin characteristics not used in regression equation]

\begin{tabular}{lll}
\hline & Contributing & \\
drainage & Mean \\
& area & annual \\
& (square & precipitation \\
Region & miles) & (inches) \\
\hline
\end{tabular}

\section{Region 1}

Maximum

1,294

201

Minimum

0.15

45.0

Region 2

$\begin{array}{lrr}\text { Maxmimum } & 3,020 & 170 \\ \text { Minimum } & .08 & 23.0\end{array}$

$\underline{\text { Region } 3}$

$\begin{array}{lrr}\text { Maximum } & 2,198 & 132 \\ \text { Minimum } & .36 & 42.0\end{array}$

$\underline{\text { Region } 4}$

$\begin{array}{lrr}\text { Maximum } & 2,220 & 108 \\ \text { Minimum } & .66 & 12.0\end{array}$

$\underline{\text { Region } 5}$

Maximum

638

Minimum

$\underline{\text { Region } 6}$

$\begin{array}{lrr}\text { Maximum } & 1,297 & 116 \\ \text { Minimum } & .5 & 10.0\end{array}$

$\underline{\text { Region } 7}$

Maximum

2,228

Minimum

Region 8

Maximum

689

.59

Minimum

Region 9

\begin{tabular}{lrr} 
Maximum & 2,500 & 40.0 \\
Minimum & .54 & 12.0 \\
\hline
\end{tabular}

${ }^{1}$ See figure 1 for location. 